\title{
ASSOCIATION OF ESCHERICHIA COLI O157:H7 IN FLOCS: \\ ROLE OF EXTRACELLULAR POLYMERIC SUBSTANCES AND \\ FATE OF PATHOGENIC ORGANISMS
}

by

Mitsuko Kanetani

B.A. (Aoyama Gakuin University, 1995), B.Sc. (Ryerson University, 2003)

A thesis presented to Ryerson University in partial fulfillment of the requirements for the degree of Master of Applied Science in the program of Environmental Applied Science and Management

Toronto, Ontario, Canada, 2005

(C) Mitsuko Kanetani 2005 
UMI Number: EC53434

\section{INFORMATION TO USERS}

The quality of this reproduction is dependent upon the quality of the copy submitted. Broken or indistinct print, colored or poor quality illustrations and photographs, print bleed-through, substandard margins, and improper alignment can adversely affect reproduction.

In the unlikely event that the author did not send a complete manuscript and there are missing pages, these will be noted. Also, if unauthorized copyright material had to be removed, a note will indicate the deletion.

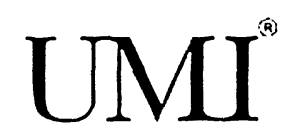

\section{UMI Microform EC53434 \\ Copyright 2009 by ProQuest LLC}

All rights reserved. This microform edition is protected against unauthorized copying under Title 17, United States Code.

ProQuest LLC

789 East Eisenhower Parkway

P.O. Box 1346

Ann Arbor, Ml 48106-1346 


\section{AUTHOR'S DECLARATION}

I hereby declare that I am the sole author of this thesis or dissertation.

I authorize Ryerson University to lend this thesis or dissertation to other institutions or individuals for the purpose of scholarly research.

\section{Mitsuko Kanetani}

I further authorize Ryerson University to reproduce this thesis or dissertation by photocopying or by other means, in total or in part, at the request of other institutions or individuals for the purpose of scholarly research.

Mitsuko Kanetani 


\title{
Association of Escherichia coli 0157:H7 in Flocs: \\ Role of Extracellular Polymeric Substances and Fate of Pathogenic Organisms
}

By Mitsuko Kanetani

Environmental Applied Science and Management, 2005

Master of Applied Science, Ryerson University

\begin{abstract}
In North America, Escherichia coli (E. coli) $\mathrm{O} 157: \mathrm{H} 7$ has been frequently associated with outbreaks of food-borne and water-borne infection. The association of $E$. coli $\mathrm{O} 157: \mathrm{H} 7$ to flocs is hypothesized to be a potential mechanism of transport and survival in natural environments. This study examines this hypothesis with a focus on the role of extracellular polymeric substances (EPS) and on E. coli $\mathrm{O} 157: \mathrm{H7}$ survival/pathogenicity in an aquatic environment. The floc characterization experiment indicated that EPS play a significant role in floc stability. The EPS distribution experiment revealed abundant hydrophobic protein throughout the floc, which contributes to floc stability and microbial adhesion. In examining survival of $E$. coli $\mathrm{O} 157: \mathrm{H} 7$ in a low nutrient water sample for 10-day incubation, more flocadherent $E$. coli $\mathrm{O} 157: \mathrm{H} 7$ survived than the free-living form since EPS provided protection, nutrients and stable sites for survival. Surviving E. coli O157:H7 exhibited both decreased host adhesion ability and $\alpha$-actinin accumulation; however, their infection ability was not affected. This suggests that low nutrient levels did not affect pathogenicity over 10 days in this study.
\end{abstract}




\section{ACKNOWLEDGEMENTS}

I would like to express my sincere gratitude and appreciation to many people who made this masters thesis possible.

In particular, I would like to thank my supervisors, Dr. Steven Liss and Dr. Debora Foster, for giving me the opportunity to continue this project from my undergraduate thesis. Their support, constant encouragement and enthusiasm made my work on this project very interesting and enjoyable.

Many thanks also go to all my colleagues in the Environmental Biotechnology Laboratory at Ryerson University. Dr. Jian Liu for her encouragement, her laboratory assistance, and for being a good friend, Belinda House for her assistance with laboratory assistance with regard to epithelial cells. The technical support of Yi Zhang was also very much appreciated.

I would also like to acknowledge that the research was supported by grants from CREStech (Ontario Centres of Excellence) and the National Science and Engineering Research Council of Canada (NSERC) awarded to Dr. Liss.

Lastly, I would like to thank my husband and friends for their strong support throughout all these years. 


\section{TABLE OF CONTENTS}

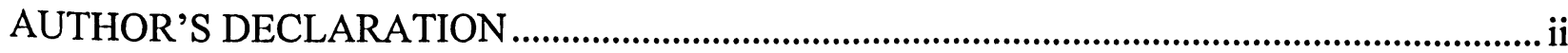

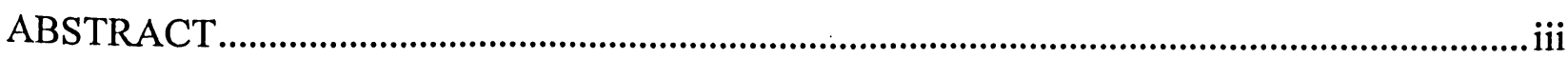

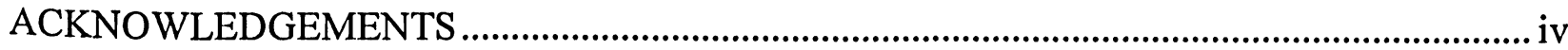

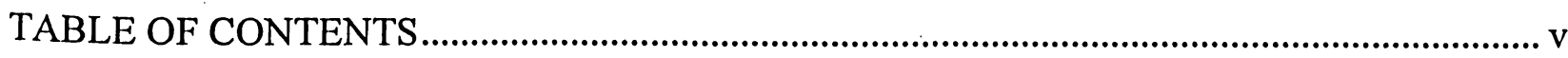

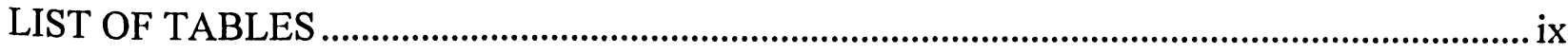

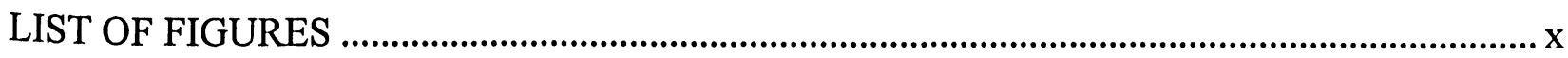

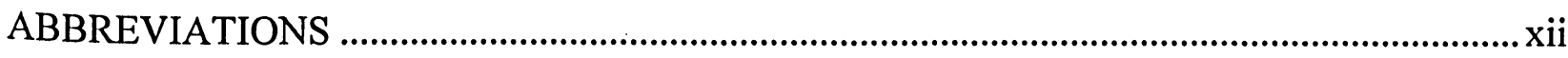

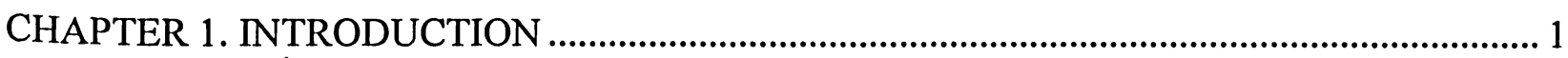

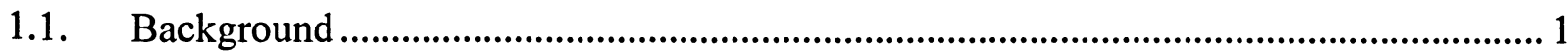

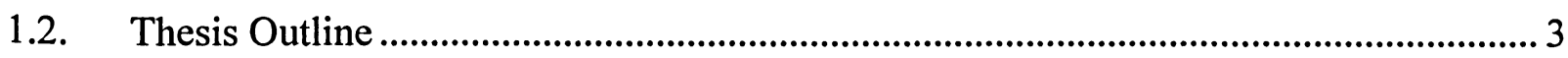

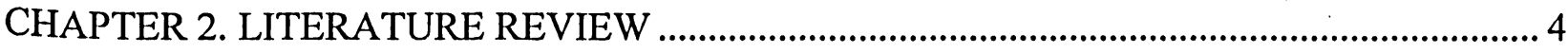

2.1. Significance of Flocs and Biofilms in Natural Environments ..................................... 4

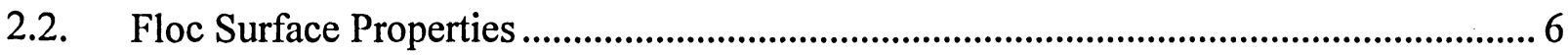

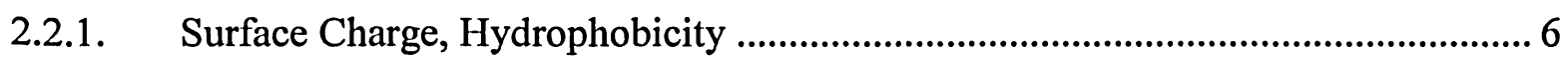

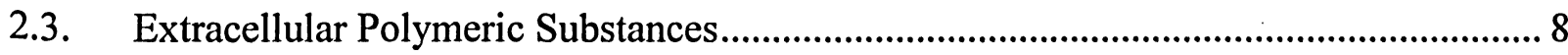

2.3.1. General Extracellular Polymeric Substances Composition ....................................... 8

2.3.2. Distribution of Extracellular Polymeric Substances in Biofilms ............................. 9

2.3.3. Properties of Extracellular Polymeric Substances .............................................. 11

2.3.4. Functions of Extracellular Polymeric Substances..................................................... 12

2.4. Bacterial Adherence in Biofilms/Flocs ...................................................................... 15

2.4.1. Gene Expression of Bacteria in Biofilms/Flocs...................................................... 16

2.5. Significance of Escherichia coli O157:H7 ................................................................... 17

2.6. Pathogenesis Enterohemorrhagic Escherichia coli ........................................................... 18

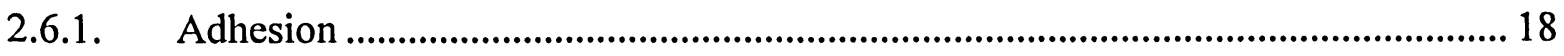

2.6.2. Virulence Factors …........................................................................................... 19

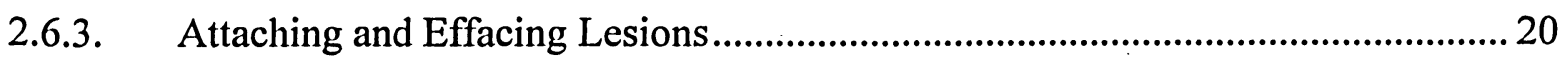

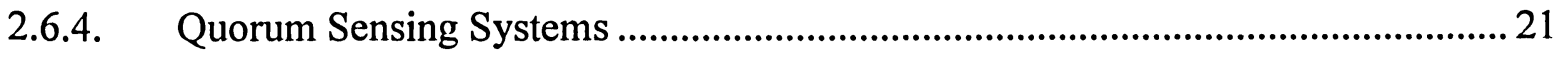

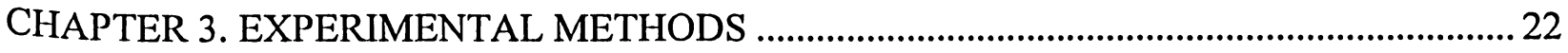

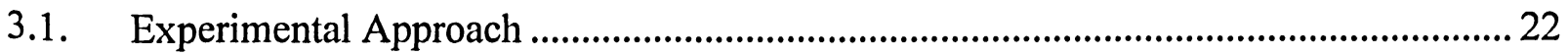




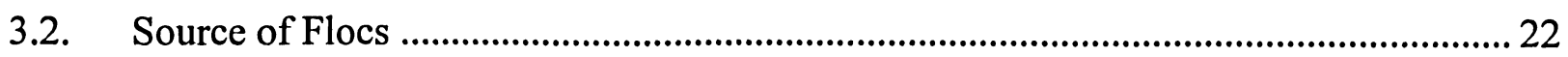

3.3. Characterization of Flocs \& Extracellular Polymeric Substances .................................. 23

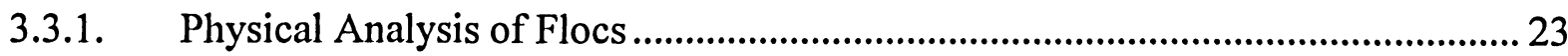

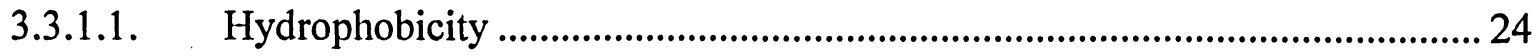

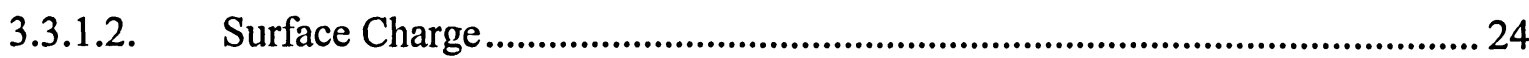

3.3.1.3. Floc Stability/Dissociation Constant............................................................. 25

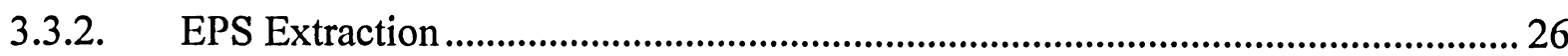

3.3.2.1 Extraction of Loosely Bound EPS Fraction.................................................. 26

3.3.2.2. Extraction of Bound EPS Fraction........................................................... 26

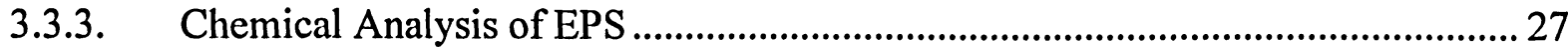

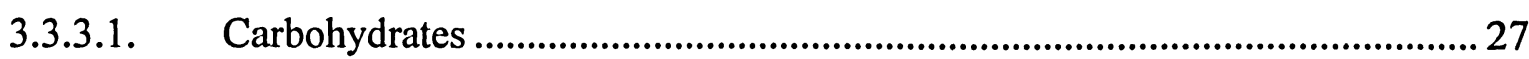

3.3.3.2. Proteins and Humic Substances ..................................................................... 27

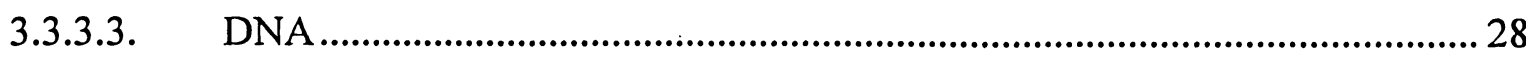

3.4. Microscopic Observation of Flocs \& Extracellular Polymeric Substances ................... 28

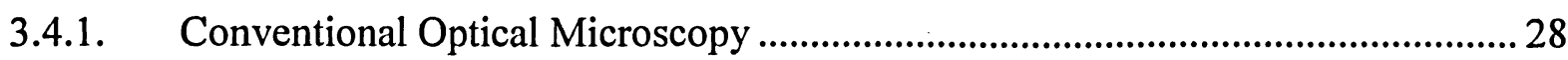

3.4.2. Confocal Laser Scanning Microscopy ..................................................................... 29

3.4.2.1. Mapping of Extracellular Polymeric Substances ....................................... 29

3.5. Escherichia coli O157:H7 Association with Flocs ........................................................ 32

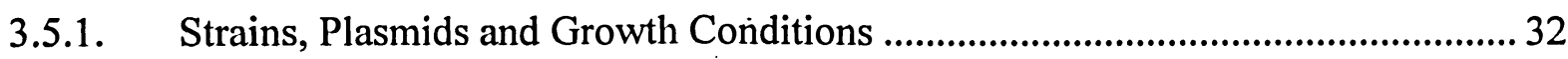

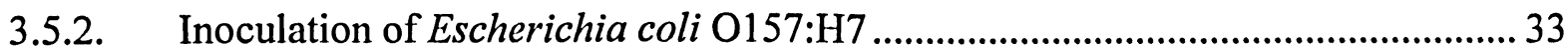

3.5.3. Enumeration of Escherichia coli O157:H7 by Plate Counts ................................. 33

3.5.4. Direct Observation of Adherent Escherichia coli O157:H7 by Confocal Laser

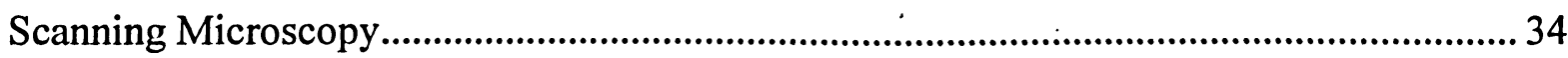

3.5.5. Pathogenicity of Escherichia coli O157:H7 Isolated From Water Samples.......... 34

3.5.5.1. Immunofluorescence Detection of $\alpha$-Actinin ............................................... 34

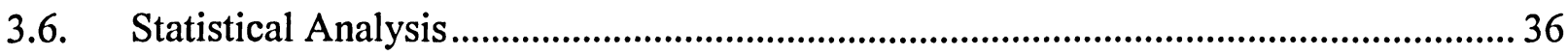

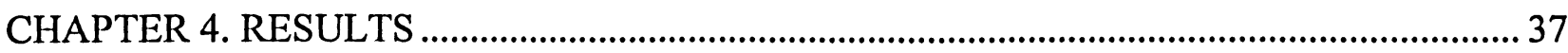

4.1. Characterization of Flocs \& Extracellular Polymeric Substances ……........................... 37

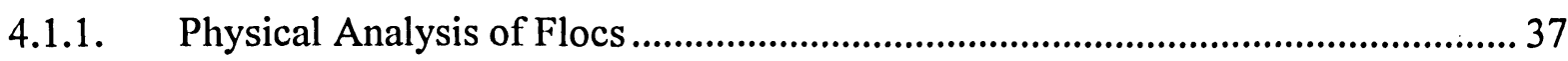

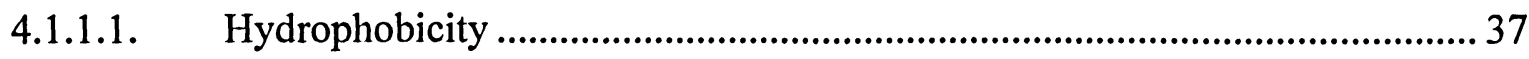

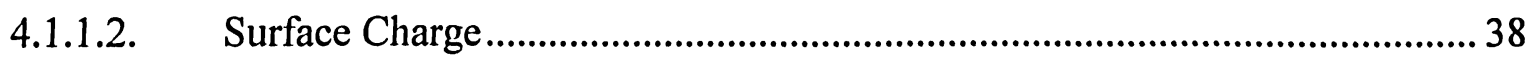


4.1.1.3. Dissociation Constant ......................................................................... 40

4.1.2. Chemical Analysis of Extracellular Polymeric Substances .................................... 45

4.2. Microscopic Observation of Extracellular Polymeric Substances................................... 48

4.2.1. Mapping of Extracellular Polymeric Substances ................................................... 48

4.2.1.1. Nucleic Acids, Lipid-hydrophobic Sites and Proteins .................................... 48

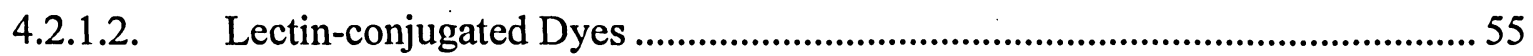

4.3. Association of Escherichia coli $\mathrm{O} 157: \mathrm{H} 7$ with Floc ....................................................59

4.3.1. Survival of Escherichia coli $\mathrm{O} 157: \mathrm{H} 7$ in Water..................................................5 59

4.3.2. Direct Observation of adherent Escherichia coli O157:H7 by CLSM ................. 61

4.3.3. Pathogenicity of Escherichia coli O157:H7 Extracted from Floc samples ........... 67

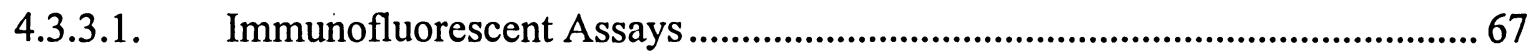

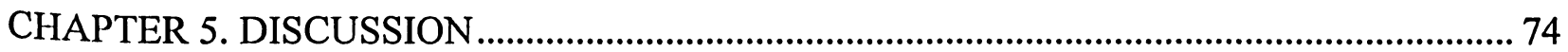

5.1. Characterization of Flocs \& Extracellular Polymeric Substances ................................. 74

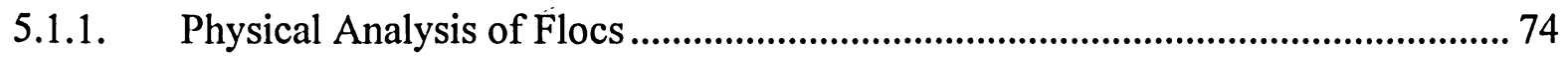

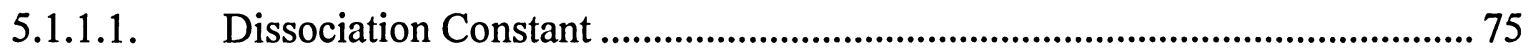

5.1.2. Chemical Analysis of Extracellular Polymeric Substances .................................. 77

5.2. Microscopic Observation of Extracellular Polymeric Substances................................. 79

5.2.1. Mapping of Extracellular Polymeric Substances................................................ 79

5.2.1.1. Nucleic Acids, Lipid-hydrophobic Sites and Protein...................................... 79

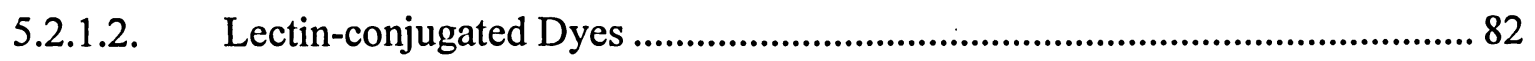

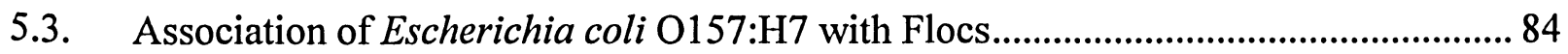

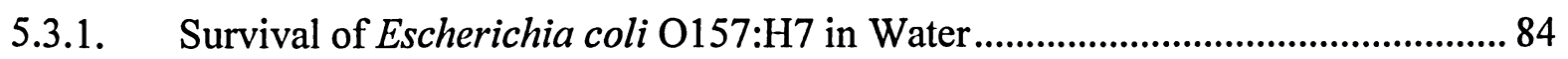

5.3.2. Direct Observation of Adherent Escherichia coli O157:H7 by Confocal Laser

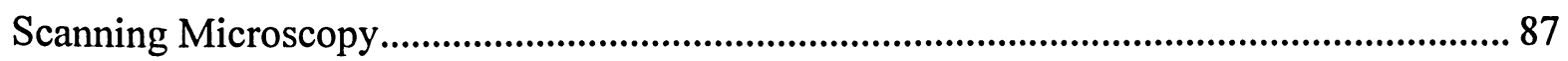

5.3.3. Escherichia coli O157:H7 Extracted from Floc Samples....................................... 88

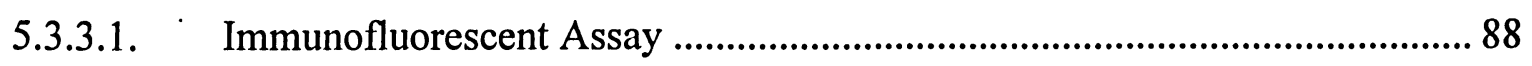

CHAPTER 6. CONCLUSIONS AND RECOMMENDATIONS ............................................. 90

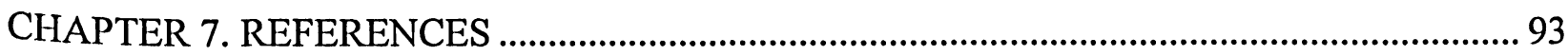

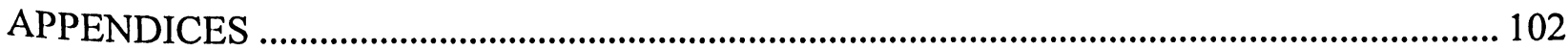

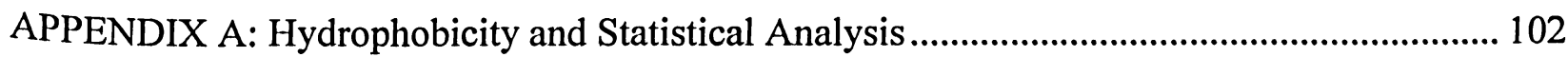

APPENDIX B: Surface Charge and Statistical Analysis............................................................... 103 
APPENDIX C: Dissociation Constant and Statistical Analysis ................................................... 104

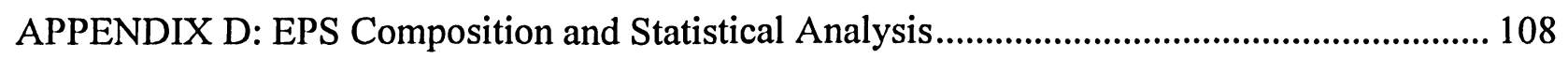

APPENDIX E: Macromolecules Detected in Enzyme Solutions ............................................... 117

APPENDIX F: Escherichia coli O157:H7 Enumeration and Statistical Analysis ........................ 118

APPENDIX G: Pathogenicity of Escherichia coli O157:H7 and Statistical Analysis ................ 122

APPENDIX H: Phase Contrast Microscopy ................................................................................... 134

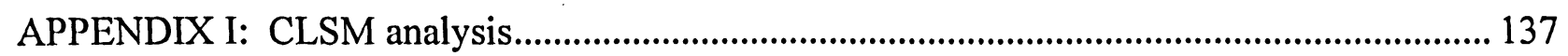




\section{LIST OF TABLES}

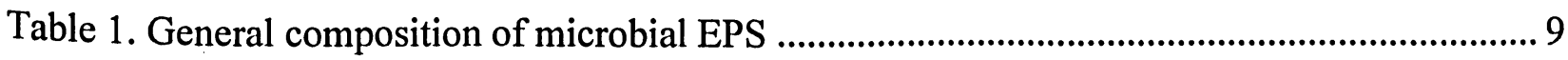

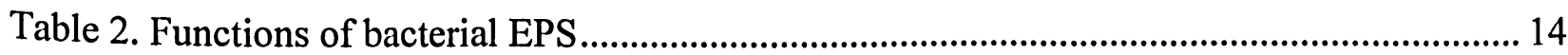

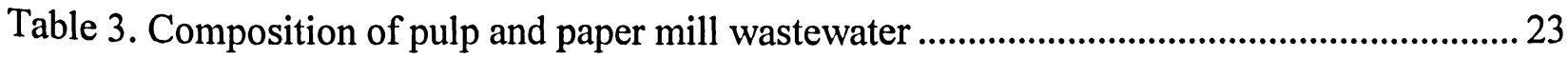

Table 4. Stains and fluor conjugated lectins used in this study ...................................................... 30

Table 5. Stock concentration and final concentration of stains and fluor conjugated lectins........ 31

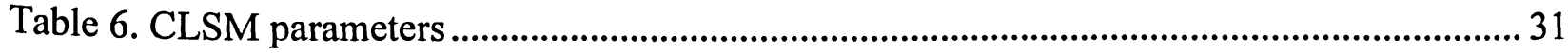

Table 7. Stains, fluor conjugated lectins, modes, assigned channels and colour............................ 32

Table 8. CLSM parameters for immunofluorescence detection ........................................................ 36

Table 9. Enumeration of adherent EHEC in floc suspended solutions ..........................................60

Table 10. Enumeration of free-living EHEC in floc suspended solutions....................................60

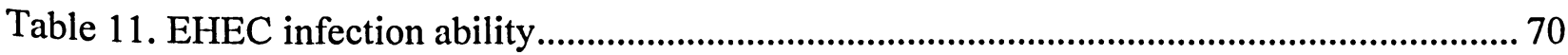




\section{LIST OF FIGURES}

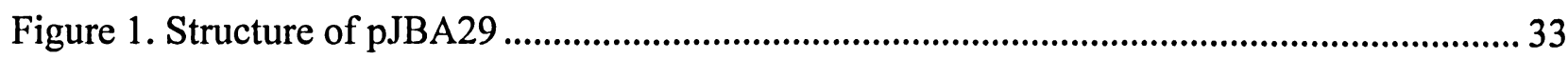

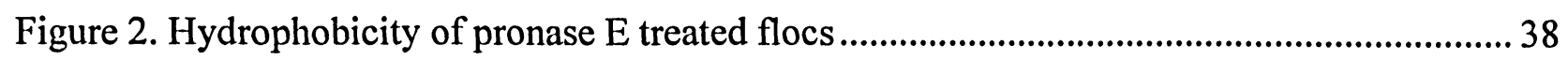

Figure 3. Hydrophobicity of proteinase $\mathrm{K}$ treated flocs............................................................ 38

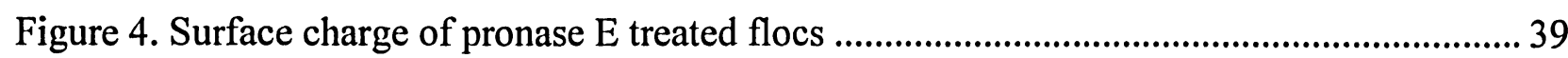

Figure 5. Surface charge of proteinase $\mathrm{K}$ treated flocs .................................................................. 39

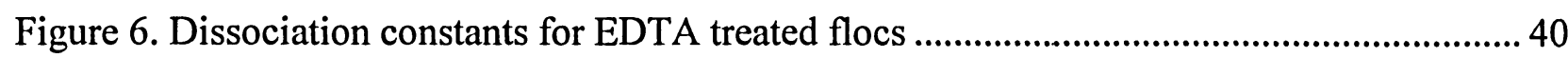

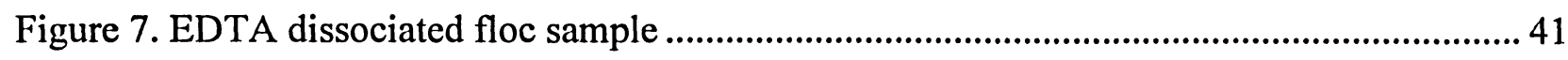

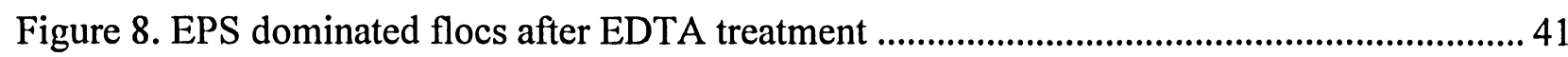

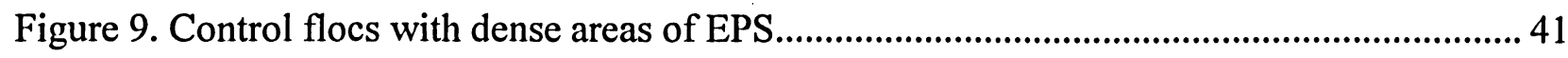

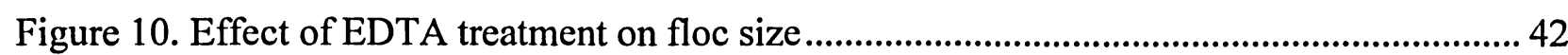

Figure 11. Effect of pronase E treatment following EDTA treatment on floc size ...................... 43

Figure 12. (a) EDTA-pronase E and (b) EDTA-proteinase K dissociated flocs........................... 44

Figure 13. EPS dominated flocs after (a) EDTA-pronase E and (b) EDTA-proteinase K

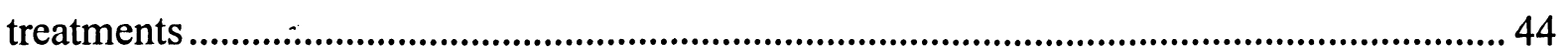

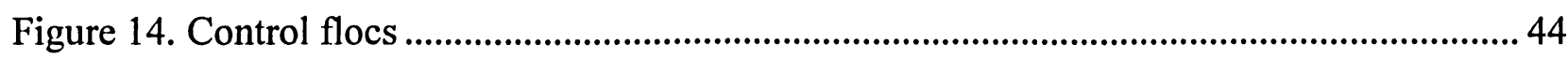

Figure 15. Effect of proteinase $\mathrm{K}$ treatment following EDTA treatment on floc size ................... 45

Figure 16. Loosely bound EPS in the presence of pronase E .......................................................... 46

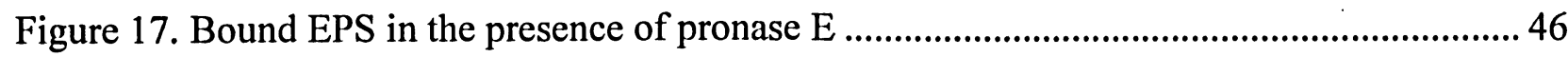

Figure 18. Loosely bound EPS in the presence of proteinase K.................................................... 47

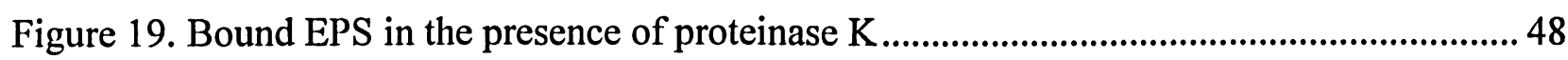

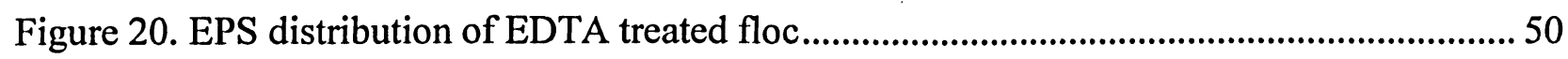

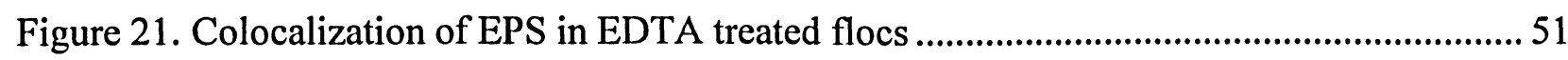

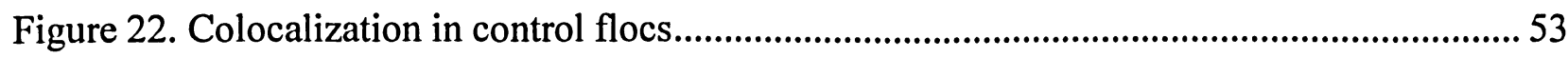

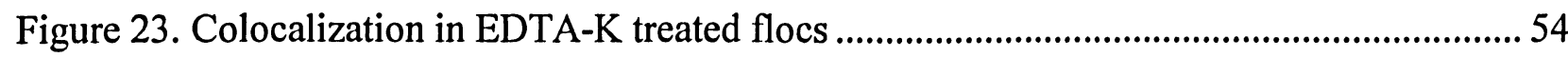

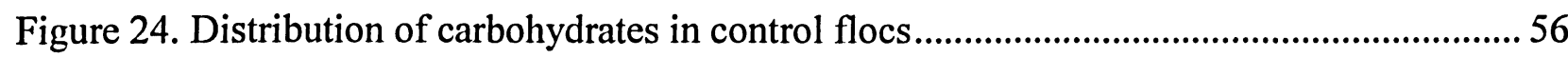

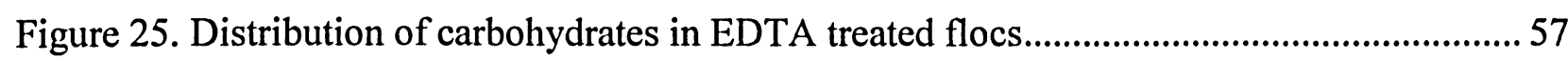

Figure 26. Distribution of carbohydrates in EDTA-K treated flocs ..............................................5

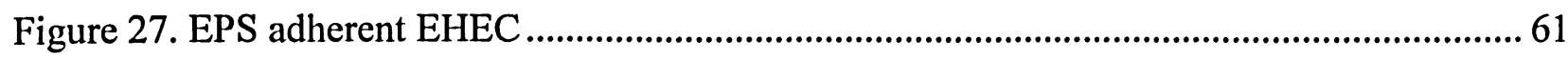

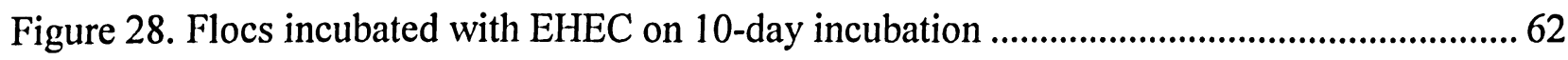


Figure 29. Adherent EHEC to flocs suspended in PBS buffer on 2-day incubation 63

Figure 30. EHEC distribution in flocs suspended in PBS buffer on 2-day incubation. 63

Figure 31. Adherent EHEC to SBR flocs suspended in SBR on 2-day incubation. 64

Figure 32. EHEC distribution in flocs suspended in SBR on 2-day incubation ...............................64

Figure 33. EHEC colonies in flocs suspended in PBS buffer on 7-day incubation........................ 65

Figure 34. EHEC distribution in flocs suspended in PBS buffer on 7-day incubation................... 65

Figure 35. EHEC colonies in flocs suspended in NSBR on 7-day incubation .............................66

Figure 36. EHEC distribution in flocs suspended in NSBR on 7-day incubation ..........................66

Figure 37. EHEC colonies in flocs suspended in SBR on 7-day incubation .................................68

Figure 38. EHEC distribution in flocs suspended in SBR on 7-day incubation ..............................69 69

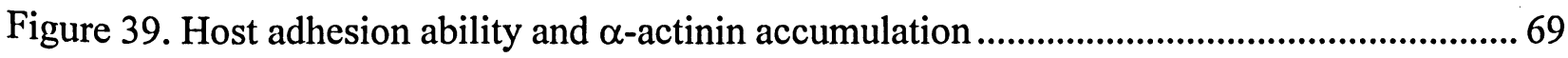

Figure 40. Microcolonies formation of EHEC from 2_BS on HEp-2 cells................................... 71

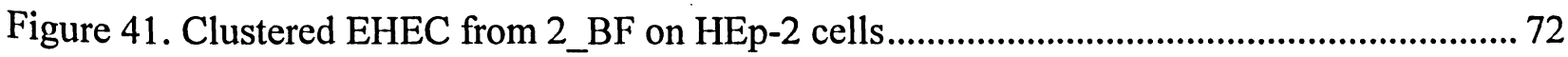

Figure 42. EHEC adhesion without $\alpha$-actinin accumulation ...................................................... 73 


\section{ABBREVIATIONS}

$\mathrm{A} / \mathrm{E}$ lesion attaching and effacing lesion

Arp2/3 actin-related protein 2 and 3

CER cation exchange resin

CFU colony forming unit

CLSM confocal laser scanning microscopy

COM conventional optical microscopy

ConA concanavalin A

DLVO Derjaugin, Landau, Verwey, and Overbeek

DMEM Dulbecco minimal Eagle medium

DNA deoxyribonucleic acid

EDTA ethylenediaminetetraacetate

E. coli Escherichia coli

EHEC enterohemorrhagic Escherichia coli

EPEC enteropathogenic Escherichia coli

EPS extracellular polymeric substances

GFP green fluorescent protein

Gal galactopyranosyl

GalNAc $\quad N$-acetylgalactosaminyl

Glc glucopyranosyl

GlcNAc $\quad N$ - acetylglucosaminyl

HUS haemolytic uremic syndrome

$\mathrm{IP}_{3} \quad$ inositol 1,4,5-triphosphate

Irg iron-regulated gene A

LB Luria-Bertani

LEE Locus of Enterocyte Effacement

LPS lipopolysaccharide

Man mannopyranosyl

MLSS mixed liquor suspended solids

NA numerical aperture

NeuNAc $\quad N$-acetylneuraminic acid 
NSBR SBR sample with replenished nutrients

N-WASP neural-Wiskott-Aldrich syndrome protein

OMP Outer Membrane Protein

PAS polyanetholsulfonic acid

PBS phosphate buffered saline

SBA soybean agglutinin

SBR sequencing batch reactor

STEC Shiga toxin-producing E. coli

Stx Shiga toxin

Tir translocated intimin receptor

TTSS type III section system

VASP vasodilator-stimulated phosphoprotein

WGA wheat germ agglutinin 


\section{CHAPTER 1. INTRODUCTION}

\subsection{Background}

Over the last several years there has been an increasing number of waterborne infection outbreaks associated with drinking water. These outbreaks were often caused by pathogenic microorganisms, including Escherichia coli (E. coli) O157:H7 (Nicholls et al., 2002). In 2000, in the case of drinking water contamination in Walkerton, Ontario, it was suggested that $E$. coli O157:H7 entered the drinking water distribution system through a well. The groundwater was contaminated with agricultural runoff from a nearby farm where cattle manure was spread on the fields (Nicholls et al., 2002, O'Connor, 2002). Recent studies have indicated that $E$. coli 0157:H7 might persist in environments for extended periods (Artz and Killham, 2002; Ogden et $a l ., 2001)$. However, the transport of $E$. coli $\mathrm{O} 157: \mathrm{H} 7$ from a source of contamination to a point of infection and the survival of E. coli $\mathrm{O} 157: \mathrm{H} 7$ in the environment during the transport have not been elucidated in detail as yet.

The association and adherence of pathogens, in particular E. coli $\mathrm{O} 157: \mathrm{H7}$, to flocs is hypothesized to be a potential mechanism of transport and survival for the pathogens. Microbial adherence to flocs and to biofilms is thought to offer many advantages to adhered microorganisms, such as protection against disinfectants and predators, resistance to toxins, and availability of reserve carbon sources (Schembri et al., 2003). While the association of pathogens with stationary biofilms (sessile fixed structures) has been intensively studied, the association of pathogens with the more mobile flocs has not been investigated to the same extent. Microbial adhesion associated with flocs, including microbial-microbial interaction, is thought to occur through the following interactions: van der Waals forces, hydrophobic interactions, and salt bridging (Jorand et al., 1998; Liao et al., 2003; Nielsen et al., 1996). These interactions are related to physicochemical properties of flocs such as hydrophobicity, surface charge and composition of extracellular polymeric substances (EPS) within the flocs. It has been proposed that proteins are involved in hydrophobic interactions within the EPS matrix (Wingender et al., 1999). Further, negatively charged amino acids in proteins are also thought to form salt bridges with polyvalent cations such as $\mathrm{Ca}^{2+}$ or $\mathrm{Fe}^{3+}$ in flocs (Flemming, 2002; Jorand et al., 1998; Wingender et al., 1999). Since EPS seem to play an important role in microbial adhesion to flocs and floc stability, it is necessary to study the distribution and composition of EPS in flocs in 
further detail. Only a few studies have been conducted in this area. For example, a mapping of EPS in biofilm has been conducted, showing the colocalization of proteins and carbohydrates in a biofilm (Lawrence et al., 2003). In this study, the mapping of EPS in flocs using targeted dyes and confocal laser scanning microscopy (CLSM) reveals macromolecular distributions of EPS, which will assist with understanding the role of EPS in microbial adhesion to flocs and floc stability.

It is also important to investigate the virulence expression of floc-adherent $E$. coli O157:H7 because virulence gene expression might be altered after pathogens have adhered to flocs. Microorganisms are known to obtain and accordingly respond to a wide range of information from their surrounding environment by modulating gene expression for successful adaptation (Decho, 1999). For example, in biofilms, non-pathogenic E. coli in the growth phase were found to enhance the expression of genes associated with biofilm formation compared to that in planktonic (free-living) form (Schembri et al., 2003). Furthermore, the virulence expression of E. coli $0157: 177$ in vivo is regulated by the quorum sensing system that allows cells to communicate with each other (Sperandio et al., 1999). However, the virulence expression of E. coli O157:H7 has not been examined in an environmental sample as yet. The current study was intended to investigate these matters in further detail.

Specific objectives of this study were:

1. To examine the relationship between floc properties and EPS. Enzymes such as pronase $\mathrm{E}$ or proteinase $\mathrm{K}$ were used to digest protein from EPS and the effects on floc properties were observed;

2. To understand the structure and distribution of EPS macromolecules. such as proteins, carbohydrates, and lipids by mapping EPS in flocs. Lectins were used to differentiate the composition of carbohydrates in the EPS and the stained flocs were then viewed by CLSM. Pronase $\mathrm{E}$ or proteinase $\mathrm{K}$ were also used to observe the underlying structure and distribution of EPS;

3. To study the fate of E. coli $\mathrm{O} 157: \mathrm{H} 7$ and their survival in water samples. Viable cells were counted by plate count and GFP (green fluorescent protein) labelled E. coli O157:H7 adhered to flocs were observed under CLSM; and

4. To study if E. coli O157:H7 remain pathogenic after being cultured in a low nutrient condition. 


\subsection{Thesis Outline}

This report contains seven chapters and appendices. Chapter 1 provides an introduction and thesis outline. Chapter 2 is a review of the literature relevant to this study. Chapter 3 describes the experimental methods used and Chapter 4 presents the results. Chapter 5 provides a discussion of the results. Chapter 6 contains conclusions and recommendations for future study. Chapter 7 contains a list of references. Lastly, statistical analyses of the experimental data are included in the appendices. 


\section{CHAPTER 2. LITERATURE REVIEW}

This chapter presents a review of the literature regarding the function and properties of llocs/biolilms, microbial adhesion to flocs and pathogenicity of E. coli O157:H7. First, the significance of flocs and biofilms in natural and engineered environments are described. Next, floc and biofilm function and physicochemical properties, including those of EPS, are reviewed. This leads to a discussion of microbial adherence in flocs/biofilms, including gene expression of microorganisms in llocs/biofilms. Lastly, the significance of $E$. coli $\mathrm{O} 157: \mathrm{H} 7$ as a pathogen that can adhere to flocs and biofilms is discussed. In particular, the pathogenicity of E. coli $\mathrm{O} 157: \mathrm{H} 7$, including, virulence factors, attaching effacing lesions and quorum sensing system, is reviewed.

\subsection{Significance of Flocs and Biofilms in Natural Environments}

Bacteria are generally known to exist in the environment as suspended cclls or attached cells. Suspended (planktonic or free-living) cells are typically found in environments such as open water in oceans and deep lakes as well as in large-scale industrial fermentors (Wolfaardt $e t$ al., 1999). Attached cells generally occur adjacent to surfàces in both natural aquatic environments and technical water systems. Attached bacteria typically occur in aggregated forms such as flocs and biofilms (Wingender et al., 1999; Wolfaardt et al., 1999).

Flocs are stable complex aggregates that consist of bioorganic and inorganic material and heterogencous microorganisms embedded in polymeric networks. known generally as extracellular polymeric substances (EPS) (Liss, 2002; Wilén et al., 2003). Flocs have been also described as individual micro-ecosystems with autonomous and interactive physical, chemical and biological functions or behaviours operating within the floc matrix (Droppo et cl., 1997). Flocs are found in natural environments such as freshwater and marine systcms. For example, freshwater flocs form flocculated fine grain sediment in the benthic regions of freshwater environments (Liss, 2002). Flocs in natural environments have been studied because they influence the fate of a contaminant that is adsorbed to the flocs and dispersed in aquatic environments. Association of flocs with contaminants regulates the surrounding water quality by their physical, chemical and/or biological activity (Droppo et al., 1997). Flocs are also found in engineered environments such as activated sludge in wastewater treatment plants and processing equipment. Activated sludge has been intensively examined in the context of seeking ways to 
improve wastewater processes such as settling and dewatering processes (Droppo, 2001; Liss, 2002).

Biofilms are stable complexes of microbial aggregates but, unlike flocs, they are typically sessile structures (Liss, 2002). Biofilms are generally found at liquid-solid interfaces (Wolf et al., 2002). Biofilms are widely recognised as important structures due to their potential for detrimental impact on human health, industrial processes and drinking water distribution systems. As such. many studies have been conducted on biofilms. For example, biofilms growing on medical devices present a considerable hygiene and infection risk (Meyer, 2003). Biolilms in industries are known to cause biocorrosion of metal and concrete, which reduces the lifetime of industrial equipment and buildings (Videla, 2002). Biofilms in drinking water distribution systems also cause material deterioration, significant energy losses and water quality deterioration (Smith et al. 2000; Williams et al., 2003; Wolf et al., 2002). If there is a disinfection failure in a drinking water treatment process, biofilms in drinking water distribution systems might pose a risk of pathogen contamination. In particular, pathogens such as $E$. coli, Legionella bozemanii, Mycobacterium smegmatus, and oocysts of Cryptosporidium parvum have been observed to readily colonize preformed biofilms isolated from drinking water systems (Smith et al., 2000). Even though a number of studies have been conducted on biofilms in controlled industrial or public systems, only a few studies have been reported regarding the association of pathogens with flocs/biofilms in natural environments. Whitman and Nevers (2003) pointed out the possibility of pathogens surviving in biofilms in beach sand. They examined E. coli distribution in sand and beach water along Lake Michigan. E. coli is an indicator organism of sewage contamination, which indicates a possible presence of human pathogens (bacteria, protozoa and viruses) (Whitman and Nevers 2003). This study suggested that beach sand acted as a source of $E$. coli and caused beach water contamination because the beach sand seemed to offer advantages to microorganisms by providing a large surface area for biofilm formation, where microflora growth was supported by a steady supply of nutrients and gases, protection from lethal sunlight and predation (Whitman and Nevers 2003). The persistence of pathogens in marine waters are also linked to the association of pathogens with flocs (Decho, 2000). The increasing salinity results in a substantial increase in cations such as $\mathrm{Na}^{+}, \mathrm{Ca}^{2+}$ and $\mathrm{Mg}^{2+}$ when going from freshwater to full seawater. Upon reaching saline water, enhanced floc formation and aggregation of suspended dissolved organic carbon, silts and clays are generally 
observed in most intertidal systems (Decho. 2000). Similar to biofilms, flocs are thought to improve the survival and propagation of adhered microorganisms. In particular, a few studies have focused on the survival of $E$. coli in sediment. Since flocs contribute to sediment formation, these studies may be useful background to the present study. It was found that the concentration of $E$. coli was higher in sediments than that in the overlaying water. Further, E. coli persisted longer when sediment was present, indicating that $E$. coli was capable of utilizing nutrients adsorbed to sediments (Brettar and Höfle, 1992; Gerba and McLeod, 1976; LaLiberte and Grimes, 1982). E. coli persisting in sediment can also be resuspended in the overlaying water when the sediment was disturbed by boating or recreational activities (An et al., 2002; Decho, 2000). Thus, it seems quite possible that pathogens adhered to flocs may persist for extended periods of time and that adhered pathogens might be occasionally transported with flocs and then resuspended. It is important to examine pathogen association with flocs, with regard to floc properties and pathogen survival and pathogenicity.

\subsection{Floc Surface Properties}

Flocs may play a key role in the pathogen transport and survival in an aquatic environment. It is important to examine properties and functions of flocs since these will affect the viability of pathogenic $E$. coli within flocs leading to transport. For example, floc size can have significant implications for pathogen dispersion in an aquatic environment since the larger flocs will gencrally settle out much faster than fincr flocs, which will likely travel with their associated pathogens much further within water systems (Liss, 2002). The properties and functions of flocs are also affected by the properties and functions of EPS that are the major component of flocs. In this section, the literature regarding the properties and functions of flocs and EPS are discussed.

\subsubsection{Surface Charge, Hydrophobicity}

Surface charge and hydrophobicity are physical properties of flocs. Both of these properties appear to influence floc formation as well as other properties of formed flocs. Surface charge is considered to be associated with both flocculation and bulking (Jin et al., 2003). The surface charge of flocs is generally negative under neutral $\mathrm{pH}$ conditions. The negative charge is contributed to by the presence of ionisable groups such as carboxyl, phosphate and amino groups in the EPS (Liss, 2002). The negative surface charge is also suggested to affect the stability of 
flocs since the negative charge on floc surfaces may' create repulsive electrostatic interactions and prevent close contact. As a result. bonds between floc fractions are weak and unstable (Jin $e t$ al., 2003; Liao et al., 2001; Wilén et al., 2003). Flocs are naturally hydrated, due to the presence of large numbers of hydroxyl. carboxyl and phosphate groups in EPS, however, floc surfaces also possess hydrophobic areas. These hydrophobic areas are contributed to by the presence of side chains in amino acids, the methyl groups in carbohydrates, and the long-chain carbon groups in lipids in EPS (Liss, 2002). Furthermore, in general. bacteria also possess a hydrophobic cell surface. Thus, hydrophobic interactions appear to be involved with floc formation and bacterial adherence to flocs (Liao et al., 2001; Olofsson et al.. 1998; Zita and Hermansson, 1997a,b). In particular, Olofsson et al. (1998) and Zita and Hermansson et al. (1997b) investigated microbial adhesion to activated sludge flocs. Both studies found that bacteria with a higher cell surface hydrophobicity attached in higher numbers to activated sludge flocs than lower cell surface hydrophobicity (more hydrophilic) bacteria (Olofsson et al., 1998; Zita and Hermansson et al.. 1997b). These findings were also supported by the results of an in situ investigation of cell surface hydrophobicity of free-living, single cells in wastewater, which showed that the majority of these bacteria possess lower cell surface hydrophobicity (more hydrophilic) (Zita and Hermansson et al., 1997a). The two surface properties, surface charge and hydrophobicity, are also believed to correlate with each other inversely. For example, as negative surface charge increases, the ionisable groups of EPS that contribute to the negative surface charge also increase the polar interactions with water molecules. which resulted in lowering the hydrophobicity (Liao et al., 2001). These surface properties. surface charge and hydrophobicity, are also related to the characteristics of EPS. It has been suggested that EPS possess both hydrophobic and hydrophilic properties. In particular, Jorand et al. (1998) found that hydrophobicity was more related to EPS protein than to total EPS content of flocs. This study showed that the hydrophobic fraction of EPS was made up of only proteins. The proteins contained amino acids with hydrophobic side groups, which seemed to contribute significantly to the hydrophobicity of flocs. On the other hand, the hydrophilic fraction of EPS was made up of both proteins and carbohydrates (Jorand $e t$ al., 1998; Liss, 2002). Thus, the ratio of proteins to carbohydrates may be somewhat representative of the hydrophobicity of the flocs. Liao et al. (2001) also found that the proportions of EPS components (proteins/carbohydrates and/or proteins/(carbohydrates+ deoxyribonucleic acid (DNA))) were more important than the quantities of individual EPS 
components in controlling hydrophobicity and surface charge for the sludge in laboratory-scale sequencing batch reactors (SBRs) (Liao et al., 2001).

\subsection{Extracellular Polymeric Substances}

The surface properties of flocs are closely related to the characteristics of EPS. EPS can be defined as organic polymers of microbial origin that are found outside of the cellular boundaries. In a floc/biofilm, EPS may be associated with nearby bacterial cell surfaces either loosely or firmly. EPS are formed when polymeric substances are actively secreted by microorganisms, released as a product of cellular lysis or adsorbed from the surrounding medium (Frolund $e t a l$., 1996; Jahn and Nielsen, 1996; Wilén and Lant. 2003; Zhang et cl., 1999). EPS form a matrix of extracellular organic material that binds heterogeneous microorganisms and other particulates together to form microbial aggregates (flocs/biofilms) (Wilén and Lant, 2003; Wingender et al., 1999).

\subsubsection{General Extracellular Polymeric Substances Composition}

EPS are known to include a variety of polymeric materials including neutral and acidic carbohydrates, lipopolysaccharides, protein, nucleic acids. (phospho)lipids, and humic acids as described in Table 1 (Bura et cl., 1998; Tsuneda et cl.. 2003; Wingender et al., 1999). The EPS composition and relative quantities of constituents may' vary spatially and temporally depending on microbial community. substrate properties and enzymatic activities such as polymerizing, modifying, and degrading of biological molecules in flocs/biofilms (Sponza, 2003; Wingender et al., 1999). Numerous environmental factors also affect EPS composition. including high levels of oxygen, desiccation, low temperatures and nutrients (COD: N: P) (Bura et al., 1998; Ryu and Beuchat, 2004). For example, a limited availability of nitrogen $(N)$ resulted in reduced amounts of proteins, while a limited availability of phosphorus $(P)$ increased proteins and carbohydrates (Bura et al., 1998). Wastewater composition also affects the quantities of EPS components. The activated sludge in wastewater from pulp-paper, textile (cotton knit fabrics) and petrochemical industries (containing more complex organics and substrates) generally contained EPS with lower amounts of proteins and higher DNA levels. 
Table 1. General composition of microbial EPS (Adapted from Wingender et al., 1999)

\begin{tabular}{lll}
\hline EPS & Principal components & Substituents \\
\hline Carbohydrates & $\begin{array}{l}\text { monosaccharides } \\
\text { uronic acids } \\
\text { amino sugars } \\
\text { amino acids }\end{array}$ & $\begin{array}{l}\text { organic: O-acetyl. } N^{N} \text {-acetyl. } \\
\text { succinyl, pyruvyl } \\
\text { inorganic: sulfatc, phosphate } \\
\text { oligosaccharides (glycoprotein) } \\
\text { fatty acids (lipoprotein) }\end{array}$ \\
$\begin{array}{l}\text { Pucleic acids } \\
\text { (Phospho)lipids }\end{array}$ & $\begin{array}{l}\text { nucleotides } \\
\text { fatty acids } \\
\text { glycerol } \\
\text { phosphate } \\
\text { ethanolamine } \\
\text { serine } \\
\text { choline } \\
\text { sugars } \\
\text { phenolic compounds } \\
\text { simple sugars } \\
\text { amino acids }\end{array}$ \\
\hline
\end{tabular}

On the other hand, the activated sludge in wastewater from the winery industry and municipal activated sludge (wastewater containing readily biodegradable organics in wastewater) generally contained EPS with a high level of proteins and a low DNA content (Bura et al., 1998; Sponza, 2003). The predominance of proteins in the municipal wastewater/activated sludge was suggested to be due to the large quantities of exoenzymes excreted in the EPS. These exoenzymes may hydrolyse a high amount of bound EPS in flocs in the presence of readily biodegradable organics (Nielsen et al., 1996; Sponza. 2003).

\subsubsection{Distribution of Extracellular Polymeric Substances in Biofilms}

Another definition of EPS indicates that EPS includes all polymers that exist outside the bacterial cell wall and which are not directly anchored in the outer membrane/murein-proteinlayer (Nielsen and Jahn, 1999). When EPS are generated and secreted by bacterial cells, EPS are initially found around bacterial cells as capsules, sheaths and slimes. This type of EPS is generally called bound EPS (Nielsen and Jahn, 1999). Capsules ("integral capsules") are firmly associated with the cell surface as discrete structures with distinct outlines. Capsular polymers are attached to the cell surface by noncovalent interactions, but may also be covalently bound to phospholipid or lipid-A-molecules at the cell surface. Sheaths are found around filamentous bacteria, such as certain cyanobacteria or bacteria of the genera Leptothrix and Sphaerotilus, as 
linear EPS-containing structures surrounding chains of cells and are analogous to capsules in nonfilamentous organisms (Wingender et al., 1999). On the other hand, slime is a loose binding to the cell surface and this type of EPS can be shed into the surrounding environment as a less organized slime (Wingender et al., 1999; Nielsen and Jahn, 1999). EPS may also exist in a dissolved state. This type of EPS is called soluble EPS. Soluble EPS include soluble macromolecules and colloids (Nielsen and Jahn, 1999).

As more EPS are formed, more EPS accumulate around and between cells to form an EPS matrix in a biofilm. At this stage, one of the major EPS components, carbohydrates, are generally distributed not only around the bacterial cells but within cell-free areas in the biofilm (Nielsen and Jahn, 1999; Strathmann et al., 2002; Wolfaardt et cl., 1999). The distribution of EPS components has been studied mainly with regard to carbohydrates. Strathmann et al. (2002) observed that bound EPS associated with bacterial cell surfaces in a biofilm predominantly contained $N$-acetylglucosamine (GlcNAc) and $N$-acetylneuraminic acid (NeuNAc), based on staining with lectin Wheat germ agglutinin (WGA). On the other hand, EPS in cell-free regions contained $\alpha$-D-glucose (Glc) and $\alpha$-D-mannose (Man), based on staining with the lectin Concanavalin A (ConA). ConA produced cloud-like regions that were heterogeneously distributed within the biofilm and were separated by dark areas. It was suggested that the unstained areas in the biofilms be due to water-filled pores and/or EPS that did not bind the lectin (Strathmann et al., 2002). Lawrence et al. (2003) also demonstrated a way to map the distribution of EPS macromolecular subcomponents of biofilm cells and matrices using CLSM. In this experiment, staining with nucleic acid-, protein-, lipophilic, and gly'coconjugate-specific fluorescent probes revealed localization and colocalization of these biomoleculcs within the cells and matrix of the biofilm. As well as these biomolecules, Jorand et al. (1998) suggested the presence of glycoproteins in the EPS matrix (Jorand et al., 1998). When the CLSM probes noted above were used in combination with glycoconjugate-specific lectins such as those from Datura stramonium or Sambucus nigra with an affinity for GlcNAc - and $N$-acetyl-D-galactosamine (GalNAc) -rich regions, respectively, the presence of nucleic acid-, protein-, or lipid-enriched regions associated with carbohydrates could be detected (Lawrence et al., 2003).

Furthermore, Higgins and Novak (1997) observed that the addition of pronase E (200 activity unit) to an activated sludge sample resulted in a release of bound carbohydrates and reduction of floc size. This was understood to indicate that the proteins and carbohydrates are 
linked like lectins within the biopolymer network. This finding suggested the mechanism of protein-carbohydrate interaction on forming and stabilizing of the EPS matrix (Higgins and Novak 1997).

\subsubsection{Properties of Extracellular Polymeric Substances}

EPS composition is directly related to EPS properties. The most important properties of EPS are adhesion, sorption, mechanical stability, cohesion of bacterial aggregates and diffusion. Since EPS are typically major components within flocs/biofilms, the physical properties of EPS are also closely related to the properties of flocs/biofilms. The EPS property of adhesion to abiotic surfaces is a prerequisite for initial and on-going biofilm growth. The extracellular surface-active polymers with lipidic components in the EPS are involved in the interaction between bacteria and surfaces (Wingender et al., 1999). Once a biofilm is formed, the sorption property of the EPS accumulates nutrients, retains water and protects against desiccation (Flemming, 2002). During growth, the EPS form a three-dimensional network (EPS matrix) to provide mechanical stability and cohesion of bacterial aggregates. In forming the EPS matrix, the following main forces are thought to be working: van der Waals forces, hydrophobic interactions, salt bridging and protein-carbohydrate interaction (Jorand et cl.. 1998; Higgins and Novak, 1997; Nielsen et al., 1996; Wilén and Lant, 2003). Derjaugin, Landau, Verwey, and Overbeek (DLVO) theory suggests that interactions between the floc/biofilm components are stabilized when van der Waals forces and the electrostatic repulsive forces that are caused by interpenetration of electrical double layers are added together (Jorand et al., 1998; Zita and Hermansson, 1994). Hydrophobic interactions between EPS and bacterial cells are also important for floc stability. Since the enzyme, pronase $\mathrm{E}$ digested proteins and disrupted hydrophobic interactions, floc dissociation occurred (Endo et al., 1976; Flemming, 2002; Higgins and Novak, 1997; Wingender et al., 1999). Further, salt bridges are thought to be formed by negatively charged EPS and/or by polyvalent cations such as $\mathrm{Ca}^{2+}$ or $\mathrm{Fe}^{3+}$ from nutrients (Flemming, 2002; Liao et al., 2002). In particular, $\mathrm{Ca}^{2+}$ has been suggested to play an important role based on the observation that addition of $\mathrm{Ca}^{2+}$ led to reflocculation of activated sludge (Zita and Hermansson, 1994). An increase in divalent cations $\left(\mathrm{Ca}^{2+}, \mathrm{Mg}^{2+}\right)$ also improved protein binding within the EPS matrix. This might be because salt bridges were formed with a relatively high content of negatively charged amino acids in the protein (Higgins and Novak, 1997; 
Wingender et al., 1999). Removal of salt bridging has been used in many studies, including EPS cxtraction experiments. It was found that the use of cation exchange resin (CER) and ethylenediaminetetraacetate (EDT $\Lambda$ ) released humic substances, protein and carbohydrates from flocs into bulk water. The release of EPS was likely to occur because the displacement of $\mathrm{Ca}^{2+}$ with $\mathrm{N}^{+}$in activated sludge flocs would reduce binding of biopolymers within the floc (Brown and Lester, 1980; Higgins and Novak, 1997; Keiding and Neilsen, 1997; Zhang et al., 1999). In addition, EDTA was used to measure a floc stability (a dissociation constant) (see more detailed description below) (Endo et al., 1976; Liao et al., 2002).

The diffusion property relates to the phenomenon that diffusion through the cell-EPS matrix of biofilms occurs generally at a slower rate than through water. This reduced rate of diffusion potentially reduces rates of nutrient and oxygen delivery to cells and may also cause the accumulation of inhibitory waste products. The diffusion property and/or the presence of charged reactive groups in EPS might also allow the maintenance of a more favourable microenvironment in an otherwise hostile environment (Wolfaardt et al., 1999).

\subsubsection{Functions of Extracellular Polymeric Substances}

EPS properties are also related to EPS function. In this section, some important EPS functions such as adhesion phenomena, matrix structure formation, supply nutrients, protection effect, and microbial physiological processes are reviewed (Tsuneda $e t a l ., 2003$; Wingender $e t$ al., 1999; Wolfaardt et al., 1999). EPS are important mediators in bacterial adhesion to surfaces. Capsular EPS are thought to be involved in the initial stage of attachment when attractive interactions take place between polymers already present on the bacterial cell surface and the attachment surface (Wolfaardt et al., 1999). Following bacterial aggregation, EPS are also involved in maintaining the structural integrity of floc/biofilms by forming a gel-like 3D network, which leads to a stable biofilm community. Attached microbial cells and microcolonies have been observed to be present in enmeshed fibrous polysaccharides structures (Wolfaardt $e t$ $a l ., 1999)$. The function of EPS in maintaining structural integrity may also lead to deflocculation, which is the collapse of floc or biofilm structure. EPS hydrolysis and deflocculation as well as inhibition of EPS production occur when bacteria in floc/ biofilm are exposed to anaerobic conditions too long. Deflocculation is frequently observed in thick biofilms where oxygen is consumed by aerobic and facultative anaerobic bacteria at the outer layers 
resulting in the creation of areas with anaerobic conditions inside the biofilm (Jin et al., 2003; Nielsen et al. 1996; Wolfaardt et al. 1999). Forming a stable bacterial aggregates also leads to establishing favourable microenvironments. EPS are believed to function to promote spatial organization of cells. For example, microcolony formation allows bacterial cell-cell recognition and interactions between bacterial cells in these close associations (Wolfaardt et al., 1999). It is important to interact among different bacteria (consortial activities) since flocs/ biofilms are generally a heterogeneous community. Consortial activities involve maximizing bacterial metabolic capabilities through co-operative interactions between two or more populations sharing a mutual habitat such that individual members interact to optimize nutrient utilization and waste cycling. Through these interactions the individual cells contribute to the overall maintenance of population or community integrity and stability and thereby their own survival (Wolfaardt et al., 1999).

In creating favourable microenvironments, EPS are also suggested to function as a protective barrier on organisms in flocs/biofilms against adverse abiotic and biotic influences from the environment, such as extreme $\mathrm{pH}$ values, elevated temperature, drying, freezing, biocides, heavy metal ions $\left(\mathrm{Cu}^{2+}, \mathrm{Pb}^{2+}\right.$ and $\left.\mathrm{Cr}^{3+}\right)$ and detergents (Wolfaardt $e t$ al., 1999). As an example, it has frequently been observed that biofilm cells can tolerate significantly higher. concentrations of certain biocides including disinfectants and antibiotics than planktonic populations. This is understood to be due mainly to physiological changes of biofilm bacteria enhancing their resistance to biocides. Some cells deeply embedded in a biofilm alter its physiology since they receive less oxygen and nutrients, so that the buried cells become more resistant to the uptake of toxic agents and antibiotics (Bower and Daeschel, 1999; Smith et al., 2000; Williams et al., 2003; Wolf et al., 2002). Furthermore, it is also assumed that barrier function of the EPS matrix (and in particular, the extracellular carbohydrates) prevents biocides or host defence mechanisms from reaching target bacteria within the biofilm by hindering diffusion and inactivating reactions with biocides (Bower and Daeschel, 1999; Davey and O'toole, 2000; Flemming, 2002; Samrakandi et al., 1997; Soda et al., 1999; Wolf et al., 2002). The function of EPS in providing bacteria in flocs/biofilms with nutrients has not been clarified yet. Some studies have indicated that EPS generally do not serve as reserve sources of carbon and energy. Other studies have shown that there appear to be at least two ways in which EPS may function as a food reservoir: (i) Production of EPS as nutrient reserve and (ii) Accumulation 
of nutrients by EPS (Wolfaardt et al., 1999). Nevertheless, it was observed that river biofilms were remarkably resilient to depletion of organic matter from the overlying waters, suggesting that a store of energy existed within the biofilm that was able to supplement cxogenous sources during periods of scarcity (Williams et al.. 2003: Wolfaardt et (cl., 1999). EPS protein, enzymes in floc/ biofilm also have an important function in obtaining nutrients from the environment. Exoenzymes released by bacteria into their external environment were generally adsorbed in EPS in floc/ biofilm. These adsorbed enzymes digest exogenous macromolecules and particulate material in the microenvironment and provide low-molecular weight nutrients, which can readily been taken up and metabolized by the bacterial cells (Wolfaardt et cl., 1999). Furthermore, these adsorbed enzymes may also be involved in the degradation of carbohydrate EPS allowing the release of biofilm bacteria and the spreading of the bacteria to new environments (Wingender $e t$ al., 1999; Wolfaardt et al., 1999).

Several of the functions of EPS are summarized in the Table 2.

Table 2. Functions of bacterial EPS (Adopted from Wingender et al., 1999)

\begin{tabular}{ll}
\hline Function & \multicolumn{1}{c}{ Relevance } \\
\hline Adhesion to surfaces & $\begin{array}{l}\text { Initial step in colonization of inert and tissue surface, accumulation of } \\
\text { bacteria on nutrient-rich surfaces in oligotrophic environments }\end{array}$
\end{tabular}

Stability of biofilms Mediation of mechanical stability of biofilms (frequently in conjunction with multivalent cations), determination of the shape of EPS structure (capsule, slime, sheath)
Aggregation of bacterial cells, formation of flocs and biofilms

Cell-cell recognition

Retention of Water

Sorption of exogenous compounds
Bridging between cells and inorganic particles trapped the environment, immobilization of mixed bacterial populations, basis for development of high cell densities, generation of a medium for communication processes. cause for biofouling and biocorrosion events

Symbiotic relationships with plants or animals, initiation of pathogenic processes

Prevention of desiccation under water-deficient conditions

Scavenging and accumulation of nutrients from the organic environment, sorption of xenobiotics (detoxification) 
Table 2. Functions of bacterial.EPS (Cont.)

\begin{tabular}{ll}
\hline $\begin{array}{l}\text { Function } \\
\text { Sorption of inorganic } \\
\text { compounds }\end{array}$ & $\begin{array}{l}\text { Accumulation of toxic metal ions (detoxification), promotion of } \\
\text { carbohydrate gel formation, mincral formation }\end{array}$ \\
$\begin{array}{l}\text { Enzymatic activitics } \\
\text { Interaction of } \\
\text { carbohydrates with } \\
\text { enzymes }\end{array}$ & $\begin{array}{l}\text { Digestion of exogenous macromolecules for nutrient acquisition, } \\
\text { release of biofilm cells by degradation of structural EPS of the biofilm }\end{array}$ \\
Protective Barrier & $\begin{array}{l}\text { Resistance to non-specific and specific host defences (complement- } \\
\text { mediated killing, phagocytosis, antibody response, free radical } \\
\text { generation), resistance to certain biocides including disinfectants and } \\
\text { antibiotics, protection of cyanobacterial nitrogenases from harmful } \\
\text { effects of oxygen }\end{array}$ \\
\hline
\end{tabular}

\subsection{Bacterial Adherence in Biofilms/Flocs}

Pathogen association with flocs thought to be deeply related to microbial adhesion to flocs and floc and EPS properties. However, microbial adhesion and floc properties have generally only been examined during floc formation in the context of seeking ways to improve wastewater processes. The mechanism of microbial adhesion onto established (preformed) flocs has been examined only a limited number of studies. In one study, Olofsson et al. (1998) reported that hydrophobic interaction is involved in microbial adhesion onto preformed flocs. They examined adhesion of hydrophilic and hydrophobic microbial cells onto sludge flocs and found the correlation between microbial cell surface hydrophobicity and the numbers of adherent cells to flocs (Olofsson et al., 1998). Furthermore, adherent hydrophobic bacterial cells in flocs were more widely dispersed on the surface of the floc and in the interior of the floc whereas hydrophilic microbial cells were found on the surface (Olofsson et al., 1998). Other studies have been focused on the surface features of flocs and microorganisms, such as extracellular polymeric substances (EPS), flagella, fimbriae and pili and their involvement in microbial adhesion (Bura et al., 1998; Park et al., 2000). As an example, Park et al. (2000) examined the involvement of filamentous cell appendages in microbial adhesion. When an activated sludge sample was treated with either pronase $\mathrm{E}$ or carbohydrate-oxidizing agent, some bacteria were released from the activated sludge flocs due to the loss of extracellular filamentous cell 
appendages. Consequently, adhesion ability of these released bacteria surface was affected significantly (Park et al., 2003). This result might indicate that EPS proteins and carbohydrates may be important in microbial adhesion. Interestingly, another study focused on the cell appendages of Myxococcus xanthus (M. xanthus) and microbial adhesion (Bchmlander and Dworkin, 1994). M. xanthus produces large amounts of extracellular material, which is in the form of extracellular matrix fibrils. It has been proposed that the fibrils are the mediators of the ccll-cell cohesion in M. xanthus, which form the basis for the social and developmental lifestyle of this organism (Behmlander and Dworkin, 1994). In order to study the biochemical interaction and structure of extracellular matrix fibrils, fibrils isolated from $M$. xanthus were treated with pronase $\mathrm{E}$ or periodic acid to digest carbohydrates. Removal of the protcins caused no detectable change in the fibrils structure, however, digestion of the carbohydrates resulted in dissolution of fibrils structure (Behmlander and Dworkin, 1994). This result indicated that the proteins were not involved in the maintenance of fibrillar structure. Furthermore, it suggested that the fibrils structure consist of a carbohydrate backbone coated with associated protein (Behmlander and Dworkin, 1994). The possible fibrils structure might serve as a clue for EPS fibrillar structure.

\subsubsection{Gene Expression of Bacteria in Biofilms/Flocs}

Bacteria sense their surrounding environmental conditions and adapt to the environment by morphological and physiological changes such as respiration rate and reproduction ability. These changes are thought to give the bacteria an optimum strategy to protect themselves against environmental stresses. The environmental stresses include temperature, pH, dissolved oxygen, some inhibitors and starvation (Özkanca and Flint, 1997). For example, starvation triggers changes in the expression of outer membrane proteins (OMPs). OMPs are related to stabilization of membrane, retaining cell shape and membrane transport. The changes in OMPs expression lead to a smaller and more rounded appearance of E. coli (Özkanca and Flint, 2002; Wang and Doyle, 1998). Microbial adhesion in flocs/ biofilms causes bacteria to change in expression of certain genes. Schembri et al. (2003) observed significant gene expression changes in E. coli K12 (non-pathogenic strain) between growth phase in biofilm and that in planktonic form and between planktonic growth phases, the exponential and stationary growth phases (Schembri $e t$ al., 2003). Highly expressed genes in biofilms were associated with cell structure such as fimA encoding type 1 fimbriae and $f l u$ encoding $\mathrm{Ag} 43$. The type 1 fimbriae and $\mathrm{Ag} 43$ are known to be 
involved with initial attachment process and autoaggregation. respectively, which enhances biofilm formation (Schembri et al., 2003). Furthermore, the expression of rpoS-rcgulated genes was also altered in biofilms. The rpoS-encoded sigma factor $\sigma$ controls the expression of genes in $E$. coli in cellular responses to a range of stresses including starvation, osmotic stress, acid shock, cold shock, heat shock, oxidative DNA damage and transition to stationary phase. Since oxygen and nutrient starvation are typically occur in the interior regions of biofilms, the rpoSregulated genes are important for $E$. coli to survive in biofilms, otherwise $E$. coli biofilm growth would be dramatically impaired (Schembri et al., 2003).

Based on the literature searching done to date, it appears that the virulence expression of E. coli $\mathrm{O} 157: \mathrm{H} 7$ that are/have been adhered to flocs has not been studied yet. It is important to investigate whether the virulence expression of adherent $E$. coli $\mathrm{O} 157: 1 \mathrm{H} 7$ to flocs remains since this will impact the importance of flocs and it might also be useful in developing a better understanding of the mechanism of virulence gene expression in this pathogen.

\subsection{Significance of Escherichia coli 0157:H7}

In North America, E. coli O157:H7 has been frequently associated with outbreaks of food-borne and water-borne diarrhea, which can result in hemorrhagic colitis and/or the lifethreatening haemolytic uremic syndrome (HUS) (Li et al., 2000). It has been found that the infectious dose of E. coli O157:H7 is as low as 50 organisms (Kuntz and Kunts. 1999; Rice, 1999; Tilden et al., 1996). In addition to the low infectious dose, other factors also enhance the risk of infection. First, the increase in pathogenic $E$. coli contamination may be associated with an increase in the spectrum of animal reservoirs. Stx-producing E. coli, including $E$. coli $0157: \mathrm{H7}$, has been found to have originated not only from cows, but also a number of animal species including sheep, goats, deer, pigs, poultry, cats, dogs and wild birds (Burnett et al., 2000; Ceponis el cl., 2005; Kaper, 1998; Nielsen and Scheutz, 2002). It was reported that seagull droppings are attributed to $E$. coli $\mathrm{O} 157: \mathrm{H} 7$ contamination at urban landfills and in intertidal sediments (Kaper, 1998; Wallance et al., 1997). Second, E. coli O157:H7 might persist in natural environments for the extended periods of time. Recent studies showed that the viability of $E$. coli O157:H7 was affected by predation, competition, bacterial inhibitors, temperature and level of nutrients, similar to non-pathogenic E. coli. E. coli O157:H7 persisted longer at lower temperatures and nutrient levels but did not survive as long in the presence of predation and 
competition (Allen et cl., 2001; Arts and Killham, 2002; Ogden et cl., 2001; Wang and Doyle, 1998). It was reported that some E. coli O157:117 was able to produce EPS and form biofilms, which are linked to its protection from environmental stresses (Ryu and Beuchat, 2004). Third, transmission routes of enterohemorrhagic E. coli (EHEC) including E. coli $\mathrm{O} 157: \mathrm{H} 7$ are increasing. Initially, transmission of $E$. coli $\mathrm{O} 157: \mathrm{H} 7 \mathrm{was}$ associated with consumption of beef products and contaminated water and person-to-person transmission. Later, the consumption of uncooked vegetables and fruits such as lettuce and apple juice were also recognised as a transmission route (Burnett et al., 2000; Rice, 1999; Wachtel et al., 2002). These vegetables and fruits are likely contaminated by animal feces during growth or processing (Besser et al., 1999; CDC, 1997; Kaper, 1998). It has been demonstrated that E. coli O157:H7 can infiltrate the core of an intact fruit (apple) as well as a punctured fruit, which makes it difficult to eliminate these pathogens.

\subsection{Pathogenesis Enterohemorrhagic Escherichia coli}

\subsubsection{Adhesion}

E. coli $\mathrm{O} 157: \mathrm{H} 7$ belongs to a group of enterohemorrhagic $E$. coli (EHEC) within a group of Shiga toxin-producing E. coli (STEC) (Johson-Henry et al., 2001). The first step in EHEC pathogenesis is the colonization of the intestinal mucosal surface, however, the mechanisms underlying the adherence of EHEC to epithelial cells is still only partly understood (Tarr et al., 2000). It has been suggested that $E$. coli 0157 adhesion is stimulated by conditions such as those in the large bowel, the presumed site of infection (Law, 2000). The ability to adhere to epithelial cells is an important virulence trait, because adherence presumably cnablcs EIIEC to deliver toxins efficiently to host organs, overcome peristaltic resistance and gain access to host derived nutrients (Tarr et al., 2000). The fimbriae and outer membrane protein (OMP) have been identified as possible EHEC adhesins (Law, 2000). For example, E. coli O157:H7 possesses an adherence-conferring protein, Iha, which confers the capacity to adhere to epithelial cells in a diffuse pattern rather than discretely localized adherence. Iha is encoded by a chromosomal gene, iha, coding for a protein similar to the IrgA (iron-regulated gene A) protein of Vibrio cholerae (Tarr et al., 2000). Many studies have also been conducted on intimin as a potential adhesin involved in both initial attachment and intimate attachment. Intimin was found 
to be critical for intimate attachment of EHFCC to the enterocyte, causing A/E lesions (Allen et al., 2001; Law. 2000; Nicholls, 2002: Rice. 1999; Tarr et al.. 2000).

\subsubsection{Virulence Factors}

Most important virulence factor in the pathogenesis of disease due to EHEC is Shiga toxin (Stx). EHEC produces Shiga toxins (Stx1 and Stx2) that are cytotoxic to human renal endothelial cells. The typical renal histopathology consists of swollen glomerular endothelial cells and deposition of platelets and fibrin within the glomeruli. The decreased glomerular filtration rate can lead to the acute renal failure seen with HUS (Kaper, 1998). EHEC also produces several effector molecules that subvert cellular processes and contribute to disease. These effectors modulate host cell pathway's to promote bacterial survival and replication within the host. In addition, the majority of E. coli $\mathrm{O} 157$ isolates possess a large 60-MDa plasmid designated pO157 however, the role of this plasmid in pathogenesis is not certain (Kaper, 1998; Law, 2000; Sperandio et al. 1999). Infections caused by EHEC result in histopathology called attaching and effacing (A/E). A/E lesions are characterized by effacement of intestinal microvilli, followed by intimate association of bacteria to host cells and pedestal structure formation containing high concentration of actin and intermediate filaments directly beneath the adherent bacteria. A/E lesion formation correlates with severity of infection in the host since a loss in absorptive intestinal surfaces may result in ionic imbalance and diarrhea production, however, its exact role in disease is unknown (Jarvis and Kaper, 1996).

The genes required for the formation of $\mathrm{A} / \mathrm{E}$ lesions are clustered together in a single chromosomal pathogenicity island known as the locus for enterocyte effacement called the LEE encodes all of the known virulence factors necessary for $\mathrm{A} / \mathrm{E}$ lesions. These genes are organized into three major regions with known functions. The middle region contains the genes eae encoding intimin, an outcr membrane protein required for intimate attachment and Tir encoding the protein translocated intimin receptor (Tir). Upstream of eae and Tir are genes encoding the type III secretion system (TTSS). The third major region of the LEE, located downstream of eae, encodes several translocated effector proteins (Acheson, et al., 1998; Law, 2000; Rice, 1999). TTSS spans both inner and outer bacterial membranes and upon contact with host cells, which has been described as a 'molecular syringe' TTSS is dependent on the E. coli secreted proteins EspA, EspB and EspD, which are proposed to form TTSS translocon. The EspA forms 
filamentous structures on the bacterial surface bridging to the host cells's surface. (Law, 2000; Li el al., 2000). These structures facilitate translocation of effector molecules such as EspB and Tir. The EspB is delivered primarily into the host cell membrane, where it becomes an integral membrane protein. EspB along with EspD probably forms a pore structure through which other bacteria effectors, such as Tir, gain access to the host cell (Law, 2000).

\subsubsection{Attaching and Effacing Lesions}

The Tir is translocated into host cells via TTSS where it forms a hairpin structure in the host cell plasma membrane with two transmembrane domains, an extracellular loop and aminoand carboxy-terminal domains that are exposed to the host cell cytoplasm. The extracellular loop of Tir interacts directly with the bacterial outer membrane protein intimin, thus anchoring the bacteria tightly to the host cell. The cytoplasmically exposed domains of Tir bind host cytoskeletal and signalling proteins and initiate $\mathrm{A} / \mathrm{E}$ lesion. This results in disassembly of microvilli in infected cells and the formation of the characteristic actin pedestal structures underneath adherent bacteria (Gruenheid et cl., 2004).

The mechanism of pedestal formation of EHEC has been studied but is not well understood yet. On the other hand, the mechanism of pedestal formation of enteropathogenic $E$. coli (EPEC) is better understood and this mechanism can be examined to assist in understanding the mechanism of pedestal formation of EHEC. EPEC is a major cause of non bloody diarrhea in infants. A crucial difference between EPEC and EIIEC is that the former do not produce Shiga toxin (Kaper, 1998).

Following initial adherence to the epithelial cells, EPEC insert virulence factors (effector molecules) via TTSS for intimate attachment into host cells. EPEC Tir is tyrosine and serine/threonine phosphorylated upon insertion into the host cell membrane, and phosphorylation of tyrosine 474 is required for pedestal formation. Pedestal structure formation requires the recruitment of neural-Wiskott-Aldrich syndrome protein (N-WASP), which is recruited to the pedestal in a Tir tyrosine phosphorylation-dependent manner. N-WASP functions to target the actin-related protein 2 and 3 (Arp2/3) complex to Tir, which is required for pedestal elongation. Both N-WASP and the Arp2/3 complex are essential for pedestal formation. Other cytoskeletal proteins recruited are $\alpha$-actinin, ezrin, cortactin, talin, fimbrin, vasodilator-stimulated phosphoprotein (VASP) and villin (Goosney et al., 2001). $\alpha$-Actinin has recently been shown to 
bind Tir directly at its $\mathrm{N}$ terminus independently of "Tir phosphorylation and may function to link Tir directly to the actin cytoskeleton. Additionally. the amino-terminus of EPEC Tir binds directly to the host actin binding and cross-linking protcin $\alpha$-actinin anchoring Tir to the host actin cytoskeleton. The focal adhesion proteins talin and vinculin have also been shown to interact directly with Tir (Devinney et al., 2001).

Considerably less is understood about the mechanism of $\Lambda / E$ lesion formation by EHEC. Unlike EPEC Tir, EHEC Tir is phosphorylated on serine or threonine but not on tyrosine, however, the role of these phosphoprylation events is still unknown. EHEC seem to have additional bacterial factors delivered to the host cell (Devinney et al.. 2001). With regard to the pedestal structure formation, $\alpha$-actinin, actin, N-WASP and the Arp 2/3 complex are recruited to the EHEC pedestal (Goosney et al., 2001). Despite the differences in the additional bacterial factors and Tir phosphorylation, EHEC forms seemingly identical pedestal structures with the host cell (Devinney et al., 2001). $\alpha$-Actinin also forms tight profiles associated with EHEC (Finlay et al., 1992). Detection methods using fluorescence microscopy or CLSM is efficient since it allows for scanning a large number of infected host cells for evidence of changes in the cytoskeleton following bacterial infection (Johnson-Henry et al., 2001; Yamamoto et al., 1994).

$\mathrm{A} / \mathrm{E}$ lesion also associated with the cellular changes including an increase in levels of inositol 1,4,5-triphosphate $\left(\mathrm{IP}_{3}\right)$ and intracellular free calcium (Dytoc et al., 1994; Goosney et al., 2001; Kaper, 1998).

\subsubsection{Quorum Sensing Systems}

Quorum sensing is a mechanism of cell-to cell signalling via the production of compounds known as autoinducers that allow a bacterium to "sense" its own population as well as the population of other bacteria in a given environment (Sperandio et al., 1999). The quorum sensing systems in E. coli $\mathrm{O} 157: \mathrm{H} 7$ regulates the expression of virulence factors such as the TTSS, the Tir and intimin in vivo (Sperandio et al., 1999). It has been proposed that the EHEC TTSS is activated by autoinducers synthesized by normal flora $E$. coli resident in the large intestine. The presence of autoinducers in the large intestine could activate the EHEC LEE genes, thereby allowing intestinal colonization mediated by intimin to proceed (Sperandio et al., 1999). However, it has not been studied if the expression of virulence factors for $E$. coli $\mathrm{O} 157: \mathrm{H} 7$ isolated from environments is affected. 


\section{CHAPTER 3. EXPERIMENTAL METHODS}

\subsection{Experimental Approach}

This chapter contains experimental protocols, including descriptions of the experimental conditions, equipment and chemicals used. It contains three major parts. The first part describes the analysis of floc characterization. This first part discusses the source of flocs, physical analyses of flocs, extraction of EPS and chemical analyses of EPS. The physical analyses of flocs conducted are surface charge, hydrophobicity and dissociation constant. Since EPS are an important part of flocs, EPS was extracted and subject to chemical analyses. The chemical analyses of the EPS conducted are carbohydrate, protein, humic acids and DNA analyses. The second part of the chapter describes the microscopic observation techniques used. beginning with the settings used for conventional optical microscopy (COM) and CLSM. This part also describes the EPS mapping protocol, including the various dyes used. The last part of this chapter describes the analysis of $E$. coli $\mathrm{O} 157: \mathrm{H} 7$ association with flocs. It begins with a description of culture conditions and inoculation of the E. coli O157:H7 strain, continues with the methods used for enumeration of the viable cells and microscopic observation of $E$. coli O157:H7 adhered to flocs, and lastly, describes immunofluorescence detection of $\alpha$-actinin assay.

\subsection{Source of Flocs}

It was initially planned that flocs would be sampled from a Toronto municipal wastewater plant, however, due to difficulties in obtaining and kecping fresh samples, it was decided to use a laboratory scale sequencing batch reactor (SBR). All cxperiments were conducted on flocs obtained from the SBR. The SBR was seeded with activated sludge from a pulp and paper mill wastewater treatment plant and then fed with pulp and paper mill wastewater as described in the following table. The SBR system was operated at pH 8-10 and room temperature with a cycle of: aeration and mixing state for 47 hours, settling for 40 minutes, discharging for 10 minutes.

In some experiments, the obtained floc samples were treated with enzymes pronase $E$ and proteinase $\mathrm{K}$ in order to examine the effect of protein removal on the stability of flocs and EPS composition/distribution. 
Table 3. Composition of pulp and paper mill wastewater (Liu, J., personal communication)

\begin{tabular}{ll}
\hline Substances & $\%$ WT \\
\hline Water & $50-65$ \\
Pulp fibre (cellulose) & $25-40$ \\
Calcium carbonate & $5-15$ \\
Kaolin clay & $1-5$ \\
Titanium dioxide & $<1.0$ \\
Starch & $<1.0$ \\
Sulfur compound & $<1.0$ \\
\hline
\end{tabular}

The enzymes, pronase $E$ and proteinase $K$ were chosen because they only work on extracellular protein. In particular, Endo et al. (1976) foumd that the concentration of DNA (an indicator of the amount of cell lysis) in the enzyme-treated sampie was same as that in the control flocs sample. Pronase $\mathrm{E}$ is a non-specific enzyme that hydrolyses proteins at a number of cleavage sites (Higgins and Novak, 1997). It has been used on an activated sludge sample and flocs formed by floc forming bacteria (Endo, et al., 1976; Higgins and Novak. 1997). Proteinase $\mathrm{K}$ is a serine endopeptidase, which is able to hydrolyse native proteins rapidly. It has been used mostly in molecular biology (Rao et al., 1998).

The floc samples were washed three times in $0.1 \mathrm{M}$ phosphate buffered saline (PBS) (pH7.4) by settling for $30 \mathrm{~min}$, removing supernatant and resuspending in PBS. After washing the floc samples, one of the enzymes $200 \mu \mathrm{g} / \mathrm{ml}$ pronase E (Sigma-Aldrich Canada, Ltd, Oakville, ON) or $200 \mu \mathrm{g} / \mathrm{ml}$ proteinase $\mathrm{K}$ (Sigma-Aldrich) were added to the floc sample and incubated for $2 \mathrm{~h}$ at $37^{\circ} \mathrm{C}$ and $150 \mathrm{rpm}$ (Higgins and Novak, 1997). Two control samples (i.e. floc samples without addition of enzyme and PBS with addition of enzyme) were also prepared (Yi. Z.. personal communication). These control samples were incubated in the same manner. After incubation, all samples were examined to characterize flocs and EPS.

\subsection{Characterization of Flocs \& Extracellular Polymeric Substances}

The physical characteristics of flocs and the chemical characteristics of EPS were examined. The chemical analyses included EPS composition analyses and EPS mapping.

\subsubsection{Physical Analysis of Flocs}

The physical analyses performed included an examination of surface charge, hydrophobicity and the dissociation constant. 


\subsubsection{Hydrophobicity}

The hydrophobicity of enzyme treated flocs and control samples was measured by the microbial adherence to hydrocarbons (MATH) method (Wilén et al., 2003). The floc samples were washed in deionized distilled water twice by centrifuging at $3000 \mathrm{xg}$ for $5 \mathrm{~min}$. Each 1 loc sample were homogenised by using a blender for $1 \mathrm{~min}$. The homogenized sample was diluted in deionized distilled water to absorbance of $1.5 \pm 0.2\left(\mathrm{I}_{0}\right)$ at $400 \mathrm{~nm}$. A $10 \mathrm{ml}$ of the diluted floc sample was mixed with $1.0 \mathrm{ml}$ hexadecane (Sigma) and vortexed for $2 \mathrm{~min}$ and then transferred to a separatory funnel. After $10 \mathrm{~min}$, when the hydrophobic and hydrophilic phases had separated completely, the aqueous phase was collected and absorbance was measured at $400 \mathrm{~nm}$ (I) (Spectronic ${ }^{\mathbb{N}} 20^{+}$, Spectronic Instruments, Rochester, NY, USA). The relative hydrophobicity of each of the samples was calculated using the following equation Eqs 1:

$$
\% \text { Hydrophobicity }=\frac{\left(\mathrm{I}_{0}-\mathrm{I}\right) 100}{\mathrm{I}_{0}}
$$

Where $\mathrm{I}_{0}$ is the initial absorbance $(=1.5 \pm 0.2)$ and $\mathrm{I}$ is the absorbance of the aqueous phase.

\subsubsection{Surface Charge}

The surface charge of the enzyme treated flocs and control samples was measured by colloidal titration (Morgan, el al., 1990). Polybrene and polyanetholsulfonic acid (PAS) were used as the standard cationic and anionic colloids with the indicator toluidine blue. The floc samples were washed in $\mathrm{pH} 7.0$ deionized distilled water twice by centrifuging at $3000 \mathrm{x}$ for 5 min prior to titration. Mixcd liquor suspended solids (MLSS) of each floc sample was measured according to Standard Methods (APHA, 1995). A $2 \mathrm{ml}$ floc sample was diluted in $40 \mathrm{ml} \mathrm{pH} 7.0$ deionized distilled water, mixed with $4.0 \mathrm{ml}$ of excess $0.001 \mathrm{~N}$ polybrene and then titrated against $0.001 \mathrm{~N}$ PAS. Electrical neutrality was reached when the colour of a sample changed from blue to violet pink. An equal volume of the blank solution was prepared by replacing a $2 \mathrm{ml}$ floc sample with $\mathrm{pH} 7.0$ deionised distilled water. The blank solution was also titrated against PAS.

The surface charge for each sample was calculated using the following equation Eqs 2:

Surface Charge (milliequivalents / MLSS $)=-\left(\mathrm{V}_{0}-\mathrm{V}\right) \times \mathrm{N} \times 1000$ $2 \times$ MLSS

Where $\mathrm{V}_{0}$ is the volume of PAS added to blank, $\mathrm{V}$ is the volume of PAS added to floc sample, $\mathrm{N}$ is normality of PAS $(=0.001 \mathrm{~N})$ and MLSS is measured in $\mathrm{g} / 1$. 


\subsubsection{Floc Stability/Dissociation Constant}

Floc stability is characterized by the dissociation constant (Zita and Hermansson, 1994; Liao et al., 2002). The dissociation constant is defined as unit absorbance/gram of biomass/washing, which is generally proportional to the number of fine particles or the mass of fine particles removed from larger flocs per washing and per gram of biomass (Liao et cl., 2002). EDTA is known to cause dissociation of flocs and was used in the determination of the dissociation constant.

First, a $15 \mathrm{ml}$ floc sample was allowed to settle for $30 \mathrm{~min}$. Following settling, the supernatant was removed and the biomass was then resuspended in 0.1M PBS (pH7.4). This step was conducted to remove fine particles and was repeated three times. After removing the line particles, a washing procedure was started. The settled biomass (containing larger flocs) was resuspended in $30 \mathrm{ml}$ of $1000 \mu \mathrm{g} / \mathrm{ml}$ EDTA or $0.1 \mathrm{M}$ PBS (control) (called the diluted floc sample). The diluted floc samples were then gently mixed in a shaker at a speed of $150 \mathrm{rpm}$ for $15 \mathrm{~min}$. The diluted floc samples were then allowed to stand for another $15 \mathrm{~min}$. A $5 \mathrm{ml}$ supernatant was taken out in duplicate and the absorbance of the supernatant was measured at $420 \mathrm{~nm}$ (Spectronic ${ }^{3} 20^{+}$, Spectronic Instruments, Rochester, NY, USA). Once the first washing procedure was completed, the diluted floc sample was next resuspended with a $10 \mathrm{ml}$ fresh EDTA or PBS solution and the next washing was performed. In total, 4 or 5 washings were performed (Liao et al., 2002). Washing was terminated when the absorbance did not increase from the previous washing. A graph of accumulated absorbance in sequential washing versus the number of sequential washings was created to obtain the dissociation constant from the linear slope (standard linear regression) of the graph (Zita and Hermansson, 1994; Liao et al., 2002).

\section{Microscopic studies}

After the last washing was conducted, $50 \mu \mathrm{l}$ of the floc sample was used for a wet mount slide. The floc structure and size were observed under COM with phase contrast at $100 \mathrm{x}$ magnification (please refer to COM section below).

\section{Protein Digestion}

After the last EDTA washing was conducted, the enzyme treatment was prepared. First, the floc samples were resuspended in PBS and allowed to settle for $30 \mathrm{~min}$. After settling, the 
supernatant was removed. This procedure from the resuspension of PBS to supernatant removal was repeated three times. The floc sample was then further resuspended in PBS and $200 \mu \mathrm{g} / \mathrm{ml}$ of an enzyme (pronase $\mathrm{E}$ or proteinase $\mathrm{K}$ ) was added to the floc sample and incubated for $2 \mathrm{~h}$ at 37 " $\mathrm{C}$ (please refer to floc source section). After incubation, the floc structure and size were observed (please refer to microscopical studies). The maximum dimension across a floc was measured. Each floc was categorized as small $(\leq 150 \mu \mathrm{m})$, medium $(150 \mu \mathrm{m}-500 \mu \mathrm{m})$ or large size ( $\geq 500 \mu \mathrm{m})$ according to the manual on the cause and control of floc bulking and foaming (Jenkins, 1993).

\subsubsection{EPS Extraction}

Two types of EPS, loosely bound EPS fraction and bound EPS fraction were extracted from the enzyme treated floc samples and the control sample.

\subsubsection{Extraction of Loosely Bound EPS Fraction}

Easily removed loosely bound EPS was collected by centrifugation. The floc samples were centrifuged at $200 \mathrm{rpm}$ for $2 \mathrm{~min}$. The loosely bound EPS present in the supernatant was stored at $-20^{\circ} \mathrm{C}$ for later EPS composition analyses. The remaining floc was subject to further extraction of bound EPS (Higgins and Novak, 1997).

\subsubsection{Extraction of Bound EPS Fraction}

Bound EPS fraction was extracted by a cation exchange resin (CER) method (Frolund $e t$ al., 1996; Liao et al., 2001). This extraction procedure is based on the method by Frolund et al., (1996). A floc sample was washed three times with extraction buffer ( $2 \mathrm{mM} \mathrm{Na}_{3} \mathrm{PO}_{4}, 4 \mathrm{mM}$ $\mathrm{NaH}_{2} \mathrm{PO}_{4}, 9 \mathrm{mM} \mathrm{NaCl}$ and $1 \mathrm{mM} \mathrm{KCl}$ at $\mathrm{pH} 7$ ) by centrifugation for $15 \mathrm{~min}$ at $1,000 \mathrm{x}$. The amount of CER (DOWEX ${ }^{\text {PD }}$ HCR-W2 Cation Exchange Resin in the sodium form, Supelco, PA, USA) was calculated as $80 \mathrm{~g}$ of resin per gram of washed MLSS and added to the floc. The floc sample with CER was then stirred at $600 \mathrm{rpm}$ for 2 hours at $4{ }^{\circ} \mathrm{C}$. The extracted EPS were harvested by centrifugation for $15 \mathrm{~min}$ at $12,000 \mathrm{x}$. After centrifugation, the bound EPS fraction present in the supernatant was stored at $-20^{\circ} \mathrm{C}$ for later EPS composition analyses.

Prior to the EPS composition analyses, all EPS samples (loosely bound and bound EPS) were centrifuged for $15 \mathrm{~min}$ at $12,000 \mathrm{x} \mathrm{g}$ again. The supernatant of the samples was analyzed 
for carbohydrates, protein, humic substances and DNA concentrations in duplicate (Kraemer, 2002).

\subsubsection{Chemical Analysis of EPS}

\subsubsection{Carbohydrates}

The concentration of carbohydrates was measured by the Gaudy method (Gaudy, 1962; Frolund et cl., 1996). The range of $0-100 \mathrm{mg} / \mathrm{L}$ D-glucose was prepared to obtain a standard curve. At $60 \mathrm{~s}$ intervals, $5 \mathrm{ml}$ ice cold anthrone reagent $(0.2 \%(\mathrm{w} / \mathrm{v})$ anthrone in $95 \%(\mathrm{v} / \mathrm{v})$ $\mathrm{H}_{2} \mathrm{SO}_{4}$ ) was added to a $2.0 \mathrm{ml}$ sample, vortexed for $30 \mathrm{~s}$ and placed in a water bath at $100{ }^{\circ} \mathrm{C}$ for $15 \mathrm{~min}$. Sequentially samples were cooled to room temperature in an ice bath and absorbance was measured at $625 \mathrm{~nm}$ (Spectronic ${ }^{(3)} 20^{+}$, Spectronic Instruments, Rochester, NY, USA).

\subsubsection{Proteins and Humic Substances}

The concentration of protein was measured by a modified Lowry method. Since the coexisting humic substances in EPS affect the protein measurement of the Lowry method, the correction of the protein concentration is required. The protein and the humic substances are measured by the same method except that the protein are measured with $\mathrm{CuSO}_{4}$ addition while the humic substances are measured without $\mathrm{CuSO}_{4}$ addition (Lowry et al., 1951; Frolund et al., 1995 and 1996; Lucarini and Kilikian, 1999). When $\mathrm{CuSO}_{4}$ is omitted the colour development is due to humic substances and chromogenic amino acids (Frolund et cl., 1995).

For the protein measurement, the range of $0-200 \mathrm{mg} / \mathrm{L}$ bovine serum albumin was prepared to obtain a standard curve. At $30 \mathrm{~s}$ intervals, $5 \mathrm{ml} \mathrm{CuSO}_{4}$ alkaline reagent $(0.5 \%(\mathrm{w} / \mathrm{v})$ $\mathrm{CuSO}_{4} \cdot 5 \mathrm{H}_{2} \mathrm{O}$ in $1 \%(\mathrm{w} / \mathrm{v})$ sodium tartrate solution and $2 \%(\mathrm{w} / \mathrm{v}) \mathrm{Na}_{2} \mathrm{CO}_{3}$ in $0.1 \mathrm{M} \mathrm{NaOH}$ solution mixed in a ratio of $1: 25$ ) was added to a $1.0 \mathrm{ml}$ sample. The sample was vortexed for $15 \mathrm{~s}$ and allowed to stand for $10 \mathrm{~min}$. After $10 \mathrm{~min}$ incubation, $0.5 \mathrm{ml} \mathrm{Folin} \mathrm{reagent}(50 \%(\mathrm{v} / \mathrm{v})$ Folin and Ciocalteu's phenol reagent in deionized distilled water (Milli-Q Water Systems, Millipore Corporation, MA)) was added to each sample at $15 \mathrm{~s}$ intervals. The sample was vortexed for $15 \mathrm{~s}$ and allowed to stand for at least $30 \mathrm{~min}$. The absorbance $\left(A_{\text {total }}\right)$ was measured at $750 \mathrm{~nm}$ (Spectronic ${ }^{\circledR} 20^{+}$, Spectronic Instruments, Rochester, NY, USA).

For the humic substances measurement, $0-100 \mathrm{mg} / \mathrm{L}$ humic acids solution was prepared to obtain a standard curve. At 30 s intervals, $5 \mathrm{ml}$ alkaline reagent $\left(2 \%(\mathrm{w} / \mathrm{v}) \mathrm{Na}_{2} \mathrm{CO}_{3}\right.$ in $0.1 \mathrm{M}$ 
NaOII solution) was added to a $1.0 \mathrm{ml}$ sample. The following procedures were the same as the protein procedure. After 30 min incubation, the absorbance ( $\left.A_{\text {hlind }}\right)$ was measured at $735 \mathrm{~nm}$ (Spectronic $20^{+}$, Spectronic Instruments, Rochester. NY, USA).

The correction of protein and humic substances measurement was performed using the following equations Eqs 3-6.

$$
\begin{aligned}
& A_{\text {total }}=A_{\text {protein }}+A_{\text {humic }} \\
& A_{\text {blind }}=0.2 A_{\text {protcin }}+A_{\text {humic }} \\
& A_{\text {protcin }}=1.25\left(A_{\text {total }}-A_{\text {blind }}\right) \\
& A_{\text {lumic }}=A_{\text {blind }}-0.2 A_{\text {protein }}
\end{aligned}
$$

Where $A_{\text {total }}$ is the total absorbance with $\mathrm{CuSO}_{4}, A_{\text {blind }}$ is the total absorbance without $\mathrm{CuSO}_{4}$, $A_{\text {humic }}$ is the absorbance due to humic substances, and $A_{\text {protein }}$ is the absorbance due to protein (Frolund et cal., 1995).

\subsubsection{DNA}

The concentration of DNA was measured by the fluorometric method (Gerhardt et al., 1994) using a standard fluorescent DNA quantitation kit (BIO-RAD Laboratories. Hercule, CA). Calf Thymus DNA was used to obtain a standard curve. $3 \mathrm{ml} 0.1 \mu \mathrm{g} / \mathrm{ml}$ Hoechst dye and an appropriate volume of a sample were mixed well. DNA in the mixed sample was measured by fluorometer (RF-Mini 150 Recording fluorometer, Shimadzu Scientific Instruments, Guelph, On) at $360 \mathrm{~nm}$ excitation and $460 \mathrm{~nm}$ emission.

\subsection{Microscopic Observation of Flocs \& Extracellular Polymeric Substances}

\subsubsection{Conventional Optical Microscopy}

Floc samples were observed using a Zeiss Axiovert 200M inverted microscope equipped with a CCD camera (Carl Zeiss Inc, Toronto, On). Wet mount slides of samples were prepared and examined under phase contrast at $100 \mathrm{x}$ magnification using a Zeiss $10 \mathrm{x} / 0.25 \mathrm{Ph} 1$ objective. Each image was digitally stored in Northern Eclipse Version 6.0 software (Empix Imagin, Inc., Mississauga, On). 


\subsubsection{Confocal Laser Scanning Microscopy}

CLSM is a microscopic technique that has been widely used in many areas. CLSM is generally described as an epilluorescent microscope that creates a thin plane-of-focus in which out-of focus light has been climinated. This can be achieved either by optical barriers (pinholes) or by the physics of light absorption (for "multiphoton" microscopy) (Wolf ct al., 2002). CLSM has been used in combination with a range of fluor-conjugated lectins to study $3 \mathrm{D}$ spatial bacterial arrangement within biofilms (Lawrence $e t a l, 2003$ ). The intense light provided by a laser source is able to penetrate thick specimens, and it can excite either intrinsic biomolecules or added fluorophors. A automated computer-controlled stepping motor is used to scan through the sample, and thus digital XY sections can be collected along the Z-dimension in real time. From these image stacks 3D images of the sample can be reconstructed via computerized image analysis methods (Lawrence et al, 1996; Neu et al, 2001). This method is used in examining the identification and distribution of EPS in flocs.

The CLSM used in this study was a Zeiss Axioplan LSM 510 (Carl Zeiss Inc, Toronto, On) equipped with a water-immersible Achroplan $63 \times 0.9$ numerical aperture (NA) lens and a $63 \mathrm{x} / 1.2 \mathrm{~W}$ NA (Zeiss Inc, Toronto On) lens. The $63 \times 0.9$ NA lens was used for observation of floc samples and the $63 \mathrm{x} / 1.2 \mathrm{~W}$ NA lens was used for observation of epithelial cells. The CLSM is also equipped with Ar lasers (excitation line $488 \mathrm{~nm}$ ) and helium-neon lasers (excitation lines $543 \mathrm{~nm}$ and $633 \mathrm{~nm})$.

\subsubsection{Mapping of Extracellular Polymeric Substances}

\section{Sample Preparation}

Two drops (approximately $300 \mu \mathrm{l}$ ) of floc sample was placed on a plankton chamber plate using a wide mouth pipette and then $700 \mu \mathrm{l} 0.75 \%$ low melting point agarose was added. In this way, the floc remains hydrated and stabilized immediately, which minimizes any floc morphological change (Droppo et al., 1996).

\section{Lectin Dyes and Stains}

Lectins are protein bound to specific carbohydrates. Generally, lectins interact with their target through multiple binding sites via hydrogen bonds, metal coordination, van der Waals and hydrophobic interaction, which increases affinity and specificity (Neu et al., 2001). This 
specificity is very useful to investigate carbohydrates moicty of glycoconjugates in the EPS matrix. Lectins conjugated with fluor have been applied in combination with CLSM to examine fully hydrated environmental biofilms (Neu and Lawrence, 1999; Lawrence et ct. 2003). In addition, the use of stains such as nucleic acids, protein and lipid-hydrophobic sites are also available (Lawrence et al, 2003). The stains used in this study were Syto61 (nucleic acids), SyproOrange (protein), Nile Red (lipid-hydrophobic sites). The fluor conjugated lectins were Canaralia ensiformis (ConA; specifically binds to mannopyranosyl and glucopyranosyl residues). Triticum vulgaris (WGA; $N$-acetylglucosaminyl residues) and Glycine max (SBA; $N$ acetylgalactosaminyl and galactopyranosyl residues). These lectins were chosen because these extracellular polymers are prominently found in EPS excreted by aquatic microorganisms (Bura et al., 1998; Hood and Schmidt, 1996; Kreamer, 2002; Lawrence et al, 2003:). Table 4 lists information about the stains and fluor conjugated lectins used in the present study.

Table 4. Stains and fluor conjugated lectins used in this study

\begin{tabular}{|c|c|c|c|}
\hline $\begin{array}{l}\text { Stains and } \\
\text { Lectins }\end{array}$ & Supplier & $\mathrm{Ex} / \mathrm{Em}^{\prime}$ & Targets \\
\hline Syto61 & Molecular Probes $^{2}$ & $628 / 645$ & Nucleic acids \\
\hline SyproOrange & Molecular Probes $^{2}$ & $470 / 570$ & Protein \\
\hline Nile Red & Sigma $^{3}$ & $552 / 636$ & Lipids, hydrophobic sites \\
\hline Concanavalin $\mathrm{A}$ (ConA) & Molecular Probes ${ }^{2}$ & $650 / 668$ & $\alpha$-mannopyranosyl \\
\hline - Alexa Fluor 647 & & & $\alpha$-glucopyranosyl residues \\
\hline $\begin{array}{l}\text { Wheat Germ Agglutinin (WGA) } \\
\text { - letramethylrhodamine }\end{array}$ & Molecular Probes ${ }^{2}$ & $555 / 580$ & $\begin{array}{l}\mathrm{N} \text {-acetylglucosaminyl } \\
\text { residues }\end{array}$ \\
\hline $\begin{array}{l}\text { Soybean Agglutinin (SBA) } \\
\text {-Alexa Fluor } 488\end{array}$ & Molecular Probes ${ }^{2}$ & $496 / 519$ & $\begin{array}{l}\alpha-\beta-N \text {-acetylgalactosaminyl } \\
\text { galactopyranosyl residue }\end{array}$ \\
\hline
\end{tabular}

Table 5 lists the stock concentration and final concentration of stains and fluor conjugated lectins used in this study. A stock solution of each stain or conjugate-conjugate was prepared and stored at $-20^{\circ} \mathrm{C}$. Staining was performed following the stabilization of flocs. Prior to staining, the stock solution was thawed and centrifuged for $2 \mathrm{~min}$ at max speed. The concentration of stock solution was appropriately diluted using 0.1M PBS (pH7.4) with $1 \mathrm{mM}$ $\mathrm{Ca}^{2+}$ and $\mathrm{Mn}^{2+}$ according to the final concentration of stains and fluorescent probes. After the agarose solidified, the diluted stains and fluorescent probes were applied to the stabilized floc sample and incubated for $1 \mathrm{~h}$ at $\mathrm{RT}$ in a dark place. After $1 \mathrm{~h}$ incubation, excess dyes were 
washed out using $0.1 \mathrm{MPBS}$ (pl 17.4) with $1 \mathrm{mM} \mathrm{Ca}^{2+}$ and $\mathrm{Mn}^{2+}$ three times. Lastly, the stabilized lloc sample was dried for 10 min at RT in a dark place.

Table 5. Stock concentration and final concentration of stains and fluor conjugated lectins

\begin{tabular}{lll}
\hline Stains and Lectins & Stock Concentration & Final Concentration' \\
\hline Syto61 & $5 \mathrm{mM}$ solution in DMSO & $2 / 1000$ of stock solution \\
SyproOrange & $5000 \times$ concentrate in DMSO $1 / 1000$ of stock solution \\
Nile Red & $1 \mathrm{mg} / \mathrm{ml}$ in acetone & $2 \mu \mathrm{g} / \mathrm{ml}$ \\
ConA & $2 \mathrm{mg} / \mathrm{ml}$ & $100 \mu \mathrm{g} / \mathrm{ml}$ \\
WGA & $1 \mathrm{mg} / \mathrm{ml}$ & $10 \mu \mathrm{glml}$ \\
SBA & $2 \mathrm{mg} / \mathrm{ml}$ & $10 \mu \mathrm{g} / \mathrm{ml}$ \\
\hline IAll stock solutions were diluted with pH 7.4 Phosphate Buffer Saline (PBS) containing &
\end{tabular}

\section{Image Acquisition}

The CLSM scanned through the sample at 2- $\mu \mathrm{m}$ z-interval in the fluorescence mode, reflectance mode and transmission mode. CLSM parameters are shown in Table 6. Each scan contained three channels that were assigned to three stains, lectin conjugate, or three different modes.

Table 6. CLSM parameters

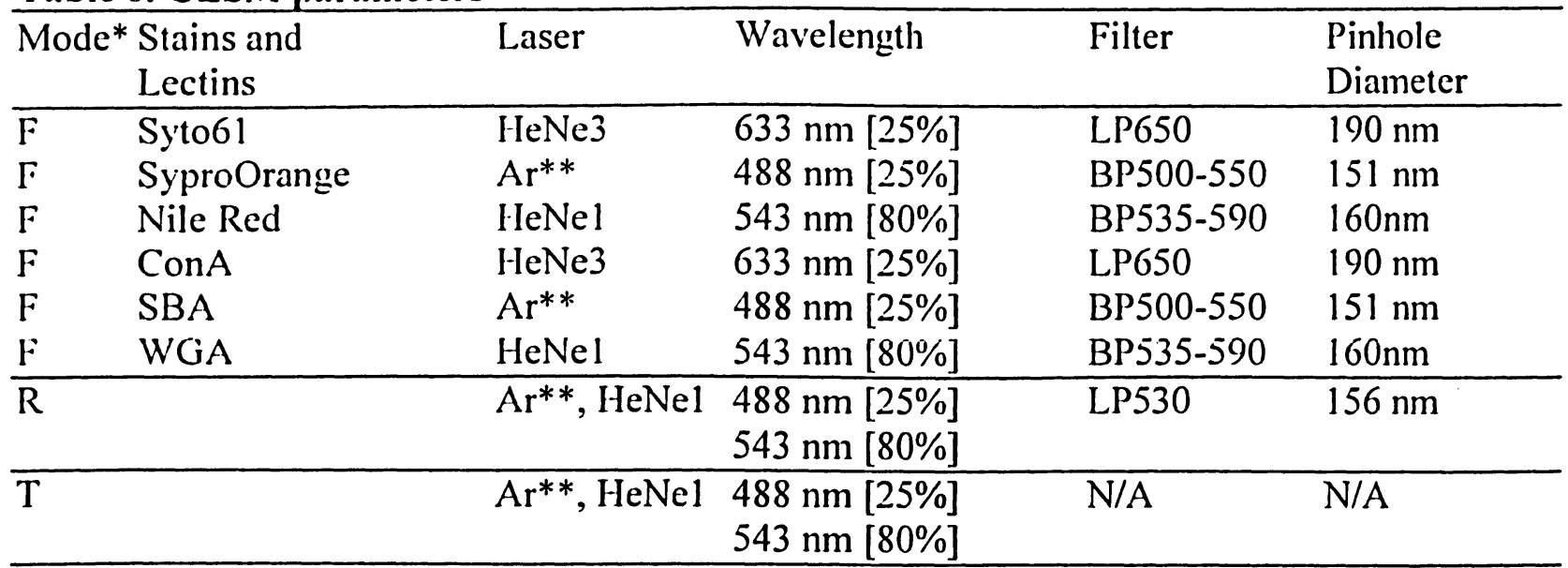

* Mode; $\mathrm{F}$ is fluorescence mode, $\mathrm{R}$ is reflectance mode and $\mathrm{T}$ is transmission mode.

**Output of Ar laser was set at $25 \%$.

Table 7 describes the combinations of stains, lectin-conjugate, modes and assigned channels and colour. Scans were performed at a scan speed of $8.96 \mu \mathrm{s} /$ pixel and line averaging of 1. In order to obtain the exact floc area in three modes, each floc area scanned in the fluorescent 
mode was immediately scanned in the reflectance or transmission mode. Scanned images were stored using LSM 510 release 2.3 software (Carl Zeiss Inc, Toronto, On).

Table 7. Stains, fluor conjugated lectins, modes, assigned channels and colour

\begin{tabular}{llll}
\hline $\begin{array}{l}\text { Stains and } \\
\text { Lectins }\end{array}$ & $\begin{array}{l}\text { Assigned } \\
\text { Channel }\end{array}$ & Mode & Assigned \\
Syto61 & 1 & Folour \\
SyproOrange & 2 & Fluorescent & Blue \\
Nile Red & 3 & Fluorescent & Green \\
\hline ConA & 1 & Fed \\
SBA & 2 & Fluorescent & Blue \\
WGA & 3 & Fluorescent & Green \\
\hline & & & Red \\
\hline
\end{tabular}

Image Analysis

LSM 510 release 2.3 software was used to create the orthogonal section images for each

z-stacked image. In this way, vertical and horizontal distribution of EPS composition was

examined easily. Images obtained were further examined/modified using Photoshop ${ }^{\mathrm{TM}} 6.0$ in order to provide more detailed filtering and image processing.

\subsection{Escherichia coli 0157:H7 Association with Flocs}

The pathogenicity of E. coli $\mathrm{O} 157: \mathrm{H} 7$ can be detected by a phenotypic examination. In this study, the presence of $E$. coli O157:H7 and their pathogenic expression in epithelial cells was examined using an antibody specifically targeted for $E$. coli $\mathrm{O} 157$ and $\alpha$-actinin. All experiments were conducted twice.

\subsubsection{Strains, Plasmids and Growth Conditions}

EHEC 86-24 (O157:H7) carrying the plasmid pJBA29 was used in this experiment. In the remainder of this document, the term EIIEC refers specifically to this strain carrying this plasmid. EHEC had been previously transformed with the plasmid pJBA 29 (Kanetani, 2003) The plasmid pJBA29 was isolated from Escherichia coli JB122, which was kindly provided by J.T. Trevors of the University of Guelph. The plasmid pJBA 29 is a $g f p$ vector of a suicide plasmid harbouring the mini-Tn 5 transposon (Figure 1). It is maintained only in strains that have the $\lambda$ pir. The transposase located outside of the mini-Tn5 operates to make the transposon move. Once it moves, it remains stable in the recipient cell's replicon (So et al., 2002). 
EHEC were grown on Luria-Bertani (LB) agar or in LB broth with $100 \mu \mathrm{g} / \mathrm{ml}$ ampicillin (amp) and $100 \mu \mathrm{g} / \mathrm{ml}$; kanamycin (kan) for $18 \mathrm{~h}$ at $37^{\circ} \mathrm{C}$ with $200 \mathrm{rpm}$ agitation. EHEC were stored at $-80{ }^{\circ} \mathrm{C}$ in $50 \% \mathrm{LB}$ broth $-50 \%(\mathrm{v} / \mathrm{v})$ glycerol stock.

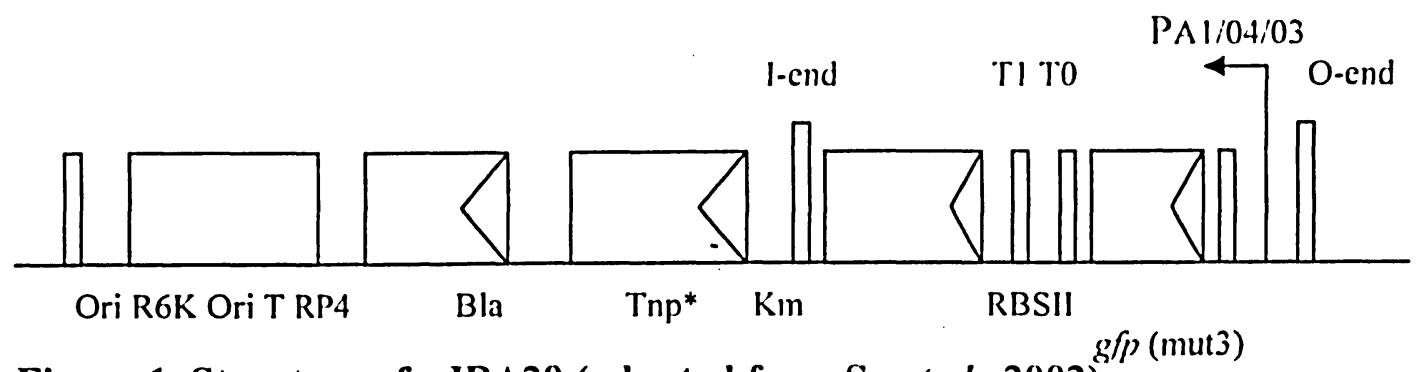

Figure 1. Structure of pJBA29 (adapted from So et al., 2002)

bla, a gene encoding $\beta$-lactamase (ampicillin resistance gene): $\mathrm{Km}$, kanamycin resistance gene: Tnp*, transposase: $g f p$ gene: RBSII, ribosome binding site of phage T5: 'T0, terminator from phage lambda: T1, terminator from the $r n \mathrm{~B}$ operon of $E$. coli: PA1/04/03, inducible (IPTG) promoter composed of the phage T7-promoter combined with two lac operators.

\subsubsection{Inoculation of Escherichia coli $\mathrm{O} 157: \mathrm{H7}$}

Focs were obtained from mixed liquor removed from the SBR and three types of samples were prepared. These were a buffer sample where flocs were suspended in $0.1 \mathrm{M}$ phosphate buffer saline (pH 7.4), an SBR sample, and an SBR sample with replenished nutrients (NSBR). The nutrients were added on day 2,5 , and 7 of incubation by removing supernatant and adding an equal volume of the SBR feed solution. These samples were then referred to as the NSBR samples. In this section, water type sample name is mentioned. Since the water type sample name was long, a shorter code name was given. For example. EHEC in flocs suspended in PBS buffer for 2 days was shortened to 2_BF by taking the number of incubation days, letter of water sample type (B is PBS buffer, S is SBR, and N is NSBR) and letter of EHEC type (F is flocadherent EHEC and $\mathrm{S}$ is free-living EHEC isolated from supernatant).

All of the floc samples were spiked with $10^{8}$ colony forming unit (CFU)/ml overnight culture of EHEC. The floc samples were shaken at $150 \mathrm{rpm}$ at room temperature and observed for 10 days.

\subsubsection{Enumeration of Escherichia coli $\mathrm{O} 157: \mathrm{H} 7$ by Plate Counts}

The number of EHEC in the free-living form and adherent form (i.e. adhered to the llocs) were daily estimated by plate counts in triplicate. The free-living form EHEC in supernatant 
were obtained by settling the floc samples for $30 \mathrm{~min}$. The adherent EHEC were obtained by breaking up the remaining floc sample utilizing syringe and vortex. These were diluted and then plated out on LB plates as indicated above. On the day following plating. the number of colonies was counted. To confirm the GFP 86-24 marking, colonies on the LB plates were examined under COM with UV or plated on DC plates (Gelda Scientific, Mississaiga. ON). DC plates contain two chromogenic substrates, 5-bromo-4-chloro-3-indolyl- $\beta$-D-glucuronide and 6-chloro3 -indolyl- $\beta$-D-galactoside. $E$. coli has enzymes to utilize both substrates. while most other known coliforms have the enzyme only for the galactoside substrate. As such, E. coli colonics appear blue, non-E. coli coliform colonies appear pink and non-coliform colonies appear white or translucent (Umble, et al., 1999 ).

\subsubsection{Direct Observation of Adherent Escherichia coli $0157: H 7$ by Confocal Laser}

\section{Scanning Microscopy}

The distribution of adherent EHEC in flocs was observed by CLSM at intervals of 2, 5 and 7 days. The flocs with adherent EHEC were stabilized in the same manner described in the sample preparation under EPS mapping. The prepared samples were scanned under CLSM in the two modes: fluorescence mode (Ar laser) and transmission mode. The CLSM parameters and image analysis procedures were performed in the same manner as those listed under EPS mapping.

\subsubsection{Pathogenicity of Escherichia coli O157:H7 Isolated From Water Samples}

\subsubsection{Immunofluorescence Detection of $\alpha$-Actinin}

The pathogenicity of EHEC extracted from both systems, flocs and supernatant, in PBS buffer, SBR and NSBR were examined. Two aspects of pathogenicity were examined. First is a level of host adhesion ability, which depends on expression of adhesions. Second is a level of $\alpha$ actinin accumulation (foci of $\alpha$-actinin), which depends on host adhesion as well as expression of other virulence factors (Foster, personal communication). Foci of $\alpha$-actinin were detected in infected epithelial cells by following the protocol previously described (Johnson-Henry et al., 2001). A single colony of EHEC was obtained from the enumeration plates for 2 day, 4 day and 10 day incubation. EHEC were grown overnight in $10 \mathrm{ml} \mathrm{LB}$ broth as indicated. $1 \mathrm{ml}$ overnight culture EHEC was grown for $2 \mathrm{~h}$ in static, $7 \mathrm{ml}$ Dulbecco minimal Eagle medium (DMEM) 
(Gibco Laboratories, Gand Island, N.Y.) at $37^{\circ} \mathrm{C}$ in $5 \% \mathrm{CO}_{2}$. The human epithelial cell line. HEp-2 was grown to $80 \%$ confluence at $37^{\circ} \mathrm{C}, 5 \% \mathrm{CO}_{2}$ in Minimal Essential Media (MEM) (Gibco) containing $10 \%$ fetal calf serum (FCS) (Cansera International Inc) and $0.1 \%$ gentamycin (Gibco BRL) in four-well chamber slides (Nunc Inc, Naperville Ill USA).

Monolayers of HEp-2 cells (approximately $10^{5}$ epithelial cells per well as determined by count with a hemocytometer slide) were washed with sterile PBS ( $\mathrm{pH}$ 7.1) two times, and then infected with approximately $10^{7}$ EHEC (total number of EHEC in DMEM was estimated by spectrophotometer at $600 \mathrm{~nm}$ and the inoculation volume was calculated) at a multiplicity of infection of 100:1 in MEM without FCS and gentamycin for 4 hours at $37^{\circ} \mathrm{C}$ in $5 \% \mathrm{CO}_{2}$. After 4 hours, non-adherent bacteria were removed from the cells by six washes with PBS. The monolayers were then fixed in $98 \%$ methanol at room temperature for $10 \mathrm{~min}$ and followed by three washes with PBS.

The fixed cells were incubated with a 1/100 dilution of goat anti E. coli O157 (Biodesign International, Saco, ME, USA) as primary antibody for $1 \mathrm{~h}$ at $37{ }^{\circ} \mathrm{C}$ with gentle shaking. After six washes with PBS, the fixed cells were incubated with a $1 / 100$ dilution of Alexa Fluor ${ }^{k} 647$ donkey anti-goat IgG conjugate (Molecular Probes, Inc, Eugene. Oreg USA) as secondary antibody with protection from light for $1 \mathrm{~h}$ at $37^{\circ} \mathrm{C}$ with gentle shaking. After six washes with PBS, the fixed cells were incubated with the second set of primary antibody, $1 / 100$ dilution of mouse anti- $\alpha$-actinin IgM (Sigma, Oakville, ON Canada) and the secondary antibody. 1 -in 100 dilution of Alexa Fluor ${ }^{\text {(3) }} 546$ goat anti-mouse IgM conjugates (Molecular Probes Inc, Eugene. Oreg USA) in the same manner as described above.

The slides were then mounted with fluorescent mounting medium (DakoCytomation Inc., Mississauga, ON) and allowed to dry overnight at $4{ }^{\circ} \mathrm{C}$. Bacterial adhesion (E. coli $\mathrm{O} 157$ staining) and foci of $\alpha$-actinin were examined under fluorescence mode and transmission mode at $6300 \mathrm{x}$ magnification using a Zeiss Ac63 $\times / 1.2 \mathrm{~W}$ objective by CLSM. The specific parameters for these assays are given in Table 8. E. coli $\mathrm{O} 157$ and foci of $\alpha$-actinin appeared green and red respectively. Two aspects of pathogenicity were examined. First is a level of host adhesion ability, which depends on expression of adhesion. Second is a level of $\alpha$-actinin accumulation, which depends on host adhesion as well as expression of other virulence factors. For each sample, the total number of epithelial cells was based on a count of a minimum of 100 or more epithelial cells (Johnson-Henry, et al., 2001). Epithelial cells with 8 or more adherent bacteria 
presented either singly or in a microcolony were scored positively for host adherence (Abe $\mathrm{et} \mathrm{al.,}$ 2002). Epithelial cells bearing 1 or more foci of $\alpha$-actinin under adherent EHEC were scored positively for $\alpha$-actinin accumulation. The ratio of each score (for host adherence or $\alpha$-actinin accumulation) to total epithelial cells was then estimated and compared. Furthermore, the ratio of $\alpha$-actinin accumulation to host adherence was also calculated as the adherent infection ability and compared.

Table 8. CLSM parameters for immunofluorescence detection

\begin{tabular}{lllllll}
\hline Mode* & & Ch & Laser & Wavelength & Filter & $\begin{array}{l}\text { Pinhole } \\
\text { Diameter }\end{array}$ \\
\hline F & O157 & 2 & HeNe3 & $633 \mathrm{~nm}[25 \%]$ & LP650 & $143 \mathrm{~nm}$ \\
$\mathrm{~F}$ & $\alpha$-actinin & 3 & HeNe1 & $543 \mathrm{~nm}[80 \%]$ & BP535-590 & $120 \mathrm{~nm}$ \\
$\mathrm{~T}$ & & $\mathrm{D}$ & Ar**, HeNe1 & $488 \mathrm{~nm}[25 \%]$ & N/A & N/A \\
& & & & $543 \mathrm{~nm}[80 \%]$ & & \\
\hline
\end{tabular}

* Mode; $\mathrm{F}$ is fluorescence mode, $\mathrm{R}$ is reflectance mode and $\mathrm{T}$ is transmission mode

** Output of Ar laser was set at $25 \%$.

\subsection{Statistical Analysis}

The results are expressed as mean \pm standard deviation. Analysis of variance was used for statistical analysis of t-test at $95 \%$ confidence. $\mathrm{P} \leq 0.05$ was considered significant. All calculations were performed with Microsoft Excel on a computer running Microsoft Windows XP. 


\section{CHAPTER 4. RESULTS}

\subsection{Characterization of Flocs \& Extracellular Polymeric Substances}

The adhesion of pathogens to flocs is hypothesized to be an important process in pathogen persistence and transport. The fate of adherent pathogens is strongly influenced by the stability of flocs. Floc stability appears to be related to EPS because EPS are involved with interparticle interactions such as salt bridges, physical enmeshment and hydrophobic interactions (Liao et al., 2002). In particular, it has been suggested that proteins, which are a major component of EPS, is important in the salt bridges of sludge flocs and in hydrophobic interactions for bacterial adhesion (Higgins and Novak, 1998). Thus, in this study, the effect of protein removal on floc stability and interparticle interactions was investigated by digesting proteins from flocs by enzyme treatment.

In the following sections, the results from the physical and chemical analyses of flocs are discussed before moving on to a discussion of the results of floc stability.

\subsubsection{Physical Analysis of Flocs}

The physical analysis of flocs involved an examination of hydrophobicity, surface charge and dissociation constant.

\subsubsection{Hydrophobicity}

Hydrophobicity of flocs is an important characteristic because it involves floc formation and pathogen adherence on flocs via hydrophobic interaction (Liao et al. 2001). As shown in Figure 2 and Figure 3, hydrophobicity decreased significantly when proteins were digested by pronase $\mathrm{E}$ or proteinase $\mathrm{K}$ for $2 \mathrm{~h}$ incubation ( $\mathrm{t}$-test, $\mathrm{P} \leq 0.05$ ). In Figure 2, the mean hydrophobicity of pronase $E$ treated floc samples was $83.5 \pm 2.1 \%$ while that of control samples was $90.2 \pm 1.4 \%$. In Figure 3, the mean hydrophobicity of proteinase $\mathrm{K}$ treated floc samples was $86.5 \pm 0.6 \%$ while that of control samples was $88.8 \pm 1.1 \%$. 


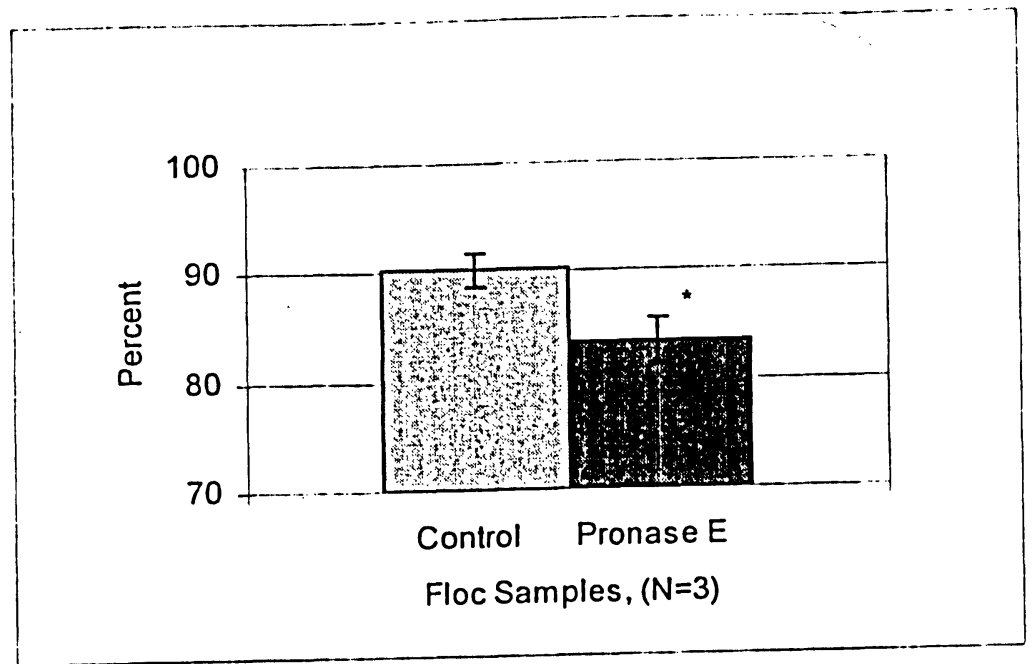

Figure 2. Hydrophobicity of pronase $E$ treated flocs

* Significantly different at $\mathrm{P} \leq 0.05$

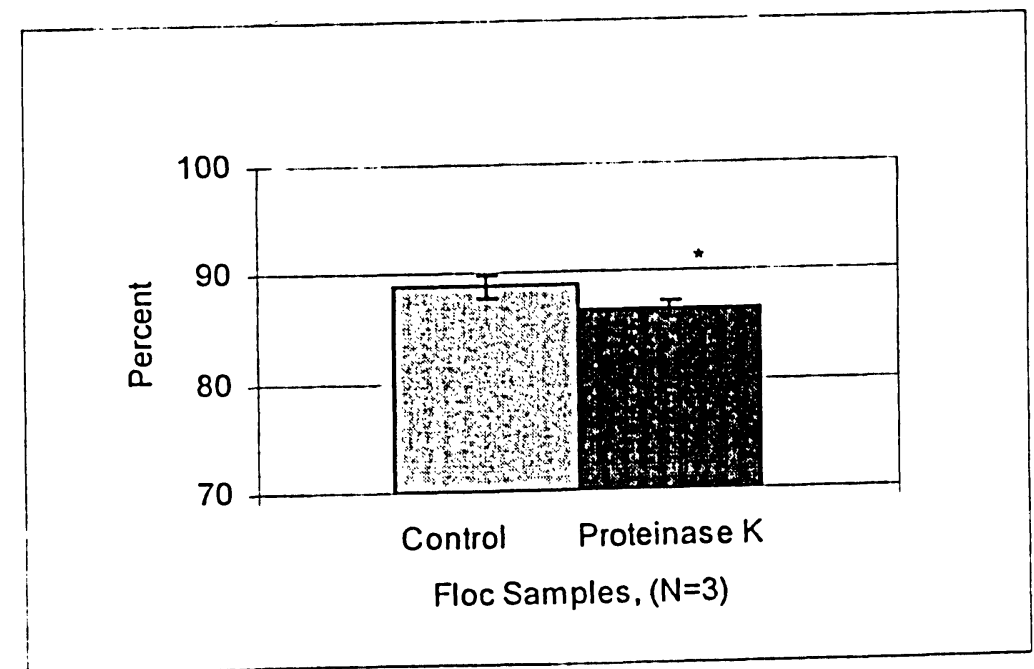

Figure 3. Hydrophobicity of proteinase $\mathrm{K}$ treated flocs

$* \mathrm{P} \leq 0.05$

\subsubsection{Surface Charge}

Surface charge has been considered to be associated with flocculation. The presence of a net negative surface charge on floc surfaces may create repulsive electrostatic interactions, which prevents close contact (Wilén et al., 2003). As a result, weaker bonding occurs between the various floc fractions (Wilén et al., 2003). It has been suggested that one of the major contributors of the negative surface charge is the functional group in proteins. Thus, it is expected that the digestion of proteins would lead to less negative charge (Wilén et al., 2003). 
However, as shown in Figure 4 and Figure 5, the mean negativity of surface charge significantly increased when proteins were digested by both enzymes ( $t$-test, $P \leq 0.05$ ). Figure 4 shows that the mean surface charge of pronase E treated lloc samples was $-0.884 \pm 0.051 \mathrm{meq} / \mathrm{g}$ MLSS while that of the control samples was $-0.735 \pm 0.038 \mathrm{meq} / \mathrm{g}$ MLSS. Figure 5 shows that the mean surface charge of proteinase K treated floc samples was $-0.866 \pm 0.038 \mathrm{meq} / \mathrm{g}$ MLSS while that of the control samples was $-0.740 \pm 0.028 \mathrm{meq} / \mathrm{g}$ MLSS.

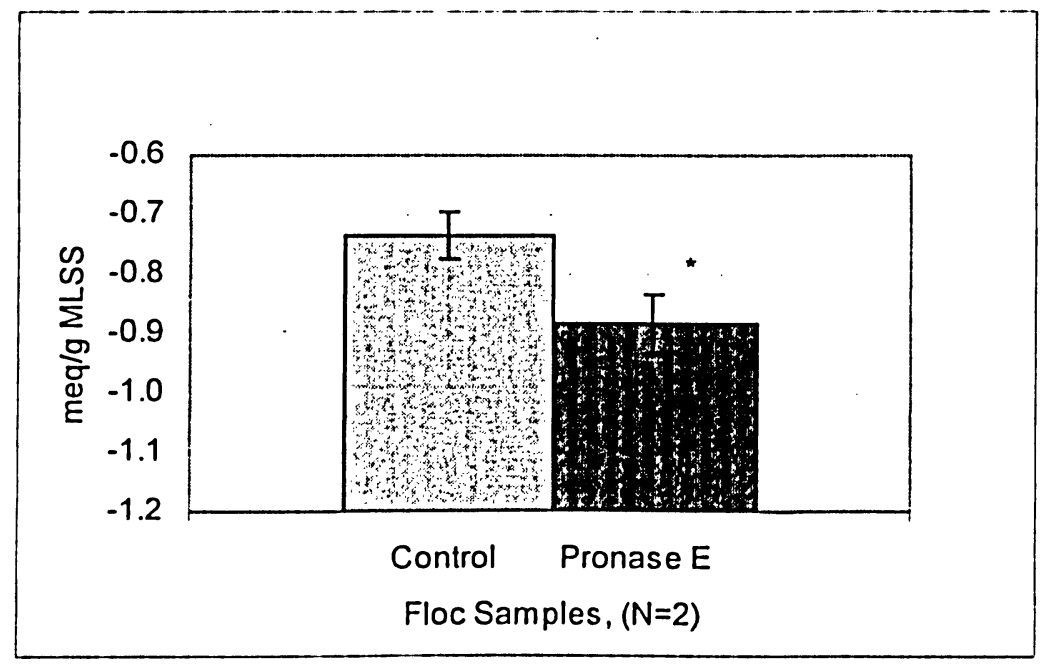

Figure 4. Surface charge of pronase $E$ treated flocs $* \mathrm{P} \leq 0.05$

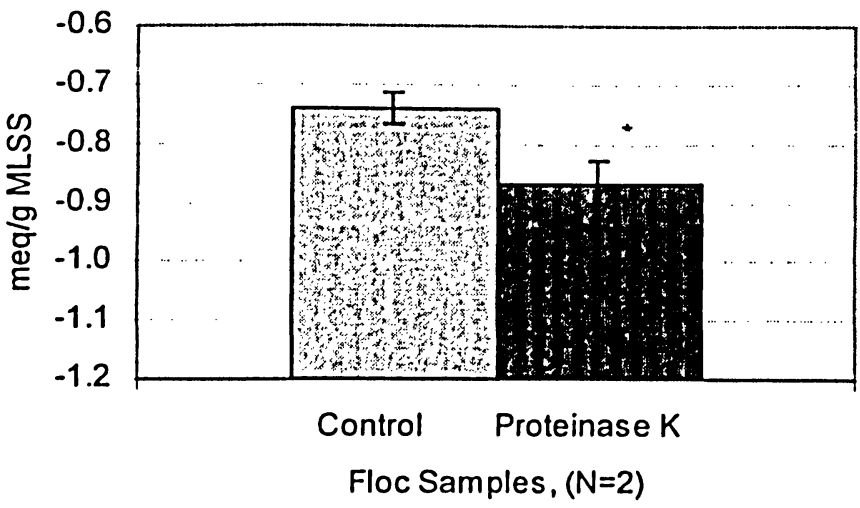

Figure 5. Surface charge of proteinase $\mathrm{K}$ treated flocs

$* \mathrm{P} \leq 0.05$ 


\subsubsection{Dissociation Constant}

The dissociation constant is a further indicator of the stability of flocs. The dissociation constant can be obtained from a standard linear regression of the accumulated absorbance in sequential washing versus the number of sequential washings (Liao et al., 2002). An example of dissociation by EDTA is shown in the Appendix C. Figure 6 shows that the mean dissociation constant of $1000 \mu \mathrm{g} / \mathrm{ml}$ EDTA treated $(0.254 \pm 0.056)$ flocs was significantly greater than that the control $(-0.03 \pm 0.014)$ ( $t$-test, $\mathrm{P} \leq 0.05)$. This indicates that EDTA significantly deflocculated flocs to generate fine unsettleable parts of the flocs.

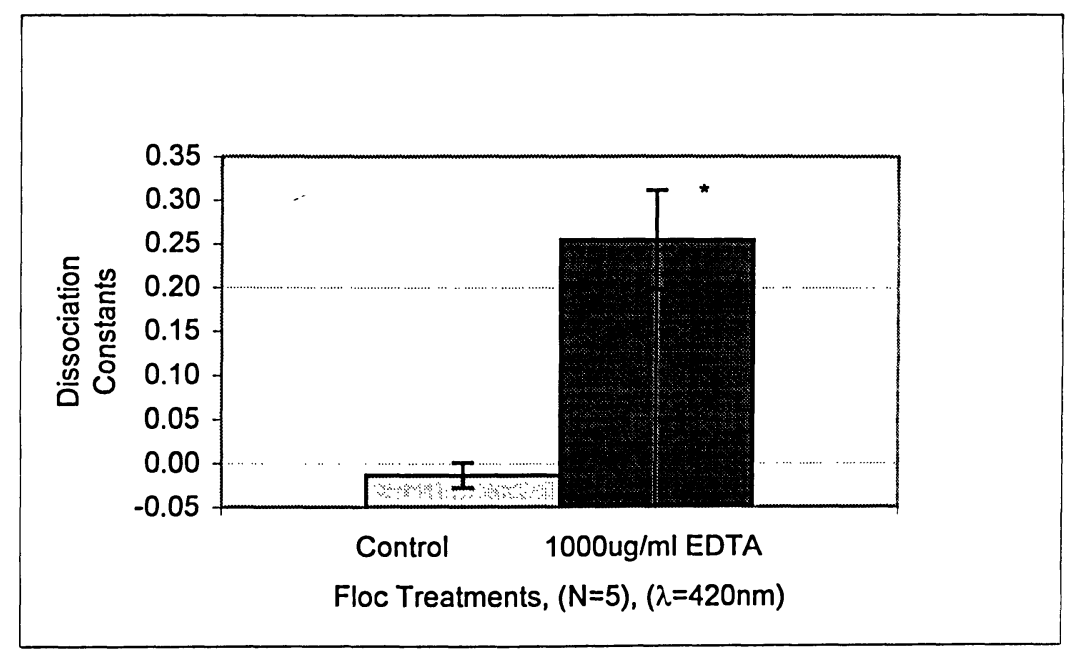

\section{Figure 6. Dissociation constants for EDTA treated flocs \\ $* \mathrm{P} \leq 0.05$}

Dissociation caused by EDTA was directly observed under COM. As Figure 7 shows, most flocs were dissociated into irregular and diffuse flocs, however some flocs remained dense and compact as shown in Figure 8. The dense and compact flocs generally contained dominant EPS areas, which were also observed in the control flocs (Figure 9). Some flocs were as large as the control flocs. Each floc in the EDTA treated and the control samples was compared in terms of the size fraction. Flocs were categorized into three size fractions, small are those flocs with a largest diameter less than $150 \mu \mathrm{m}$, medium are from more than $150 \mu \mathrm{m}$ to less than $500 \mu \mathrm{m}$, large is more than $500 \mu \mathrm{m}$. 


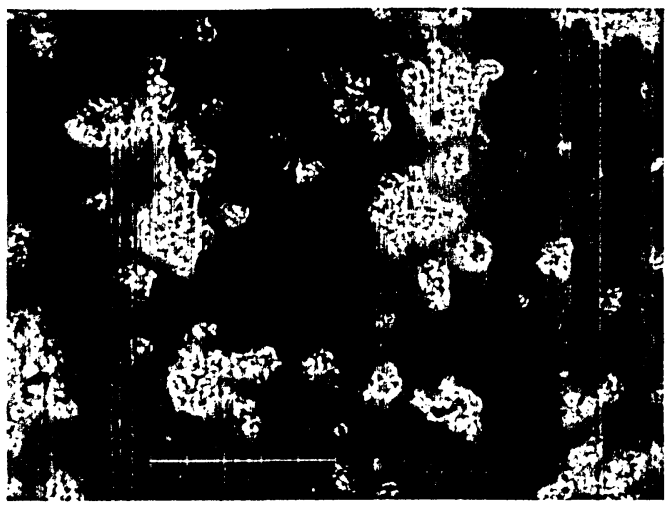

Figure 7. EDTA dissociated floc sample

Floc sample was treated with $1000 \mu \mathrm{g} / \mathrm{ml}$ EDTA for $105 \mathrm{~min}$ (4 EDTA washings).

Flocs were observed under phase contrast $\mathrm{x} 100$. Scale bar $=250 \mu \mathrm{m}$.

Most flocs were dissociated into irregular and diffused flocs by EDTA.

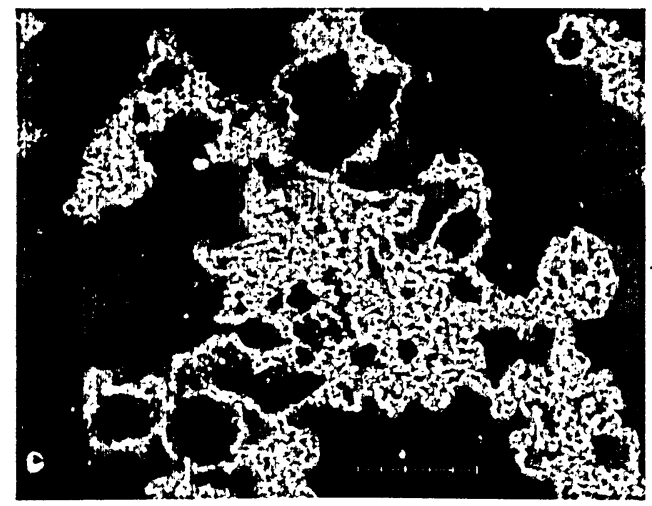

Figure 8. EPS dominated flocs after EDTA treatment

Flocs were observed under phase contrast $\times 100$. Scale bar $=250 \mu \mathrm{m}$.

Dominant EPS areas (dark areas) were found in large flocs after EDTA treatment.

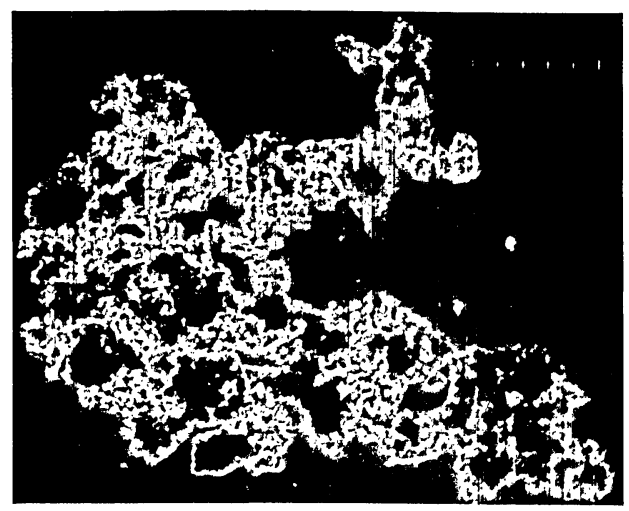

Figure 9. Control flocs with dense areas of EPS

Floc sample was treated with $0.1 \mathrm{M}$ PBS for $105 \mathrm{~min}$ (4 PBS washings).

Flocs were observed under phase contrast $\times 100$. Scale bar $=250 \mu \mathrm{m}$.

Rounded and dense Control flocs with dominant EPS areas were observed. 
Figure 10 shows the small flocs dominate in both treatment samples. The $80.5 \pm 6.5 \%$ flocs was small size fraction in the EDTA treated sample while the $63.5 \pm 12.7 \%$ flocs was small fraction in the control sample. The EDTA treated sample contained more small flocs, however, there was no significant difference between the two ( $t$-test, $P \leq 0.05$ ). On the other hand, the significantly lower medium fractions in EDTA treated sample (13.8 $\pm 5.9 \%$ flocs) were observed when compared with that in the control sample (26.8 $\pm 5.9 \%$ flocs) (t-test, $\mathrm{P} \leq 0.05)$. The large fraction also decreased in the EDTA treated sample $(5.75 \pm 1.98 \%$ flocs $)$ compared to the control sample $(9.68 \pm 7.0 \%$ flocs $)$, however, there was no significant difference ( $t$-test, $\mathrm{P} \leq 0.05)$.

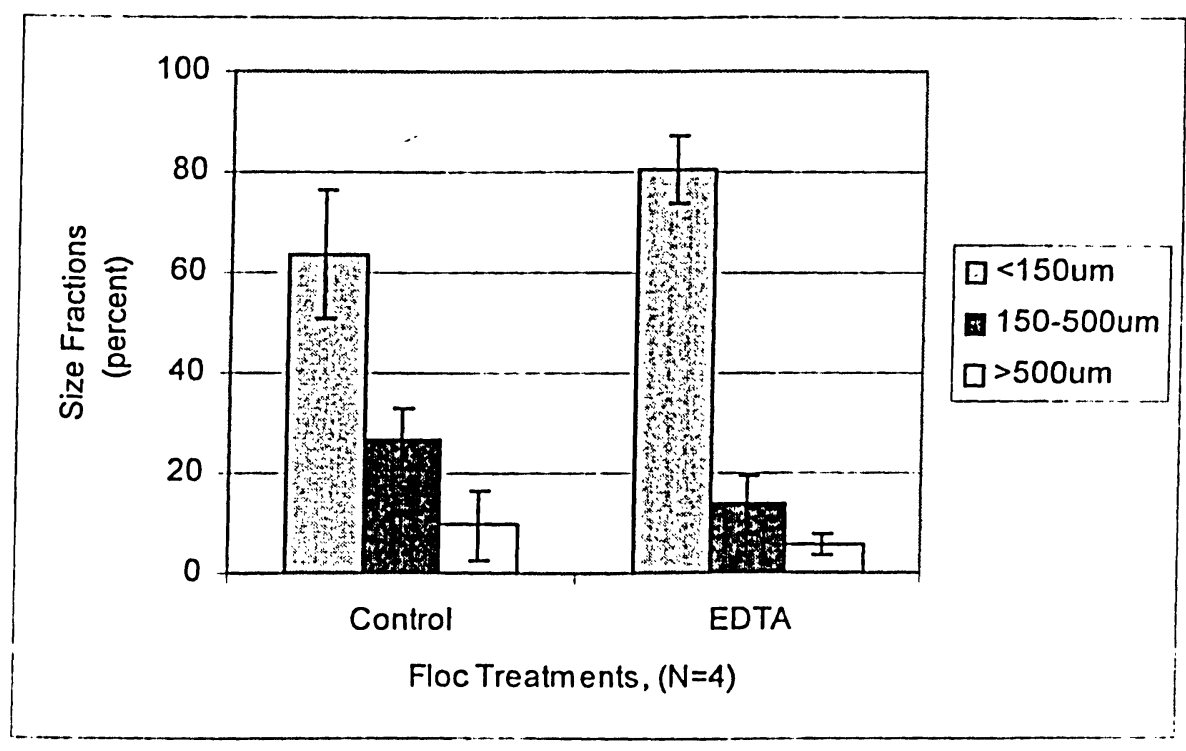

Figure 10. Effect of EDTA treatment on floc size

In order to examine if digestion of proteins leads to complete floc dissociation, the EDTA treated samples were further treated with $200 \mu \mathrm{g} / \mathrm{ml}$ pronase $\mathrm{E}$ or $200 \mu \mathrm{g} / \mathrm{ml}$ proteinase $\mathrm{K}$ for $2 \mathrm{~h}$ incubation.

Figure 12 and Figure 13 show that not all flocs were completely dissociated after enzyme treatments. Some flocs dissociated into smaller flocs that contained dense EPS areas. Interestingly, some large flocs appear to be composed of branches of dense EPS areas. These branches were not observed in the control sample (Figure 14). The size fraction of the enzyme treated flocs and the control samples were compared in the same manner as above. Similar to EDTA treated sample, Figure 11 shows the small flocs dominated in both pronase $E$ treatment 
and control samples. The small size fraction of pronase $\mathrm{E}$ treated $(68.99 . \pm 10.03 \%$ tlocs) was larger than the control $(57.97 \pm 13.89 \%$ flocs $)$. The medium fraction of pronase $E$ was lower (22.62 $\pm 5.43 \%$ flocs) compared to the control (33.27 $\pm 12.00 \%$ flocs). The large fraction of pronase E $(8.386 \pm 6.331 \%$ flocs $)$ was also lower compared to the control $(8.748 \pm 4.618 \%$ flocs). However, these differences in the size fractions between two samples were not statistically significant (t-test, $\mathrm{P} \leq 0.05)$.

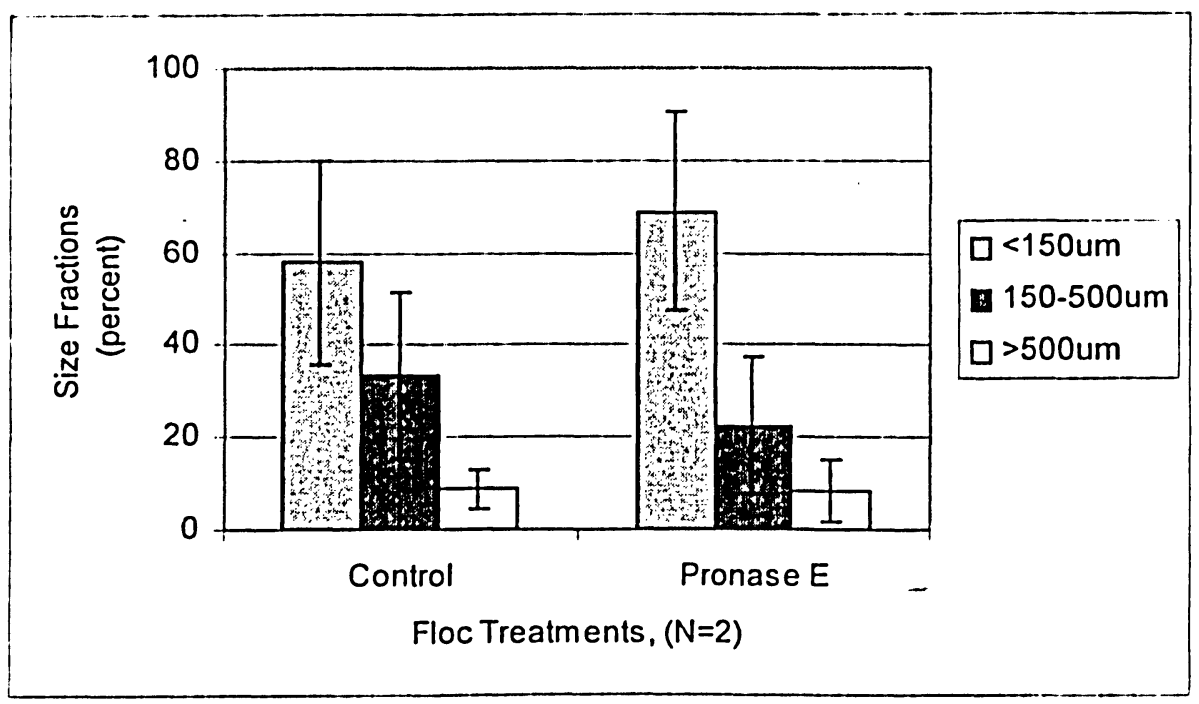

Figure 11. Effect of pronase $E$ treatment following EDTA treatment on floc size

Similar to the trend of the EDTA and pronase E treated samples, Figure 15 shows that the small flocs dominated in both proteinase $\mathrm{K}$ treatment and control samples. Contrary to the size fractions in the EDTA and pronase $\mathrm{E}$ treated samples, lower small size fraction in the proteinase $\mathrm{K}$ treated sample $(53.45 \pm 21.63 \%$ flocs $)$ was found compared to the control $(62.72 \pm 22.08 \%$ flocs). Furthermore, higher medium fraction of the proteinase K treated sample (34.94 $\pm 14.96 \%$ flocs) compared to the control $(29.87 \pm 18.25 \%$ flocs $)$ and higher large fraction of the proteinase $\mathrm{K}$ treated sample $(11.60 \pm 6.717 \%$ flocs $)$ compared to the control $(7.409 \pm 4.060 \%)$. were observed. Even though the fractions in the proteinase $\mathrm{K}$ treated sample did not significantly differ from that in the control (t-test, $\mathrm{P} \leq 0.05$ ), these results might indicate that some flocs became larger in size during proteinase $\mathrm{K}$ treatment. 

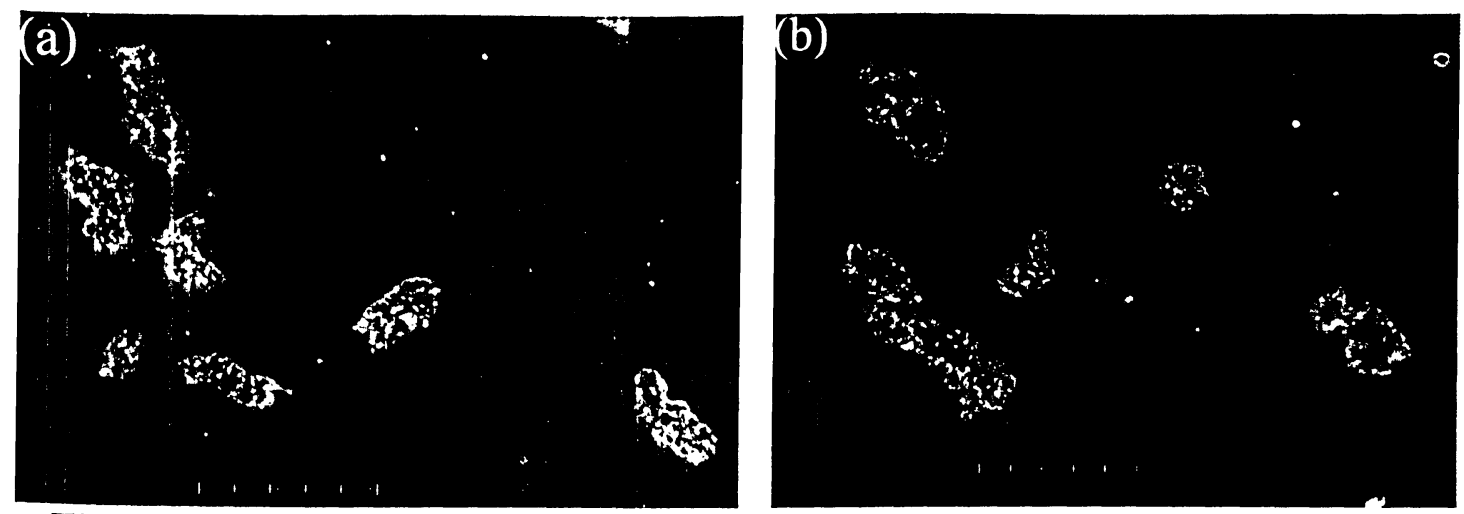

Figure 12. (a) EDTA-pronase $\mathrm{E}$ and (b) EDTA-proteinase $\mathrm{K}$ dissociated flocs EDTA treated flocs were further treated with (a) $200 \mu \mathrm{l} / \mathrm{ml}$ pronase E or (b) $200 \mu \mathrm{g} / \mathrm{ml}$ proteinase K. Flocs were observed under phase contrast $x 100$. Scale bar $=250 \mu \mathrm{m}$.
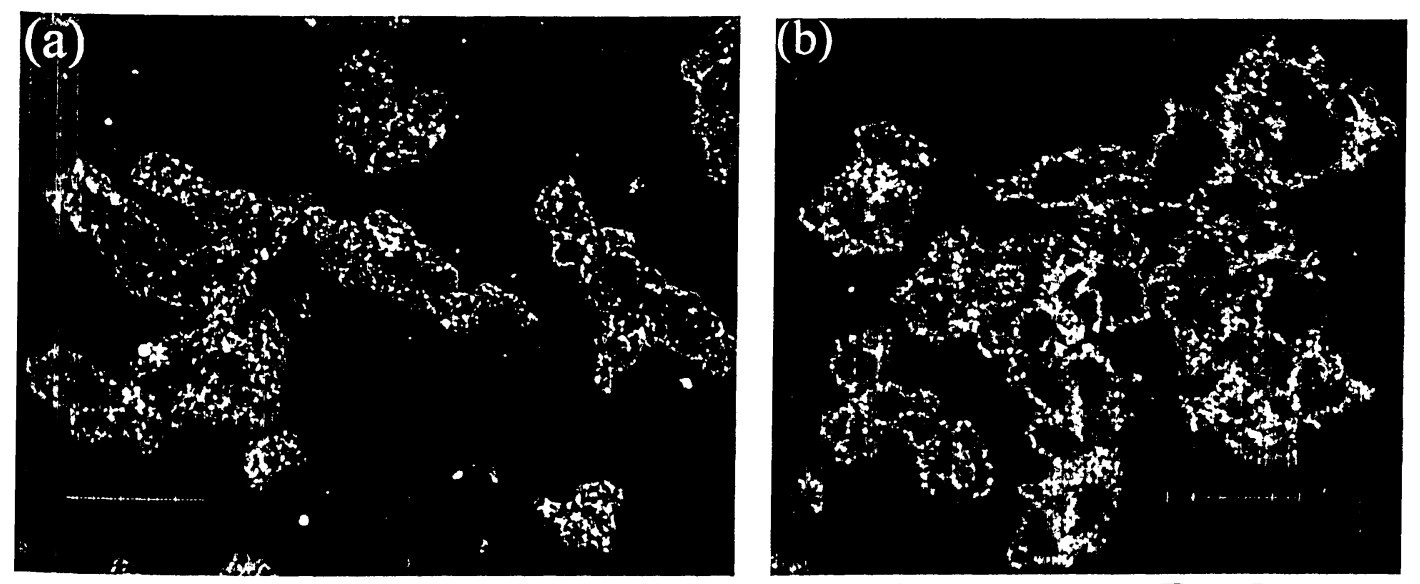

Figure 13. EPS dominated flocs after (a) EDTA-pronase E and

(b) EDTA-proteinase K treatments

Flocs were observed under phase contrast $x 100$. Scale bar $=250 \mu \mathrm{m}$.

Dominant EPS areas (dark areas) were found in the flocs. Some flocs appear to be composed of branches of dense EPS areas (shown in (b).

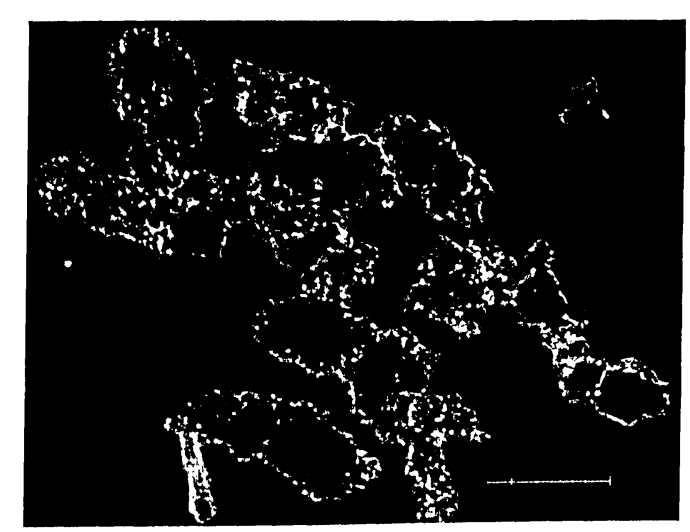

Figure 14. Control flocs

Flocs were observed under phase contrast $\mathrm{x} 100$. Scale $\mathrm{bar}=250 \mu \mathrm{m}$. 


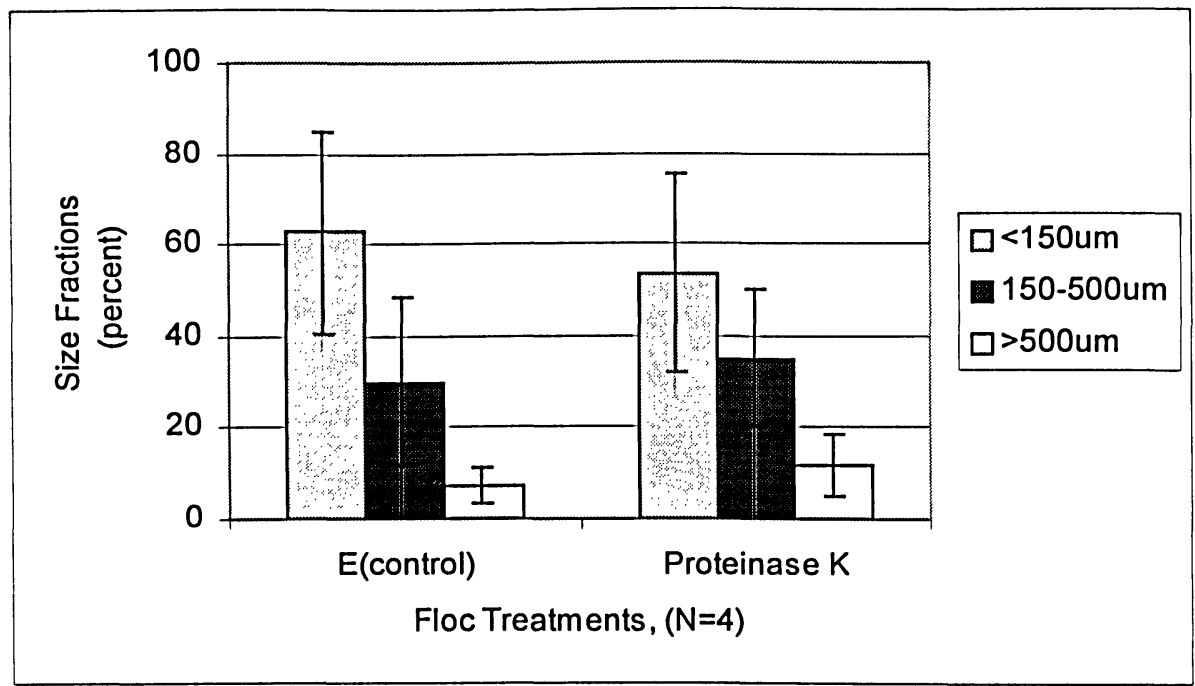

Figure 15. Effect of proteinase $\mathrm{K}$ treatment following EDTA treatment on floc size

\subsubsection{Chemical Analysis of Extracellular Polymeric Substances}

EPS are known to include carbohydrates, proteins, humic substances and DNA. It is important to chemically analyse each EPS component since it has been suggested that each EPS component contributes to floc characteristics such as hydrophobicity and surface charge. In this study, two types of EPS were analysed. The first was loosely bound EPS, which is the EPS fraction present in supernatant after centrifugation. The other was bound EPS, which is the EPS fraction present in supernatant after centrifugation following the CER extraction method (Higgins and Novak, 1997; Wilén et al., 2003).

Figure 16 illustrates the results for the loosely bound EPS. The dominant humic substances and proteins in the pronase E treated sample $(15.0 \pm 1.5 \mathrm{mg} / \mathrm{g}$ MLSS, $5.75 \pm 1.08$ $\mathrm{mg} / \mathrm{g}$ MLSS) were significantly lower compared to the control $(38.1 \pm 1.1 \mathrm{mg} / \mathrm{g}$ MLSS, $9.35 \pm$ $1.38 \mathrm{mg} / \mathrm{g}$ MLSS) $(\mathrm{P} \leq 0.05)$. On the other hand, carbohydrates in the pronase $\mathrm{E}$ treated sample $(23.7 \pm 2.0 \mathrm{mg} / \mathrm{g}$ MLSS $)$ were significantly higher compared to the control $(10.8 \pm 0.3 \mathrm{mg} / \mathrm{g}$ MLSS) $(\mathrm{P} \leq 0.05)$. DNA was a minor component in both samples, pronase $\mathrm{E}(0.018 \pm 0.000 \mathrm{mg} / \mathrm{g}$ MLSS) and control $(0.023 \pm 0.000 \mathrm{mg} / \mathrm{g}$ MLSS). 


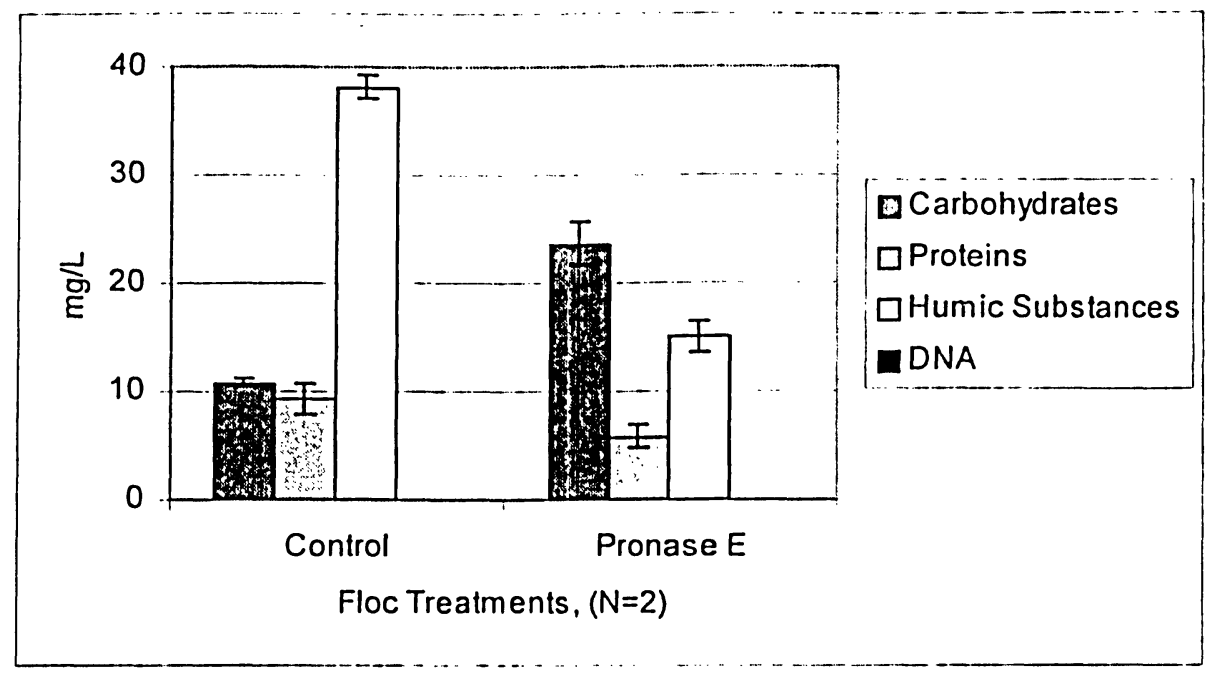

Figure 16. Loosely bound EPS in the presence of pronase $E$

Figure 17 illustrates the results for bound EPS. The humic substances and proteins in the pronase E treated sample $(20.8 \pm 0.6 \mathrm{mg} / \mathrm{g}$ MLSS, $21.3 \pm 2.4 \mathrm{mg} / \mathrm{g}$ MLSS) were significantly higher compared to the control ( $14.4 \pm 1.6 \mathrm{mg} / \mathrm{g}$ MLSS. $17.1 \pm 1.6 \mathrm{mg} / \mathrm{g}$ MLSS) $(P \leq 0.05)$. Carbohydrates were also higher but there were no significant differences between the two samples, pronase $\mathrm{E}(6.44 \pm 1.71 \mathrm{mg} / \mathrm{g}$ MLSS $)$ and control $(4.07 \pm 0.70 \mathrm{mg} / \mathrm{g}$ MLSS $)(\mathrm{P} \leq 0.05)$. Again, DNA was a minor component in both samples, pronase $\mathrm{E}(0.038 \pm 0.001 \mathrm{mg} / \mathrm{g}$ MLSS $)$ and control $(0.037 \pm 0.001 \mathrm{mg} / \mathrm{g}$ MLSS $)$.

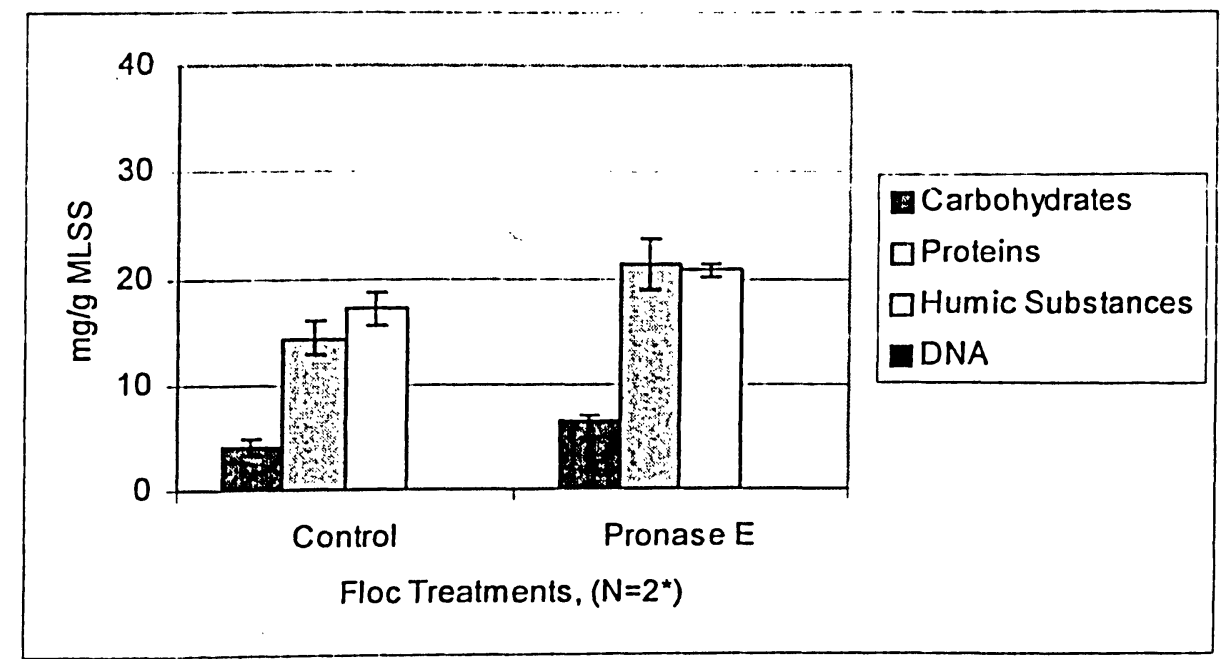

Figure 17. Bound EPS in the presence of pronase $E$

* N=3 for Humic Substances 
Figure 18 illustrates the results for looscly bound EPS and proteinase $\mathrm{K}$. The dominant humic substances and carbohydrates in the protcinase $\mathrm{K}$ treated sample $(58.8 \pm 2.6 \mathrm{mg} / \mathrm{g}$ MLSS, $10.5 \pm 0.9 \mathrm{mg} / \mathrm{g}$ MLSS) were significantly higher compared to the control $(53.0 \pm 3.5 \mathrm{mg} / \mathrm{g}$ MLSS, $7.80 \pm 1.43 \mathrm{mg} / \mathrm{g}$ MLSS $)(P \leq 0.05)$. On the other hand. proteins in the proteinase $\mathrm{K}$ treated sample were lower $(2.99 \pm 1.77 \mathrm{mg} / \mathrm{g}$ MLSS $)$ but it did not differ significantly from the control $(4.41 \pm 1.08 \mathrm{mg} / \mathrm{g}$ MLSS $)(P \leq 0.05)$. DNA was again a minor component in both samples, proteinase $\mathrm{K}(0.018 \pm 0.000 \mathrm{mg} / \mathrm{g}$ MLSS $)$ and control $(0.021 \pm 0.000 \mathrm{mg} / \mathrm{g}$ MLSS $)$.

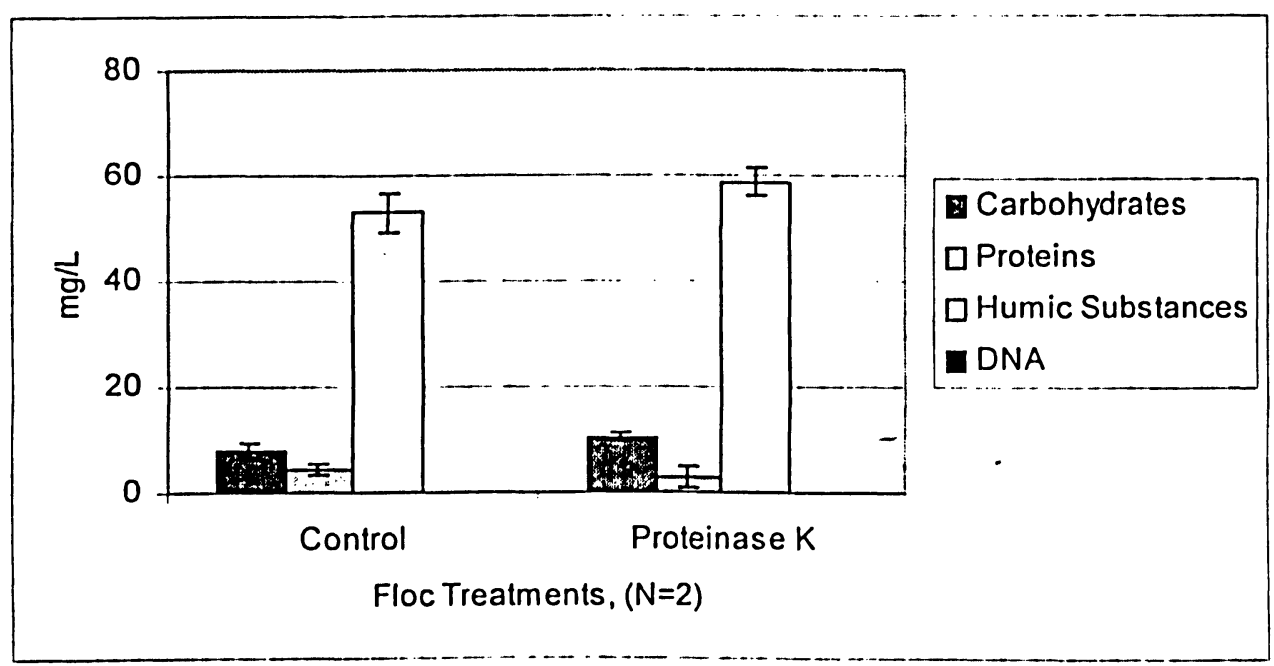

Figure 18. Loosely bound EPS in the presence of proteinase $K$

Figure 19 illustrates the results for the bound EPS in the proteinase $\mathrm{K}$ treatment. Similar to the bound EPS in the pronase $\mathrm{E}$ treatment, humic substances in the proteinase $\mathrm{K}$ treated sample $(27.5 \pm 4.8 \mathrm{mg} / \mathrm{g}$ MLSS) were significantly higher compared to the control (19.6 \pm 6.4 $\mathrm{mg} / \mathrm{g}$ MLSS) $(\mathrm{P} \leq 0.05)$. Proteins and carbohydrates were also higher but there were no significant differences between the two samples, proteinase K $(14.6 \pm 1.3 \mathrm{mg} / \mathrm{g}$ MLSS, $3.49 \pm 1.6 \mathrm{mg} / \mathrm{g}$ MLSS) and control $(9.27 \pm 1.05 \mathrm{mg} / \mathrm{g}$ MLSS, $3.30 \pm 1.6 \mathrm{mg} / \mathrm{g}$ MLSS $)(\mathrm{P} \leq 0.05)$. DNA was again a minor component in both samples, proteinase $\mathrm{K}(0.0315 \pm 0.0084 \mathrm{mg} / \mathrm{g}$ MLSS $)$ and control $(0.0333 \pm 0.0058 \mathrm{mg} / \mathrm{g}$ MLSS $)$. 


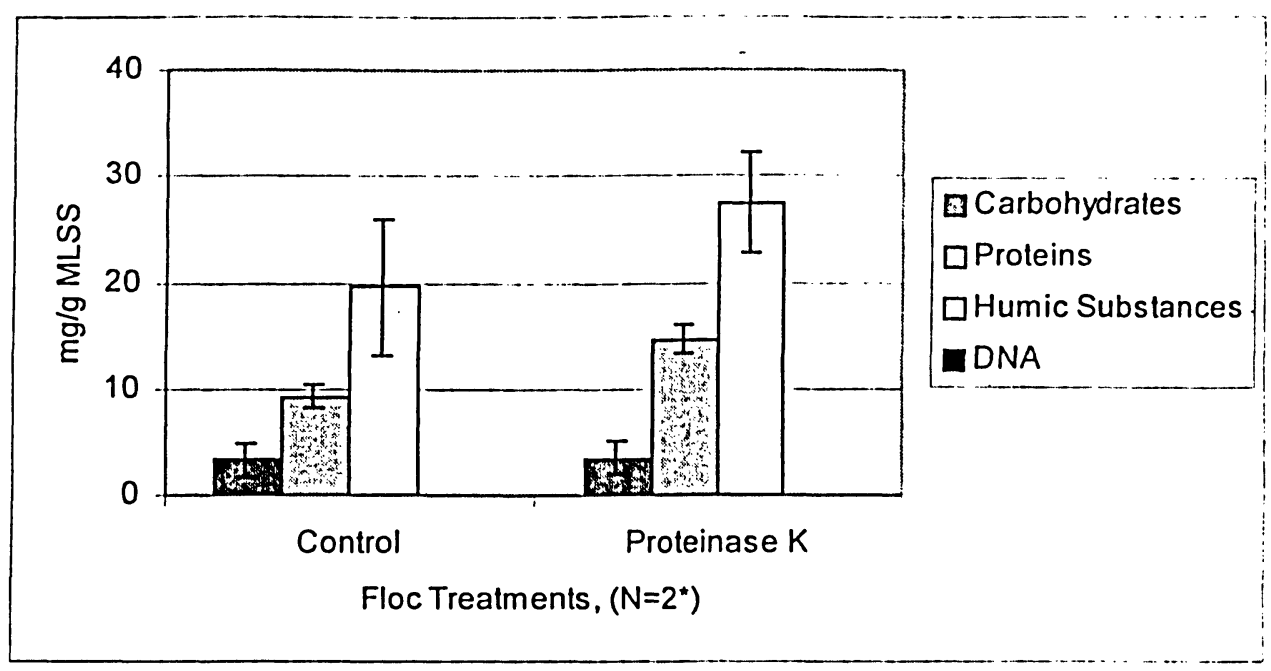

Figure 19. Bound EPS in the presence of proteinase $K$

$* \mathrm{~N}=3$ for Humic Substances

\subsection{Microscopic Observation of Extracellular Polymeric Substances}

Microscopic observation of EPS is very useful because it provides a non-destructive analysis that gives useful information about spatial distribution of EPS and localization of EPS composition.

\subsubsection{Mapping of Extracellular Polymeric Substances}

\subsubsection{Nucleic Acids, Lipid-hydrophobic Sites and Proteins}

Floc samples were first treated with $1000 \mu \mathrm{g} / \mathrm{ml}$ EDTA for $135 \mathrm{~min}$ and then treated with proteinase $\mathrm{K}$ for $120 \mathrm{~min}$ (this full treatment is referred to as EDTA-K treatment). After the treatment, EDTA, EDTA-K and control floc samples were stained with dyes, Syto 61 (blue), Nile red (red) and SyproOrange (green), which are specific to nucleic acids, lipids-hydrophobic sites and proteins. The stained samples were observed under CLSM to examine the distribution of EPS components in flocs. The CLSM micrographs in Figures 20-26, 30, 32, 34, 36 and 38 show two-dimensional orthogonal sections of the three-dimensional flocs and are made up of three panels. In each Figure, Panel A shows an $x y$ image at the $z$ plane. Panel B shows a yz image at the $x$ plane. Panel $C$ shows an $x z$ image at the $y$ plane. In this way, both the vertical and horizontal distribution of EPS components can be observed. 
In all samples, nucleic acids, lipids-hydrophobic sites and proteins were detected. Nucleic acids appear blue, lipid-hydrophobic sites appear red and proteins appear green. These macromolecules generally exist heterogeneously, horizontally and vertically throughout the flocs. As an example, Figure 20 shows nucleic acids, lipid-hydrophobic sites and proteins distribution in EDTA-treated flocs along with the same floc image in a reflectance mode. The macromolecules seem to be localized where dense floc areas are found in the reflectance mode. In addition, proteins appear to be the most abundant and are distributed uniformly such that they cover the floc. Figure 20 also seems to indicate that there are large areas of the flocs that include colocalization of two or more macromolecules. It seems that the degree of colocalization varies depending on the type of macromolecules. The degree of macromolecule colocalization is examined in the following images, initially dealing with EDTA-treated flocs and then covering the EDTA and enzyme treated flocs.

Figure 21 illustrates that a high degree of colocalization of nucleic acids, lipids-hydrophobic sites and proteins occurred in the EDTA-treated flocs. This colocalization appears as white/light blue areas and is indicated by arrows. This colocalization appears to be present at the surface/periphery of the floc. Further, Figure 21 (b) shows a relatively large colocalization of nucleic acids and lipid-hydrophobic sites (magenta). Dense nucleic acids appear to cover the whole floc whereas less dense (dot-like) lipid-hydrophobic site appears to be localized in the floc. The nucleic acid dye stains extracellular nucleic acids and microorganisms. The lipidhydrophobic site dye seems to stain extracellular lipids and probably microorganisms based on the size of the red dots. Thus, the colocalization of nucleic acids and lipid-hydrophobic sites seems to indicate the association of microorganisms with extracellular lipids and attribution of microorganisms to the hydrophobic properties in flocs. It is also noted that some lipidhydrophobic sites are also distributed around nucleic acids and the interior of the floc. Figure 21 (c) also shows a large colocalization of nucleic acids and proteins, which appears as cyan. This colocalization appears to cover most of the floc, which might indicate that the association of microorganisms and extracellular proteins as well as the presence of proteins in on surface of the microorganisms. Similar to the lipid-hydrophobic sites, proteins are also found around nucleic acids and in the interior of the floc. Figure 21 (d) shows yellow areas, representing the colocalization of lipid-hydrophobic sites and proteins. Similar to the colocalization of nucleic acids and lipid-hydrophobic sites, this colocalization appears to be relatively large and present at 


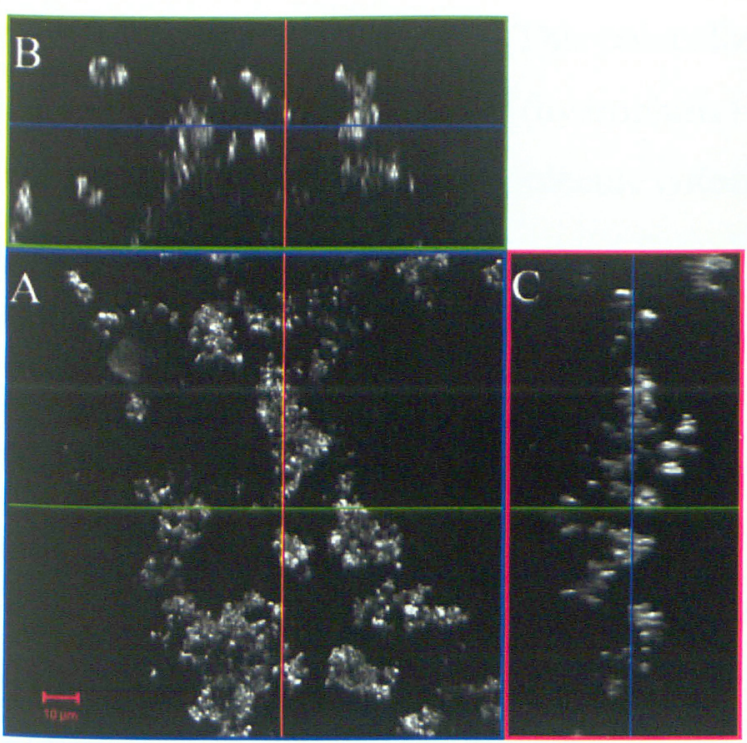

(a)

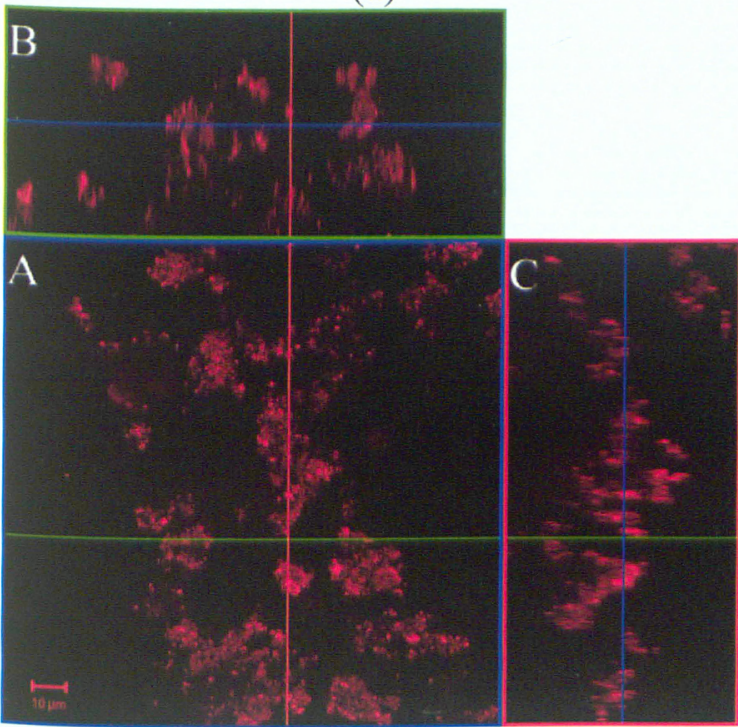

(c)

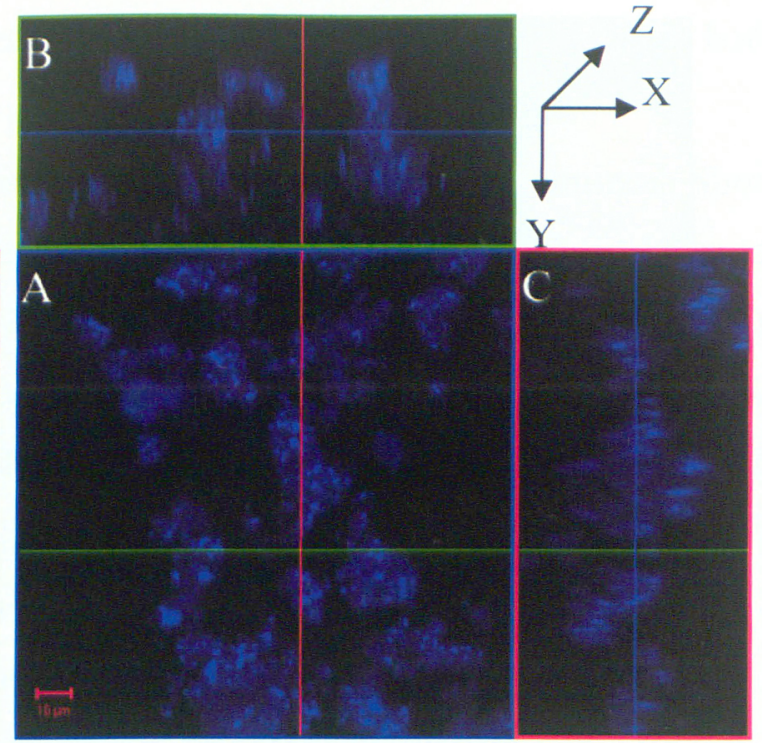

(b)

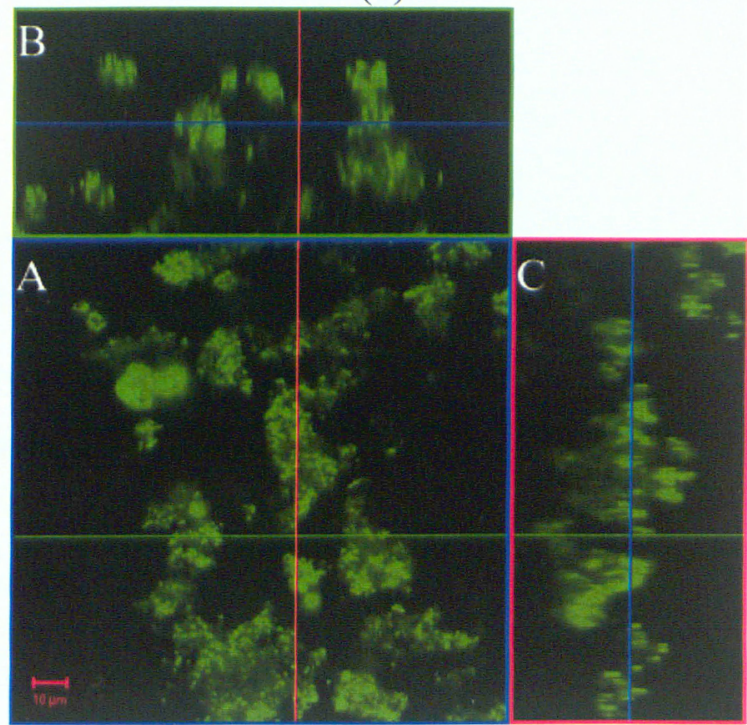

(d)

Figure 20. EPS distribution of EDTA treated floc

Flocs were treated with $1000 \mu \mathrm{g} / \mathrm{ml}$ EDTA and then stained with Syto 61 (nucleic acids) (b),

Nile Red (lipid-hydrophobic sites) (c) and SyproOrange (proteins) (d) and shown in CLSM orthogonal micrographs. Panel A shows an xy image at $\mathrm{z}$ plane $=18 \mu \mathrm{m}$ (which is shown as the blue line in panel B and C). Panel B shows a yz image at the $\mathrm{x}$ plane (which is shown as the green line in panel A). Panel $\mathrm{C}$ shows an $\mathrm{xz}$ image at the y plane (which is shown as the red line in panel A). The same location of the flocs was taken under (a) reflectance mode.

Scale bar $=10 \mu \mathrm{m}$. 

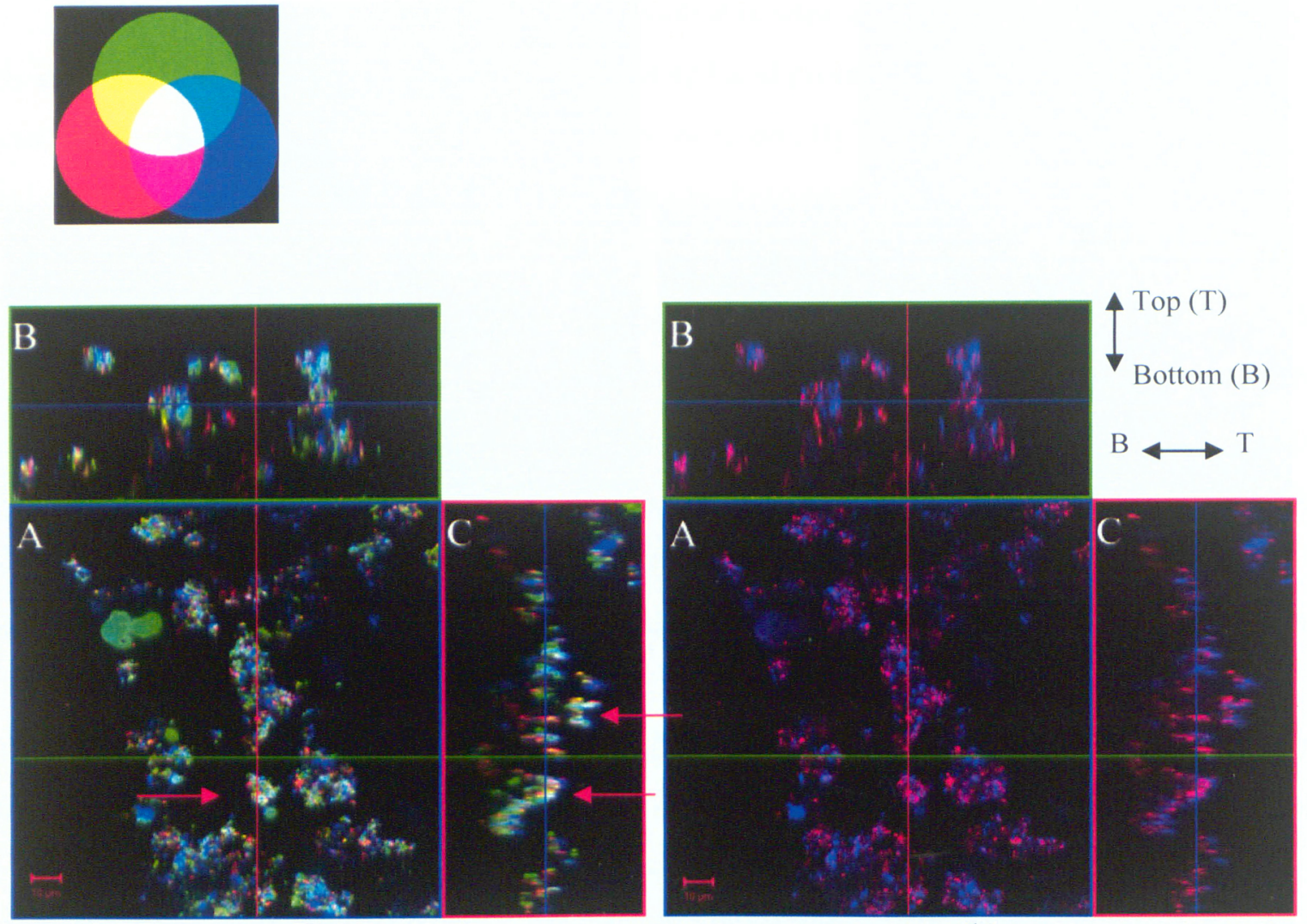

(a)

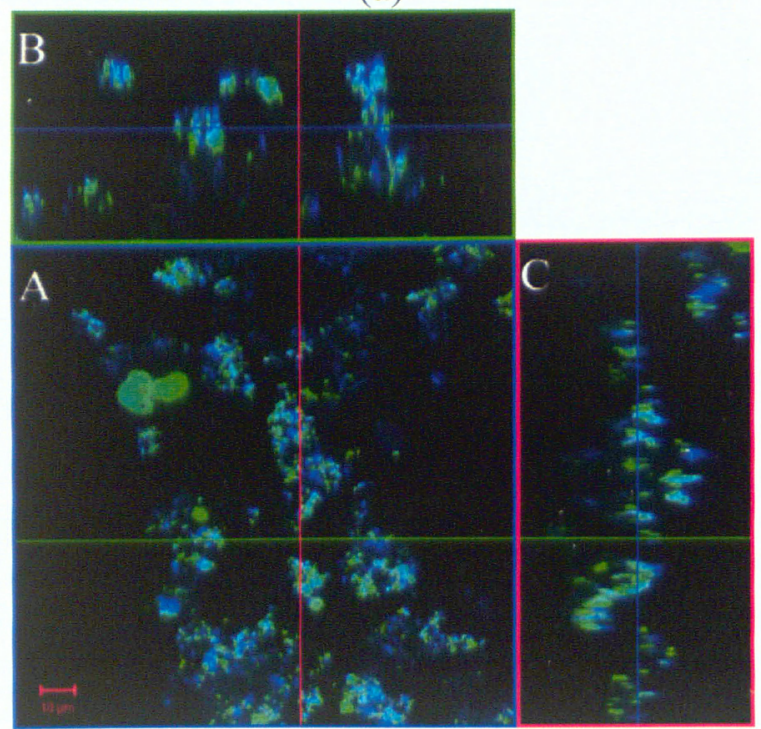

(c)

(b)

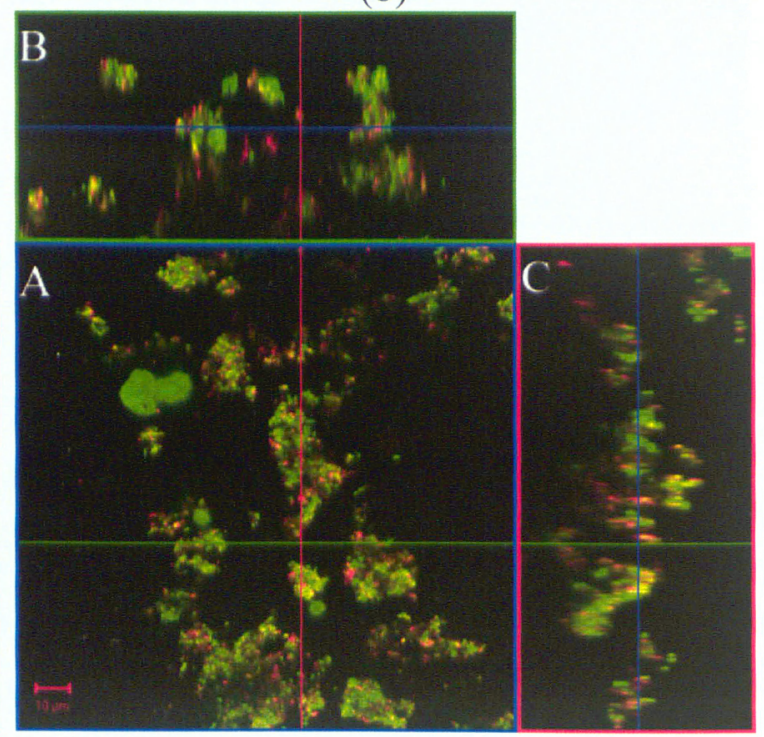

(d)

Figure 21. Colocalization of EPS in EDTA treated flocs

CLSM orthogonal micrographs show colocalization of (a) composite, (b) nucleic-lipid, (c) nucleic-proteins, (d) proteins-lipid of Figure 20 flocs. Scale bar $=10 \mu \mathrm{m}$. Colocalization is indicated by arrows. 
the surface/periphery of the flocs. This colocalization also seems to indicate that there are both hydrophobic and non-hydrophobic (hydrophilic) proteins in the EDTA-treated floc.

Next, the degree of macromolecule colocalization in the control floc is examined. Similar to the colocalization in the EDTA-treated floc above, Figure 22 (b) illustrates a relatively large colocalization of nucleic acids, lipids-hydrophobic sites and proteins in the control floc (which are indicated by arrows). In the control floc, the colocalization of pairs of macromolecules is also found. Figure 22 (c) shows a large area of colocalization of nucleic acids and lipid-hydrophobic sites, which appears magenta. Compared to the EDTA-treated floc, the control floc contained a greater degree of this type of colocalization. This might indicate the close association of microorganisms with either extracellular lipids or floc hydrophobicity. It is also noted that the lipid-hydrophobic sites are distributed throughout the control floc. In addition, the lipidhydrophobic sites are found around nucleic acids. Figure 22 (d) also shows the colocalization of nucleic acids and proteins, which appears cyan. Similar to the EDTA-treated floc, a higher degree of colocalization occurred, which appears to cover most of the control floc. This might also indicate the association of microorganisms and extracellular proteins. Similar to the lipidhydrophobic sites, proteins are also found around nucleic acids and in the interior of the flocs. Figure 22 (e) shows the colocalization of proteins and lipid-hydrophobic sites, which appears yellow. Compared to the EDTA-treated floc, it seems that the control floc had more proteins colocalized with lipid-hydrophobic sites.

Next, the degree of macromolecule colocalization in the EDTA-K floc is examined. Similar to the images above, Figure 23 illustrates the high degree of colocalization of nucleic acids, lipids-hydrophobic sites and proteins. Similar to the EDTA-treated floc, this colocalization appears to cover the whole floc. Furthermore, the colocalization of pairs of two macromolecules is also easily found in the EDTA-K floc. However, it seems that the EDTA-K floc contains a lower degree of colocalization of nucleic acids and proteins. This might be because the EDTA-K floc contained a smaller amount of proteins compared to nucleic acids. However, some proteins are found in the interior of the floc such as beneath the colocalization (Figure 23(d) panel B and C) and around nucleic acids. In addition, most proteins seem to colocalize with lipidhydrophobic sites, indicating most proteins are hydrophobic in the EDTA-K floc. 


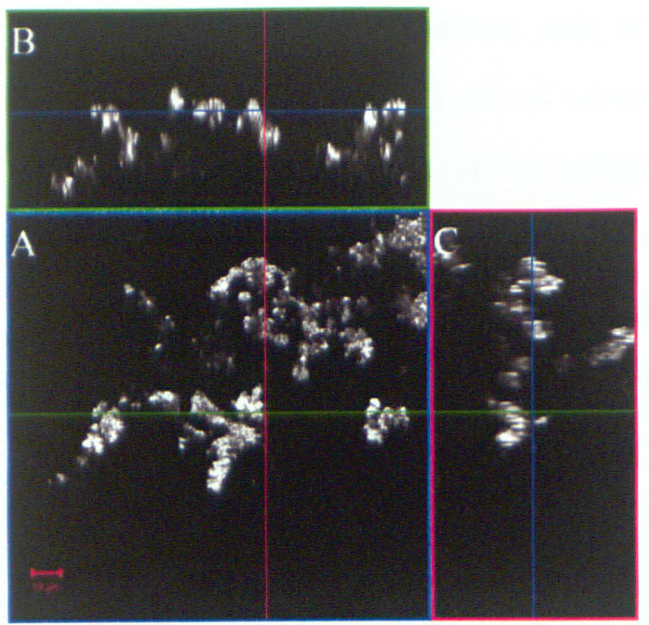

(a)

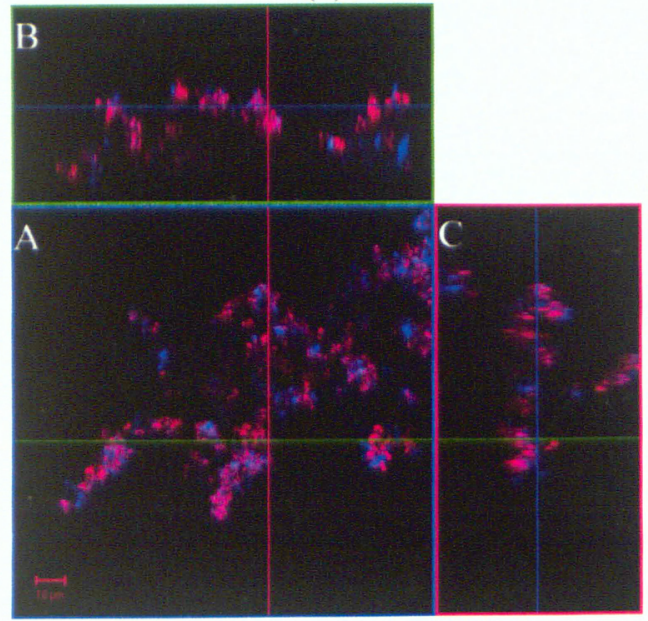

(c)

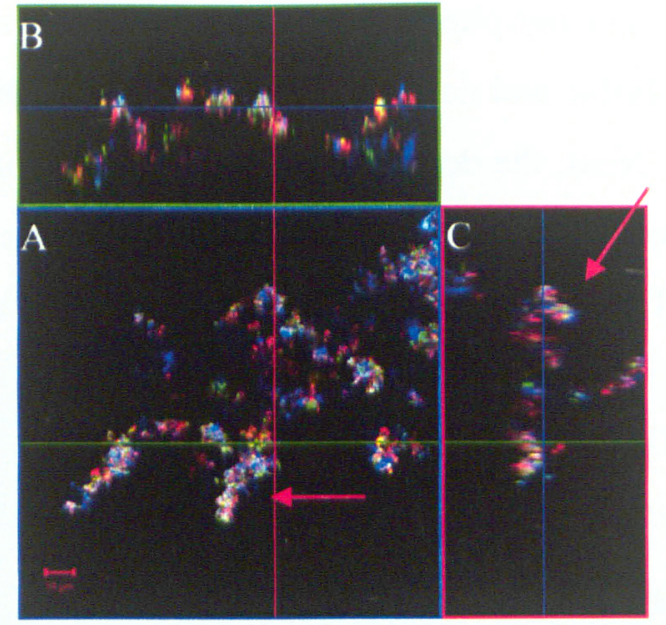

(b)

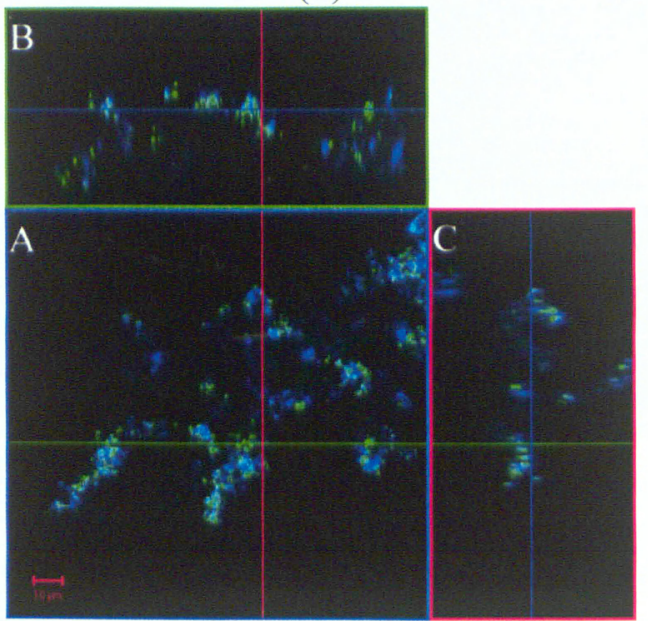

(d)

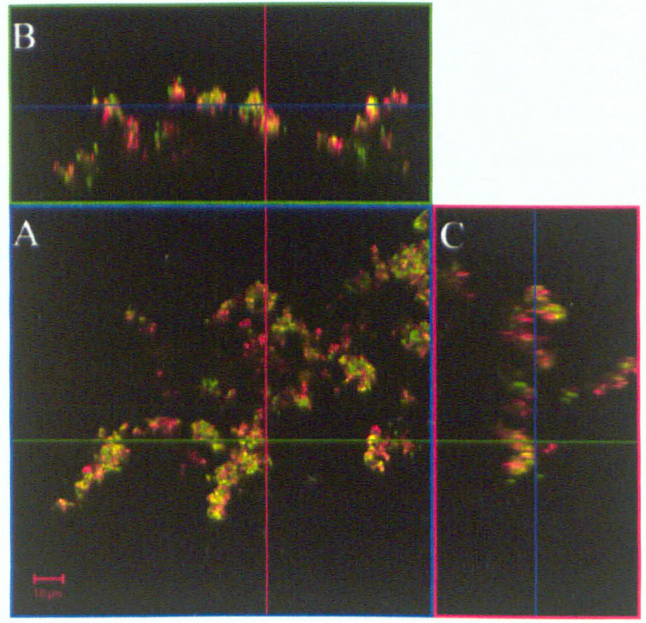

(e)

Figure 22. Colocalization in control flocs

CLSM orthogonal micrographs show (a) reflectance mode and colocalization of (b) composite, (c) nucleic-lipid, (d) nucleic-proteins and (e) proteins-lipid. $\mathrm{z}$ plane $=36 \mu \mathrm{m}$, Scale bar $=10 \mu \mathrm{m}$. 


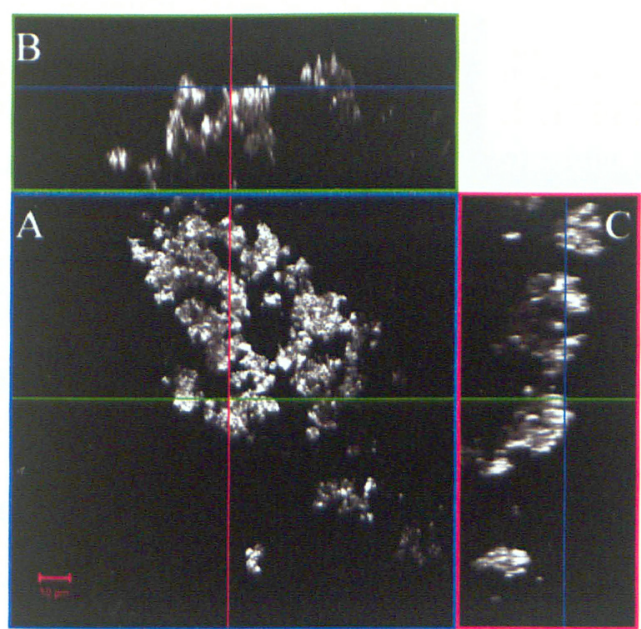

(a)

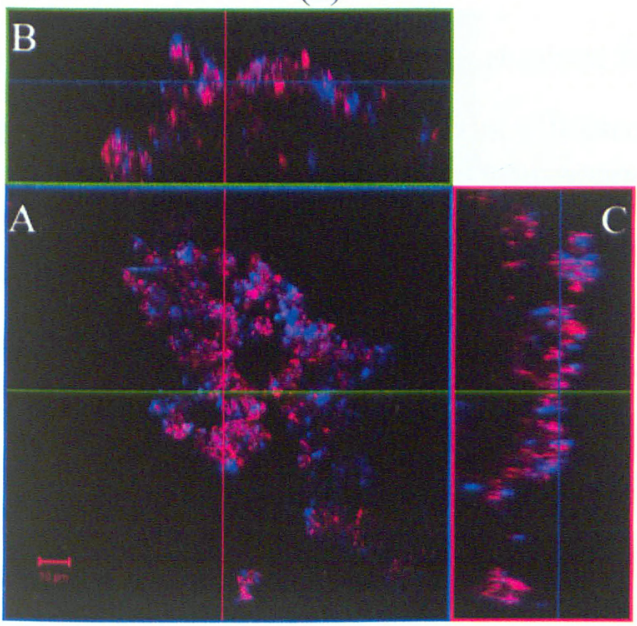

(c)

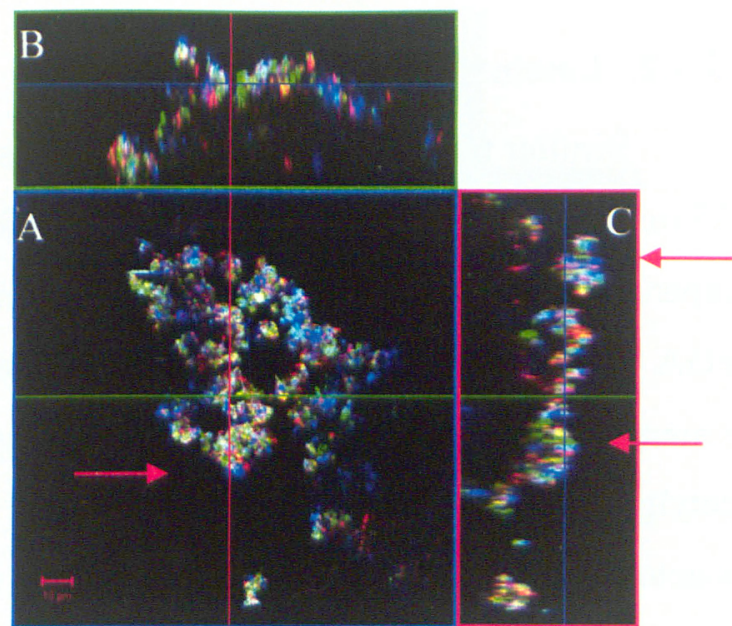

(b)
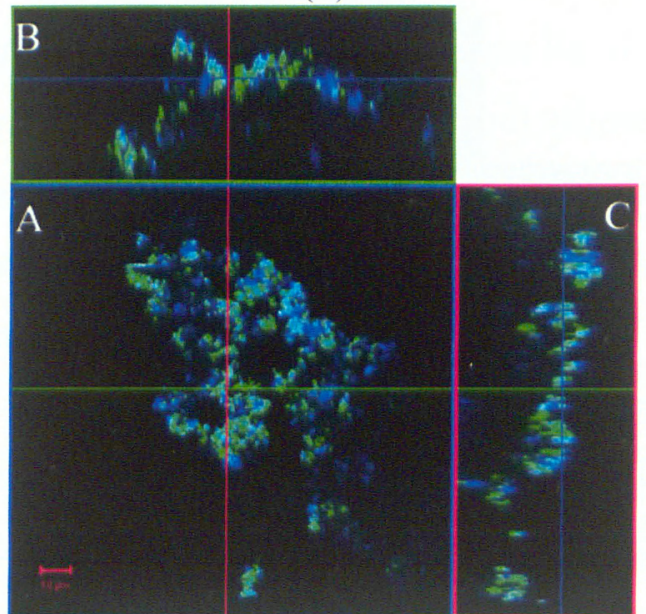

(d)
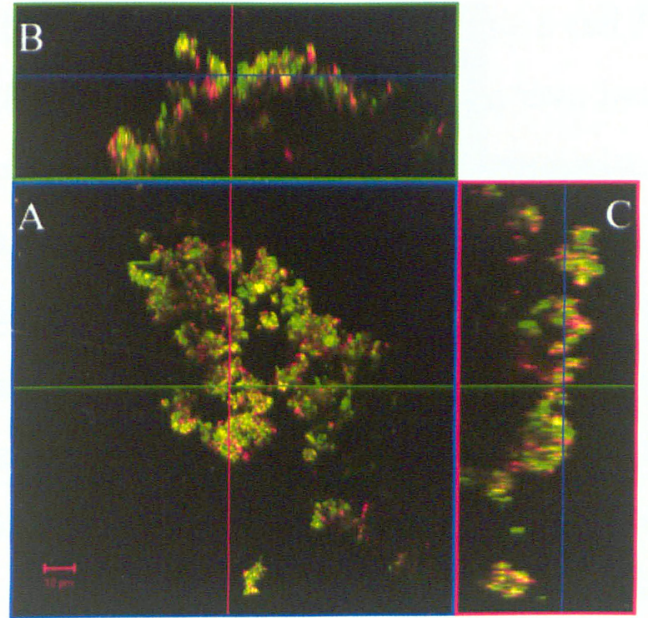

(e)

Figure 23. Colocalization in EDTA-K treated flocs

EDTA treated flocs were further treated with $200 \mu \mathrm{g} / \mathrm{ml}$ proteinase K. CLSM orthogonal micrographs show (a) reflectance mode and colocalization of (b) composite, (c) nucleic-lipid, (d) nucleic-proteins and (e) proteins-lipid. $\mathrm{z}$ plane $=24 \mu \mathrm{m}$ Scale bar $=10 \mu \mathrm{m}$. 


\subsubsection{Lcctin-conjugated Dyes}

Similar to the previous method, floc samples were treated with $1000 \mu \mathrm{g} / \mathrm{ml}$ EDTA for $135 \mathrm{~min}$ and then treated with proteinase $\mathrm{K}$ for $120 \mathrm{~min}$. Control floc samples were also prepared. After each treatment, flocs were stained with lectin-conjugate dyes, ConA (blue), WGA (red), and SBA (green). These dyes are specific to carbohydrate residues. ConA is specific to mannopyranosyl (Man) and glucopyranosyl (Glc) residue. WGA is specific to $\mathrm{N}$ acetylglucosaminyl (GlcNAc) residues. SBA is specific to $N$-acetylgalactosaminyl (GalNAc) and galactopyranosyl $(\mathrm{Gal})$ residues. The stained samples were observed under CLSM to examine distribution of carbohydrates in flocs.

In all samples, ConA, WGA and SBA stained areas were detected. These carbohydrates are generally thought to exist heterogeneously, horizontally and vertically throughout the flocs. However, the distribution pattern of the stained areas appeared different. Figure 24 shows ConA, WGA and SBA distribution in the control flocs, along with the same floc shown in a reflectance mode. In the control floc, WGA bound in a relatively large area of floc from the surface to the interior of the floc. Contrary to WGA, ConA bound in the very small area of the periphery of the floc. SBA also bound to small areas that were scattered around the surface of the flocs. Each lectin dye stained distinct area and very limited amount of colocalization was observed. Figure 25 shows ConA, WGA and SBA distribution in the EDTA-treated floc along with a reflectance mode image of the floc. WGA has a similar distribution pattern as the control however, it seems that ConA and SBA have bound over a larger area. In particular, SBA shows a more diffusive and cloud-like staining pattern from the surface to the interior of the flocs, which led to an increased in the overlap with WGA. Figure 26 shows ConA, WGA and SBA distribution in the EDTA-K treated floc, along with a reflectance mode image of the floc. ConA and WGA have similar distribution patterns as the control. Similar to the EDTA-treated floc, SBA in the EDTA$\mathrm{K}$ treated floc seems to have bound in a larger area of floc from the surface to the interior of the floc. SBA also showed a more diffusive and cloud-like staining pattern, which increased colocalization with WGA at the surface and the interior of floc. 


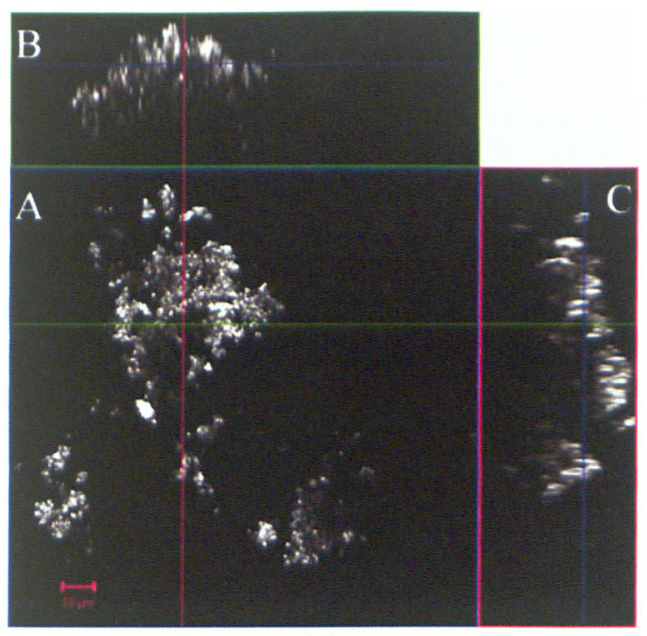

(a)

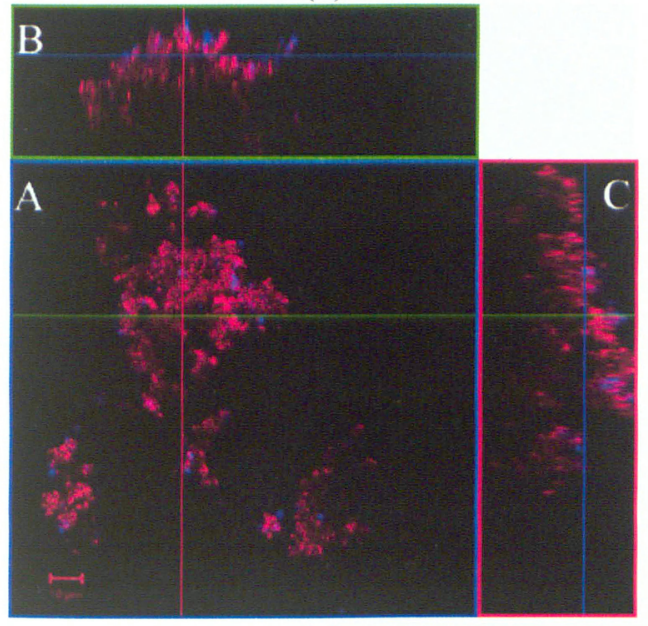

(c)

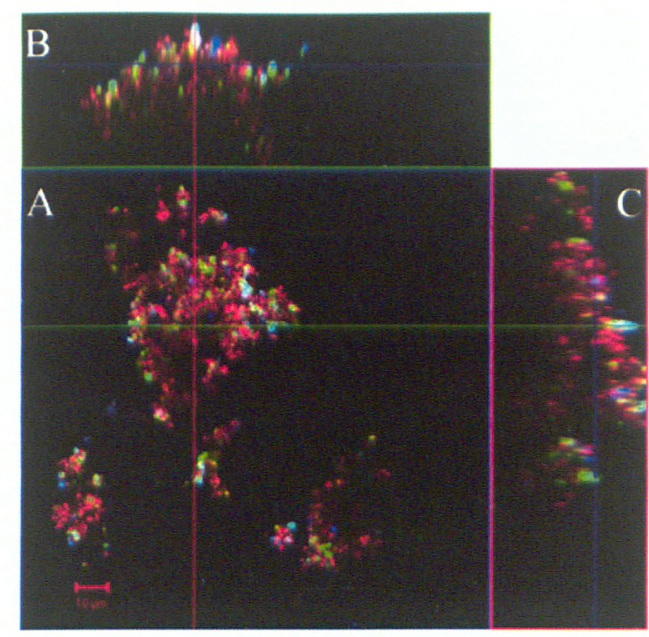

(b)

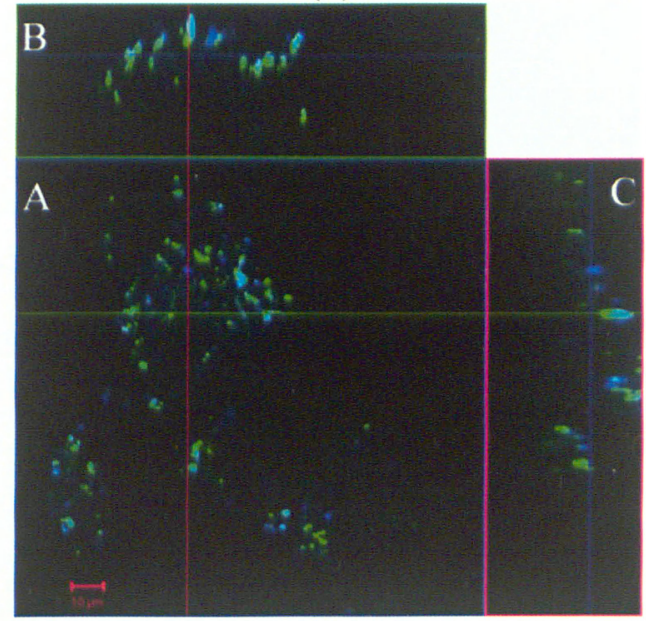

(d)

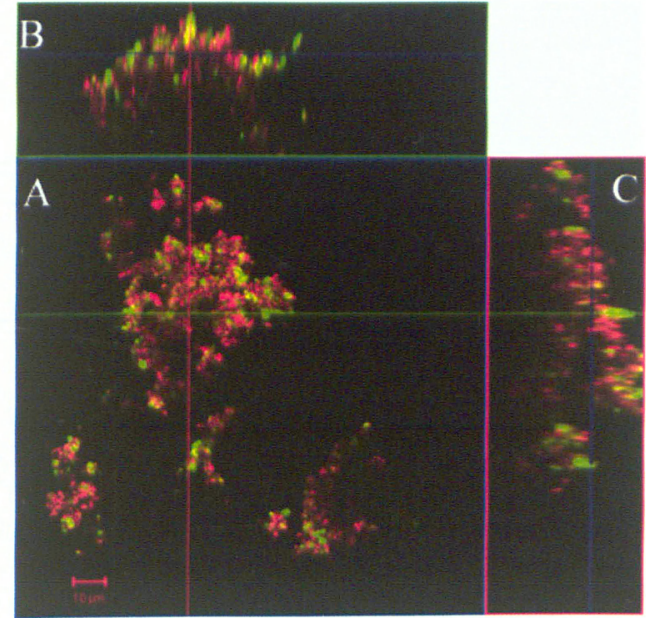

(e)

Figure 24. Distribution of carbohydrates in control flocs

CLSM orthogonal micrographs show (a) reflectance mode and colocalization of (b) composite of ConA (Man, Glc residues), WGA (GlcNAc residues) and SBA (Gal, GalNAc) (c) ConA and WGA, (d) ConA and SBA (e) SBA and WGA. $z$ plane $=16 \mu \mathrm{m}$, Scale bar $=10 \mu \mathrm{m}$. 


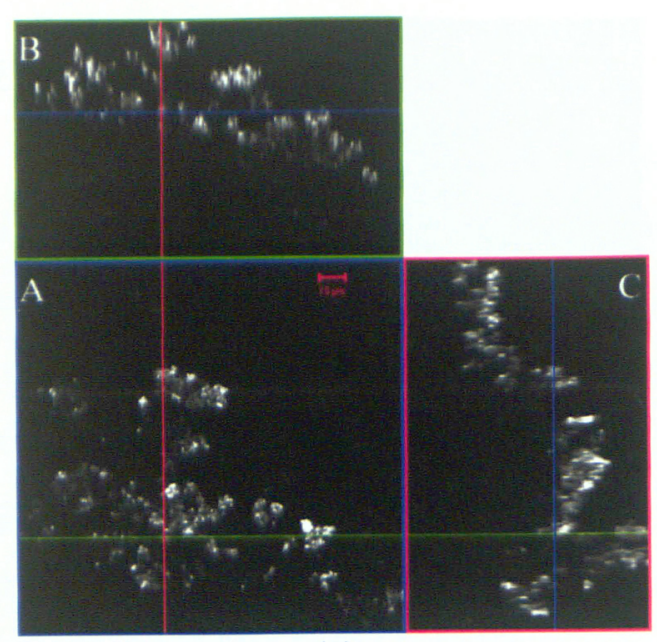

(a)

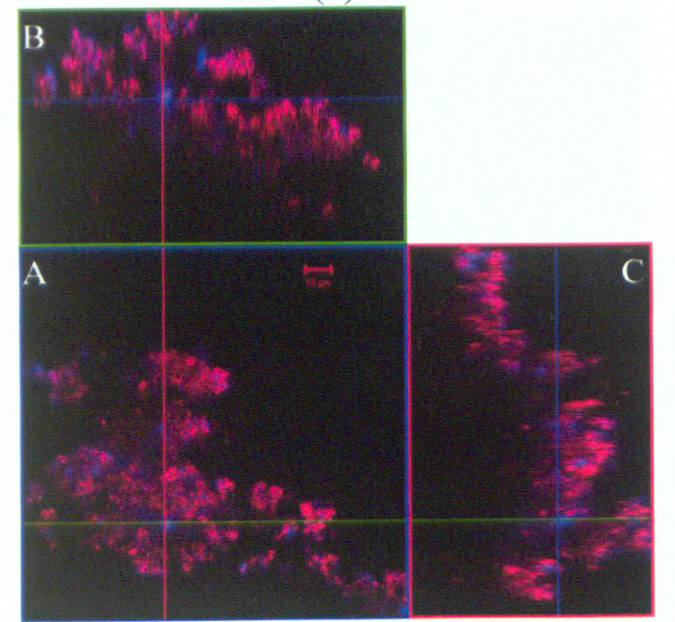

(c)

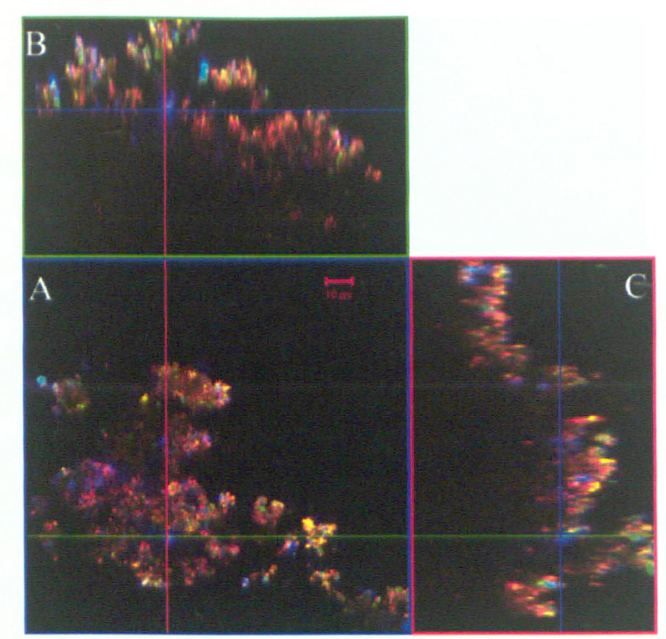

(b)

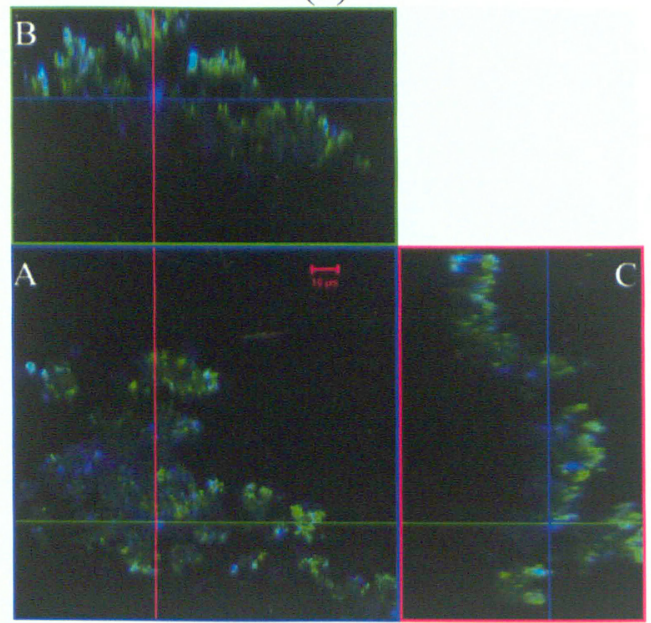

(d)

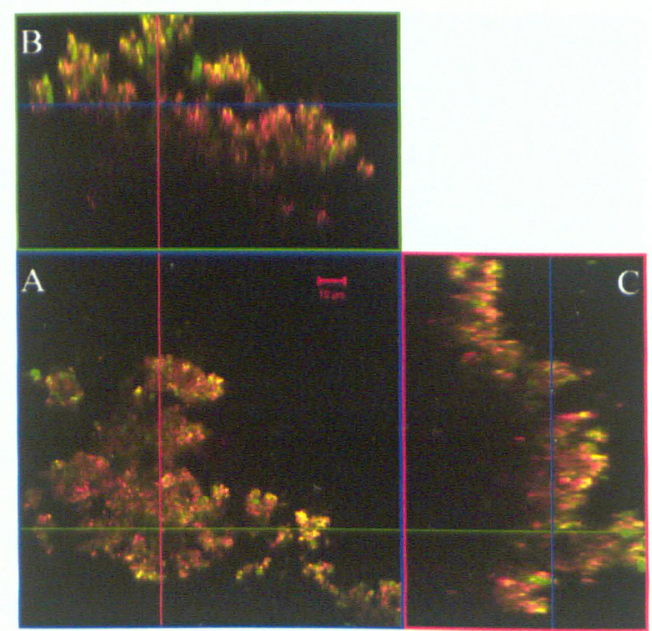

(e)

Figure 25. Distribution of carbohydrates in EDTA treated flocs

Flocs were treated with $1000 \mu \mathrm{g} / \mathrm{ml}$ EDTA. CLSM orthogonal micrographs show (a) reflectance mode and colocalization of (b) composite (c) ConA and WGA, (d) ConA and SBA (e) SBA and WGA. z plane $=36 \mu \mathrm{m}$, Scale bar $=10 \mu \mathrm{m}$. 


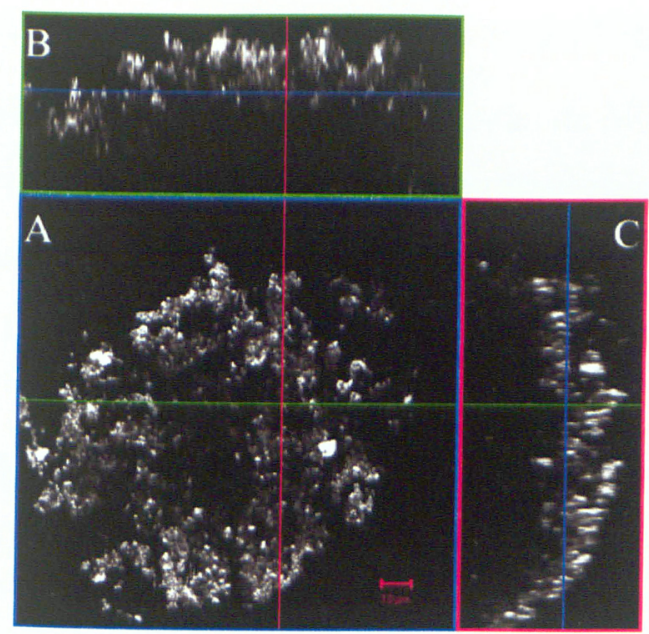

(a)

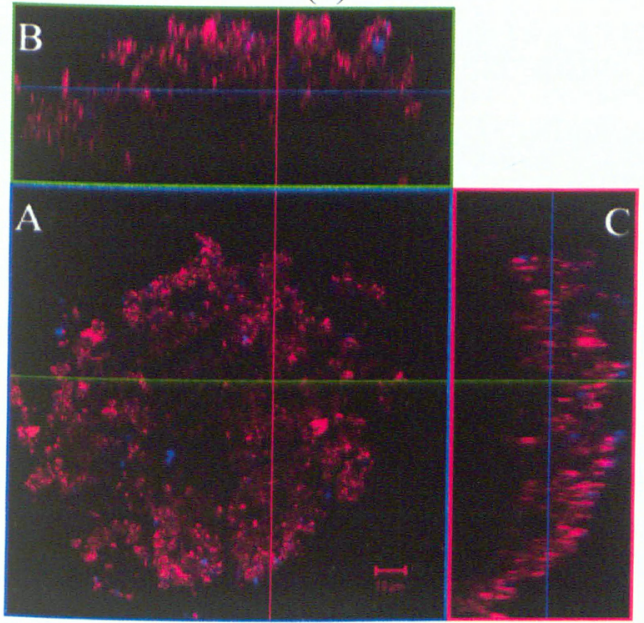

(c)

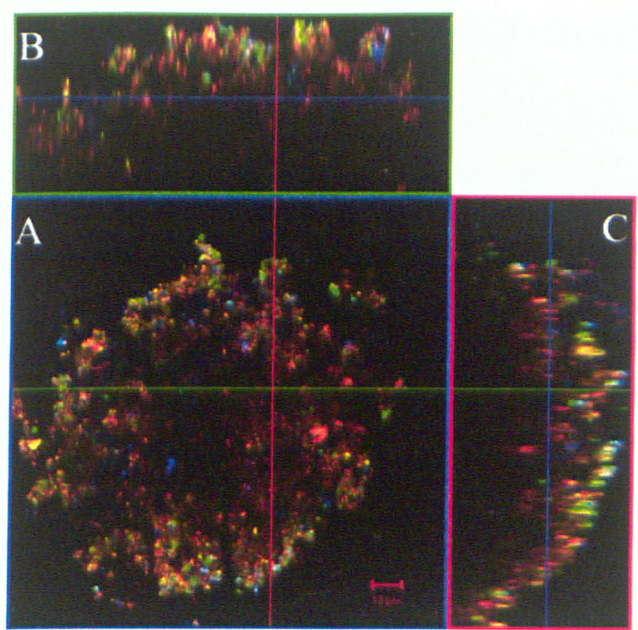

(b)

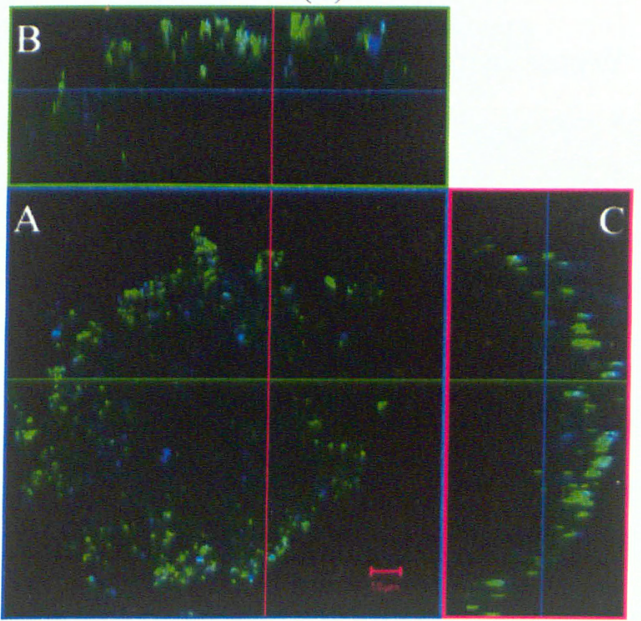

(d)
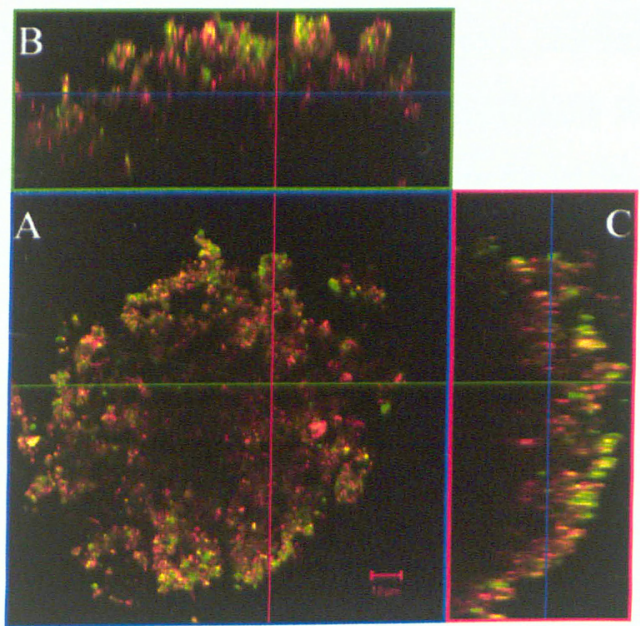

(e)

Figure 26. Distribution of carbohydrates in EDTA-K treated flocs

EDTA treated flocs were further treated with $200 \mu \mathrm{g} / \mathrm{ml}$ proteinase K. CLSM orthogonal micrographs show (a) reflectance mode and colocalization of (b) composite (c) ConA and WGA, (d) ConA and SBA (e) SBA and WGA. z plane $=28 \mu \mathrm{m}$, Scale bar $=10 \mu \mathrm{m}$. 


\subsection{Association of Escherichia coli $0157: H 7$ with Floc}

It is known that $E$. coli $\mathrm{O} 157: \mathrm{H} 7$ can survive in an adverse environment for extended periods of time and then cause health problems through food and water contamination. However, it is not clearly known how they survive in some environments, and in particular, natural aquatic environments. It is also not clearly known if they still retain the capability to infect in such environments. In this study, the survival of E. coli O157:H7 (referred as EHEC) in floc suspended water, in particular, due to its association with flocs, is examined. Adherent EHEC were isolated from flocs and their pathogenicity was also investigated.

\subsubsection{Survival of Escherichia coli O157:H7 in Water}

Water samples containing SBR flocs in PBS buffer, NSBR and SBR were inoculated with $10^{8} \mathrm{CFU} / \mathrm{ml} \mathrm{EHEC} \mathrm{and} \mathrm{the} \mathrm{number} \mathrm{of} \mathrm{surviving} \mathrm{EHEC} \mathrm{(both} \mathrm{free-living} \mathrm{and} \mathrm{adhered} \mathrm{to}$ flocs) in each water sample was estimated by plate count for a period of 10 days. This experiment was conducted twice. Table 9 and Table 10 show that there was a gradual decrease in the number of EHEC adhered to flocs and in free-living form in all samples. The order of highest survival of EHEC of each form remained the same for each sample solution type. The highest number of EHEC surviving at the 10-day incubation was in the PBS buffer sample (adherent; $1.05 \times 10^{5} \pm 0.04 \times 10^{5} \mathrm{CFU} / \mathrm{ml}$ and free-living form; $\left.3.82 \times 10^{3} \pm 0.17 \times 10^{3} \mathrm{CFU} / \mathrm{ml}\right)$. The second highest survival was observed in the SBR sample with nutrients replenished (adherent; $2.51 \times 10^{2} \pm 0.15 \times 10^{2} \mathrm{CFU} / \mathrm{ml}$ and free-living form; $\left.3.66 \times 10^{1} \pm 0.00 \times 10^{1} \mathrm{CFU} / \mathrm{ml}\right)$. The lowest survival was in the SBR (adherent; $1.35 \times 10^{2} \pm 0.21 \times 10^{2} \mathrm{CFU} / \mathrm{ml}$ and free-living form; $\left.1.61 \times 10^{1} \pm 0.00 \times 10^{1} \mathrm{CFU} / \mathrm{ml}\right)$. The number of adherent and free-living EHEC surviving in the PBS buffer sample at the 10-day incubation was a significantly higher level than in the other two samples $(\mathrm{P} \leq 0.05)$.

Furthermore, Table 9 and Table 10 also show that, in all samples, more adherent EHEC survived than free-living EHEC. However, there were no significant survival differences between the types of EHEC in each sample $(\mathrm{P} \leq 0.05)$. Moreover, it is important to estimate what degree of EHEC adhered to the EPS area, since the more stable EPS area allows EHEC to persist in water for a longer time posing higher risk of infection. Thus, flocs with adhered EHEC were further treated with proteinase $\mathrm{K}$. 
Table 9. Enumeration of adherent EHEC in floc suspended solutions $(\mathrm{N}=2)$

\begin{tabular}{llll}
\hline Water PBS Buffer & NSBR & SBR \\
Day $(\mathrm{s})$ CFU $/ \mathrm{ml}$ & CFU/ml & CFU/ml \\
\hline $0^{*}$ & 0 & 0 & 0 \\
2 & $8.04 \times 10^{7} \pm 4.87 \times 10^{7}$ & $8.02 \times 10^{6} \pm 3.28 \times 10^{6}$ & $8.02 \times 10^{6} \pm 3.28 \times 10^{6}$ \\
4 & $1.63 \times 10^{7} \pm 0.98 \times 10^{7}$ & $1.40 \times 10^{5} \pm 0.06 \times 10^{5}$ & $2.47 \times 10^{5} \pm 0.55 \times 10^{5}$ \\
$6^{* *}$ & $3.30 \times 10^{6}$ & $1.50 \times 10^{4}$ & $5.10 \times 10^{4}$ \\
8 & $1.01 \times 10^{6} \pm 0.15 \times 10^{6}$ & $9.75 \times 10^{2} \pm 3.18 \times 10^{2}$ & $1.20 \times 10^{4} \pm 0.08 \times 10^{4}$ \\
10 & $1.05 \times 10^{5} \pm 0.04 \times 10^{5}$ & $2.51 \times 10^{2} \pm 0.15 \times 10^{2}$ & $1.35 \times 10^{2} \pm 0.21 \times 10^{2}$ \\
\hline
\end{tabular}

PBS buffer, NSBR and SBR held at $25^{\circ} \mathrm{C}$ by counting on LB plates with Kan and Amp

${ }^{*} 1 \times 10^{8} \mathrm{CFU} / \mathrm{ml}$ EHEC was inoculated, which are assumed as free-living form.

*** One plate count was used.

Table 10. Enumeration of free-living EHEC in floc suspended solutions $(\mathrm{N}=\mathbf{2})$

\begin{tabular}{llll}
\hline Water & PBS Buffer & NSBR & SBR \\
Day(s) & CFU/ml & CFU/ml & CFU/ml \\
\hline $0^{*}$ & $1 \times 10^{8}$ & $1 \times 10^{8}$ & $1 \times 10^{8}$ \\
2 & $1.21 \times 10^{8} \pm 0.09 \times 10^{8}$ & $7.20 \times 10^{3} \pm 3.67 \times 10^{3}$ & $7.20 \times 10^{3} \pm 3.67 \times 10^{3}$ \\
4 & $5.74 \times 10^{5} \pm 0.37 \times 10^{5}$ & $7.74 \times 10^{3} \pm 5.92 \times 10^{3}$ & $1.53 \times 10^{4} \pm 1.12 \times 10^{4}$ \\
$6^{* *}$ & $4.00 \times 10^{4}$ & $1.00 \times 10^{3}$ & $1.00 \times 10^{3}$ \\
8 & $2.54 \times 10^{4} \pm 0.02 \times 10^{4}$ & $4.00 \times 10^{1} \pm 1.41 \times 10^{1}$ & $9.00 \times 10^{1} \pm 0.00 \times 10^{1}$ \\
10 & $3.82 \times 10^{3} \pm 0.17 \times 10^{3}$ & $3.66 \times 10^{1} \pm 0.00 \times 10^{1}$ & $1.61 \times 10^{1} \pm 0.00 \times 10^{1}$ \\
\hline
\end{tabular}

PBS buffer, NSBR and SBR held at $25^{\circ} \mathrm{C}$ by counting on LB plates with Kan and Amp ${ }^{*} 1 \times 10^{8} \mathrm{CFU} / \mathrm{ml}$ EHEC was inoculated, which are assumed as free-living form.

** One plate count was used.

Figure 27 shows that the ratio of adherent EHEC in the EPS to total adherent EHEC in PBS buffer and SBR remained similar for 10 days of incubation. However, the ratio of adherent EHEC in the EPS to total adherent EHEC in NSBR showed a spike at 6 days of incubation and then dropped significantly. Among the three water samples, the NSBR sample had a significantly higher percentage of EHEC in the EPS $(19.2 \pm 1.6 \%)$ compared to the SBR $(15.0 \pm 1.9 \%)$ and the PBS buffer $(6.10 \pm 0.48 \%)$ at the 10-day incubation $(\mathrm{P} \leq 0.05)$. Furthermore, the flocs on the 10-day incubation from each sample were also examined under COM and are shown in Figure 28. Figure 28 (a) shows that the floc in the PBS buffer (PBS floc) is degrading due to starvation. Figure 28 (b) shows that the floc in NSBR (NSBR floc) includes dense EPS areas. Figure 28 (c) shows that the floc in SBR (SBR floc) has not degraded as much as the PBS floc and has less dense EPS than the NSBR floc. 


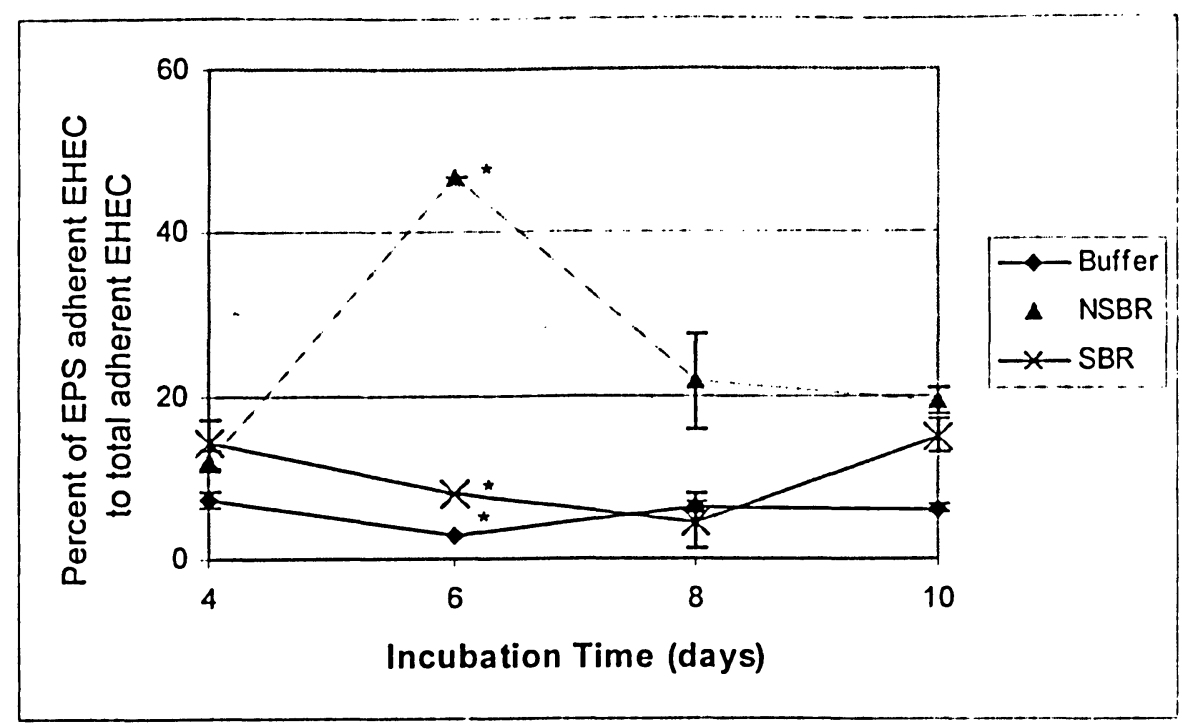

Figure 27. EPS adherent EHEC

Flocs in PBS buffer, NSBR and SBR were dissociated by proteinase K. EHEC was isolated from the non-dissociated flocs and enumerated by plating on LB plates with Kan and Amp.

* On the $6 \mathrm{~d}$ incubation, one plate count was used.

\subsubsection{Direct Observation of adherent Escherichia coli 0157:H7 by CLSM}

The distribution of adherent EHEC in flocs were observed under CLSM. Figure 29 and Figure 30 show the distribution of EHEC in flocs suspended in PBS buffer on a 2-day incubation. In Figure 29B, EHEC are seen as the green fluorescent spots indicated with arrows. In general, EHEC dispersed individually in flocs. Figure 30 is the orthogonal section of Figure 29 illustrating that adherent EHEC generally appear to locate at/near the surface of flocs. The average width of the green band on $\mathrm{z}$ axis is approximately $6.6 \mu \mathrm{m}$, which serves as an indicator for EHEC distribution. Figure 31 and Figure 32 demonstrates the distribution of EHEC in flocs suspended in SBR on a 2-day incubation. Similar to the above figures, Figure 31 demonstrates that EHEC are dispersed individually in flocs. Figure 32 shows that adherent EHEC generally appear to locate at/near the surface of flocs. In particular, Panel C (Figure 32) illustrates that EHEC are on the top of the dark dense EPS area. The average width of the green band on $\mathrm{z}$ axis is approximately $5.3 \mu \mathrm{m}$. 


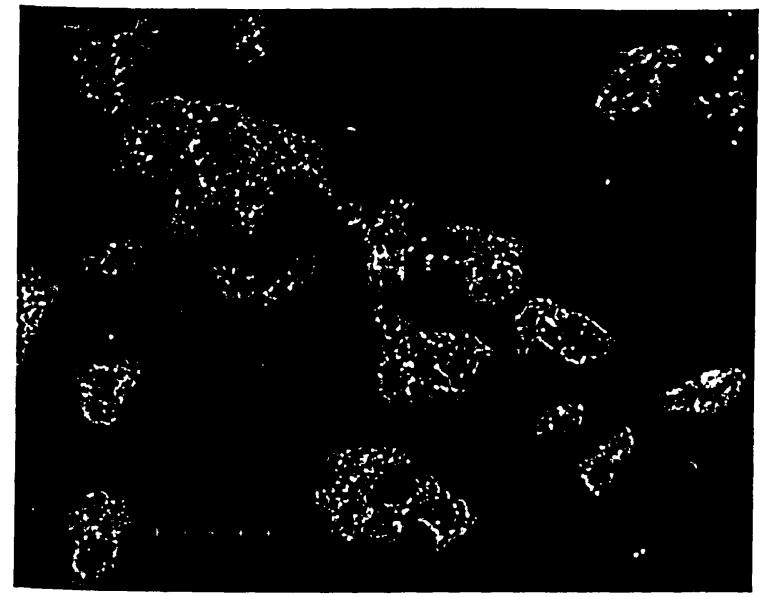

(a)

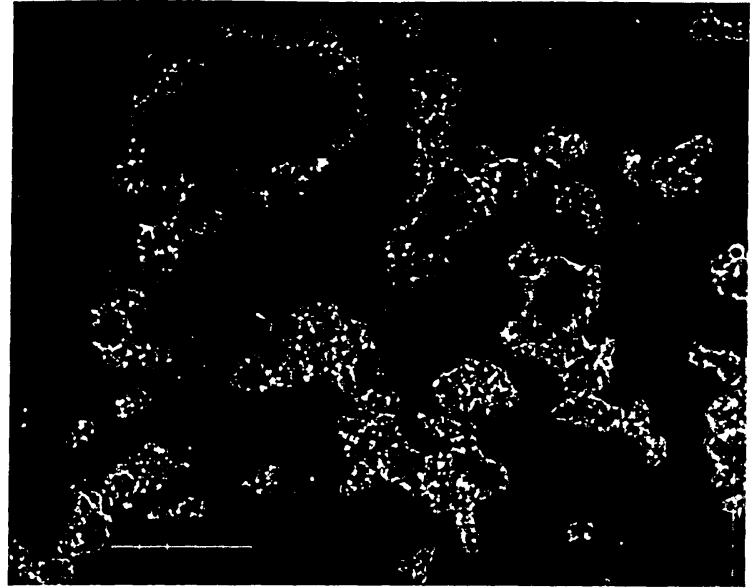

(b)

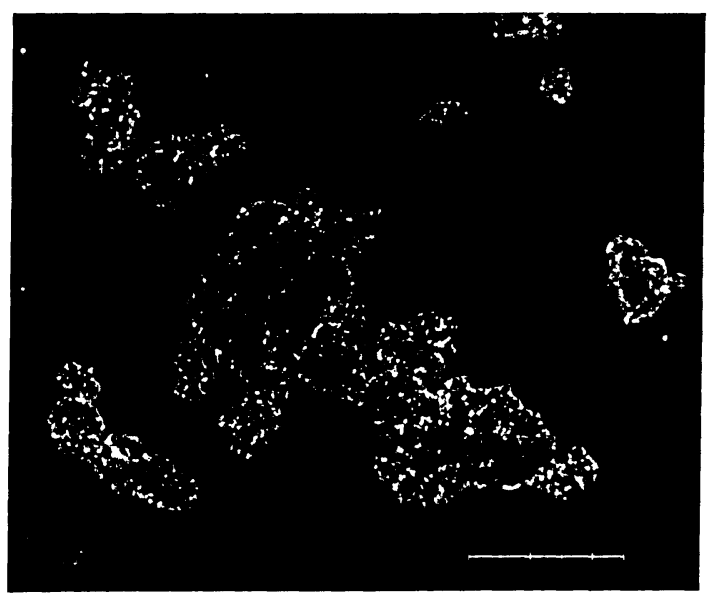

(c)

Figure 28. Flocs incubated with EHEC on 10-day incubation

$10^{8} \mathrm{CFU} / \mathrm{ml}$ E. coli $\mathrm{O} 157: \mathrm{H} 7$ was inoculated and incubated with flocs suspended in (a) PBS buffer, (b) NSBR and (c) SBR. Flocs were observed under phase contrast $x 100$. Scale bar $=250$ $\mu \mathrm{m}$. Note that NSBR has more distinct EPS areas than the other two.

Figure 33 and Figure 34 show the distribution of EHEC in PBS flocs at 7-day incubation. In Figure 33B, EHEC colonies are indicated with arrows. More individual EHEC are also seen within proximity than there were in the 2-day incubation. Figure 34 is an orthogonal section illustrating that adherent EHEC generally appear to locate at/near the surface of flocs. The average width of the green band on $\mathrm{z}$ axis is approximately $9.2 \mu \mathrm{m}$. This result is much wider than the 2-day incubation, indicating that the EHEC distribution has spread inward into the flocs. Figure 34 also reveals that this floc has a loose structure. 
Figure 35 and Figure 36 show the distribution of EHEC in NSBR flocs at 7-day incubation. In Figure 35, EHEC colonies are also indicated with arrows. The EHEC, including individual bacteria, appear to associate with dense EPS areas.
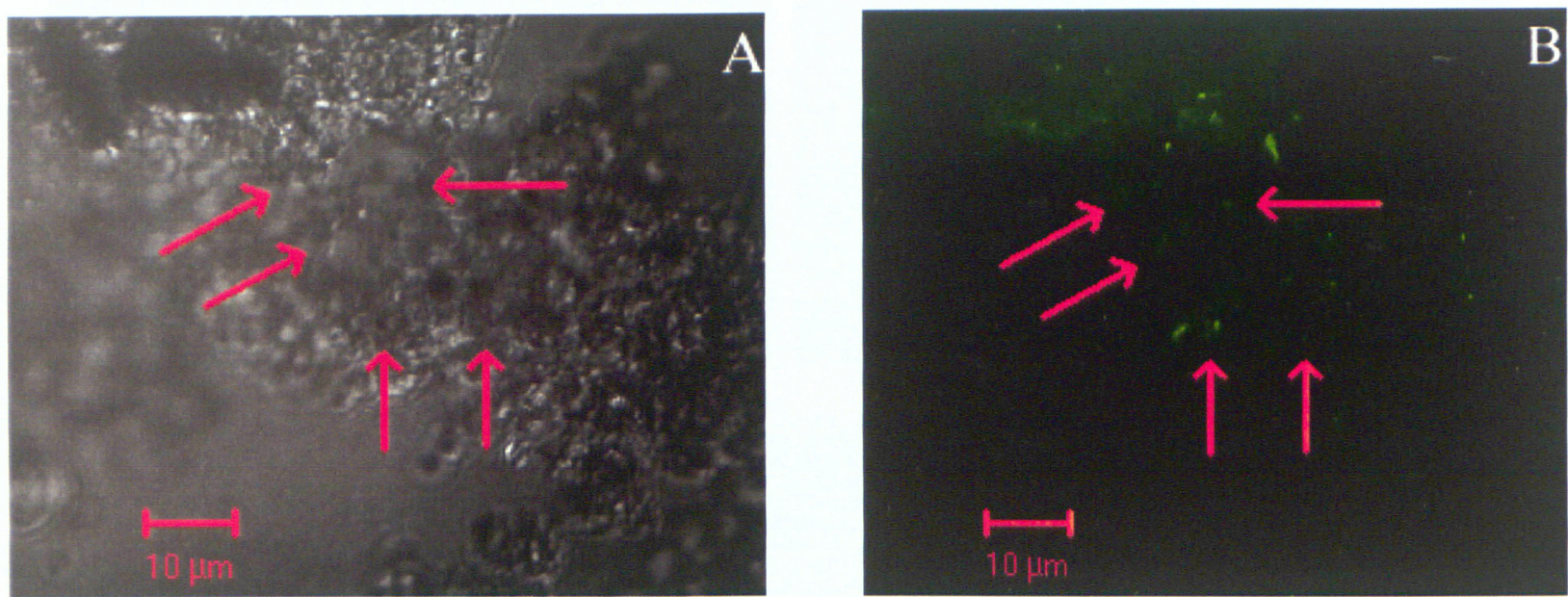

Figure 29. Adherent EHEC to flocs suspended in PBS buffer on 2-day incubation CLSM micrographs show (A) flocs in transmission mode and (B) adherent EHEC (GFP) in fluorescent mode. Some EHEC are indicated by arrows. $\mathrm{z}$ plane $=30 \mu \mathrm{m}$, Scale bar $=10 \mu \mathrm{m}$.

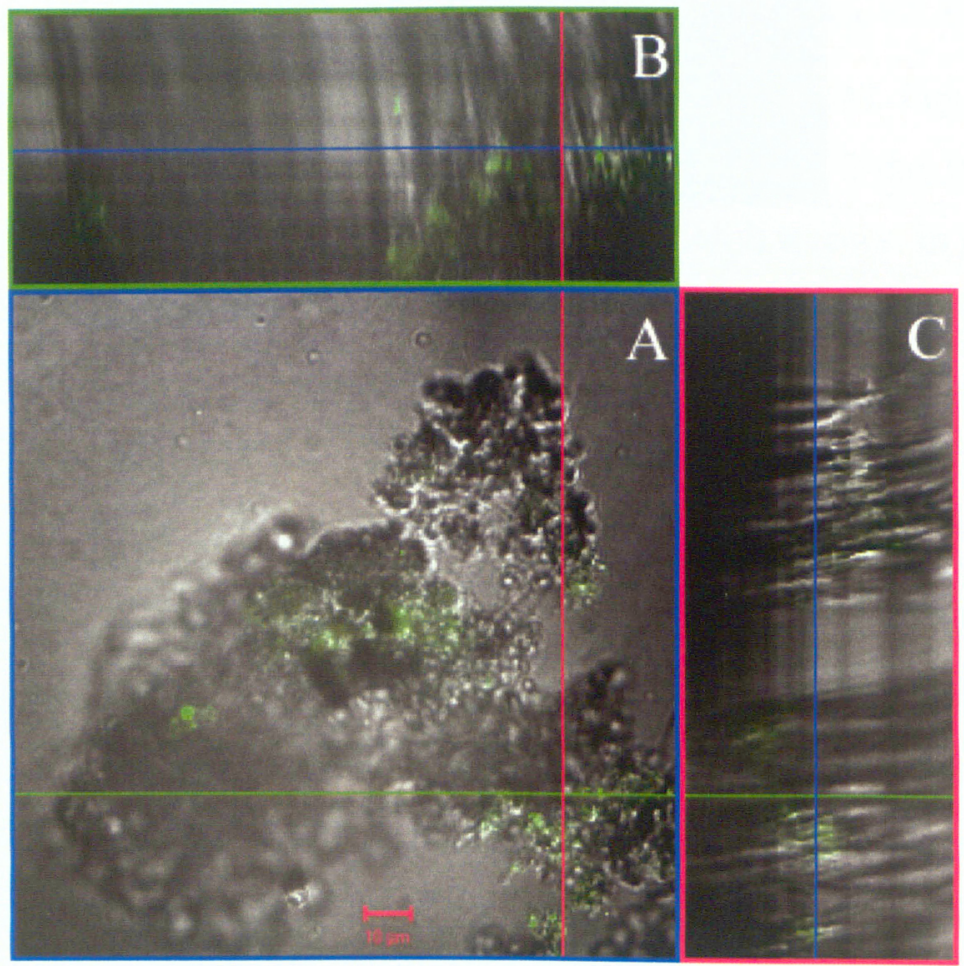

Figure 30. EHEC distribution in flocs suspended in PBS buffer on 2-day incubation CLSM orthogonal micrographs show adherent EHEC distribution in flocs shown in Image 15. Scale bar $=10 \mu \mathrm{m}$. EHEC generally appear to locate at/near the surface of flocs such that the average length of the green band on $\mathrm{z}$ axis shown in Panel $\mathrm{C}$ is approximately $6.6 \mu \mathrm{m}$. 

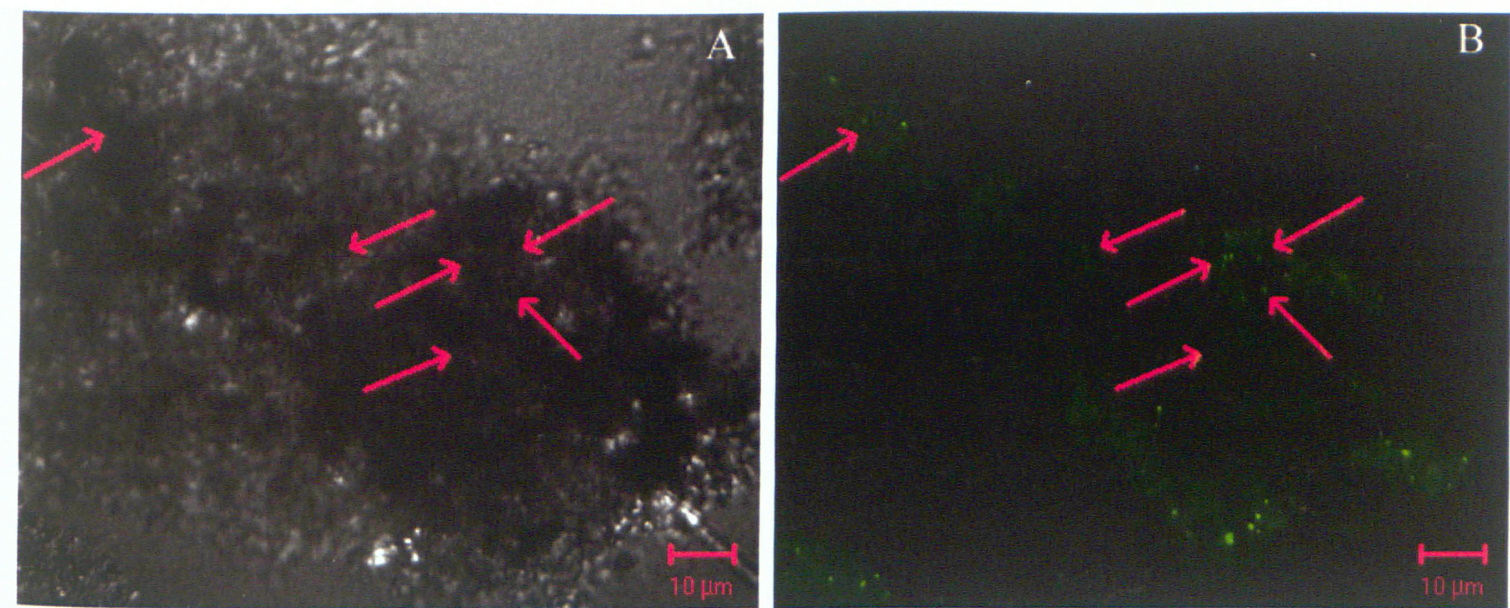

Figure 31. Adherent EHEC to SBR flocs suspended in SBR on 2-day incubation CLSM micrographs show (A) flocs in transmission mode and (B) adherent EHEC (GFP) in fluorescent mode. Some E. coli are indicated by arrows. z plane $=6 \mu \mathrm{m}$, Scale bar $=10 \mu \mathrm{m}$.

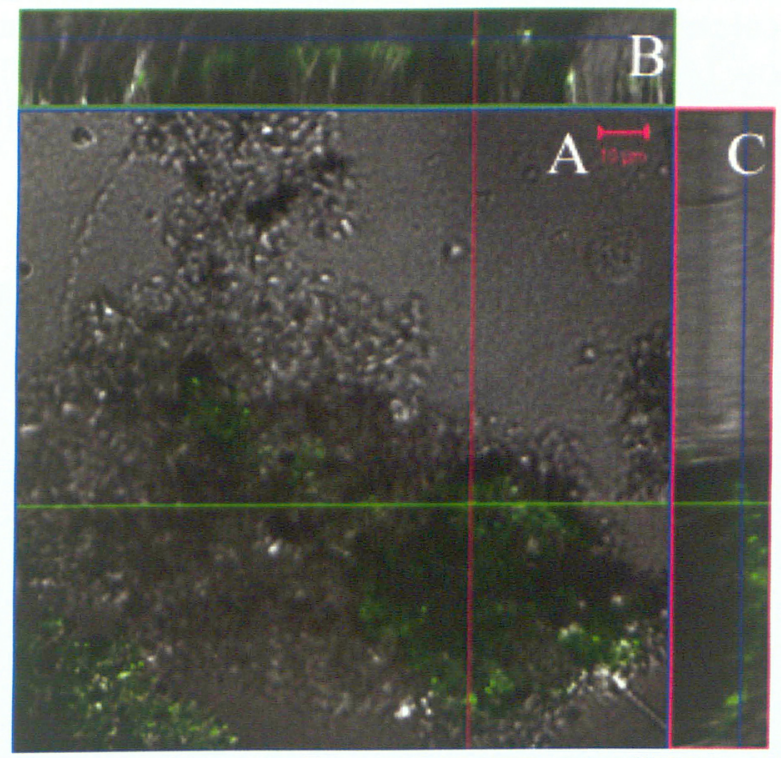

Figure 32. EHEC distribution in flocs suspended in SBR on 2-day incubation

CLSM orthogonal micrographs show adherent EHEC distribution in flocs shown in Image 17. Scale bar $=10 \mu \mathrm{m}$. EHEC generally appear to locate at $/$ near the surface of flocs such that the average length of the green band on $\mathrm{z}$ axis shown in Panel $\mathrm{C}$ is approximately $5.3 \mu \mathrm{m}$.

Note that EHEC adhered on the top of the dark dense EPS area shown in Panel C. 

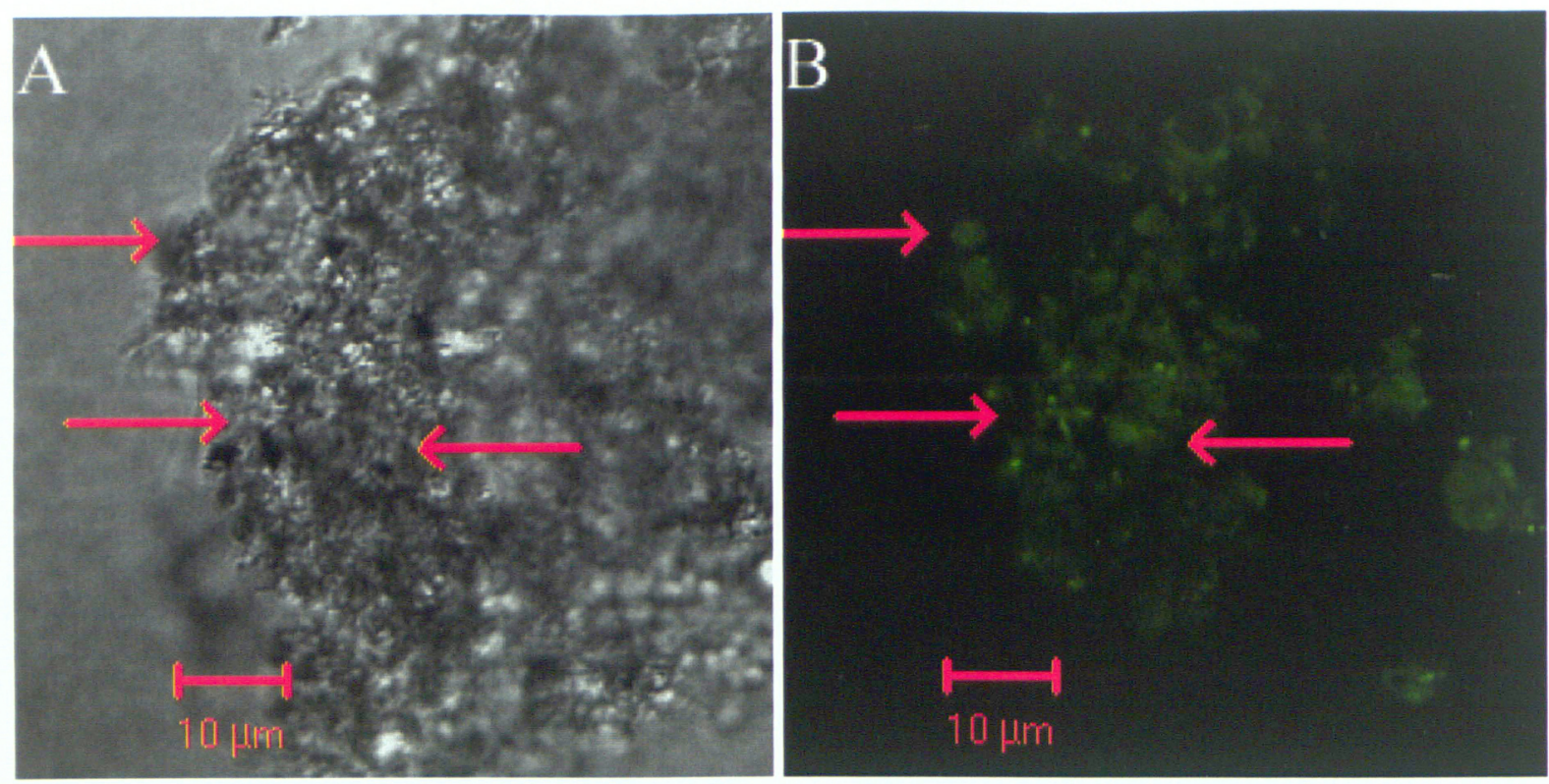

Figure 33. EHEC colonies in flocs suspended in PBS buffer on 7-day incubation CLSM micrographs show (A) flocs in transmission mode and (B) adherent EHEC (GFP) in fluorescent mode. Some EHEC colonies are indicated by arrows. $\mathrm{z}$ plane $=20 \mu \mathrm{m}$, Scale bar $=$ $10 \mu \mathrm{m}$.

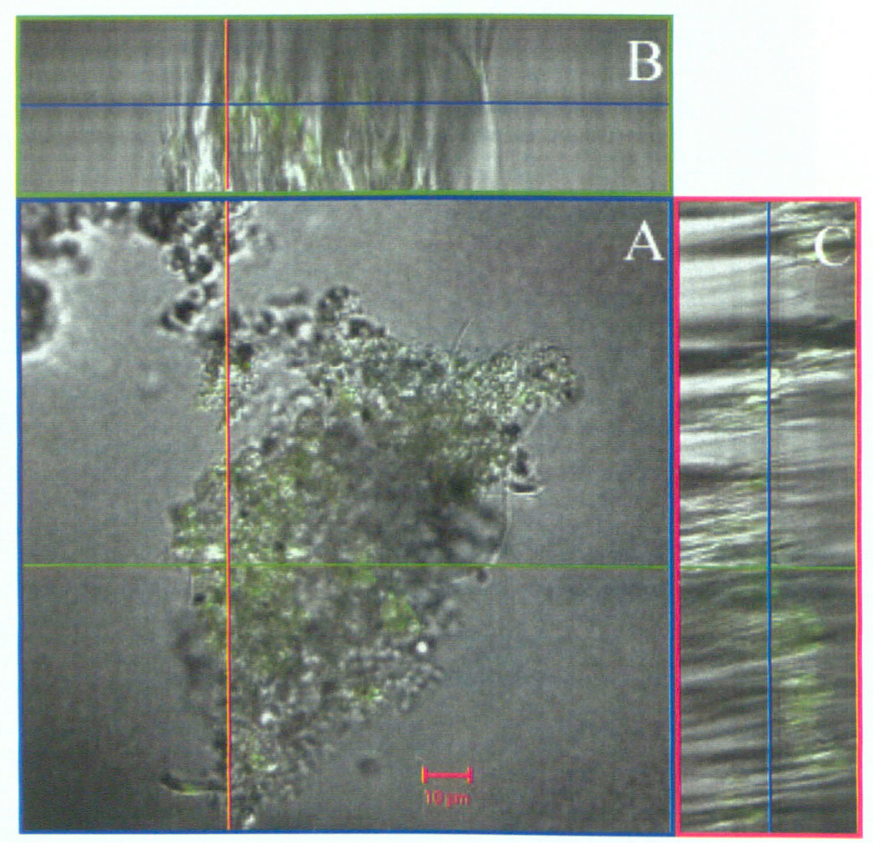

Figure 34. EHEC distribution in flocs suspended in PBS buffer on 7-day incubation CLSM orthogonal micrographs show adherent EHEC distribution in flocs shown in Image 19. Scale bar $=10 \mu \mathrm{m}$. EHEC generally appear from the surface of flocs to the interior of flocs. The average length of the green band on $\mathrm{z}$ axis shown in Panel $\mathrm{C}$ is approximately $9.2 \mu \mathrm{m}$. Note that this floc appears to have a loose structure. 

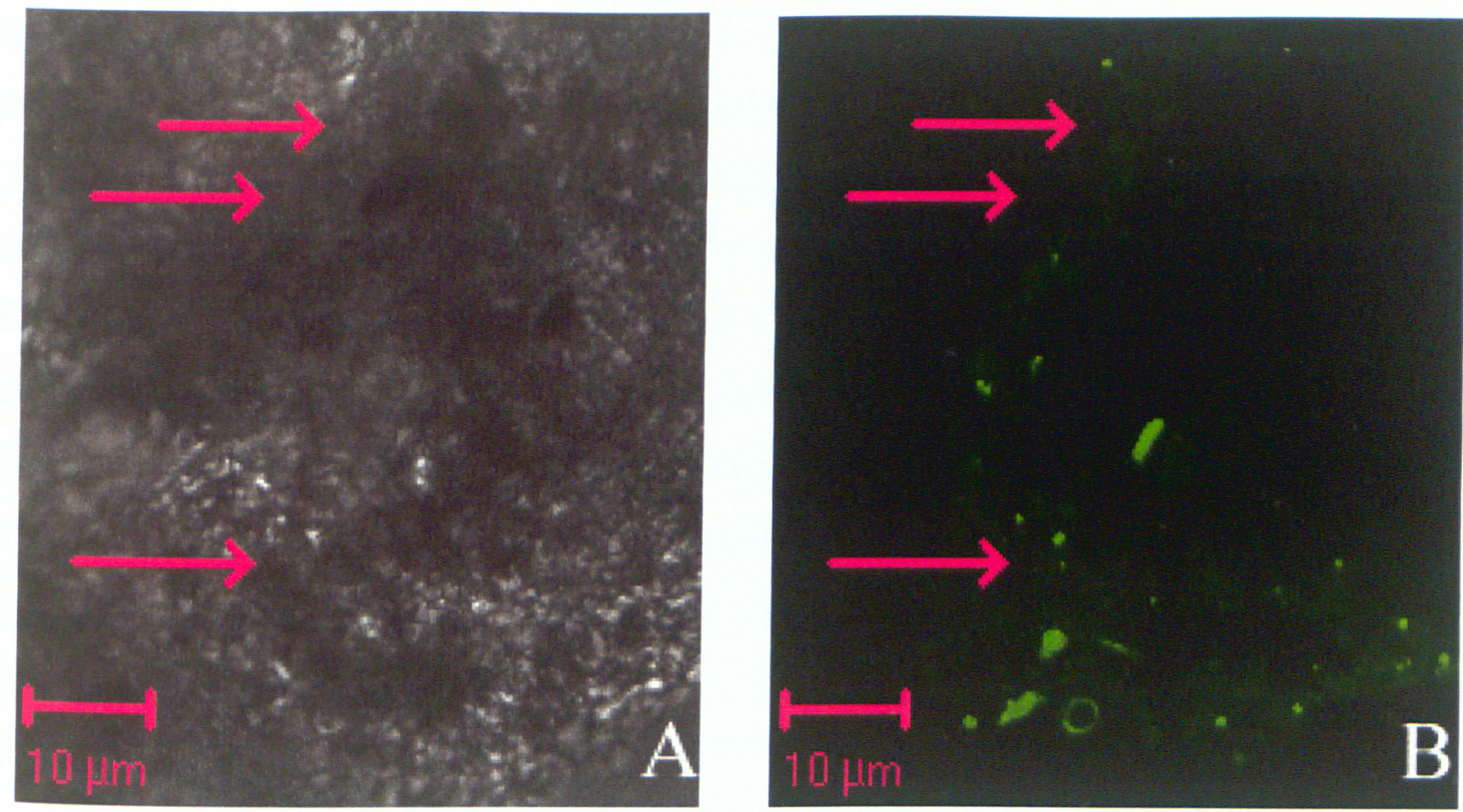

Figure 35. EHEC colonies in flocs suspended in NSBR on 7-day incubation

CLSM micrographs show (A) flocs in transmission mode and (B) adherent EHEC (GFP) in fluorescent mode. Some EHEC colonies are indicated by arrows. $\mathrm{z}$ plane $=49 \mu \mathrm{m}$, Scale bar $=$ $10 \mu \mathrm{m}$.

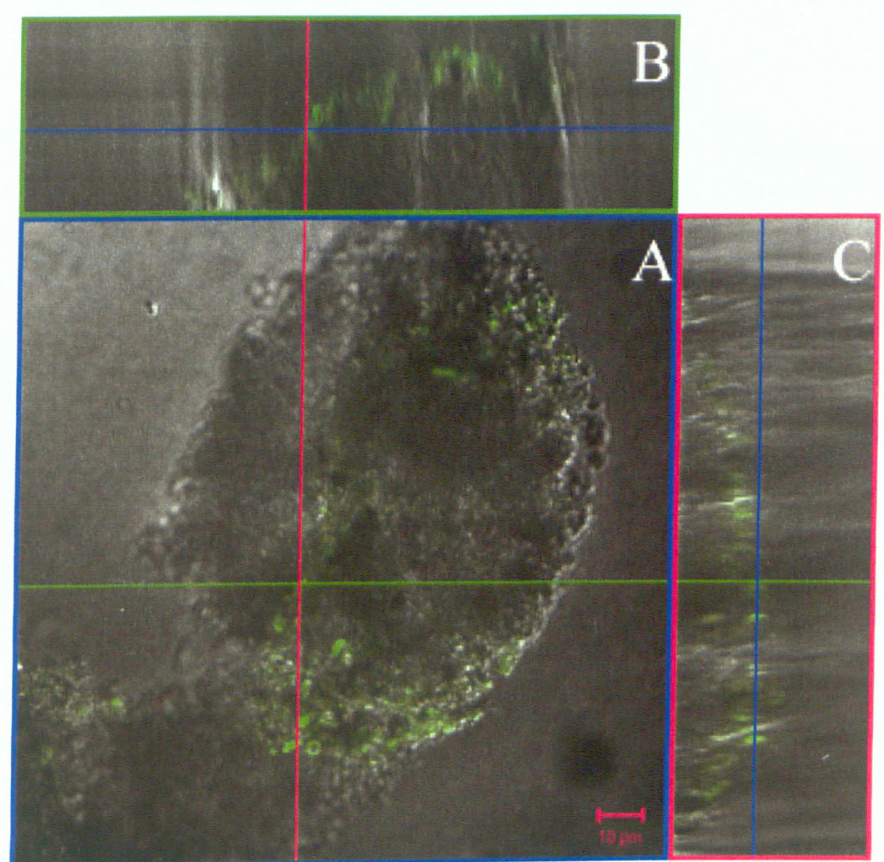

Figure 36. EHEC distribution in flocs suspended in NSBR on 7-day incubation

CLSM orthogonal micrographs show adherent EHEC distribution in flocs shown in Image 21.

Scale bar $=10 \mu \mathrm{m}$. EHEC appear to associate with the border between EPS areas and the remainder of the flocs. The average length of the green band on $\mathrm{z}$ axis shown in Panel $\mathrm{C}$ is approximately $7.6 \mu \mathrm{m}$. 
Figure 36 is an orthogonal section illustrating that adherent EHEC generally appear to be in the interior of NSBR flocs. The average width of the green band on $\mathrm{z}$ axis is approximately 7.6 $\mu \mathrm{m}$. This result is again wider than the flocs in SBR at the 2-day incubation but somewhat narrower than the PBS flocs at 7-day incubation. Again this indicates that the EHEC distribution spreads inward of flocs. Both Figures also show a compact and dense floc with a large EPS area.

Figure 37 and Figure 38 show the distribution of EHEC in SBR flocs at 7-day incubation. There are a smaller number of adherent EHEC, including individual cells, which is in agreement with the plate counts. Figure 38 is an orthogonal section illustrating that adherent EHEC generally appear to locate at/near the surface of flocs. The average width of the green band on $\mathrm{z}$ axis is approximately $7.4 \mu \mathrm{m}$. This result is also wider than the 2-day incubation, which might indicate that the EHEC distribution spreads inward into the flocs. In addition, Figure 38 shows that this floc is less compact and dense than the NSBR floc.

\subsubsection{Pathogenicity of Escherichia coli O157:H7 Extracted from Floc samples}

Since it has been observed that EHEC were able to survive in water samples, it is important to investigate if these EHEC retain pathogenicity in this environment. The EHEC were isolated from water samples and then their pathogenicity were observed based on $\alpha$-actinin accumulation in epithelial HEp-2 cells. In this study, the effects of the environment (free-living

or in flocs, types of water samples and various incubation times (2- or 10-days)) on pathogenicity were examined.

\subsubsection{Immunofluorescent Assays}

In each sample examined, EHEC isolated from the water samples were generally able to adhere to and infect epithelial cells after $4 \mathrm{~h}$ incubation. However, based on a detailed CLSM image analysis, it appears that the degree of EHEC adherence to cells and the subsequent $\alpha$ actinin accumulation differed. For each samples, the ratio of host adhesion ability and $\alpha$-actinin accumulation were estimated and shown in Figure 39. These results show that levels of host adhesion ability in all water samples were lower than that in the positive control of EHEC grown in a rich medium. In most water samples, the difference was significant except for 10_SF and 10_SS (P $\leq 0.05)$. Similarly, levels of $\alpha$-actinin accumulation in all water samples were also lower than the control but there was no significant difference in the following water samples, 2_SF, 
10_BS, 10_SF and 10_SS $(\mathrm{P} \leq 0.05)$. When the type of EHEC was compared, floc-adherent EHEC showed higher levels of host adhesion ability and $\alpha$-actinin accumulation than free-living EHEC, but these were not significantly different in both cases $(\mathrm{P} \leq 0.05)$. The free-living EHEC also showed higher (10_SS) and lower (2_SS) levels of both compared to the floc-adherent EHEC. With respect to the type of water sample, it did not seem to have any significant effect on the levels of host infection ability and $\alpha$-actinin accumulation because only 10_SF showed significantly higher levels of host adhesion ability and $\alpha$-actinin accumulation than 10_NF $(\mathrm{P} \leq 0.05)$. Lastly, the effect of the incubation time (2- or 10-days) of EHEC was also examined. In general, EHEC at the longer incubation time showed higher levels of host adhesion ability and $\alpha$-actinin accumulation. In particular, significantly higher levels were found in BF, BS and SS Solutions $(\mathrm{P} \leq 0.05)$.
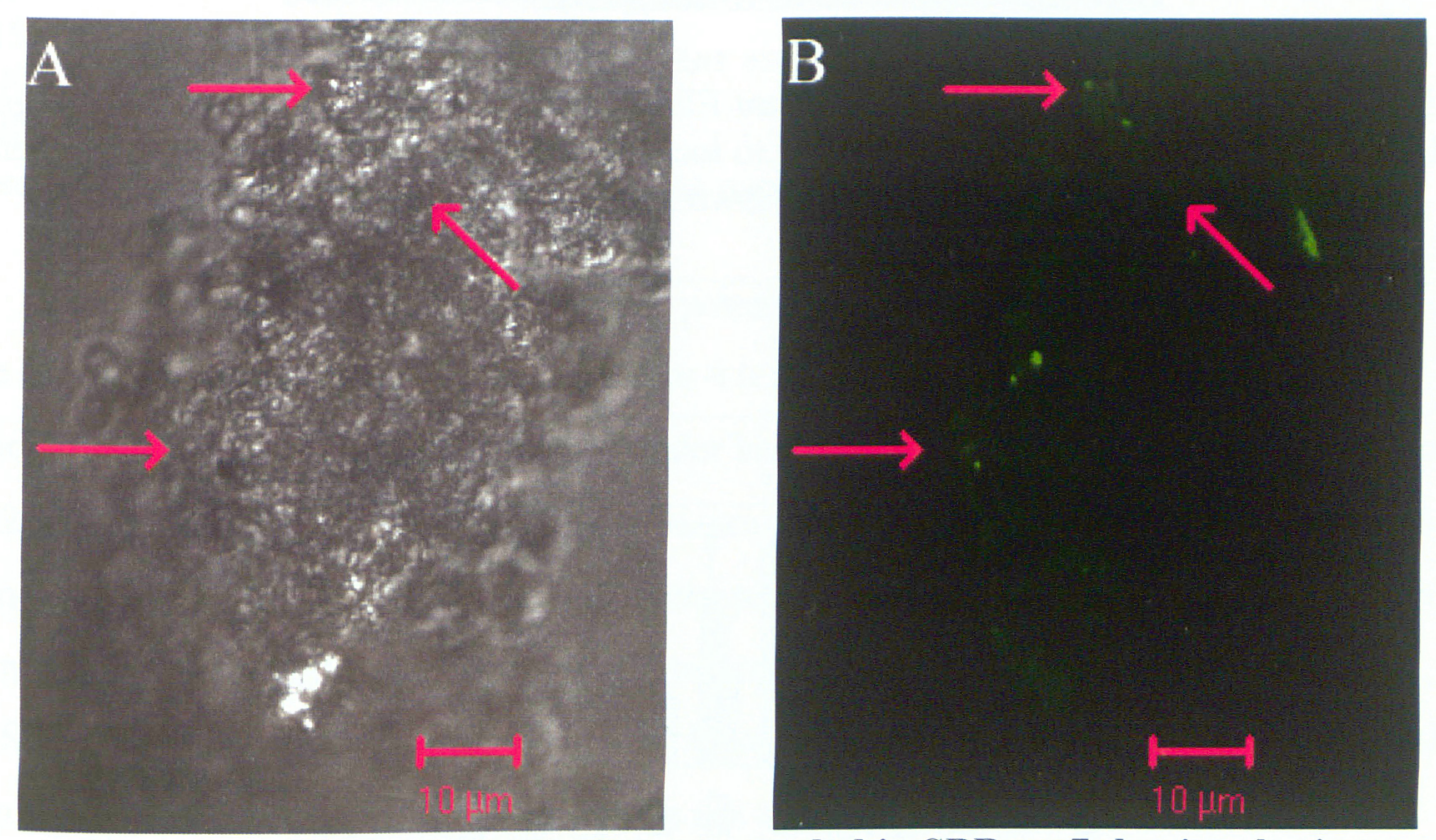

Figure 37. EHEC colonies in flocs suspended in SBR on 7-day incubation

CLSM micrographs show (A) flocs in transmission mode and (B) adherent EHEC (GFP) in fluorescent mode. Some EHEC colonies are indicated by arrows. $\mathrm{z}$ plane $=29 \mu \mathrm{m}$, Scale bar $=10 \mu \mathrm{m}$. 


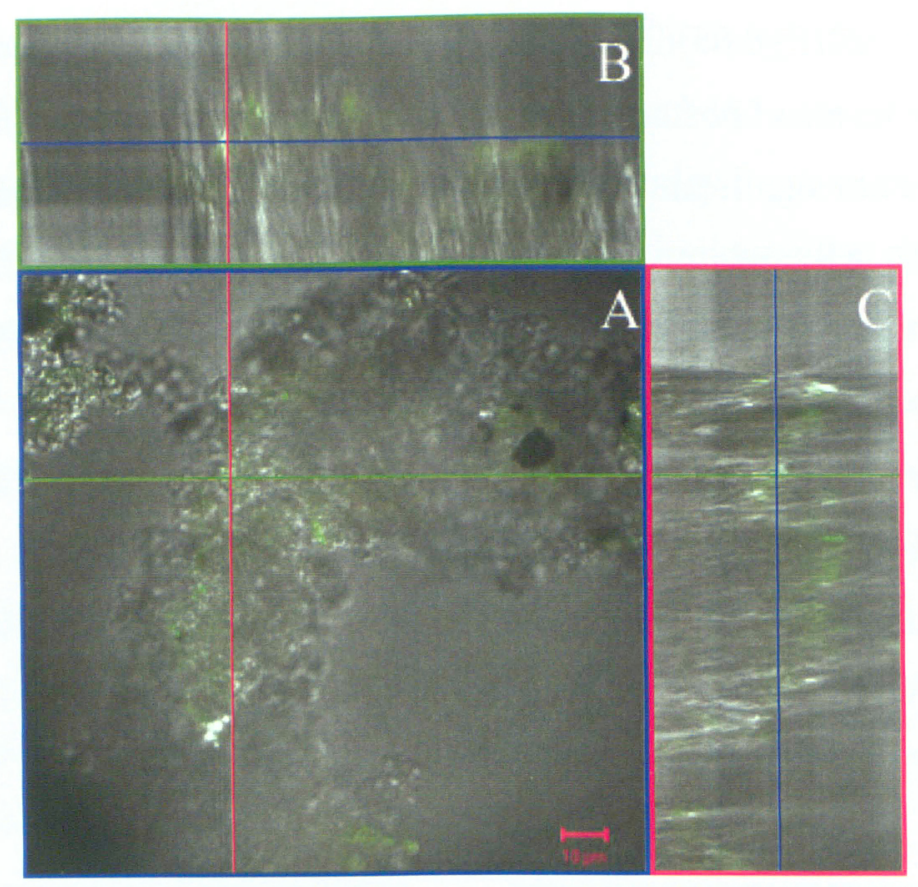

Figure 38. EHEC distribution in flocs suspended in SBR on 7-day incubation CLSM orthogonal micrographs show adherent EHEC distribution in flocs shown in Image 23. Scale bar $=10 \mu \mathrm{m}$. EHEC generally appear to locate at/near the surface of flocs. The average length of the green band on $\mathrm{z}$ axis shown in Panel $\mathrm{C}$ is approximately $7.4 \mu \mathrm{m}$.

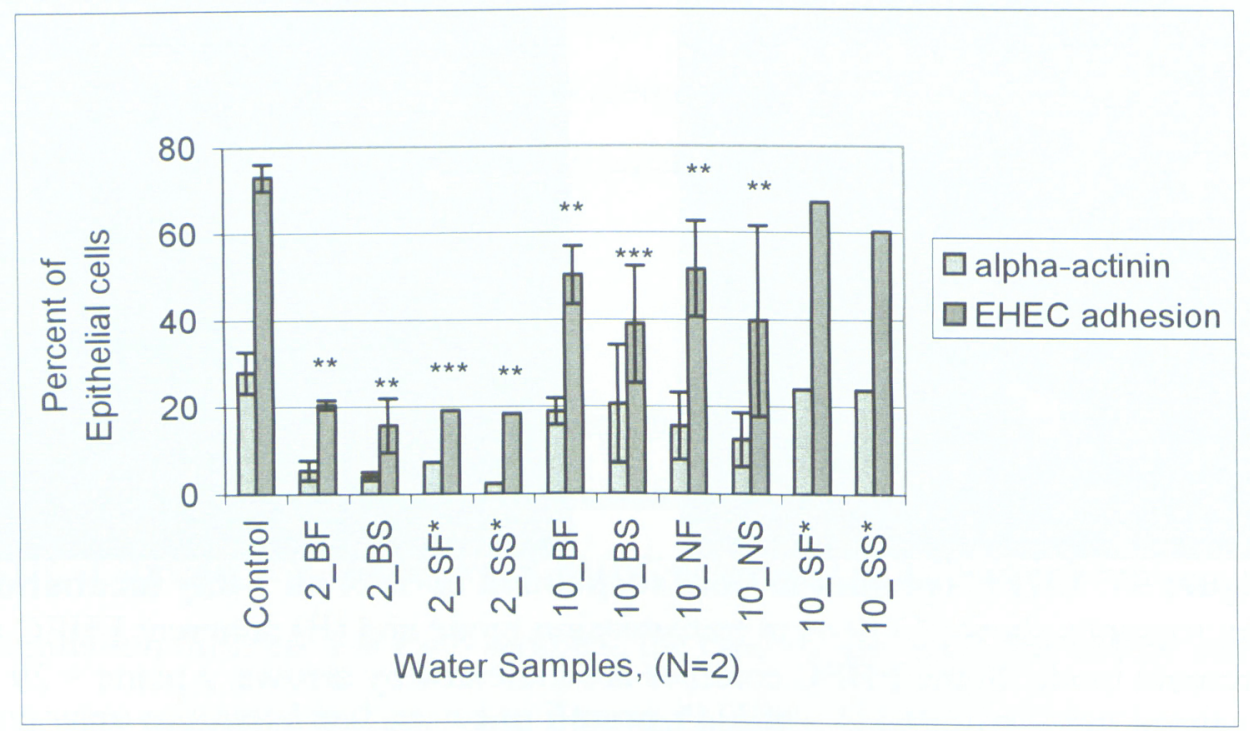

Figure 39. Host adhesion ability and $\alpha$-actinin accumulation

*These results were based on the data from one experiment.

** Significantly different on both host adhesion ability (EHEC adhesion) and $\alpha$-actinin accumulation compared to those of the control at $\mathrm{P} \leq 0.05$ *** Significantly different only on host adhesion ability (EHEC adhesion) compared to those of the control at $\mathrm{P} \leq 0.05$. 
Since $\alpha$-actinin accumulation depends on bacterial adhesion as a precursor, it is also important to determine whether the ratio of $\alpha$-actinin accumulation to bacterial adhesion was altered. This ratio is expressed as an infection ability, which is shown in Table 11. These results show that the infection ability appears to be unchanged with respect to the type of EHEC (floc adherent or free-living), water sample type or incubation time $(\mathrm{P} \leq 0.05)$.

\section{Table 11. EHEC infection ability $(\mathrm{N}=2)$}

Water Samples

Control

$2 \mathrm{BF}$

2 BS

$2 \mathrm{SF}^{*}$

$2 \mathrm{SS}^{*}$

$1 \overline{0} \mathrm{BF}$

10 BS

$10 \mathrm{NF}$

$10 \mathrm{NS}$

$10 \mathrm{SF}^{*}$

10 SS*
Ratio of $\alpha$-Actinin Accumulation to Host Adherence (\%)

$$
\begin{aligned}
& 38.51 \pm 7.28 \\
& 23.71 \pm 14.03 \\
& 28.66 \pm 19.79 \\
& 32.14 \pm 9.45 \\
& 15.48 \pm 8.99 \\
& 38.02 \pm 10.38 \\
& 50.23 \pm 22.54 \\
& 30.45 \pm 9.17 \\
& 34.09 \pm 20.06 \\
& 36.02 \pm 2.77 \\
& 39.39 \pm 9.44
\end{aligned}
$$

*These results were based on the data from one experiment.

Interestingly, various EHEC adhesion patterns such as microcolonies and aggregated single bacteria in clusters were observed. After $4 \mathrm{~h}$ infection time, very few discrete EHEC microcolonies and $\alpha$-actinin accumulation under bacterial adherence was found. Those samples were 2_BF, 2_BS, and 10_NF. As an example, microcolony and actin accumulation in 2_BS are shown in Figure 40. Other EHEC adhered in clusters, which was observed in all samples, but $\alpha$ actinin accumulation at the site of bacterial attachment was found in 2_BF, 10_BF, 10_NF, $10 \_$NS and 10_SS. As an example, EHEC in clusters and actin accumulation in 2_BF are shown in Figure 41. Sometimes, EHEC adhesion was not accompanied by foci of $\alpha$-actinin accumulation. As an example, 10_SS are shown in Figure 42. 

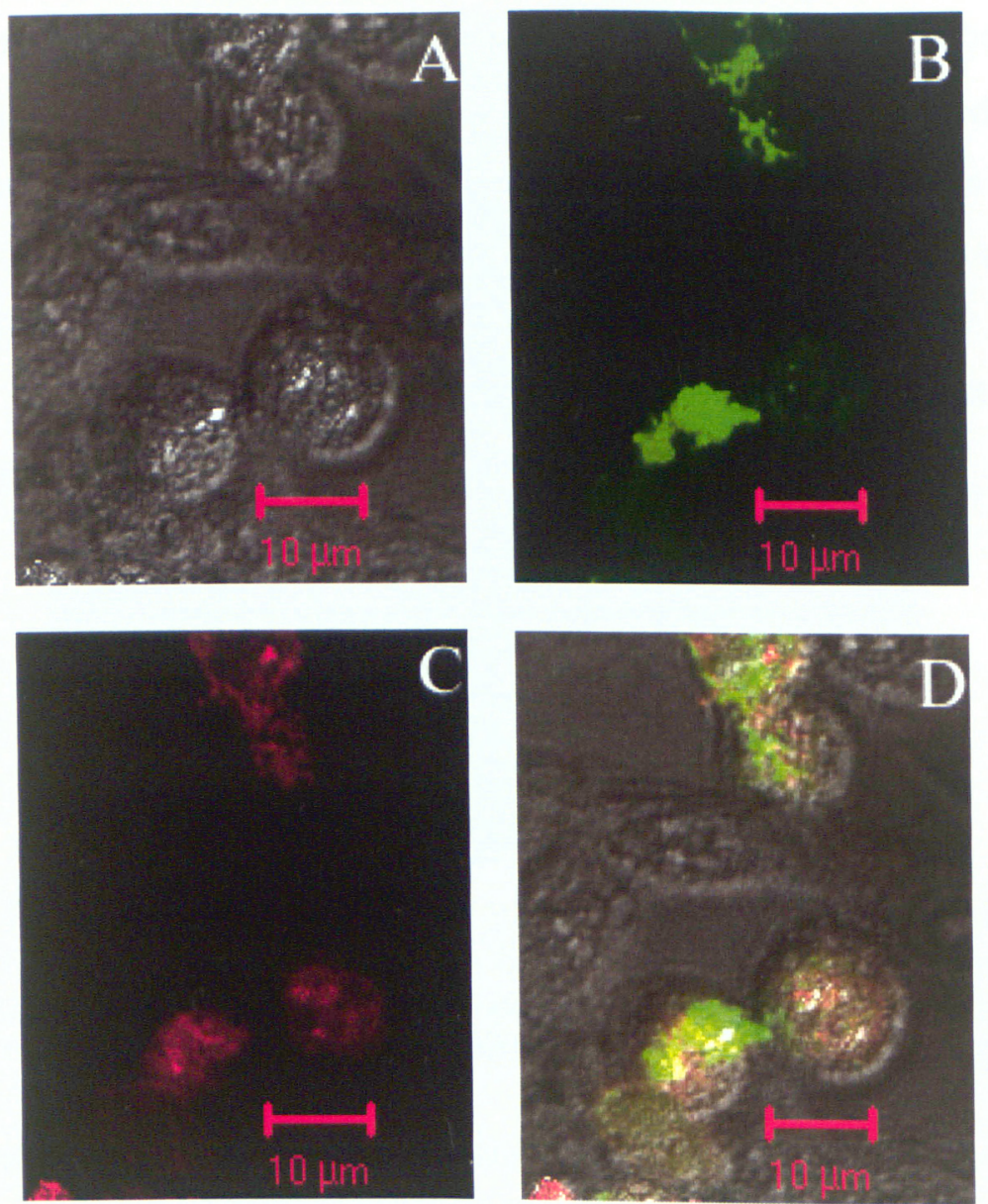

Figure 40. Microcolonies formation of EHEC from 2 BS on HEp-2 cells

EHEC was isolated from supernatant in PBS buffer at 2-day incubation. HEp-2 cells infected with the EHEC for $4 \mathrm{~h}$ at $37^{\circ} \mathrm{C}$. CLSM micrographs show (A) HEp-2 cells in transmission mode, (B) EHEC microcolonies detected by $\mathrm{O} 157$ antibody in fluorescent mode, (C) accumulation of $\alpha$-actinin detected by $\alpha$-actinin antibody and (D) composite. The accumulation of $\alpha$-actinin caused by adhered EHEC is seen as bright foci of fluorescent yellow. Scale bar $=10 \mu \mathrm{m}$. 

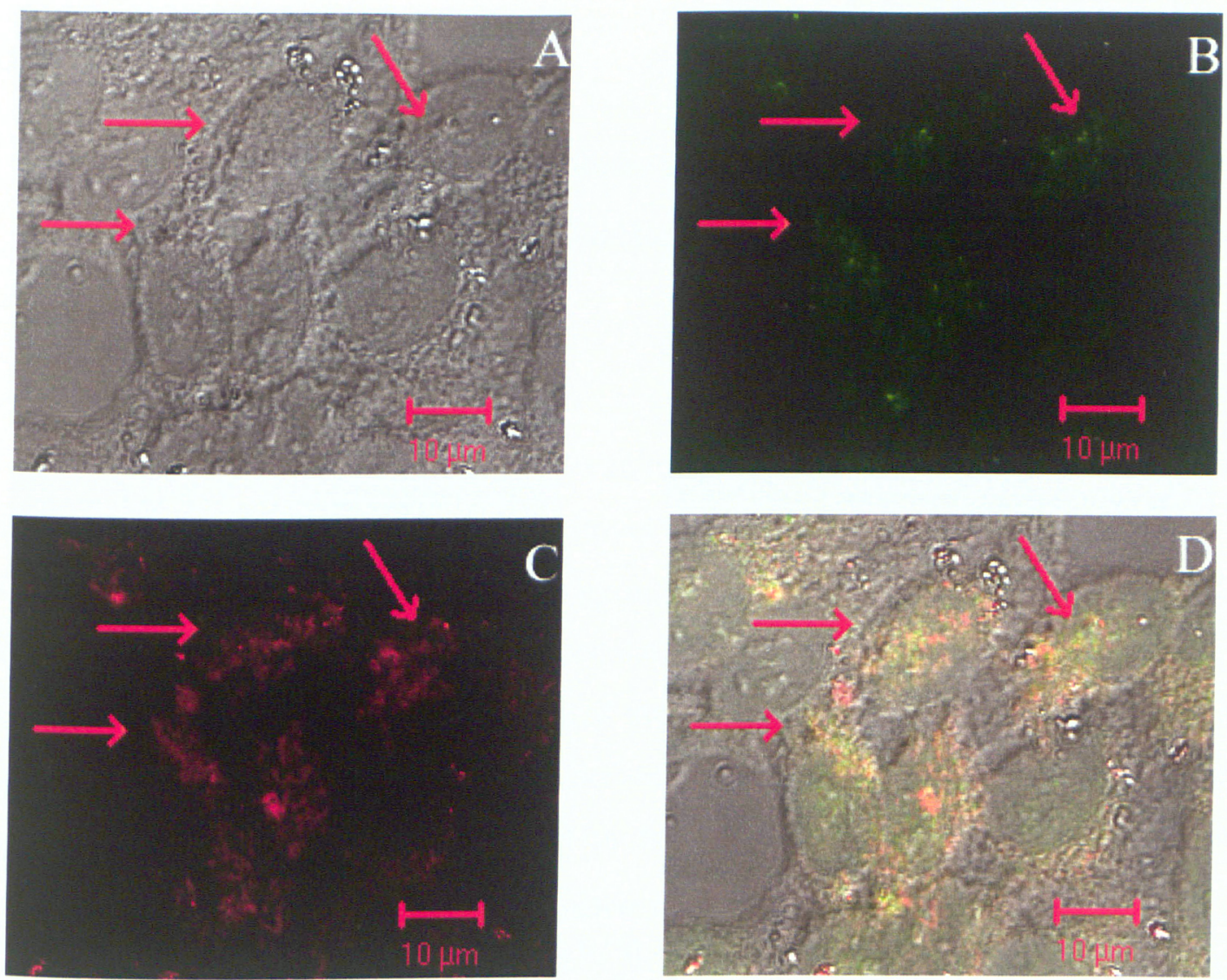

Figure 41. Clustered EHEC from 2_BF on HEp-2 cells

EHEC was isolated from flocs suspended in PBS buffer at 2-day incubation. HEp-2 cells infected with the EHEC for $4 \mathrm{~h}$ at $37^{\circ} \mathrm{C}$. CLSM micrographs show (A) HEp-2 cells in transmission mode, (B) EHEC microcolonies detected by $\mathrm{O} 157$ antibody in fluorescent mode, (C) accumulation of $\alpha$-actinin detected by $\alpha$-actinin antibody and (D) composite. EHEC in clusters are indicated by arrows. Scale bar $=10 \mu \mathrm{m}$. 

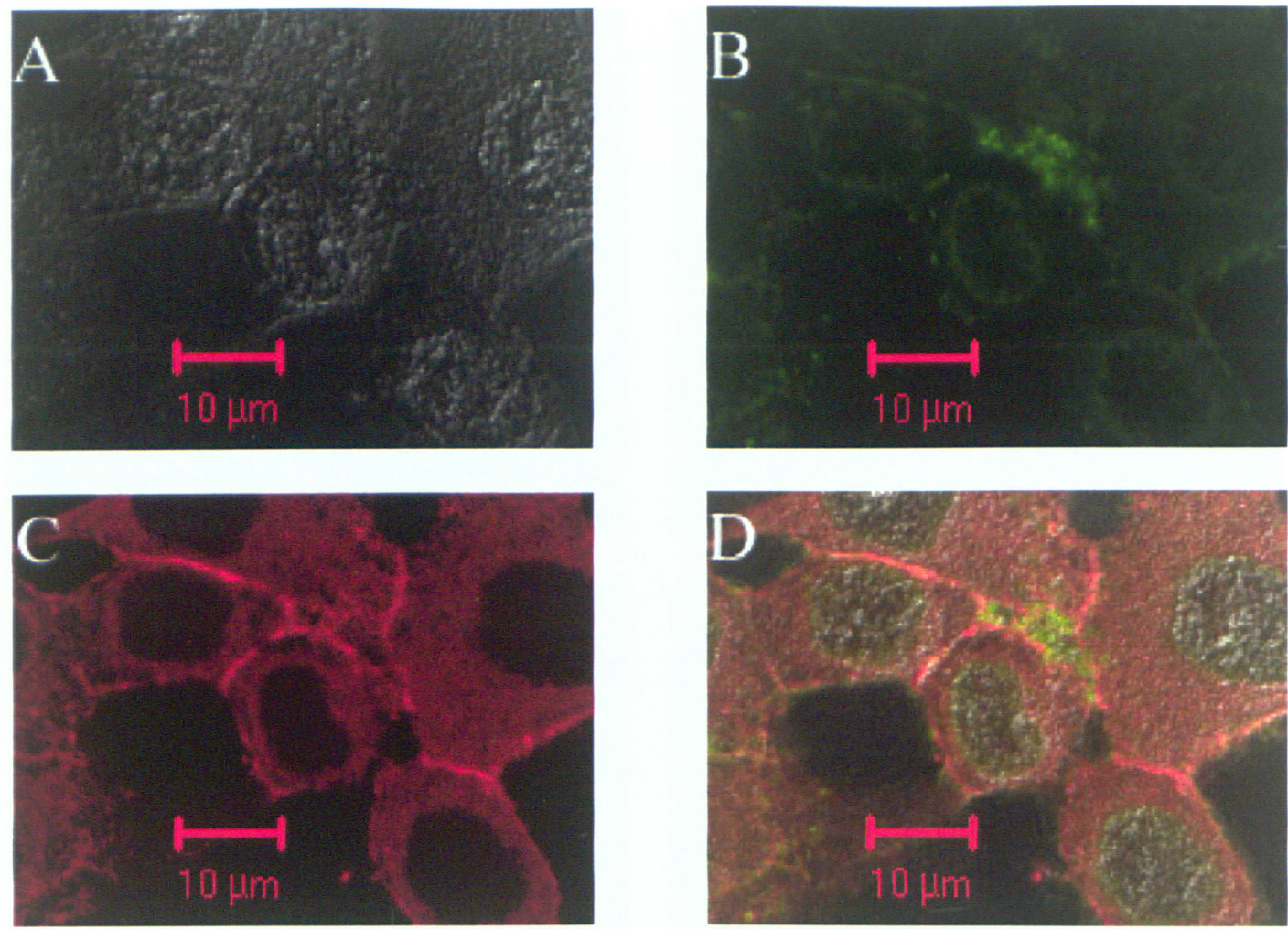

Figure 42. EHEC adhesion without $\alpha$-actinin accumulation

EHEC was isolated from supernatant in SBR at 10 day incubation. HEp-2 cells infected with the EHEC for $4 \mathrm{~h}$ at $37^{\circ} \mathrm{C}$. CLSM micrographs show (A) HEp-2 cells in transmission mode, (B) EHEC microcolonies detected by $\mathrm{O} 157$ antibody in fluorescent mode, (C) accumulation of $\alpha$ actinin detected by $\alpha$-actinin antibody and (D) composite. Scale bar $=10 \mu \mathrm{m}$. 


\section{CHAPTER 5. DISCUSSION}

\subsection{Characterization of Flocs \& Extracellular Polymeric Substances}

The characterization of flocs and EPS included both a physical analysis of flocs and a chemical analysis of EPS

\subsubsection{Physical Analysis of Flocs}

The physical analysis of flocs involved an examination of hydrophobicity, surface charge and dissociation constant. Hydrophobicity is important for floc formation and microbial adherence (including pathogens) on flocs via hydrophobic interaction (Liao et al., 2001). Surface charge is considered to be associated with flocculation contact (i.e. floc formation) (Wilén et al., 2003). The dissociation constant is a measure of the stability of flocs. Since these properties are also related to the properties of EPS in flocs (Jorand et al., 1998; Liao et al., 2001; Wilén et al., 2003), the present study focused on the effect on these properties when there were variations in EPS composition.

In particular, the experiments focused on the removal of EPS proteins. EPS proteins were digested by enzymes, pronase $\mathrm{E}$ or proteinase $\mathrm{K}$, and then subject to surface characterization. These enzyme treatments were expected to have a relatively significant effect on these surface properties of flocs. Each enzyme treatment significantly lowered the hydrophobicity of the floc sample compared to the control floc sample (t-test, $\mathrm{p} \leq 0.05$ ) (Figures 2 and 3 ). Each enzyme treatment also significantly increased the negative surface charge of the same floc sample compared to the control floc sample (t-test, $p \leq 0.05$ ) (Figures 4 and 5 ). The increased negative surface charge and lowered hydrophobicity might both have occurred because the initial flocs were dissociated into smaller flocs. This dissociation of flocs by enzyme treatment is in agreement with studies by Endo et al. (1976) and Higgins and Novak (1997). In dissociation, the smaller flocs have a larger surface area and present a larger surface charge because former "inner floc charge" is exposed as a "surface charge". The surface charge was measured by a colloidal titration method, in which excess cationic polymer was added to the floc sample prior to the titration. The increased surface area reacted with the cationic polymers to a fairly large degree as indicated by the lower amount of titrant (anionic) that was required to reach electrical neutrality (in accord with Mikkelsen, 2003). As a result, a greater negative surface charge was indicated. 
Because of this negative surface charge, the floc surface appeared strongly polar, which resulted in stronger interactions with water molecules. Therefore, decreased hydrophobicity was observed (as suggested by Liao et al., 2001).

The change in surface charge and hydrophobicity may also have been clue related to an increase in humic substances. As discussed in more detail below, the enzyme treatments resulted in an increase in humic substances in bound EPS. An increase in humic substances contributes to an increase in the negativity of surface charge because humic substances are a complicated mixture of polyaliphatic and polyaromatic compounds, containing carboxylic, phenolic and other functional groups, which give a highly negative charge density to the surface (Jones and Bryan. 1998; Wilén et al., 2003).

\subsubsection{Dissociation Constant}

Salt bridges are one of the factors involved in stabilizing flocs. Divalent cations are suggested to be involved in salt bridges by binding with negatively charged EPS (Flemming. 2002; Liao et al., 2002). The divalent cation $\mathrm{Ca}^{2+}$ has been suggested to play an important role since the addition of $\mathrm{Ca}^{2+}$ leads to reflocculation of activated sludge and the removal of $\mathrm{Ca}^{2+}$ leads to dissociation of flocs (Higgins and Novak, 1997; Liao et al., 2002; Zita and Hermansson, 1994). The stability of flocs due to salt bridges has been examined using the dissociation constant as an indicator of floc stability - a greater dissociation constant indicates a poorer stability (Liao et al., 2002).

In the present study, a floc sample was treated with $1000 \mu \mathrm{g} / \mathrm{ml}$ EDTA. As expected, the mean dissociation constant of the EDTA treated flocs was significantly greater than that of the control (t-test, $\mathrm{p} \leq 0.05$ ) (Figures 6 ). This appears to indicate that EDTA causes dissociation of flocs. The EDTA treated flocs were then examined directly by microscope and size measurements were taken. In both the control and the EDTA treated floc samples, small size (less than $150 \mu \mathrm{m}$ ) flocs were dominant. Medium size (between $150 \mu \mathrm{m}$ and $500 \mu \mathrm{m}$ ) flocs were the second most abundant and large size (larger than $500 \mu \mathrm{m}$ ) flocs were the least represented (Figure 10). Interestingly, the ratio of the size fraction was different between the EDTA treated flocs and the control samples. The EDTA treated floc sample contained a higher amount of small flocs (not statistically significant) and a lower amount of medium flocs (statistically significantly). This result is in accordance with the findings of Liao et al. (2002) who found that 
EDTA caused dissociation of activated sludge flocs. The major effect of EDTA was the disruption of salt bridges via the $\left[\mathrm{H}_{2} \text { EDTA }\right]^{2-}$ ion removing divalent cations that were involved in the salt bridges in flocs (Liao et al., 2002). The EDTA treated floc sample was also directly observed under COM. As expected, smaller (dissociated) flocs were observed. However. relatively large flocs were also observed. Interestingly, the large flocs were found in the vicinity of fine particles generated by dissociation of other flocs (Figure 7). This indicates that the large flocs were somehow able to withstand the dissociation by EDTA. The large flocs appeared to contain one or more dark, distinct EPS areas. This may indicate that the presence of EPS is important in the stability of flocs. This is in agreement with the general idea of EPS being involved in the formation and stability of flocs due to hydrophobic interactions and physical enmeshment (Liao et al., 2002). Since proteins in the EPS have been suggested to be important in hydrophobic interactions within the EPS matrix, the next step was to remove the proteins from the flocs in order to examine the floc stability.

The EDTA treated samples were further treated by enzymes, either pronase $\mathrm{E}$ or proteinase $\mathrm{K}$ and then examined by COM. Similar to the EDTA treated flocs, some enzyme treated flocs were further deflocculated (dissociated) but others seemed to remain relatively large. This observation was contrary to the finding by Endo et al. (1976) that pronase E treatment led to complete deflocculation and the finding by Park et al. (2000) that pronase E treatment led to removal of proteinaceous structures. Interestingly, the remaining larger flocs appeared to contain branches of dense EPS areas. These branches were not observed in the control sample (Figure 12). The enzyme treated flocs were also categorized by size (Figures 14 and 15). Similar to control and the EDTA treated floc samples, the small size (less than $150 \mu \mathrm{m}$ ) flocs werc dominant. The pronase $\mathrm{E}$ treated flocs contained a higher amount of small flocs and lower amount of medium flocs (between $150 \mu \mathrm{m}$ and $500 \mu \mathrm{m}$ ) compared to the control flocs (not statistically significant). It seems that only medium size flocs were susceptible to dissociation by pronase $\mathrm{E}$. On the contrary, the proteinase $\mathrm{K}$ treated flocs showed a lower amount of small flocs and a higher amount of medium and large flocs than the control flocs. Even though the size fractions did not significantly differ from the control sample (t-test, $\mathrm{p} \leq 0.05$ ), this result might indicate that some flocs became larger during proteinase $\mathrm{K}$ treatment due to reflocculation This reflocculation seems to be linked to the observation of large flocs consisting of branches of EPS areas after reflocculation. Reflocculation of previously deflocculated sludge flocs has been 
observed by Biggs and Lant (2000) and Jin et al. (2003). The reflocculation mechanism has not been clarified yet, however, it has been suggested that dissociated floc fragments collide with each other during stirring. Although some of collisions cause an attachment whereas others do not, it has been proposed that the EPS composition and internal molecular binding forces are involved in the reflocculation ability (Jin et al., 2003). Nevertheless, the results in this study seem to infer that EPS are resistant to chemical and enzymatic dissociation and is quite important for floc stability.

\subsubsection{Chemical Analysis of Extracellular Polymeric Substances}

The chemical analysis of EPS in the present study involves a quantification of EPS components. EPS components are suggested to play an important role in floc characteristics, including flocculation, stability and reflocculation (Jorand et al., 1998; Liao et al., 2002; Wilén et al., 2003). Two types of EPS, loosely bound EPS and bound EPS were analysed. Loosely bound EPS was obtained in supernatant after centrifugation. Bound EPS was obtained in supernatant after cation exchange resin (CER) extraction (Higgins and Novak, 1997; Wilén $c t$ al., 2003). These two types of EPS were observed following separate treatment of the flocs with two different enzymes, pronase $\mathrm{E}$ and proteinase K. All EPS solutions (including the control) were quantified for humic substances, protein, carbohydrates and DNA.

In loosely bound EPS, the pronase E treated flocs released a significant amount of carbohydrates from the flocs into the supernatant after the centrifuge $(p \leq 0.05)$, which was indicated by a higher concentration of carbohydrates. In addition, the pronase $E$ treated flocs contained a significantly lower concentration of humic substances and protein $(p \leq 0.05)$ (Figure $16)$. On the other hand, the proteinase $K$ treated flocs contained significantly higher concentrations of humic substances and carbohydrates ( $\mathrm{p} \leq 0.05$ ) (Figure 18). The proteinase $K$ treated flocs also resulted in a lower concentration of protein (however, not statistically significant). It is difficult to determine the effect of enzyme treatments on humic substances in loosely bound EPS because the results in both samples contradicted each other. However, the addition of enzymes to the floc samples appeared to cause a release of carbohydrates from bound EPS (see below), which was also found by Higgins and Novak (1997). This might have occurred because the enzymes disrupted the protein-carbohydrate interaction in the EPS matrix (Higgins and Novak, 1997). On the other hand, a decrease in the concentration of protein in loosely bound 
EPS might be caused by two possibilities. One is that increased carbohydrate concentration in loosely bound EPS might have interfered with the protein measurement (Lowry method). Even though the Lowry method is sensitive and precise enough to detect a single amino acid, sugars such as glucose and sucrose are known to interfere with this type of protein measurement (Lucarini and Kilikian, 1999). The other cause may be that proteins in the loosely bound EPS became bound to the flocs (reflocculation), which might be explained by the increased concentration of proteins in the bound EPS in the enzyme treated flocs (as discussed further below). The removal of proteins from supernatant was observed by Wilén et al. (2000) when the anaerobic sludge (deflocculated) floc was reflocculated by oxygen. This study showed that the number of bacteria and the amount of protein and humic substances correlated well with the turbidity in the supernatant (Wilén et al. (2000).

The bound EPS extracted by the CER method was analysed in the same manner as the loosely bound EPS. The pronase $\mathrm{E}$ treated flocs contained significantly higher concentrations of humic substances and proteins ( $p \leq 0.05$ ) (Figure 17). Similar to the loosely bound EPS, the proteinase $\mathrm{K}$ treated flocs resulted in a significantly higher concentration of humic substances $(p \leq 0.05)$ (Figure 19). The proteinase $K$ treated flocs also contained a higher concentration of proteins, however, it was not statistically significant. An increase in the concentration of proteins in bound EPS may be caused by the presence of the enzymes in flocs. Alternatively, hydrophobic proteins in the loosely bound EPS might bind to the bound EPS via hydrophobic interactions. Some fraction of proteins in EPS was found to be hydrophobic due to amino acids with hydrophobic side groups (Jorand et al., 1998). Lastly, the enzyme treatments might cause an increase in extractable proteins in the CER method. Some studies observed the inefficiency of the CER method to extract proteins (including enzymes) from activated sludge flocs (Frolund $e t$ al., 1996; Gessesse et al., 2003). For example, Frølund et al. (1996) demonstrated that $50 \%$ of total proteins in activated sludge floc were extractable protein by the CER method (Frølund $e t$ $a l ., 1996)$. In the present study, it may be possible that added enzymes digested non-extractable proteins, which became extractable by the CER method. The increase in the humic substances concentration might have occurred because humic substances became more easily extracted due to the enzyme treatments. A study by Keilding and Nielsen (1997) suggested that humic substances are generally weakly linked to the EPS matrix. Interestingly, a high concentration of humic substances in the enzyme treated floc seems to be related to dissociation of flocs. 
According to DLVO theory, high negative charge density of the humic substances may have led to higher repulsive forces between molecules in flocs (Jin et al., 2003; Liao et al., 2001; Wilén et al., 2003). In particular, Wilén é al. (2003) observed a negative correlation between the concentration of humic substances and reflocculation. In the same study, a positive correlation between the concentration of protein and reflocculation was found. The importance' of protein in flocculation was also observed in the study by Higgins and Novak (1997) and in the present study, where the digestion of proteins from flocs led to the dissociation of flocs. In the present study, the enzyme treatment of flocs appears to generally result in the dissociation of some flocs based on the effect of both the increased humic acid and protein concentrations.

\subsection{Microscopic Observation of Extracellular Polymeric Substances}

Microscopic observation is very useful because it reveals the non-destructed distribution of EPS composition and colocalization of EPS components. This gives useful information about the role of EPS composition in the physicochemical characteristics of flocs.

\subsubsection{Mapping of Extracellular Polymeric Substances}

\subsubsection{Nucleic Acids, Lipid-hydrophobic Sites and Protein}

Floc samples were treated with $1000 \mu \mathrm{g} / \mathrm{ml}$ EDTA for $135 \mathrm{~min}$ and then treated with proteinase $\mathrm{K}$ for $120 \mathrm{~min}$ (this treatment is called EDTA-K treatment). Pronase $\mathrm{E}$ was not used because it seemed to contain carbohydrates (data is shown in the Appendix E). After the treatment, EDTA, EDTA-K and control floc samples were stained with dyes, Syto 61, Nile Red and SyproOrange, which are specific to nucleic acids, lipids-hydrophobic sites and protein. The stained samples were observed under CLSM. Nucleic acids appear blue, lipid-hydrophobic sites appear red and proteins appear green.

In all samples, nucleic acids, lipids-hydrophobic sites and proteins were detected. These macromolecules generally existed heterogeneously, horizontally and vertically throughout the flocs. The macromolecules seem to be localized where dense floc areas were found in the reflectance mode (Figure 20). Further, the colocalization of the macromolecules was also observed. The distribution of each component was observed along with the colocalization examination (Figures 21-23). In general, a high degree of colocalization of nucleic acids, lipidshydrophobic sites and proteins occurred in all samples. This colocalization of three 
macromolecules appears to occur more frequently at the surface/periphery of the floc. The colocalization of pairs of components was also observed. First, the colocalization of nucleic acids and lipid-hydrophobic sites was examined. This colocalization was observed in all samples. Generally, a dense blue colour of nucleic acids covered the whole floc. This indicates that the nucleic acids dye likely stained microorganisins as well as the extracellular nucleic acids. Thus, the nucleic acid stained area was assumed to be equivalent to the bacterial biomass as has been done in other studies which used nucleic acids dye to examine bacterial biomass in biofilm material (Lawrence et cl., 1998; Neu and Lawrence, 1999). In this way, the colocalization of nucleic acids and the other macromolecules (such as lipid-hydrophobic sites (here) and proteins (below)) will reveal the distribution of the other macromolecule (lipid-hydrophobic or protein sites) throughout the floc. The Nile Red appears to stain many small, localized areas, which seemed to stain extracellular lipids and microorganisms. Lipids are released to the extracellular space when cell lysis occurs and gram-negative bacteria secret integral cellular components such as lipopolysaccharides (LPS). Microorganisms also have lipid-hydrophobic surface membranes, which consist of phospholipids and lipopolysaccharides (LPS) (in gram-negative bacteria) (Wingender et al., 1999). Thus, the colocalization of nucleic acids and lipid-hydrophobic sites indicates possible hydrophobic interactions between EPS and microorganisms and between microorganisms. This is in accordance with past studies (Flemming, 2002; Liao et al., 2001; Olofsson et al., 1998; Zita and Hermansson, 1997a,b). In the present study, the intense colocalization of nucleic acids and lipid-hydrophobic sites covered from the surface to the interior of the control and EDTA-K treated floc. This seems to show that most microorganisms were embedded in the EPS matrix by hydrophobic interactions. On the other hand, the less intense colocalization was present in scattered areas of EDTA treated floc. It might indicate that removal of salt bridges affected the structure of the EPS matrix. Furthermore, all samples contained lipid-hydrophobic sites (i.e. without colocalization with nucleic acids) in the interior of flocs suggesting the hydrophobic nature of the EPS matrix. This is in agreement with the spectroscopic study by Ganaye et al. (1997) showing that the inside of activated sludge flocs contained highly pronounced hydrophobic zones (Ganaye et al., 1997). Interestingly, the degree of colocalization of the EDTA-K seems be similar to that of the control floc. This seems to contradict the result above showing that hydrophobicity of the enzyme treated flocs was significantly lower than the control floc (see Physical Analysis Section above). This unusual 
result might be because the hydrophobicity result obtained in the physical analysis section above was a collective value from various flocs in a sample (i.e. a mean value from all floc samples), whereas the CLSM observations were focused on a single floc. Since some flocs with dense EPS areas showed resistance to deflocculation by EDTA and proteinase $\mathrm{K}$, it appears that the stability of these particular flocs was related to hydrophobic interactions in the EPS matrix. However, not all nucleic acids were covered by lipid-hydrophobic sites, which indicates that some EPS are hydrophilic. This result is in accordance with the study by Jorand $c t$ al. (1998).

Next, the colocalization of nucleic acids and proteins was examined. SyproOrange appeared to stain large areas of flocs, which seemed to stain extracellular proteins and microbial proteinaceous structure such as S-layer, pili and flagella (Park et al., 2000). This colocalization might suggest the association of microorganisms with extracellular proteins (enzymes) as well as the presence of proteinaceous structure. This observation is consistent with a study by Gessesse et al. (2003) that suggested that the most of part of the enzymes are bound on the cell surface. By keeping enzymes on or near the surface, cells can have a better access to hydrolysis products for immediate uptake for intracellular metabolism (Gessesse et al., 200̄3). In the present study, all samples contained a relatively large degree of colocalization from the surface to the interior of flocs, which might indicate protein involvement in the EPS matrix. The least degree of colocalization was found in the control floc because the least amount of protein was present. This result was in agreement with the results of chemical analysis indicating that the control floc contained a lower concentration of protein (as bound EPS) than the enzyme treated flocs. On the other hand, the larger degree of colocalization was found in EDTA and EDTA_K samples. It may be because the SyproOragne was able to stain due to better accessibility. The treatment of cells by chelating agents (EDTA) and detergents is known to release cell surface bound proteins (Gessesse et al., 2003). The released bound proteins may be trapped in the EPS matrix, which were more easily stained by SyproOrange. Nevertheless, the dense EPS areas in EDTA and EDTA_K treated flocs contain a large amount of proteins stabilizing the flocs. Despite the expectation that lower protein would be detected in the EDTA-K treated floc due to the enzymatic treatment, EDTA-K treated floc appeared to contain as much protein as the control (Figures 22 and 23). In addition, proteins without the colocalization with nucleic acids were also found around nucleic acids stained areas in all samples. In particular, EDTA-K treated floc 
contained intense protein stained areas, some of which might be attributed by the added enzymes present in flocs.

Lastly, the colocalization of protein and lipid-hydrophobic sites was examined. This type of colocalization shows hydrophobic proteins in flocs. Hydrophobic proteins are important because proteins are suggested to be involved in hydrophobic interactions for formation, stability of llocs and bacterial adherence (Wingender et al., 1999). Similar to the other types of colocalization, a relatively large colocalization was found in all samples. Most of the proteins seem to be hydrophobic in the control floc. This is also in agreement with the observation by Gessesse $c t$ al. (2003) that proteins (enzymes) were attached to the floc components (e.g. the cell wall of individual cells) predominantly by hydrophobic interactions (Gessesse $e t$ al., 2003). The lower amount of hydrophobic proteins in the EDTA-K floc and the least amount of hydrophobic and a fairly large amount of hydrophilic proteins were found in the EDTA treated floc. These results may be related to the treatment of cells by the EDTA treatment, which disrupted hydrophobic interactions and release cell surface bound proteins (Gessesse et al., 2003). In addition, these results also appear to be linked to the results for the dissociation constant (see above), which showed that the control floc was the most stable floc in this study. The differing amounts of hydrophobic protein between EDTA and EDTA-K floc might be related to the ability of the EDTA-K to reflocculate. The greater the amount of hydrophobic protein, the more likely is the chance to have reflocculation, which might be the case in the EDTA-K treatment.

\subsubsection{Lectin-conjugated Dyes}

Extracellular carbohydrates are also suggested to maintain the floc structure by forming the EPS matrix (Wolfaardt et al., 1999). In order to examine distribution of extracellular carbohydrate components in flocs, lectin-conjugated dyes ConA, WGA and SBA were used. The lectin-conjugated dyes are specific to carbohydrate residues; ConA is specific to mannopyranosyl (Man) and glucopyranosyl (Glc) residues, WGA is specific to $N$-acetylglucosaminyl residues (GlcNAc) and SBA is specific to $N$-acetylgalactosaminyl (GalNAc) and galactopyranosyl $(\mathrm{Gal})$ residues. The stained floc samples were observed under CLSM. ConA appears blue, WGA appears red and SBA appears green (Figure 24, 25 and 26). In all samples, ConA, WGA and SBA were all detected. WGA was a dominant component and was distributed widely from the floc surface to the interior of floc. Similar to WGA, other stained areas generally 
existed heterogeneously. horizontally and vertically throughout the flocs however. each stain was also observed in localized and discrete areas. The different stain patterns of indicate heterogeneous production of extracellular material within the lloc population (Strathmann et al., 2002). In this section, the distribution of each stained area is examined.

In the control floc, Con $\Lambda$ bound to very small areas, which were found mostly along the periphery of the floc. WGA bound to a relatively large area, which seemed to cover from the periphery to the interior of the floc. WGA also appears to have stained inside of ConA. Similar to ConA, SBA bound to small areas that scattered around the periphery of flocs, some of which were overlapped with WGA but rarely ConA. In the EDTA treated floc, WGA had a similar distribution pattern as that in the control, however, it seems that ConA and SBA bouncl to more areas. In the EDTA-K treated floc, ConA and WGA had a similar distribution pattern as those in the control, however, SBA also seemed to bind to a larger area. Thus, SBA in both non-control samples showed a more diffusive and cloud-like staining pattern. An increase in SBA bound to EPS may be related to these treatments that generally dissociated flocs. There are two possible causes. One cause is that greater amount of the dye reached the internal of flocs due to the smaller size. The other cause might be related to the removal of divalent cations and digesting of protein. The removal of cations and proteins might have led to better lectin binding. It might indicate an EPS structure in which protein is around the carbohydrates. Interestingly, a known fibril structure, the cell appendages of Myxococcus xanthus, is suggested to be a carbohydrate backbone coated with protein. The librils are suggested to be involved in the cell-cell cohesion (Behmlander and Dworkin. 1994). The current results seem to indicate that a similar structure occurs in EPS but further study is needed.

Contrary to the current study, ConA used in other studies has shown a cloud-like (diffusive) pattern, which was suggested to be associated with microcolonies and bacterial cell clusters. In addition, ConA was also observed in spaces between bacterial cells, indicating the presence of EPS (Neu et al., 2001; Strathmann et al., 2002). When the ConA staining pattern in the current study was compared to the nucleic acid staining in the control floc in the section above, the ConA did not seem to be associated with microcolonies. Instead, the ConA might have stained mannopyranosyl and glucopyranosyl residues in EPS. Since the WGA staining pattern was similar to the nucleic acid staining pattern, WGA seems to bind to cell surface structures. WGA binding to cell surface structures has been reported to be a characteristic of 
Gram-positive bacteria, where the peptidoglycan-containing cell walls (containing GlcNAc and $\mathrm{N}$-acetylnuramic acid (NeuNAc) can be exposed directly to the external medium and are easily accessible for lectin binding. In addition, it has been reported that leakage or release of the cell component from the periplasmic space to the cell surface can occur during biofilm development (Strathmann et al., 2002). Furthermore, it is also observed that WGA stained not only bacteria but also spaces between bacteria (Lawrence et al., 1998). SBA might have stained the cell surface structures and the GalNAc and Gal residues in EPS. It is known that both sugar compounds are found in bacterial surface structure such as in peptidoglycan and LPS, which might be indicated by the colocalization of WGA and SBA.

\subsection{Association of Escherichia coli 0157:H7 with Flocs}

It has been suggested that flocs are potentially resistant to dissociation (deflocculation) due to additional stability provided by EPS in the flocs. This additional stability of flocs might allow the flocs to act as transport for pathogens in an aquatic environment. The above sections deal with this concept from the floc side but it is also important to investigate from the pathogen side. In the following, the term EHEC refers to E. coli $\mathrm{O} 157: \mathrm{H7}$. In particular, two points were investigated. i) Does EHEC adhere to flocs and does the adherence to flocs lead to increased survival? ii) Do adherent EHEC still retain the capability of infection in such environments. In this study, the survival of pathogenic EHEC in various water types containing flocs is examined. Moreover, the pathogenicity of free-living and adherent EHEC that were extracted from flocs was also investigated.

\subsubsection{Survival of Escherichia coli $0157: 117$ in Water}

Water samples containing SBR flocs in PBS buffer, SBR with nutrients replenished (called NSBR), and SBR were inoculated with $10^{8} \mathrm{CFU} / \mathrm{ml}$ EHEC. The number of EHEC (both free-living and adhered to flocs) in each water sample was estimated by plate count for a period of 10 days. This experiment was conducted twice (Tables 9 and 10).

In all samples, EHEC was found in two forms, free-living and adherent to flocs. The difference between these two forms probably depends on the surface hydrophobicity of EHEC in a population. In the present study, free-living EHEC was likely to have a hydrophilic surface and adherent EHEC to flocs was likely to have a hydrophobic surface. According to the observation by Olofsson et al. (1998), E. coli O157: $\mathrm{H} 7$ population had heterogeneous hydrophobicity and 
more hydrophobic bacteria generally adhered in higher numbers to sludge flocs. By contrast, less hydrophobic bacteria tended to remain free-living forms (Olofsson et al., 1998). Furthermore, some fraction of EHEC used in the present experiment might have become more hydrophobic and adhered to flocs since the bacterial growth conditions are thought to affect the hydrophobicity of bacteria. Burnett et al. (2000) suggested that $E$. coli cells grown in a nutrientlimited medium were more hydrophobic than cells grown in tryptic soy broth (rich nutrient medium), probably due to changes in bacterial membrane fatty acid composition that are brought about by the nutrient-limited environment (Burnett $e t$ al., 2000).

EHEC also showed a gradual decrease in the viable cell counts, regardless of the type of . EHEC, adhered to flocs and in free-living form, or type of water in all samples. The gradual decrease in the viable cell counts might be caused by lower nutrient levels, predation (grazing pressure) and competition by native microflora (Brettar and Höfle, 1992; Gerba and McLeod, 1976; LaLiberte and Grimes, 1982, Wang and Doyle, 1997).

In the present study, higher number of adherent EHEC survived than free-living EHEC in all samples. Higher survival of adherent EHEC is consistent with findings by other studies that found higher concentrations of coliforms (indicator organism) and enteric pathogenic bacteria existed in sediments than in the overlaying water. These studies also found that non-pathogenic adherent $E$. coli was capable of utilizing nutrients adsorbed to estuarine sediments (including flocs) so that $E$. coli persisted longer when sediment was present (Brettar and Höfle, 1992; Gerba and McLeod, 1976; LaLiberte and Grimes, 1982). In addition, sediments were suggested to provide protection from predation since bacterial grazers were not able to graze on large (sediment) particles (Brettar and Höfle, 1992). However, in the present experiment, the number of surviving EHEC in the two forms was not significantly different $(p \leq 0.05)$. There might be two possible reasons. The first is that free-living as well as adherent EHEC were able to obtain nutrients from flocs. During 10 days incubation, flocs were degrading in PBS buffer and SBR due to lack of nutrients. Since the degradation of floc causes dissociation of flocs, nutrients such as carbohydrates were released from flocs into the bulk water. The release of carbohydrates from dissociated flocs was observed in the EPS chemical analysis of the present study and other studies (Higgins and Novak, 1997; Keiding and Neilsen, 1997). Furthermore, a COM micrograph taken at 10 days incubation revealed the degraded flocs suspended in PBS buffer (Figure 28). Compared to the flocs suspended in NSBR, PBS flocs appear to be thinner and 
without distinct EPS areas. Thus, some free-living EHEC may have been able to survive by obtaining some nutrients released from flocs. The second reason is that starvation may have caused free-living EHEC to go through physiological changes such as decreased respiration rate and loss of reproduction ability in order to protect themselves against environmental stresses (Özkanca and Flint, 1997).

Since nutrient level is one of the important factors for the survival of EHEC, the effect of nutrients on survival was also examined by placing EHEC in PBS buffer, NSBR and SBR containing flocs. Both adherent and free-living EHEC in the PBS buffer sample showed significantly higher level of survival at the 10-day incubation than that in NSBR and SBR samples $(\mathrm{p} \leq 0.05)$. Unexpectedly, the lowest nutrient level of the PBS buffer showed the highest EHEC survival. This might be related to a form of nutrients available in PBS. The released nutrients from degrading flocs may be the form easily utilized by EHEC. Past studies observed that nutrients bound to the fresh sediment material in PBS buffer were easily released and utilized by non-pathogenic E. coli (Gerba and McLeod, 1976; Hendricks, 1970). Even though nutrient was added to NSBR, it did not seem to have improved the survival of EHEC. This might be because SBR and NSBR could not support the EHEC growth such that more EHEC died than that could be replaced by the reproduction rate.

As the next step, the number of EHEC adhered to dense EPS areas in flocs were also estimated. Since adherent EHEC showed higher survival than the free-living form, adherent EHEC on the more stable EPS areas may be able to persist in water for extended periods of time and increase the infection risk. To estimate the adherent EHEC to EPS, the flocs with adhered EHEC were further treated with proteinase $\mathrm{K}$. This part of the experiment was conducted from 4 days incubation because it has been reported that the bulk of EHEC was detected on sediment particles after 3 days from inoculation (Brettar and Höfle, 1992). It was found that the NSBR had a significantly higher percentage of adherent EHEC to the EPS area than other samples $(p \leq 0.05)$ (Figure 39). It might be because larger dense EPS areas in NSBR flocs would be resistant to proteinase $\mathrm{K}$ treatment so that it is likely that a higher number of adherent EHEC was isolated from these areas. This indicates the importance of floc stability because stable flocs are able to provide a stable area for EHEC survival. Thus, the addition of nutrients retained dense EPS areas and floc stability, which supported EHEC survival (Wingender et al., 1999; Wolfaardt et al., 1999). 


\subsubsection{Direct Observation of Adherent Escherichia coli $0157: 117$ by Confocal Laser}

\section{Scanning Microscopy}

CLSM is very useful to observe the spatial distribution of EHEC in flocs in conjunction with the observation of the EPS composition. Water samples containing $10^{8} \mathrm{CFU} / \mathrm{ml}$ EHEC were incubated with flocs suspended in PBS buffer, NSBR and SBR. First, the distribution of EHEC in flocs suspended in PBS buffer and SBR at the 2-days incubation was investigated (Figure 2932). Flocs in NSBR were not examined at this stage since the first nutrient was added at 2-day incubation. In both samples, most adherent EHEC appear to locate at/near the surface of flocs, which are coincident with hydrophobic lipid sites and hydrophobic proteins observed in the EPS mapping (shown above). It might suggest that EHEC adhesion occurred via hydrophobic interaction. In particular, hydrophobic interaction seems to be involved in the SBR flocs since most EHEC in the SBR were found on the top of the dark dense EPS area. In all samples, EHEC generally dispersed individually in flocs, which might indicate that EHEC did not reproduce as much due to the stressful environment.

Second, the distribution of EHEC in flocs suspended in PBS buffer, NSBR and SBR at 7day incubation were observed (Figure 33-38). In all samples, the distribution of EHEC scems to spread inward into the flocs. This is consistent to the finding by Olofsson et al. (1998) that adhered cells were found not only on the surface of flocs but also in the interior of the floc (Olofsson ct al., 1998). This suggests that adherent EHEC migrated toward dense EPS areas because EPS are known to provide nutrients and protection (Tsuneda et cl.. 2003; Wingender $e t$ al., 1999; Wolfaardt et al., 1999). Interestingly the distribution of EHEC in NSBR seems to be limited compared to that in the PBS buffer. The adherent EHEC colonies and individual cells in NSBR flocs seem to associate with the border between dense EPS areas and the remainder of the flocs. The degree of EHEC distribution might be related to the floc conditions such that PBS flocs were generally degraded while NSBR flocs seemed to be more stable with dense EPS areas. These different floc conditions would exhibit a different diffusion rate in the inside of flocs. Since the dense EPS areas in NSBR flocs were likely to have a slower diffusion rate of nutrients and oxygen delivery to adhered cells, the deep interior of dense EPS areas would not be an optimal environment for EHEC (Wolfaardt et al., 1999). On the other hand, flocs in PBS buffer had a loose structure without dense EPS areas. In such floc structures, diffusion rate would be similar to that of water, which makes bacteria to obtain nutrients and oxygen easier (Wolfaardt $e t$ 
al., 1999). Thus, adherent EHEC in PBS buffermight have largely dispersed through these flocs. Interestingly, in all samples at 7-day incubation, colonies as well as individual EHEC were observed, which might show that EHEC had some ability to adapt to the stressful environment.

\subsubsection{Escherichia coli O157:H7 Extracted from Floc Samples}

Since EHEC was able to persist in water samples, it is important to investigate if these EHEC retain pathogenicity. The pathogenicity was examined based on $\alpha$-actinin accumulation in epithelial HEp-2 cells. In this study, the effect of three factors on pathogenicity were examined: i) the type of EHEC (free-living or in flocs), ii) nutrient level in water samples (PBS buffer, NSBR and SBR) and iii) incubation times in the water samples (2- or 10-days). Furthermore, the patterns of EHEC adherence and $\alpha$-accumulation were also examined.

\subsubsection{Immunofluorescent Assay}

In the present study, two aspects of pathogenicity were examined. First is a level of host adhesion ability, which depends on expression of adhesions. Second is a level of $\alpha$-actinin accumulation (foci of $\alpha$-actinin), which depends on host adhesion as well as expression of other virulence factors. EHEC recovered from the water samples were generally able to adhere to and infect epithelial cells after $4 \mathrm{~h}$ incubation (Figure 39). Compared to the positive control, EHEC grown in a rich nutrient medium, EHEC in most water samples had significantly lower levels of host adherence and $\alpha$-actinin accumulation except for10_SF and 10_SS (host adhesion level) and 2_SF, 10_BS, 10_SF and 10_SS ( $\alpha$-actinin accumulation) ( $\mathrm{p} \leq 0.05)$. In general, it seems that pathogenicity of EHEC recovered from the water samples was somehow affected. When the EHEC type on the pathogenicity was examined, it does not seriously seem to affect the pathogenicity in the present study based on the following results. First, the free-living EHEC showed both higher and lower level of the pathogenicity than the floc-adherent EHEC. Second, floc-adherent EHEC did not show significantly higher levels of host adhesion ability and $\alpha$ actinin accumulation than free-living EHEC ( $\leq \leq 0.05)$. This may be because all EHEC recovered from the water samples were grown in Dulbecco's modified Eagle's medium (DMEM) prior to the infection and observation in the immunofluorescent assay. It seems that DMEM stimulated the adherence of EHEC by increasing the expression of the Locus for enterocyte effacement (LEE) encoded genes such as esp $A, \operatorname{esp} B$ and tir since this nutrient-rich medium containing 
$\mathrm{HCO}_{3}{ }^{-}$ions provided an optimal growth environment similar to human intestine (Abe et al., 2002). Next, the water samples with different nutrient levels were compared. It was found that only floc-adherent EHEC incubated in SBR for 10 days (10_SF) appeared to have significantly higher levels of host adhesion ability and $\alpha$-actinin accumulation than the NBSR sample $\left(10 \_N \hat{F}\right)(p \leq 0.05)$. This may suggest that the effect of the nutrient level of the water samples was also insignificant on the pathogenicity. This result may shows that less metabolically active EHEC (due to low nutrient levels) was able to easily respond to optimal growth conditions (DMEM medium). Lastly, the effect of incubation time in the water samples (2 or 10-days) on pathogenicity was examined. Unexpectedly, EHEC from the longer incubation time had higher levels of host adhesion ability and $\alpha$-actinin accumulation. This seems to be contrary to an earlier study that reported that pathogenic E. coli (such as enteropathogenic E. coli (EPEC)) isolated from environments (non-treated water, such as recreational lakes, dams, mines, rivers and wells) had lost its virulence-related genes (Valentini et al., 1992). This unexpected result might be related to EHEC adaptation to the environment since it is known that bacteria go through morphological and physiological changes for their survival (Özkanca and Flint, 1997).

In order to examine the EHEC ability to cause infection, the ratio of $\alpha$-actinin accumulation to bacterial adhesion was compared (Table 11). These results show that the infection ability of EHEC recovered from the water samples was not significantly different from that from the control $(p \leq 0.05)$. This may suggest that EHEC from the water samples retained the similar level of ability to express type III secretion effectors once the host adhesion occurred. Furthermore, the infection ability appears to be unchanged with respect to the type of EHEC (floc adherent or free-living), water sample type or incubation time $(\mathrm{P} \leq 0.05)$. These results were important because it suggests that EHEC retain their infection ability even in the unfavourable growth condition such as natural environments.

Overall, EHEC adhering to flocs and, in particular EPS areas, survived for longer periods of time than free-living EHEC. Even though the surviving EHEC exhibited a decreased host adhesion ability, the infection ability of EHEC was not affected once host adhesion occurred. The fact that any surviving EHEC remained infectious is significant due to the low infectious dose of this EHEC strain. 


\section{CHAPTER 6. CONCLUSIONS AND RECOMMENDATIONS}

The purpose of this study was to investigate the potential role of flocs in transport and survival of Escherichia coli O157:H7 (EHEC) via adherence to flocs in a nutrient deprived environment. In particular, three objectives were examined. First, the relationship between floc properties and EPS was investigated. Second, the distribution of components in EPS was examined. Lastly, survival and pathogenicity of EHEC in flocs suspended in water samples was investigated. The main conclusions drawn from this study are:

1. Removal of salt bridging and disruption of hydrophobic interactions did not completely dissociate flocs because EPS might be resistant to chemical and enzymatic dissociation.

2. Digestion of protein by enzymes released carbohydrate from flocs into the surrounding bulk water, which indicates the disruption of protein-carbohydrate interaction in the EPS matrix.

3. Individual EPS components seem to be involved in floc characteristics. Proteins in the EPS matrix contribute to stability of flocs via hydrophobic interactions and affect surface characteristics of floc, such as negative surface charge and hydrophobicity. An increase in humic substances in the EPS matrix might cause a dissociation of flocs.

4. CLSM analysis revealed a high degree of colocalization of nucleic acids, lipidhydrophobic sites and proteins in control, EDTA and EDTA - proteinase K treated flocs. Colocalization indicates the hydrophobic interaction between EPS and microorganisms and between microorganisms as well as the distribution of hydrophobic and hydrophilic EPS.

5. CLSM analysis also showed that $N$-acetylglucosaminyl residues were the dominant carbohydrates in all samples. The $N$-acetylglucosaminyl residues bind to EPS as well as to cell surface structures. EDTA and EDTA- proteinase $\mathrm{K}$ treatment showed a larger area of $N$-acetylgalactosaminyl and galactopyranosyl residues in EPS. 
6. EHEC survived in low nutrient water for 10 days. Adherence to flocs improved the survival rate because the flocs seemed to provide nutrients and protection. The CLSM analysis showed that EHEC was distributed from the surface to the interior of the flocs. In particular, EHEC adherence to EPS areas is significant because the more stable EPS area allowed EHEC to persist in water for a longer time. This increases the infection risk.

7. Even EHEC grown in low nutrient water for 10 days were able to adhere to epithelial cells and cause infection. However, the EHEC did show a decreased ability to adhere to epithelial cells and $\alpha$-actinin accumulation (pathogenicity).

8. EHEC grown in low nutrient water for the longer incubation time showed a higher level of pathogenicity than that for the shorter incubation time. This may be due to EHEC adaptation to the environment but further study is needed to verify.

9. Adhesion to epithelial cells is an important trait since it is the precursor of infection. Once the host adhesion occurred, the level of $\alpha$-actinin accumulation caused by EHEC grown in low nutrient water was as high as that by the EHEC grown in a rich nutrient medium.

As described above, this study focused on floc properties, and in particular EPS, and their role in survival of EHEC. The significance of this study was to examine not only the association of EHEC with flocs but also the fate of pathogenicity when EHEC were grown in a nutrient deprived environment. This study has provided the above important conclusions, however, some of the experiments could be improved.

In this study, the experimental approach contained three major parts. The first part was the analysis of floc characterization. The second part was the EPS mapping using CLSM. The last part was the survival of EHEC in association with flocs.

In the first part, it would be easier to characterize EPS if the enzymes used are replaced with other chemical agents such as $0.5 \%$ Triton X-100 (Gessesse et al., 2003) since the presence of the added enzymes might have affected the measurement of floc properties and EPS 
composition. Use of Triton X-100 was expected to detach enzymes bound on the surface of cells or adsorbed in the EPS matrix with little or no cell disruption (Gessesse et al., 2003).

In the second part, other types or various combinations of lectin dyes and other stains could be explored in order to better observe the colocalization of these macromolecules (such as nucleic acids, lipid-hydrophobic sites and protein). In this study, nucleic acid could have been used with lectin dyes in order to better indicate the relationship between microorganisms and carbohydrate distribution.

In the last part, the EHEC survival experiment could be extended since the EHEC remained pathogenicity even after 10 days of low nutrient growth condition. It would be useful to determine if pathogenicity continues for a longer time period.

This study can also be developed into various new directions. First, it may be useful to have an experimental setting that is more relevant to natural environments. For example, the experimental approach used in this study might be applied to a new study using lake water with lake sediment. In such a study, not only the survival of EHEC in flocs and fate of pathogenicity but also the effect of competition with natural microflora and predation can be examined. The results of the new study might lead to a modeling of EHEC contamination in the environment.

Next, the fate of pathogenicity might be examined by different methods. In this study, pathogenicity was indirectly examined using immunofluorescence $\alpha$-actinin assay. This method is easy and simple, however, it only shows the phenotypic characteristics. Alternatively, DNA microarray technology could be used to allow for simultaneous examination of the virulence genes and their expression (Chizhikov et al., 2001). Thus, the relationship between multiple virulence genes would be revealed. This type of study will show the mechanisms of virulence factors when EHEC are present in a low nutrient condition (equivalent to natural environmental condition) for a long time. It might also indicate when EHEC lose its pathogenicity since some studies reported that pathogenic $E$. coli (such as enteropathogenic E. coli (EPEC)) isolated from environment (non-treated water-recreational lakes, dams, mines, rivers and wells) had lost its virulence-related genes (Valentini et al., 1992). 


\section{CHAPTER 7. REFERENCES}

$\Lambda$ be, H., Tatusno, I., Tobe, T., Okutani, A., Sasakawa, C. (2002) Bicarbonate ion stimulates the expression of Locus of Enterocyte Effacement-encoded genes in Enterohemorrhagic Escherichia coli O157:H7. Infect Immun. 70: 3500-3509.

Acheson, D.W.K., Lincicome, L.L., Jacewicz, M.S., Keusch, G.T. (1998) Shiga toxinproducing Escherichia coli: yesterday, today, and tomorrow. In Escherichia coli O157:H7 and other Shiga-toxin- producing E. coli strains, ed by Kaper, J.B., O'Brien, A.D. American Society for Microbiology, Washington D.C., USA. pp.1-11.

Allen, N.L., Hilton, A.C., Btts, R., Penn, C.W. (2001) Use of representational difference analysis to identif; 197: 195-201.

APHA (1992) Standard methods for the examination of water and wastewater. $18^{\text {th }} \mathrm{ed}$. American Public Health Association, American Water Works Association, Water Environmental Federation, Washington, USA.

Artz, R.R.E., Killham, K. (2002) Survival of Escherichia coli O157:H7 in private drinking water wells: influences of protozoan grazing and elevated copper concentrations. FEMS Microbiol Lett. 216: 117-122.

Behmlander, R.M., Dworkin, M. (1994) Biochemical and structural analyses of the extracellular matrix fibrils of Myxococcus xanthus. J Bacteriol. 176: 6295-6303.

Besser, R.E., Griffin P.M., Slutsker, L. (1999) Escherichia coli O157:H7 gastroenteritis and the hemolytic uremic syndrome: an emerging infectious disease. Annu Rev Med. 50: 355367.

Bloom, P.D., Russell, R.G., Boedcker, E.C. (1998) Interleukin-1 receptor antagonist protects against tissue injury in an animal model of hemorrhagic colitis. In Escherichia coli O157:H7 and other Shiga-toxin- producing E. coli strains, ed by Kaper, J.B., O'Brien, A.D. American Society for Microbiology, Washington D.C., USA. pp.278-283.

Bower, C.K., Daeschel, M.A. (1999) Resistance responses of microorganisms in food environments. Inter J Food Microbiol. 51: 33-44.

Brown, M.J., Lester, J.N. (1980) Comparison of bacterial extracellular polymer extraction methods. Appl Environ Microbiol. 40: 179-185.

Bura, R., Chung, M., Liao, B., Finlayson, C., Lee, B.C, Droppo, I.G., Leppard, G.G., Liss, S.N. (1998) Composition of extracellular polymeric substances in the activated sludge floc matrix. Water Sci Tehenol 37: 325-333. 
Burnett, S.T., Chen, J., Beuchat, L.R. (2000) Attachment of Escherichia coli O157:H7 to the surfaces and internal structures of apples as detected by confocal scanning laser microscopy. $\Lambda p p l$ Environ Microbiol. 66: 4679-4687.

Centers for Disease Control (CDC) (1997) Outbreaks of Escherichia coli O157:H7 infection associated with eating alfalfa sprouts- Michigan and Virginia. Morgid Mortal Weekly Rep. 46: 741-744.

Ceponis, P.J.M., Riff, J.D., Sherman, P.M. (2005) Epithelial cell signalling responses to enterohemorrhagic Escherichia coli infection. Mem Inst Oswaldo Cruz, Rio de Janeiro. 100: 199-203.

"Chizhikov, V., Rasooly, A., Chumakov, K., Levy, D.D. (2001) Microarray analysis of microbial virulence factors. Appl Environ Microbiol. 67: 3258-3263.

Davey M.E., O'toole, G.A. (2000) Microbial biofilms: from ecology to molecular genetics. Mirobiol Mol Biol Rev. 64:847-867.

Decho, A.W. (1999) Chemical communication within microbial biofilms: chemotaxis and quorum sensing in bacterial cells. In Microbial extracellular polymeric substances: characterization, structure, and function, ed by Wingender, J., Neu, T.R., Flemming, H. Springer-Verlag Berlin Heidelberg. Germany. pp 155-169.

Decho A.W. (2000) Microbial biofilms in intertidal systems: an overview. Cont Shelf Res. 20: 1257-1273.

Dworkin, M. (1999) Fibrils as extracellular appendages of bacteria: their role in contactmediated cell-cell interactions in Myxococcus xanthus. BioEssays. 21: 590-595.

Droppo, I.G., Flannigan, D.T., Leppard, G.G., Jaskot, C., Liss, S.N. (1996) Floc Stabilization for multiple microscopic techniques. Appl Environ Microbiol. 62: 3508-3515.

Droppo, I.G., Lcppard, G.G., Flannigan D.T., Liss S.N. (1997) The fresh water floc: functional relationship of water and organic and inorganic floc constituents affecting suspended sediment properties. Water Air Soil Poll. 99: 43-53.

Droppo, I.G. (2001) Rethinking what constitutes suspended sediment. Hydrol Process. 15: 1551-1564.

Dytoc, M.T., Ismaili, A., Philpott, D.J., Soni, R., Brunton, J.L., Sherman, P.M. (1994) Distinct binding properties of eaeA-negative verocytotoxin-producing Escherichia coli of serotype O113:H21. Infect Immun. 62: 3494-3505.

Endo, T., Nakamura, K., Takahashi, H. (1976) Pronase-susceptible floc forming bacteria: relationship between flocculation and calcium ion. Agr Biol Chem. 40: 2289-2295. 
Finlay, B.B., Rosenhine, I., Donnenberg, M.S., Kaper, J.B. (1992) Cytoskeletal composition of attaching and effacing lesions associated with enteropathogenic Escherichia coli adherence to HeLa cells. Infect Immun. 60: 2541-2543.

Flemming, H.C. (2002) Biofouling in water systems - cases, causes and countermeasures. Appl Microbial Biotechnol. 59: 629-640.

Frolund, B., Griebe, T., Nielsen, P.H. (1995) Enzymatic activity in the activated-sludge floc matrix. Appl Microbiol Biotechnol. 43: 755-761.

Frolund, B., Palmgren, R., Keiding, K., Nielsen, P.H. (1996) Extraction of extracellular polymers from activated sludge using a cation exchange resin. Wat. Res. 30: 1749-1758.

Frolund, B., Palmgren, R., Keiding, K., Niclsen, P. H. (1996) Extraction of extracellular polymers from activated sludge using a cation exchange resin. Wat. Res. 30: 1749-1758.

Ganaye, V.A., Keiding, K., Viriot, M.L., Vogel, T.M., Block. J.C. (1997) Evaluation of soil organic matter polarity by pyrene fluorescence spectrum variations. Environ Sci Tech. 31: 2701-2706.

Gaudy, A.F. (1962) Colorimetric determination of protein and carbohydrate. Indust Water Wastes. 7: 17-22.

Gerhardt, P., Murray, R.G.E., Wood, W. A., Krieg, N.R. (1994) Methods for general and molecular bacteriology. American Society for Microbiology, Washington, D. C.

Gessesse, A., Dueholm, T., Petersen, S.B., Nielsen, P.H. (2003) Lipase and protease extraction from activated sludge. Wat. Res. 37: 3652-3657.

Goosney, D.L., Devinney, R., Finlay, B.B. (2001) Recruitment of cytoskeletal and signalling proteins to enteropathogenic and enterohemorrhagic Escherichia coli pedestals. Infect Immun. 69: 3315-3322.

Gruenheid, S., Sekirov, I., Tomas, N.A., Deng, W., O’Donnell, P., Goode, D., Li, Y., Frey, E.A., Brown, N.F., Metalnikov, P., Pawson, T., Ashman, K., Finlay, B.B. (2004) Indentification and characterization of NleA, a non-LEE encoded type III translocated virulence factor of Enterohaemorrhagic Escherichia coli O157:H7. Mol Microbiol. 51: 12331249.

Higgins, M.J., Novak, J.T. (1997) Characterization of exocellular protein and its role in bioflocculation. J Environ Eng. 123: 479-85.

Hood, M.A., Schmidt, J.M. (1996) The examination of Seliberia stellata exopolymers using lectin assays. Microb Ecol. 31: 281-290. 
Jahn, A., Nielsen, P.H. (1996) Extraction of extraccllular polymeric substances (EPS) from biofilms using a cation exchange resin. Water Sci Tech. 32: 157-164.

Jarvis, K.G., Kaper, B.B. (1996) Secretion of extracellular proteins by Enterohemorrhagic Escherichia coli via a putative type III secretion system. Infect Immun. 64: 4826:4829.

Jenkins, D., Richàrd, M.G., Daigger, G.T. (1993) Manual on the cause and control of activated sludge bulking and foaming. 2ed. Lewis Publishers Inc. Michigan, USA.

Jin, B., Wilén, B., Lant, P. (2003) A comprehensive insight into floc characteristics and their impact on compressibility and settleability of activated sludge. Chem Eng J. 95: 221-234.

- Johnson-Henry, K., Wallance, J.L., Basappa, N.S., Soni, R., Wu, G.K.P., Sherman, P.M. (2001) Inhibition of attaching and effacing lesion formation following enteropathogenic Escherichia coli and Shiga-toxin-producing E. coli infection. Infect Immun. 69: 7152-7158.

Jones, M.N., Bryan, D.N. (1998) Colloidal properties of humic substances. Adv Colloid Interface Sci. 78: 1-48.

Jorand, F., Guicherd, P., Urbain, V., Manem, J., Block, J.C. (1994) Hydrophobicity of activated sludge flocs and laboratory-grown bacteria. Water Sci Tech. 30: 211-218.

Jorand, F., Boué-Bigne, F., Block, J.C., Urbain, V. (1998) Hydrophobic/hydrophilic properties of activated sludge exopolymeric substances. Water Sci Tech. 37: 307-315.

Kanetani, M. (2003) Survival of GFP labeled Eshcerichia coli O157:H7 in flocs. BSc. Thesis, Department of Chemistry and Biology, Ryerson University.

Kaper, J.B. (1998) Entcrohemorrhagic Escherichia coli. Curr Opin Microbiol. 1: 103-108.

Keiding, K., Nielsen, P.J. (1997) Desorption of organic macromolecules from activated sludge: effect of ionic composition. Wat. Res. 31: 1665-1672.

Knutton, S., Baldwin, T., Williams, P.H., McNeish, A.S. (1989) Actin accumulation at sites of bacterial adhesion to tissue culture cells: basis of a new diagnostic test for enteropathogenic and enterohemorrhagic Escherichia coli. Infect Immun. 57: 1290-1298.

Kreamer, H.E. (2002) Characterization of microbial aggregates in relation to membrane biofouling in submerged membrane bioreactors. MASc. Thesis, Graduate Department of Environmental Applied Science and Management, Ryerson University.

Kuntz, T.B., Kunts, S.T. (1999) Enterohemorrhagic E. coli infection. Prim Care Update Ob/Gyns. 6: 192-196.

Law, D. (2000) Virulence factors of Escherichia coli $\mathrm{O} 157$ and other Shiga toxin-producing E. coli. J. Appl Microbiol. 88: 729-745. 
Lawrence, J.R., Korber, D.R., Wolfaardt, G.M., Caldwell, D.E. (1996) Analytical imaging and microscopy techniques. In Manual of environmental microbiology, ed by Hurst, C.J., Knudsen, G.R., Mclnerney, J.J. Stetzenbach. L.D.. Walter M.V. ASM. Washington. pp29-51.

Lawrence, J.R., Neu, T.R., Swerhone, G.D.W. (1998) Application of multiple parameter imaging for the quantification of algal, bacterial and exopolymer components of microbial biofilms. J Microbiol Meth. 32: 253-261.

Lawrence, J.R., Swerhone, G.D.W., Leppard, G.G.. Araki, T., Zhang, X., West, M.M., Hitchcock, A.P. (2003) Scanning transmission X-Ray, laser scanning, and transmission electron microscopy mapping of the exopolymeric matrix of microbial biofilms. Appl Environ Microbiol. 69: 5555-5562.

Li, Y., Frey, E., Mackenzie, A.M.R., Finlay, B.B. (2000) Human Response to Escherichia coli $\mathrm{O} 157: \mathrm{H} 7$ infection:antibodies to secreted virulence factors. Infet Immun. 68:5090-5095.

Liao, B.Q., Allen, D.G., Droppo, I.G., Leppard, G.G., Liss, S.N. (2001) Surface properties of sludge and their role in biofilocculation and setteability. Wat. Res. 35: 339-350.

Liao, B.Q., Allen, D.G., Leppard, G.G., Droppo, I.G., Liss, S.N. (2002) Interparticle interactions affecting the stability of sludge flocs. J. Colloid Interf Sci. 249: 372-380.

Liss, S.N. (2002) Microbial flocs, suspended biofilms. In The encyclopaedia of environmental microbiology, ed by Bitton G. John Wiley \& Sons, New York. pp.2000-2012.

Lowry, O.H., Rosebrough, N.J., Farr, A.L., Randall, R.J. (1951) Protein measurement with the folin regent. Anal Biochem. 193: 265-275.

Lucarini, A.C., Kilikian, B.V. (1999) Comparative study of Lowry and Bradford methods: interfering substances. Biotechnol Tech. 13: 149-154.

Meyer, B. (2003) Approaches to prevention, removal and killing of biofilms. Int Biodeter Biodegr 51: 249-253.

Mikkelsen, L.H. (2003) Applications and limitations of the colloid titration method for measuring activated sludge surface charges. Wat. Res. 37: 2458-2466.

Morgan, J.W., Forster, C.F., Evison, L. (1990) A comparative study of the nature of biopolymers extracted from anaerobic and activated sludges. Wat. Res. 24: 743-751.

Neu, T.R., Lawrence, J.R. (1999) In situ characterization of extracellular polymeric substances (EPS) in biofilm systems. In Microbial extracellular polymeric substances: characterization, structure, and function, ed by Wingender, J., Neu, T.R., Flemming, H. Springer-Verlag Berlin Heidelberg. Germany. pp21-47. 
Neu, T.R., Swerhone, G.D.W., Lawrence, J.R. (2001) Assessment of lectin-binding analysis for in situ detection of glycoconjugates in biofilm systems. Microbiol. 147: 299-313.

Nicholls, L., Grant, T.H., Robins-Browne, R.M. (2002) Identilication of a novel genetic locus that is required for in vitro adhesion of a clinical isolate of enterohaemorrhagic Escherichia coli to epithelial cells. Mol Microbiol. 35(2): 275-288.

Nielsen, E.M., Scheutz, F. (2002) Characterization of Escherichici coli O157 isolates from Danish cattle and human patients by genotyping and presence and variants of virulence genes. Vet Microbiol. 88: 259-273.

Nielsen, P.H., Jahn, A. (1999) Extraction of EPS. In Microbial extracellular polymeric substances: characterization, structure, and function, ed by Wingender, J., Neu, T.R., Flemming, H. Springer=Verlag Berlin Heidelberg. Germany. pp50-72.

Nielsen, P.H., Frølund, B., Keiding, K. (1996) Changes in the composition of extracellular polymeric substances in activated sludge during anaerobic storage. Appl Microbiol Biotechnol. 44: 823-830.

Nowak, E. (2003) Characterization of activated sludge flocs by confocal laser scanning microscopy and image analysis. MASc. Thesis, Graduate Department of Environmental Applied Science and Management, Ryerson University.

O'Connor, D. (2002) The Walkerton Inquire: The events of May 2000 and related issues. Part One. Toronto: Queen's Printer for Ontario.

Ogden, I.D., Fenlon, D.R., Vinten, A J.A., Lewis, D. (2001) The fate of Escherichia coli O157 in soil and its potential to contaminate drinking water. Int J Food Microbiol. 66: 111117.

Olofsson, A., Zita, A, Hermansson, M. (1998) Floc stability and adhesion of greenfluorescent-protein-marked bacteria to flocs in activated sludge. Microbiol. 144: 519-528.

Palmgre, R., Nielsen, P. H. (1996) Accumulation of DNA in the exopolymeric matrix of activated sludge and bacterial cultures. Water Sci Tech. 34: 233-240.

Park, Y.S., Kim, D.S., Park, T.J., Song, S.K. (2000) Effect of extracellular polymeric substances (EPS) on the attachment of activated sludge. Bioprocess Eng 22: 1-3.

Paul, J.H., Jeffrey, W.H. (1985) Evidence for separate adhesion mechanisms for hydrophilic and hydrophobic surfaces in Vibrio proteolytica. Appl Environ Microbiol. 50: 431-437.

Rao, M.B., Tanksale, A.M., Ghatge, M.S., Deshpande, V.V. (1998) Molecular and biotechnological aspects of microbial proteases. Microbiol. Mol Biol. Rev. 62: 597-635. 
Rice,-E.W. (1999) Escherichia coli. In Waterborne pathogens AWWA manual M48 first edition, ed by American water works association. American Water Works. Denver, CO. pp.75-78.

Ryu, Jee-Hoon, Beuchat, L.R. (2004) Factors affecting production of extracellular carbohydrate complexes by Escherichia O157:H7. Inter J Food Microbiol. 95: 189-204.

Schembri, M.A., Kjærgaard, K., Klemm, P. (2003) Global gene expression in Escherichia coli biofilms. Mol Microbiol. 48: 253-267.

Sherman, P., Soni, R., Petric, M., Karmali, M. (1987) Surface properties of the vero cytotoxin-producing Escherichia coli O157:H7. Infect Immun. 55: 1824-1829.

So, J., تim, H.T., Oh, E., Heo, T., Koh, S., Leung, K.T., Lee, revors; J.T. (2002) Visualizing the infection process of Xanthomonas campetris in cuivage using green fluorescent protein. World J. Microbiol. Biotechnol. 18: 17-21.

Sperandio, V., Mellies, J.L., Nguyen, W., Shin, S., Kaper, J.B. (1999) Quorum sensing controls expression of the type III secretion gene transcription and protein secretion in enterohemorrhagic and enteropathogenic Escherichia coli. PNAS. 96: 15196-15201.

Sponza, D.T. (2003) Investigation of extracellular polymer substances (EPS) and physicochemical properties of different activated sludge flocs under steady-state conditions. Enzyme Microb Tech 32: 375-385.

Strathmann, M., Wingender, J., Flemming, H. (2002) Application of fluorescently labelled lectins for the visualization and biochemical characterization of polysaccharides in biofilms of Pseudomonas aeruginosa. J Microbiol Methods 50: 237-248.

Tarr, P.I., Bilge, S.S., Vary, Jr, J.C., Jelacic, S., Habeeb, R.L., Ward, T.R., Baylor, M.R., Besser, T.E. (2000) Iha: a novel Escherichia coli 0157:I17 adherence-conferring molecule encoded on a recently acquired chromosomal island of conserved structure Infect Immun. 68: 1400-1407.

Tilden, J., Young, W., McNamara, A., Custer, C., Boesel, B., Lambert-Fail, M., Majkowski, J., Vugia, D., Werner, S.B., Hollingworth, J., Morris, J.G. (1996) A new route of transmission for Escherichia coli: infection from dry fermented salami. Am J Public Health. 86: 1142-1145.

Tsuneda, S., Aikawa, H., Hayashi, H., Yuasa, A., Hirata, A. (2003) Extracellular polymeric substances responsible for bacterial adhesion onto solid surface. FEMS Microbiol Lett. 223: 287-292.

Umble, A.K., Kolo, L.E., Newvine, L.A., Roth, G.N., Roth, J.N. (1999) Coliform counts. Water Environ Tech. 11: 57-59. 
Valentini, S. R., Gomes, T.A.T., Falcão, D. P. (1992) Lack of virulence factors in Escherichic coli strains of enteropathogenic serogroups isolated from water. Appl Environ Microbiol. 58:412-414.

Wachtel, M.R., Whitehand, L.C., Mandrell, R.E. (2002) Association of Escherichia coli O157:H7 with preharvest leaf lettuce upon exposure to contaminated irrigation water. J Food Prot. 65: 18-25.

Wallance, J.S., Cheasty, T., Jones, K. (1997) Isolation of vero cytotoxin-producing Escherichia coli 0157 from wild birds. J. Appl Microbiol. 82: 399-404.

Whitman, R.L., Nevers, M.B. (2003) Foreshore Sand as a Source of Escherichia coli in Nearshore Water of a Lake Michigan Beach. Appl Environ Microbiol. 69:5555-5562.

Wilén, B., Keiding, K., Nielsen, P.H. (2000) Anaerobid deflocculation and aerobic. reflocculation of activated sludge. Wat. Res. 34: 3933-3942.

Wilén, B., Jin, B., Lant, P. (2003) The influence of key chemical constituents in activated sludge on surface and flocculating properties. Wat. Res. 37: 2127-2139.

Williams, M.M., Braun-Howland, E.B. (2003) Growth of Escherichia coli in model distribution system biofilms exposed to hypochlorous acid or monochloramine. Appl Environ Microbiol. 69:5463-5271.

Wingender, J., Neu, T.R., Flemming, H. (1999) What are bacterial extracellular polymeric substances? In Microbial extracellular polymeric substances: characterization, structure, and function, ed by Wingender, J., Neu, T.R., Flemming, H. Springer-Verlag Berlin Heidelberg. Germany. pp1-19.

Wolf, G., Crespo, J.G., Reis, M.A.M. (2002) Optical and spectroscopic methods for biofilm examination and monitoring. Rev Environ Sci Biotech 1: 227-251.

Wolfaardt, G.M., Lawrence, J.R., Robarts, R.D., Caldwell D.E. (1998) In situ characterization of biofilm exopolymers involved in the accumulation of chlorinated organics. Microb Ecol. 35: 213-223.

Wolfaardt, G.M., Lawrence, J.R., Korber, D.R. (1999) Function of EPS. In Microbial extracellular polymeric substances: characterization, structure, and function, ed by Wingender, J., Neu, T.R., Flemming, H. Springer-Verlag Berlin Heidelberg. Germany. pp171-199.

Wang, G., Doyle, M.P (1998) Survival of enterohemorrhagic Escherichia coli O157:H7 in water. J Food Prot. 61: 662-667. 
Yamamoto, T., Kaneko, M., Changchawalit, S., Serichantalergs, O., ljuin, S., Echeverria, P. (1994) Actin accumulation associated with clustered and localized adherence in Escherichia coli isolated from patients with diarrhea. Infect Immun. 62: 2917-2929.

Zhang, X., Bishop, P.L., Kinkle, B.K. (1999) Comparison of extraction methods for quantifying extracellular polymers in biofilm. Water Sci Tech. 39: 211-218.

Zita, A., Hermansson, M. (1994) Effects of ionic strength on bacterial adhesion and stability of flocs in a wastewater activated sludge system. Appl Environ Microbiol. 60: 3041-3048.

Zita, A., Hermansson, M. (1997a) Determination of bacterial cell surface hydrophobicity of single cells in cultures and in wastewater in situ. FEMS Microbiol. Lett. 152: 299-306.

Zita, A., Hermansson, M. (1997b) Effects of bacterial cell surface structure and hydrophobicity on attachment to activated sludge flocs. Appl Environ Microbiol. 63: 11681170. 


\section{APPENDICES}

APPENDIX A:

Pronase $\mathbf{E}$ and Proteinase $\mathrm{K}$

\begin{tabular}{|c|c|c|c|c|}
\hline Exp \# & $\begin{array}{c}\text { Pronase E } \\
\text { Concentration }(\mu \mathrm{g} / \mathrm{ml})\end{array}$ & $\begin{array}{c}\text { Hydrophobicity } \\
\%\end{array}$ & $\begin{array}{c}\text { Proteinase } \mathrm{K} \\
\text { Concentration }(\mu \mathrm{g} / \mathrm{ml})\end{array}$ & $\begin{array}{c}\text { Hydrophobicity } \\
\%\end{array}$ \\
\hline 1 & 0 & 89.26 & 0 & 88.83 \\
\hline 1 & 0 & 88.83 & 0 & 87.53 \\
\hline 2 & 0 & 88.83 & 0 & 90.08 \\
\hline 2 & 0 & 90.89 & 0 & 90.08 \\
\hline 3 & 0 & 91.16 & 0 & 88.83 \\
\hline 3 & 0 & 92.32 & 0 & 87.53 \\
\hline 1 & 200 & 86.16 & 200 & 87.08 \\
\hline 1 & 200 & 83.72 & 200 & 86.62 \\
\hline 2 & 200 & 80.50 & 200 & 86.62 \\
\hline 2 & 200 & 83.21 & 200 & 86.85 \\
\hline 3 & 200 & 82.16 & 200 & 86.62 \\
\hline 3 & 200 & 85.69 & 200 & 85.21 \\
\hline
\end{tabular}

\section{Pronase E}

t-Test: Two Samples Assuming Unequal Variance at $95 \%$ Confident Interval

\begin{tabular}{lll} 
& Control $(0 \mu \mathrm{g} / \mathrm{ml})$ & $200 \mu \mathrm{g} / \mathrm{ml}$ Pronase E \\
\hline Mean & 90.22 & 83.57 \\
Standard Deviation & 1.45 & 2.13 \\
Variance & 2.103538379 & 4.54621126 \\
Observations & 3 & 3 \\
Hypothesized Mean Difference & 0 & \\
df & 10 & \\
$\mathrm{P}(\mathrm{T}<=\mathrm{t})$ Two-tail & 0.00015296 \\
$\mathrm{t}$ Critical Two-tail & 2.63 & \\
$\mathrm{t}$ Stats & 5.890615284 \\
\hline & Significantly Different \\
\hline
\end{tabular}

\section{Proteinase K}

t-Test: Two Samples Assuming Unequal Variance at 95\% Confident Interval

\begin{tabular}{lll} 
& Control $(0 \mu \mathrm{g} / \mathrm{ml})$ & $200 \mu \mathrm{g} / \mathrm{ml}$ Proteinase K \\
\hline Mean & 88.81 & 86.50 \\
Standard Deviation & 1.14 & 0.66 \\
Variance & 1.307179606 & 0.43350083 \\
Observations & 3 & 3 \\
Hypothesized Mean Difference & 0 & \\
df & 10 & \\
$\mathrm{P}(T<=t)$ Two-tail & 0.00264065 & \\
t Critical Two-tail & 2.63 & \\
t Stats & 3.970635589 & \\
\hline
\end{tabular}


APPENDIX B:

Surface Charge and Statistical Analysis

Pronase $E$ and Proteinase $\mathrm{K}$

\begin{tabular}{|c|c|c|c|c|}
\hline Exp \# & $\begin{array}{c}\text { Pronase } E \\
\text { Concentration }(\mu \mathrm{g} / \mathrm{ml})\end{array}$ & $\begin{array}{c}\text { Surface Charge } \\
\text { meq/g MLSS }\end{array}$ & $\begin{array}{c}\text { Proteinase K } \\
\text { Concentration }(\mu \mathrm{g} / \mathrm{ml})\end{array}$ & $\begin{array}{c}\text { Surface Charge } \\
\text { meq/g MLSS }\end{array}$ \\
\hline 1 & 0 & -0.783 & 0 & -0.711 \\
\hline 1 & 0 & -0.75 & 0 & -0.75 \\
\hline 2 & 0 & -0.704 & 0 & -0.725 \\
\hline 2 & 0 & -0.704 & 0 & -0.775 \\
\hline 1 & 200 & -0.822 & 200 & -0.882 \\
\hline 1 & 200 & -0.862 & 200 & -0.912 \\
\hline 2 & 200 & -0.921 & 200 & -0.828 \\
\hline 2 & 200 & -0.931 & 200 & -0.844 \\
\hline
\end{tabular}

\section{Pronase E}

t-Test: Two Samples Assuming Unequal Variance at 95\% Confident Interval

\begin{tabular}{lll}
\hline Proanse E & Control & $200 \mu \mathrm{g} / \mathrm{ml}$ Pronase E \\
\hline Mean & -0.735 & -0.884 \\
Standard Deviation & 0.038 & 0.0512 \\
Variance & 0.001487269 & 0.002626712 \\
Observations & 2 & 2 \\
Hypothesized Mean Difference & 0 & - \\
df & 6 & \\
$P(T<=t)$ Two-tail & 0.00430667 & \\
$t$ Critical Two-tail & 2.97 & \\
t Stats & 4.454850568 \\
\hline
\end{tabular}

Proteinase $\mathrm{K}$

t-Test: Two Samples Assuming Unequal Variance at 95\% Confident Interval

\begin{tabular}{lll}
\hline Proteinase K & Control & $200 \mu \mathrm{g} / \mathrm{ml}$ Proteinase K \\
\hline Mean & -0.740 & -0.866 \\
Standard Deviation & 0.028 & 0.038 \\
Variance & 0.00080621 & 0.001430137 \\
Observations & 2 & 2 \\
Hypothesized Mean Difference & 0 & \\
df & 6 & \\
P(T<=t) Two-tail & 0.00221706 & \\
$t$ Critical Two-tail & 2.97 & \\
t Stats & 5.101901479 \\
\hline
\end{tabular}




\section{APPENDIX C: $\quad$ Dissociation Constant and Statistical Analysis}

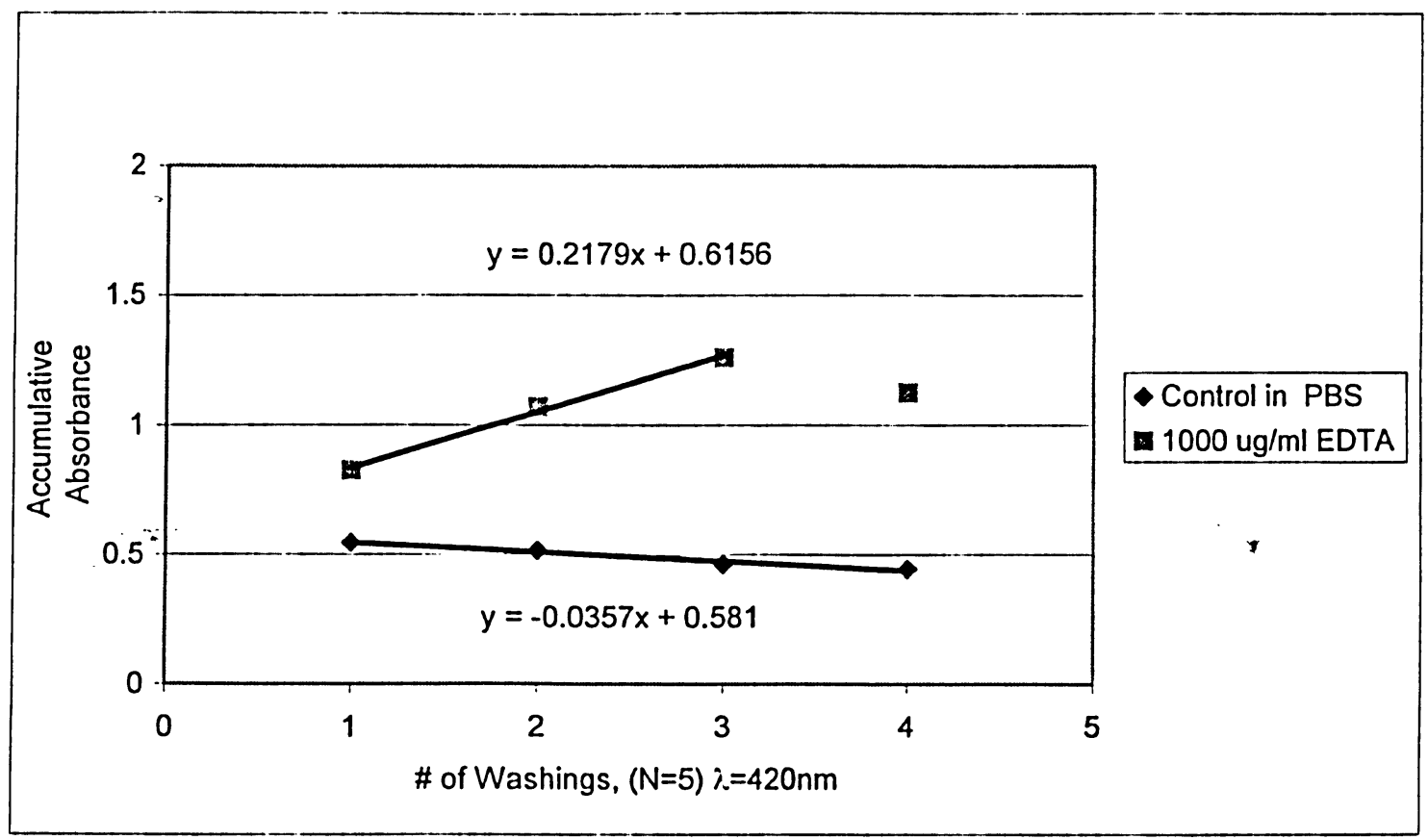

Figure A1. Example of EDTA dissociation; Slope is a dissociation constant

Dissociation Constant

\begin{tabular}{|c|c|c|}
\hline Exp \# & Control & $1000 \mu \mathrm{g} / \mathrm{ml}$ EDTA \\
\hline 1 & -0.0072 & 0.218 \\
\hline 2 & -0.0068 & 0.213 \\
\hline 3 & -0.016 & 0.342 \\
\hline 4 & -0.036 & 0.218 \\
\hline 5 & 0.001 & 0.281 \\
\hline
\end{tabular}

t-Test: Two Samples Assuming Unequal Variance at 95\% Confident Interval

\begin{tabular}{lll}
\hline & Control & $1000 \mu \mathrm{g} / \mathrm{ml}$ EDTA \\
\hline Mean & -0.0129 & 0.254 \\
Standard Deviation & 0.0141 & 0.056 \\
Variance & 0.000198088 & 0.003189373 \\
Observations & 5 & 5 \\
Hypothesized Mean Difference & 0 & \\
df & 8 & \\
$\mathrm{P}(\mathrm{T}<=\mathrm{t})$ Two-tail & 0.00027288 & \\
$\mathrm{t}$ Critical Two-tail & 2.75 & \\
$\mathrm{t}$ Stats & 6.153713912 \\
\hline
\end{tabular}


Percentage of Size Fractions in Control and EDTA

\begin{tabular}{|c|c|c|c|c|c|c|}
\hline \multirow{2}{*}{ Exp \# } & \multicolumn{3}{|c|}{ Control } & \multicolumn{3}{c|}{$1000 \mu \mathrm{g} / \mathrm{ml}$ EDTA } \\
\cline { 2 - 7 } & Small & Medium & Large & Small & Medium & Large \\
\hline 1 & 73.76 & 21.28 & 4.96 & 87.36 & 9.67 & 2.97 \\
\hline 2 & 67.92 & 24.53 & 7.55 & 72.73 & 21.59 & 5.68 \\
\hline 3 & 45.00 & 35.00 & 20.00 & 84.12 & 8.82 & 7.06 \\
\hline 4 & 67.36 & 26.42 & 6.22 & 77.68 & 15.02 & .7 .30 \\
\hline
\end{tabular}

t-Test: Two Samples Assuming Unequal Variance at 95\% Confident Interval

\begin{tabular}{lll}
\hline Small & Control & EDTA Treated \\
\hline Mean & 63.51 & 80.47 \\
Standard Deviation & 12.67 & 6.54 \\
Variance & 160.6502516 & 42.82129733 \\
Observations & 4 & 4 \\
Hypothesized Mean Difference & 0 & \\
df & 6 & \\
$P(T<=t)$ Two-tail & 0.06906141 & \\
t Critical Two-tail & 2.97 & \\
t Stats & 2.210863386 & \\
\hline
\end{tabular}

t-Test: Two Samples Assuming Unequal Variance at 95\% Confident Interval

\begin{tabular}{lll}
\hline Medium & Control & EDTA Treated \\
\hline Mean & 26.81 & 13.78 \\
Standard Deviation & 5.86 & 5.89 \\
Variance & 34.34970251 & 34.6778442 \\
Observations & 4 & 4 \\
Hypothesized Mean Difference & 0 & \\
df & 6 & \\
$P(T<=t)$ Two-tail & 0.02014023 & \\
$t$ Critical Two-tail & 2.97 & \\
$t$ Stats & 3.137174645 & \\
\hline
\end{tabular}

t-Test: Two Samples Assuming Unequal Variance at 95\% Confident Interval

\begin{tabular}{lll}
\hline Large & Control & EDTA Treated \\
\hline Mean & 9.682 & 5.752 \\
Standard Deviation & 6.959 & 1.984 \\
Variance & 48.42500473 & 3.938246522 \\
Observations & 4 & 4 \\
Hypothesized Mean Difference & 0 & \\
df & 6 & \\
$P(T<=t)$ Two-tail & 0.34674069 & \\
$t$ Critical Two-tail & 2.97 & \\
t Stats & 1.0207782 & \\
\hline
\end{tabular}


Percentage of Size Fractions in Control and Pronase E

\begin{tabular}{|c|c|c|c|c|c|c|}
\hline \multirow{2}{*}{ Exp\# } & \multicolumn{3}{|c|}{ Control } & \multicolumn{3}{c|}{ Pronase E } \\
\cline { 2 - 7 } & Small & Medium & Large & Small & Medium & Large \\
\hline 1 & 64.36 & 28.22 & 7.43 & 77.33 & 21.33 & 1.33 \\
\hline 2 & 58.97 & 26.92 & 14.10 & 57.86 & 28.57 & 13.57 \\
\hline 3 & 33.77 & 54.55 & 11.69 & 71.79 & 17.95 & 10.26 \\
\hline 4 & 65.24 & 26.19 & -8.57 & & & \\
\hline 5 & 67.53 & 30.52 & 1.95 & & & \\
\hline
\end{tabular}

$\mathrm{t}$-Test: Two Samples Assuming Unequal Variance at $95 \%$ Confident Interval

\begin{tabular}{lll}
\hline Small & Control & Pronase E Treated \\
\hline Mean & 57.97 & 68.99 \\
Standard Deviation & 13.89 & 10.03 \\
Variance & 192.95909 & 100.681683 \\
Observations & 5 & 3 \\
Hypothesized Mean Difference & 0 & \\
df & 6 & \\
$P(T<=t)$ Two-tail & 0.24565480 & \\
$t$ Critical Two-tail & 2.97 & \\
t Stats & 1.28656325 \\
\hline
\end{tabular}

t-Test: Two Samples Assuming Unequal Variance at 95\% Confident Interval

\begin{tabular}{lll}
\hline Medium & Control & Pronase E Treated \\
\hline Mean & 33.28 & 22.62 \\
Standard Deviation & 12.00 & 5.43 \\
Variance & 144.033656 & 29.4522228 \\
Observations & 5 & 3 \\
Hypothesized Mean Difference & 0 & \\
df & 6 & \\
$P(T<=t)$ Two-tail & 0.13843541 & \\
$t$ Critical Two-tail & 2.97 & \\
t Stats & 1.70834483 \\
\hline
\end{tabular}

t-Test: Two Samples Assuming Unequal Variance at 95\% Confident Interval

\begin{tabular}{lll}
\hline Large & Control & Pronase E Treated \\
\hline Mean & 8.748 & 8.386 \\
Standard Deviation & 4.618 & 6.331 \\
Variance & 21.3272837 & 40.08712 \\
Observations & 5 & 3 \\
Hypothesized Mean Difference & 0 & \\
df & 6 & \\
$P(T<=t)$ Two-tail & 0.64221915 & \\
$t$ Critical Two-tail & 2.97 & \\
t Stats & 0.48897391 & \\
\hline
\end{tabular}


Percentage of Size Fractions in Control and Proteinase $\mathrm{K}$

\begin{tabular}{|c|c|c|c|c|c|c|}
\hline \multirow{2}{*}{ Exp \# } & \multicolumn{3}{|c|}{ Control } & \multicolumn{3}{c|}{ Proteinase K } \\
\cline { 2 - 7 } & Small & Medium & Large & Small & Medium & Large \\
\hline 1 & 64.36 & 28.22 & 7.43 & 40.61 & 44.24 & 15.15 \\
\hline 2 & 87.52 & 10.53 & 1.95 & 85.36 & 12.77 & 1.87 \\
\hline 3 & 33.77 & 54.55 & 11.69 & 48.34 & 39.07 & 12.58 \\
\hline 4 & 65.24 & 26.19 & 8.57 & 39.50 & 43.70 & 16.81 \\
\hline
\end{tabular}

t-Test: Two Samples Assuming Unequal Variance at 95\% Confident Interval

\begin{tabular}{lll}
\hline Small & Control & Proteinase K Treated \\
\hline Mean & 62.72 & 53.45 \\
Standard Deviation & 22.08 & 21.63 \\
Variance & 487.45977 & 468.0007 \\
Observations & 4 & 4 \\
Hypothesized Mean Difference & 0 & \\
df & 6 & \\
$P(T<=t)$ Two-tail & 0.57064777 & \\
t Critical Two-tail & 2.97 & \\
t Stats & 0.5996935 & \\
\hline
\end{tabular}

t-Test: Two Samples Assuming Unequal Variance at 95\% Confident Interval

\begin{tabular}{lll}
\hline Medium & Control & Proteinase K Treated \\
\hline Mean & 29.87 & 34.94 \\
Standard Deviation & 18.25 & 14.96 \\
Variance & 333.06075 & 223.9392 \\
Observations & 4 & 4 \\
Hypothesized Mean Difference & 0 & \\
df & 6 & \\
$P(T<=t)$ Two-tail & 0.68273475 & \\
$t$ Critical Two-tail & 2.97 & \\
t Stats & 0.4292383 & \\
\hline
\end{tabular}

t-Test: Two Samples Assuming Unequal Variance at 95\% Confident Interval

\begin{tabular}{lll}
\hline Large & Control & Proteinase K Treated \\
\hline Mean & 7.409 & 11.60 \\
Standard Deviation & 4.060 & 6.72 \\
Variance & 16.488237 & 45.12065 \\
Observations & 4 & 4 \\
Hypothesized Mean Difference & 0 & \\
df & 6 & \\
$P(T<=t)$ Two-tail & 0.33470645 & \\
$t$ Critical Two-tail & 2.97 & \\
$t$ Stats & 1.0487088 & \\
\hline
\end{tabular}


APPENDIX D: $\quad$ EPS Composition and Statistical Analysis

Loosely Bound EPS in Pronase E treated Flocs

Carbohydrates

\begin{tabular}{|c|c|c|}
\hline Exp \# & $\begin{array}{c}\text { Control } \\
(\mathrm{mg} / \mathrm{L})\end{array}$ & $\begin{array}{c}\text { Pronase E Treated } \\
(\mathrm{mg} / \mathrm{L})\end{array}$ \\
\hline 1 & 11.03 & 20.74 \\
\hline 1 & - & 25.16 \\
\hline 2 & 10.59 & 23.87 \\
\hline 2 & - & 24.97 \\
\hline
\end{tabular}

t-Test: Two Samples Assuming Unequal Variance at $95 \%$ Confident Interval

\begin{tabular}{lll}
\hline Carbohydrates & Control & Pronase E Treated \\
\hline Mean & 10.81 & 23.68 \\
Standard Deviation & 0.31 & 2.04 \\
Variance & 0.095922 & 4.1839068 \\
Observations & 2 & 2 \\
Hypothesized Mean Difference & 0 & \\
df & 4 & \\
$P(T<=t)$ Two-tail & 0.00076203 & \\
$t$ Critical Two-tail & 3.50 & \\
t Stats & 9.241048247 \\
\hline
\end{tabular}

\section{Proteins}

\begin{tabular}{|c|c|c|}
\hline Exp \# & $\begin{array}{c}\text { Control } \\
(\mathrm{mg} / \mathrm{L})\end{array}$ & $\begin{array}{c}\text { Pronase E Treated } \\
(\mathrm{mg} / \mathrm{L})\end{array}$ \\
\hline 1 & 9.538 & 5.926 \\
\hline 1 & 10.63 & 4.739 \\
\hline 1 & & 5.556 \\
\hline 2 & 7.886 & 4.368 \\
\hline 2 & & 6.918 \\
\hline 2 & & 6.976 \\
\hline
\end{tabular}


t-Test: Two Samples Assuming Unequal Variance at 95\% Confident Interval

\begin{tabular}{lll}
\hline Proteins & Control & Pronase E Treated \\
\hline Mean & 9.352 & 5.747 \\
Standard Deviation & 1.382 & 1.083 \\
Variance & 1.911127049 & 1.173324186 \\
Observations & 2 & 2 \\
Hypothesized Mean Difference & 0 & \\
df & 7 & \\
$P(T<=t)$ Two-tail & 0.02436389 & \\
$t$ Critical Two-tail & 2.84 & \\
t Stats & 2.859251254 & \\
\hline
\end{tabular}

Humic Substances

\begin{tabular}{|c|c|c|}
\hline Exp \# & $\begin{array}{c}\text { Control } \\
(\mathrm{mg} / \mathrm{L})\end{array}$ & $\begin{array}{c}\text { Pronase E Treated } \\
(\mathrm{mg} / \mathrm{L})\end{array}$ \\
\hline 1 & 15.00 & 38.08 \\
\hline 1 & 16.93 & 37.76 \\
\hline 1 & 13.31 & - \\
\hline 1 & 13.20 & - \\
\hline 2 & 13.54 & 39.56 \\
\hline 2 & 15.26 & 37.00 \\
\hline 2 & 15.60 & - \\
\hline 2 & 16.91 & - \\
\hline
\end{tabular}

t-Test: Two Samples Assuming Unequal Variance at 95\% Confident Interval

\begin{tabular}{lll}
\hline Humic substances & Control & Pronase E Treated \\
\hline Mean & 14.97 & 38.10 \\
Standard Deviation & 1.51 & 1.07 \\
Variance & 2.287770669 & 1.152336474 \\
Observations & 2 & 2 \\
Hypothesized Mean Difference & 0 & \\
df & 10 & \\
$P(T<=t)$ Two-tail & $6.96014 \mathrm{E}-10$ & \\
t Critical Two-tail & 2.633769327 & \\
$\mathrm{t}$ Stats & $5.00 \mathrm{E}+06$ & \\
\hline
\end{tabular}


DNA

\begin{tabular}{|c|c|c|}
\hline Exp\# & $\begin{array}{c}\text { Control } \\
\mathrm{mg} / \mathrm{L}\end{array}$ & $\begin{array}{c}\text { Pionase E Treated } \\
\mathrm{mg} / \mathrm{L}\end{array}$ \\
\hline 1 & 0.022429 & 0.018351 \\
\hline 2 & 0.022769 & 0.018351 \\
\hline
\end{tabular}

$\mathrm{t}$-Test: Two Samples Assuming Unequal Variance at $95 \%$ Confident Interıal

\begin{tabular}{lll}
\hline DNA & Control & Pronase E Treated \\
\hline Mean & 0.02260 & 0.01835 \\
Standard Deviation & 0.00024 & 0 \\
Variance & $5.77437 \mathrm{E}-08$ & 0 \\
Observations & 2 & 2 \\
Hypothesized Mean Difference & 0 & \\
df & 2 & \\
$P(T<=t)$ Two-tail & 0.02545 & \\
$t$ Critical Two-tail & 6.20537 &. \\
t Stats & 2.95488 & \\
\hline & Not Significantly Different
\end{tabular}

Bound EPS in Pronase E treated Flocs

Carbohydrates

\begin{tabular}{|c|c|c|}
\hline Exp \# & $\begin{array}{c}\text { Control } \\
\text { (mg/g MLSS) }\end{array}$ & $\begin{array}{c}\text { Pronase E Treated } \\
\text { (mg/g MLSS) }\end{array}$ \\
\hline 1 & 4.344 & 4.969 \\
\hline 1 & 4.600 & 5.400 \\
\hline 2 & 4.284 & 6.639 \\
\hline 2 & 3.037 & 8.776 \\
\hline
\end{tabular}

t-Test: Two Samples Assuming Unequal Variance at $95 \%$ Confident Interval

\begin{tabular}{lll}
\hline Carbohydrates & Control & Pronase E Treated \\
\hline Mean & 4.066 & 6.446 \\
Standard Deviation & 0.700 & 1.707 \\
Variance & 0.489596285 & 2.914190737 \\
Observations & 2 & 2 \\
Hypothesized Mean Difference & 0 & \\
df & 6 & \\
$P(T<=t)$ Two-tail & 0.06167657 & \\
$t$ Critical Two-tail & 2.968681656 & \\
t Stats & 2.293154466 \\
\hline
\end{tabular}


Proteins

\begin{tabular}{|c|c|c|}
\hline Exp \# & $\begin{array}{c}\text { Control } \\
\text { (mg/g MLSS) }\end{array}$ & $\begin{array}{c}\text { Pronase E Treated } \\
\text { (mg/g MLSS) }\end{array}$ \\
\hline 1 & 12.53 & 21.11 \\
\hline 1 & 13.86 & 24.70 \\
\hline 2 & 14.85 & 19.66 \\
\hline 2 & 16.31 & 19.66 \\
\hline
\end{tabular}

$\mathrm{t}$-Test: Two Samples Assuming Unequal Variance at $95 \%$ Confident Interval

\begin{tabular}{lll}
\hline Proteins & Control & Pronase E Treated \\
\hline Mean & 14.39 & 21.28 \\
Standard Deviation & 1.594 & 2.380 \\
Variance & 2.542570636 & 5.663549036 \\
Observations & 2 & 2 \\
Hypothesized Mean Difference & 0 & \\
df & 6 & \\
$P(T<=t)$ Two-tail & 0.00425639 & \\
$t$ Critical Two-tail & 2.968681656 & - \\
$\mathrm{t}$ Stats & 4.465837264 & \\
\hline
\end{tabular}

\section{Humic substances}

\begin{tabular}{|c|c|c|}
\hline Exp \# & $\begin{array}{c}\text { Control } \\
\text { (mg/g MLSS) }\end{array}$ & $\begin{array}{c}\text { Pronase E Treated } \\
\text { (mg/g MLSS) }\end{array}$ \\
\hline 1 & 18.15 & 20.97 \\
\hline 1 & 18.11 & 19.93 \\
\hline 2 & 17.44 & 21.15 \\
\hline 2 & 14.71 & 21.15 \\
\hline
\end{tabular}

$\mathrm{t}$-Test: Two Samples Assuming Unequal Variance at 95\% Confident Interval

\begin{tabular}{lll}
\hline Humic Substances & Control & Pronase E Treated \\
\hline Mean & 17.10 & 20.80 \\
Standard Deviation & 1.63 & 0.59 \\
Variance & 2.658875288 & 0.344758513 \\
Observations & 2 & 2 \\
Hypothesized Mean Difference & 0 & \\
df & 6 & \\
$P(T<=t)$ Two-tail & 0.014770987 & \\
$t$ Critical Two-tail & 2.968681656 & \\
$\mathrm{t}$ Stats & 3.384739102 \\
\hline
\end{tabular}


DNA

\begin{tabular}{|c|c|c|}
\hline Exp\# & $\begin{array}{c}\text { Control } \\
\mathrm{mg} / \mathrm{gMLSS}\end{array}$ & $\begin{array}{c}\text { Pronase E Treated } \\
\mathrm{mg} / \mathrm{gMLSS}\end{array}$ \\
\hline 1 & 0.03693 & 0.03826 \\
\hline 2 & 0.03784 & 0.03675 \\
\hline
\end{tabular}

t-Test: Two Samples Assuming Unequal Variance at $95 \%$ Confident Interval

\begin{tabular}{lll}
\hline DNA & Control & Pronase E Treated \\
\hline Mean & 0.03738 & 0.03751 \\
Standard Deviation & 0.0006408 & 0.001068 \\
Variance & $4.10622 \mathrm{E}-07$ & $1.14062 \mathrm{E}-06$ \\
Observations & 2 & 2 \\
Hypothesized Mean Difference & 0 & \\
df & 2 & \\
$\mathrm{P}(\mathrm{T}<\mathrm{t})$ Two-tail & 0.90195010 & \\
$\mathrm{t}$ Critical Two-tail & 6.205373211 & \\
$\mathrm{t}$ Stats & 0.139334588 & \\
\hline & Not Significantly Different
\end{tabular}

\section{Loosely Bound EPS in Proteinase K Treated Flocs}

\section{Carbohydrates}

\begin{tabular}{|c|c|c|}
\hline Exp \# & $\begin{array}{c}\text { Control } \\
(\mathrm{mg} / \mathrm{L})\end{array}$ & $\begin{array}{c}\text { Proteinase K Treated } \\
(\mathrm{mg} / \mathrm{L})\end{array}$ \\
\hline 1 & 6.054 & 10.00 \\
\hline 1 & 7.659 & 10.45 \\
\hline 2 & 7.956 & 9.756 \\
\hline 2 & 9.551 & 11.67 \\
\hline
\end{tabular}

t-Test: Two Samples Assuming Unequal Variance at 95\% Confident Interval

\begin{tabular}{lll}
\hline Carbohydrates & Control & Proteinase K Treated \\
\hline Mean & 7.805 & 10.47 \\
Standard Deviation & 1.433 & 0.85 \\
Variance & 2.052439757 & 0.724875629 \\
Observations & 2 & 2 \\
Hypothesized Mean Difference & 0 & \\
df & 6 & \\
$P(T<=t)$ Two-tail & 0.02483381 & \\
$t$ Critical Two-tail & 2.968681656 & \\
t Stats & 2.973847586 \\
\hline
\end{tabular}


Proteins

\begin{tabular}{|c|c|c|}
\hline Exp \# & $\begin{array}{c}\text { Control } \\
(\mathrm{mg} / \mathrm{L})\end{array}$ & $\begin{array}{c}\text { Proteinase K Treated } \\
(\mathrm{mg} / \mathrm{L})\end{array}$ \\
\hline 1 & 3.076 & 0.3631 \\
\hline 1 & 4.066 & 1.354 \\
\hline 1 & - & 3.076 \\
\hline 1 & - & 4.066 \\
\hline 2 & 5.584 & 1.734 \\
\hline 2 & 4.898 & 3.229 \\
\hline 2 & - & 4.305 \\
\hline 2 & - & 5.799 \\
\hline
\end{tabular}

t-Test: Two Samples Assuming Unequal Variance at $95 \%$ Confident Interval

\begin{tabular}{lll}
\hline Proteins & Control & Proteinase K Treated \\
\hline Mean & 4.406 & 2.991 \\
Standard Deviation & 1.082 & 1.773 \\
Variance & 1.171768579 & 3.142619835 \\
Observations & 2 & 2 \\
Hypothesized Mean Difference & 0 & \\
$\mathrm{df}$ & 10 & \\
$\mathrm{P}(\mathrm{T}<=\mathrm{t})$ Two-tail & 0.12056875 & \\
$\mathrm{t}$ Critical Two-tail & 2.633769327 & \\
$\mathrm{t}$ Stats & 1.696894287 \\
\hline
\end{tabular}

\section{Humic substances}

\begin{tabular}{|c|c|c|}
\hline Exp \# & $\begin{array}{c}\text { Control } \\
(\mathrm{mg} / \mathrm{L})\end{array}$ & $\begin{array}{c}\text { Proteinase K Treated } \\
(\mathrm{mg} / \mathrm{L})\end{array}$ \\
\hline 1 & 57.43 & 60.32 \\
\hline 1 & 56.80 & 60.99 \\
\hline 1 & - & 59.61 \\
\hline 1 & - & 60.28 \\
\hline 2 & 50.87 & 59.29 \\
\hline 2 & 53.06 & 61.72 \\
\hline 2 & - & 59.20 \\
\hline 2 & - & 56.84 \\
\hline 3 & 51.00 & 55.85 \\
\hline 3 & 48.60 & 53.49 \\
\hline
\end{tabular}


t-Test: Two Samples Assuming Unequal Variance at $95 \%$ Confident Interval

\begin{tabular}{lll} 
Humic substances & Control & Proteinase K Treated \\
\hline Mean & 52.96 & 58.76 \\
Standard Deviation & 3.52 & 2.57 \\
Variance & 12.37313635 & 6.62844137 \\
Observations & 3 & 3 \\
Hypothesized Mean Difference & 0 & \\
df & 14 & \\
$P(T<=t)$ Two-tail & 0.019649541 & \\
$t$ Critical Two-tail & 2.509568731 & \\
$t$ Stats & 2.633560143 & \\
\hline
\end{tabular}

Significantly Different ${ }^{-}$

DNA

\begin{tabular}{|c|c|c|}
\hline Exp\# & $\begin{array}{c}\text { Control } \\
\mathrm{mg} / \mathrm{L}\end{array}$ & $\begin{array}{c}\text { Proteinase K Treated } \\
\mathrm{mg} / \mathrm{L}\end{array}$ \\
\hline 1 & 0.02260 & 0.01835 \\
\hline 2 & 0.01933 & 0.01775 \\
\hline
\end{tabular}

t-Test: Two Samples Assuming Unequal Variance at $95 \%$ Confident Interval

\begin{tabular}{lll}
\hline DNA & Control & Proteinase K Treated \\
\hline Mean & 0.02096 & 0.018049 \\
Standard Deviation & 0.00231 & 0.000427 \\
Variance & $5.35685 \mathrm{E}-06$ & $1.82501 \mathrm{E}-07$ \\
Observations & 2 & 2 \\
Hypothesized Mean Difference & 0 & \\
df & 2 & \\
$P(T<=t)$ Two-tail & 0.31833020 & \\
$t$ Critical Two-tail & 6.205373211 & \\
t Stats & 1.088063755 & \\
\hline
\end{tabular}


Bound EPS in Proteinase K Treated Flocs

Carbohydrates

\begin{tabular}{|c|c|c|}
\hline Exp \# & $\begin{array}{c}\text { Control } \\
\text { (mg/g MLSS) }\end{array}$ & $\begin{array}{c}\text { Proteinase K Treated } \\
\text { (mg/g MLSS) }\end{array}$ \\
\hline 1 & 2.167 & 2.144 \\
\hline 1 & 1.747 & 2.144 \\
\hline 2 & 4.827 & 4.136 \\
\hline 2 & 4.479 & 5.534 \\
\hline
\end{tabular}

$\mathrm{t}$-Test: Two Samples Assuming Unequal Variance at $95 \%$ Confident Interval

\begin{tabular}{lll}
\hline Carbohydrates & Control & Proteinase K Treated \\
\hline Mean & 3.305 & 3.489 \\
Standard Deviation & 1.572 & 1.655 \\
Variance & 2.472030054 & 2.740042192 \\
Observations & 2 & 2 \\
Hypothesized Mean Difference & 0 & \\
df & 6 & \\
$\mathrm{P}(T<=\mathrm{t})$ Two-tail & 0.87714442 & \\
$\mathrm{t}$ Critical Two-tail & 2.968681656 \\
$\mathrm{t}$ Stats & 0.161309117 \\
\hline & Not Significantly Different \\
\hline
\end{tabular}

Protcins

\begin{tabular}{|c|c|c|}
\hline Exp \# & $\begin{array}{c}\text { Control } \\
\text { (mg/g MLSS) }\end{array}$ & $\begin{array}{c}\text { Proteinase K Treated } \\
\text { (mg/g MLSS) }\end{array}$ \\
\hline 1 & 8.801 & 12.81 \\
\hline 1 & 8.020 & 15.40 \\
\hline 2 & 10.00 & 14.34 \\
\hline 2 & 10.26 & 15.80 \\
\hline
\end{tabular}

t-Test: Two Samples Assuming Unequal Variance at 95\% Confident Interval

\begin{tabular}{lll}
\hline Proteins & Control & Proteinase K Treated \\
\hline Mean & 9.271 & 14.59 \\
Standard Deviation & 1.050 & 1.34 \\
Variance & 1.101627131 & 1.786615744 \\
Observations & 2 & 2 \\
Hypothesized Mean Difference & 0 & \\
df & 6 & \\
$P(T<=t)$ Two-tail & 0.00095417 & \\
t Critical Two-tail & 2.968681656 & \\
t Stats & 6.012269296 \\
\hline
\end{tabular}


Humic Substances

\begin{tabular}{|c|c|c|}
\hline Exp \# & $\begin{array}{c}\text { Control } \\
\text { (mg/g MLSS) }\end{array}$ & $\begin{array}{r}\text { Proteinase K Treated } \\
\text { (mg/g MLSS) }\end{array}$ \\
\hline 1 & 27.93 & 33.36 \\
\hline 1 & 26.78 & 33.67 \\
\hline 2 & 18.44 & 22.69 \\
\hline 2 & 16.98 & 23.67 \\
\hline 3 & 12.38 & 26.20 \\
\hline 3 & 14.94 & 25.41 \\
\hline
\end{tabular}

t-Test: Two Samples Assuming Unequal Variance at 95\% Confident Interval

\begin{tabular}{lll}
\hline Humic stiostances & Control & Proteinase K Treated \\
\hline Mean & 19.57 & 27.50 \\
Standard Deviation & 6.37 & 4.82 \\
Variance & 40.59373572 & 23.25376766 \\
Observations & 3 & 3 \\
Hypothesized Mean Difference & 0 & \\
df & 10 & \\
$P(T<=t)$ Two-tail & 0.037201205 & \\
t Critical Two-tail & 2.633769327 & \\
t Stats & 2.401793608 & \\
\hline
\end{tabular}

DNA

\begin{tabular}{|c|c|c|}
\hline Exp\# & $\begin{array}{c}\text { Control } \\
\mathrm{mg} / \mathrm{gMLSS}\end{array}$ & $\begin{array}{c}\text { Proteinase K Treated } \\
\mathrm{mg} / \mathrm{gMLSS}\end{array}$ \\
\hline 1 & 0.0374 & 0.0375 \\
\hline 2 & 0.0292 & 0.0256 \\
\hline
\end{tabular}

t-Test: Two Samples Assuming Unequal Variance at 95\% Confident Interval

\begin{tabular}{lll}
\hline DNA & Control & Proteinase K Treated \\
\hline Mean & 0.0333 & 0.0315 \\
Standard Deviation & 0.0058 & 0.0084 \\
Variance & $3.34426 E-05$ & $7.14978 \mathrm{E}-05$ \\
Observations & 2 & 2 \\
Hypothesized Mean Difference & 0 & \\
df & 2 & \\
P(T<=t) Two-tail & 0.83289643 & \\
t Critical Two-tail & 6.205373211 & \\
t Stats & 0.220361471 & \\
\hline
\end{tabular}


APPENDIX E:

Macromolecules Detected in Enzyme Solutions

\begin{tabular}{|c|c|c|c|c|}
\hline $\begin{array}{c}\text { Pronase } E \\
(\mu \mathrm{g} / \mathrm{ml})\end{array}$ & $\begin{array}{c}\text { Carbohydrates } \\
(\mathrm{mg} / \mathrm{L})\end{array}$ & $\begin{array}{c}\text { Proteins } \\
(\mathrm{mg} / \mathrm{L})\end{array}$ & $\begin{array}{c}\text { Humic substances } \\
(\mathrm{mg} / \mathrm{L})\end{array}$ & $\begin{array}{c}\text { DNA } \\
(\mathrm{mg} / \mathrm{L})\end{array}$ \\
\hline 200 & 3.953 & 108.4 & 88.0 & 0.074 \\
\hline 200 & 3.953 & 109.6 & 87.6 & 0.046 \\
\hline 200 & - & 88.75 & 77.2 & - \\
\hline 200 & - & 88.69 & 74.7 & - \\
\hline Av. & 3.953 & 98.86 & 81.88 & 0.06 \\
\hline $\begin{array}{c}\text { Proteinase } \mathrm{K} \\
(\mu \mathrm{g} / \mathrm{ml})\end{array}$ & & & & \\
\hline 200 & 0.000 & 10.06 & 10.7 & 0.000 \\
\hline 200 & 0.000 & 9.07 & 10.1 & 0.000 \\
\hline 200 & 0.000 & 18.72 & 2.8 & - \\
\hline 200 & - & 11.70 & 4.7 & - \\
\hline 200 & - & 10.20 & 7.0 & - \\
\hline Av. & 0.000 & 10.26 & 8.1 & 0.000 \\
\hline
\end{tabular}


APPENDIX F: $\quad$ Escherichia coli 0157:H7 Enumeration and Statistical Analysis Enumeration of EHEC*

\begin{tabular}{|c|c|c|c|c|c|c|}
\hline Day & \multicolumn{2}{|c|}{ Buffer } & \multicolumn{2}{c|}{ NSBR } & \multicolumn{2}{c|}{ SBR } \\
\hline Types** & Flocs & Supernatant & Flocs & Supernatant & Flocs & Supernatant \\
\hline 0 & $1.00 \mathrm{E}+08$ & $1.00 \mathrm{E}+08$ & $1.00 \mathrm{E}+08$ & $1.00 \mathrm{E}+08$ & $1.00 \mathrm{E}+08$ & $1.00 \mathrm{E}+08$ \\
\hline 2 & $1.27 \mathrm{E}+08$ & $1.31 \mathrm{E}+08$ & $4.30 \mathrm{E}+06$ & $3.20 \mathrm{E}+03$ & $4.30 \mathrm{E}+06$ & $3.20 \mathrm{E}+03$ \\
& $1.40 \mathrm{E}+08$ & $1.13 \mathrm{E}+08$ & $4.80 \mathrm{E}+06$ & $3.20 \mathrm{E}+03$ & $4.80 \mathrm{E}+06$ & $3.20 \mathrm{E}+03$ \\
& $4.30 \mathrm{E}+07$ & $1.26 \mathrm{E}+08$ & $1.10 \mathrm{E}+07$ & $9.60 \mathrm{E}+03$ & $1.10 \mathrm{E}+07$ & $9.60 \mathrm{E}+03$ \\
& $4.60 \mathrm{E}+07$ & $1.24 \mathrm{E}+08$ & $1.10 \mathrm{E}+07$ & $9.50 \mathrm{E}+03$ & $1.10 \mathrm{E}+07$ & $9.50 \mathrm{E}+03$ \\
& $4.60 \mathrm{E}+07$ & $1.09 \mathrm{E}+08$ & $9.00 \mathrm{E}+06$ & $1.05 \mathrm{E}+04$ & $9.00 \mathrm{E}+06$ & $1.05 \mathrm{E}+04$ \\
\hline 4 & $3.00 \mathrm{E}+06$ & $6.20 \mathrm{E}+05$ & $5.40 \mathrm{E}+05$ & $1.22 \mathrm{E}+03$ & $2.67 \mathrm{E}+06$ & $3.00 \mathrm{E}+03$ \\
& $9.00 \mathrm{E}+06$ & $5.20 \mathrm{E}+05$ & $9.90 \mathrm{E}+05$ & $1.38 \mathrm{E}+03$ & $2.19 \mathrm{E}+06$ & $3.14 \mathrm{E}+03$ \\
& $2.15 \mathrm{E}+07$ & $5.60 \mathrm{E}+05$ & $1.47 \mathrm{E}+05$ & $1.11 \mathrm{E}+04$ & $3.00 \mathrm{E}+05$ & $2.38 \mathrm{E}+04$ \\
& $2.18 \mathrm{E}+07$ & $5.90 \mathrm{E}+05$ & $1.36 \mathrm{E}+05$ & $1.20 \mathrm{E}+04$ & $1.90 \mathrm{E}+05$ & $2.38 \mathrm{E}+04$ \\
& $2.62 \mathrm{E}+07$ & $5.80 \mathrm{E}+05$ & $1.37 \mathrm{E}+05$ & $1.30 \mathrm{E}+04$ & $2.50 \mathrm{E}+05$ & $2.28 \mathrm{E}+04$ \\
\hline 6 & $3.30 \mathrm{E}+06$ & $4.00 \mathrm{E}+04$ & $1.50 \mathrm{E}+04$ & $1.00 \mathrm{E}+03$ & $5.10 \mathrm{E}+04$ & $1.00 \mathrm{E}+03$ \\
\hline 8 & $1.11 \mathrm{E}+06$ & $2.55 \mathrm{E}+04$ & $1.20 \mathrm{E}+03$ & $3.00 \mathrm{E}+01$ & $1.26 \mathrm{E}+04$ & $9.00 \mathrm{E}+01$ \\
& $9.00 \mathrm{E}+05$ & $2.52 \mathrm{E}+04$ & $7.50 \mathrm{E}+02$ & $5.00 \mathrm{E}+01$ & $1.15 \mathrm{E}+04$ & $9.00 \mathrm{E}+01$ \\
\hline 10 & $1.02 \mathrm{E}+05$ & $3.70 \mathrm{E}+03$ & $2.40 \mathrm{E}+02$ & $3.66 \mathrm{E}+01$ & $1.50 \mathrm{E}+02$ & 16 \\
& $1.08 \mathrm{E}+05$ & $3.94 \mathrm{E}+03$ & $2.61 \mathrm{E}+02$ & $3.66 \mathrm{E}+01$ & $1.20 \mathrm{E}+02$ & 16 \\
\hline
\end{tabular}

Unit; CFU/ml

*EHEC refers to Escherichia coli $\mathrm{O} 157: \mathrm{H7}$

$* *$ Types of EHEC $i$ Form: Adherent to flocs = Flocs, Free-living = Supernatant

Types of EHEC Forms (Adherent to flocs = Flocs, Frec-living = Supernatant) t-Test: Two Samples Assuming Unequal Variance at $95 \%$ Confident Interval

\begin{tabular}{lll}
\hline \# EHEC in Buffer (10d) & Flocs & Supernatant \\
\hline Mean & $1.05 E+05$ & $3.82 E+03$ \\
Standard Deviation & $4.24 E+03$ & $1.70 E+02$ \\
Variance & $1.80 E+07$ & $2.88 E+04$ \\
Observations & 2 & 2 \\
Hypothesized Mean Difference & 0 & \\
df & 3 & \\
$P(T<=t)$ Two-tail & 0.01868560 & \\
$t$ Critical Two-tail & 4.176545190 & \\
$t$ Stats & 4.656503734 & \\
\hline
\end{tabular}


t-Test: Two Samples Assuming Unequal Variance at 95\% Confident Interval

\begin{tabular}{lll}
\hline \# EHEC in NSBR (10d) & Flocs & Supernatant \\
\hline Mean & $2.51 E+02$ & $3.66 E+01$ \\
Standard Deviation & $1.48 E+01$ & $0.00 E+00$ \\
Variance & $2.21 E+02$ & $0.00 E+00$ \\
Observations & 2 & 2 \\
Hypothesized Mean Difference & 0 & \\
df & 3 & \\
P(T<=t) Two-tail & 0.03122555 & \\
t Critical Two-tail & 4.176545190 & \\
t Stats & 3.836394171 & Supernatant \\
\hline & Not Significantly Different \\
\hline & & $1.60 E+01$ \\
\hline \# EHEC in SBR (10d) & Flocs & $0.00 E+00$ \\
\hline Mean & $1.35 E+02$ & $0.00 E+00$ \\
Standard Deviation & $2.12 E+01$ & 2 \\
Variance & $4.50 E+02$ & \\
Observations & 2 & \\
Hypothesized Mean Difference & 0 & \\
df & 3 & \\
P(T<=t) Two-tail & 0.07982519 & \\
t Critical Two-tail & 4.176545190 & \\
t Stats & 2.607957867 & \\
& Not Significantly Different
\end{tabular}

Types of Water Samples

\begin{tabular}{lll}
\hline \# EHEC in Flocs & Buffer & SBR \\
\hline Mean & $1.05 \mathrm{E}+05$ & $1.35 \mathrm{E}+02$ \\
Standard Deviation & $4.24 \mathrm{E}+03$ & $2.12 \mathrm{E}+01$ \\
Variance & $1.80 \mathrm{E}+07$ & $4.50 \mathrm{E}+02$ \\
Observations & 2 & 2 \\
Hypothesized Mean Difference & 0 & \\
df & 3 & \\
P(T<=t) Two-tail & 0.01820475 & \\
t Critical Two-tail & 4.176545190 & \\
t Stats & 4.701541911 & \\
\hline
\end{tabular}


t-Test: Two Samples Assuming Unequal Variance at 95\% Confident Interval

\begin{tabular}{lll}
\hline \# EHEC in Flocs & Buffer & NSBR \\
\hline Mean & $1.05 \mathrm{E}+05$ & $2.51 \mathrm{E}+02$ \\
Standard Deviation & $4.24 \mathrm{E}+03$ & $1.48 \mathrm{E}+01$ \\
Variance & $1.80 \mathrm{E}+07$ & $2.21 \mathrm{E}+02$ \\
Observations & 2 & 2 \\
Hypothesized Mean Difference & 0 & \\
df & 3 & \\
P(T<=t) Two-tail & 0.01822626 & \\
t Critical Two-tail & 4.176545190 & \\
t Stats & 4.699468263 & \\
\hline & Significantly Different \\
\hline & & SBR \\
\hline \# EHEC in Supernatant & Buffer & $1.60 \mathrm{E}+01$ \\
\hline Mean & $3.82 \mathrm{E}+03$ & $0.00 \mathrm{E}+00$ \\
Standard Deviation & $1.70 \mathrm{E}+02$ & $0.00 \mathrm{E}+00$ \\
Variance & $2.88 \mathrm{E}+04$ & 2 \\
Observations & 2 & \\
Hypothesized Mean Difference & 0 & \\
df & 3 & \\
P(T<=t) Two-tail & 0.02007598 & \\
t Critical Two-tail & 4.176545190 & \\
t Stats & 4.534304026 & \\
\hline & Significantly Different &
\end{tabular}

Significantly Different

Enumeration of EHEC adhered to EPS

\begin{tabular}{|c|c|c|c|}
\hline Day & BF & NSBR & SBR \\
\hline 4 & $1.52 E+06$ & $1.52 E+04$ & $3.04 E+04$ \\
& $1.83 E+06$ & $1.83 E+04$ & $3.66 E+04$ \\
\hline 6 & $9.00 E+04$ & $7.00 E+03$ & $4.00 E+03$ \\
\hline 8 & $6.25 E+04$ & $2.00 E+02$ & $8.90 E+02$ \\
& $6.25 E+04$ & $2.00 E+02$ & $1.03 E+03$ \\
\hline 10 & $6.80 E+03$ & 45 & 20 \\
& $6.00 E+03$ & 51 & 20 \\
\hline
\end{tabular}

Unit; CFU/ml 
Percentage of Adherent EHEC in EPS (10d)

$\therefore \quad \mathrm{t}$-Test: Two Samples Assuming Unequal Variance at $95 \%$ Confident Interval

\begin{tabular}{lll}
\hline \% Adherent EHEC in EPS & NSBR & SBR \\
\hline Mean & $1.92 E+01$ & $1.50 E+01$ \\
Standard Deviation & 1.669018 & 1.924501 \\
Variance & 2.785622 & 3.703704 \\
Observations & 2 & 2 \\
Hypothesized Mean Differènce & 0 & \\
df & 6 & \\
$P(T<=t)$ Two-tail & 0.01701995 & \\
$t$ Critical Two-tail & 2.968681656 & \\
t Stats & 3.27067 & \\
\hline
\end{tabular}

Significantly Different

\begin{tabular}{|c|c|c|}
\hline \% Adherent EHEC in EPS & Buffer & SBR \\
\hline$\overline{M e a n}$ & $6.10 E+00$ & $1.50 E+01$ \\
\hline Standard Deviation & 0.484229 & 1.924501 \\
\hline Variance & 0.234478 & 3.703704 \\
\hline Observations & 2 & 2 \\
\hline Hypothesized Mean Difference & 0 & \\
\hline df & 6 & \\
\hline$P(T<=t)$ Two-tail & 0.00180139 & - \\
\hline t Critical Two-tail & 2.968681656 & \\
\hline t Stats & 5.316397 & \\
\hline
\end{tabular}


APPENDIX G: Pathogenicity of Escherichia coli O157:H7 and Statistical Analysis

\begin{tabular}{|c|c|c|c|c|c|}
\hline \multirow{2}{*}{$\begin{array}{c}\text { Water } \\
\text { Samples }\end{array}$} & \multicolumn{3}{|c|}{ \# of Epithelial cells } & \multicolumn{2}{|c|}{$\%$} \\
\hline & Total & EHEC & $\alpha$-actinin & EHEC & $\alpha$-actinin \\
\hline Control 11 & 42 & 37 & 19 & 88.10 & 45.24 \\
\hline Control 12 & 43 & 32 & 10 & 74.42 & 23.26 \\
\hline Control_1_3 & 32 & 19 & 9 & 59.38 & 28.13 \\
\hline Control 14 & 31 & 21 & 8 & 67.74 & 25.81 \\
\hline Control 15 & 30 & 24 & 9 & 80.00 & 30.00 \\
\hline Control 1 & 52 & 30 & 10 & 57.69 & 19.23 \\
\hline Control 2 & 63 & 49 & 15 & 77.78 & 23.81 \\
\hline Control 3 & 52 & 28 & 12 & 53.85 & 23.08 \\
\hline Control 4 & 39 & 38 & 13 & 97.44 & 33.33 \\
\hline $2 B F 1$ & 58 & 9 & 3 & 15.52 & 5.17 \\
\hline $2 B F 2$ & 77 & 20 & 8 & 25.97 & 10.39 \\
\hline 2 BF 3 & 81 & 16 & 4 & 19.75 & 4.94 \\
\hline $2 B F 11$ & 45 & 4 & 0 & 8.89 & 0.00 \\
\hline $2 \mathrm{BF} 12$ & 37 & 11 & 3 & 29.73 & 8.11 \\
\hline 2. BF 13 & 26 & 6 & 1 & 23.08 & 3.85 \\
\hline 2 BS 1 & 62 & 9 & 4 & 14.52 & 6.45 \\
\hline 2_BS_ 2 & 60 & 5 & 1 & 8.33 & 1.67 \\
\hline 2 BS 3 & 78 & 8 & 2 & 10.26 & 2.56 \\
\hline 2 BS 11 & 56 & 13 & 2 & 23.21 & 3.57 \\
\hline 2 BS 12 & 73 & 10 & 6 & 13.70 & 8.22 \\
\hline 2 BS 13 & 58 & 14 & 1 & 24.14 & 1.72 \\
\hline 2 SF 31 & 33 & 15 & 4 & 45.45 & 12.12 \\
\hline $2 S F 32$ & 7 & 5 & 1 & 71.43 & 14.29 \\
\hline 2 SF 33 & 32 & 17 & 3 & 53.13 & 9.38 \\
\hline $2 S F 1$ & 89 & 7 & 2 & 7.87 & 2.25 \\
\hline 2 SF 2 & 95 & 8 & 2 & 8.42 & 2.11 \\
\hline 2 SF 3 & 34 & 14 & 6 & 41.18 & 17.65 \\
\hline 2 SS 11 & 17 & 9 & 3 & 52.94 & 17.65 \\
\hline 2 SS 12 & 32 & 15 & 3 & 46.88 & 9.38 \\
\hline 2 SS 13 & 43 & 14 & 3 & 32.56 & 6.98 \\
\hline 2 SS 1 & 81 & 14 & 2 & 17.28 & 2.47 \\
\hline 2 SS 2 & 78 & 8 & 2. & 10.26 & 2.56 \\
\hline 2 SS 3 & 51 & 14 & 1 & 27.45 & 1.96 \\
\hline $10 \mathrm{BF} 11$ & 43 & 26 & 13 & 60.47 & 30.23 \\
\hline $10 \mathrm{BF} 12$ & 44 & 19 & 8 & 43.18 & 18.18 \\
\hline $10 \mathrm{BF} 13$ & 82 & 28 & 14 & 34.15 & 17.07 \\
\hline $10 \mathrm{BF} 1$ & 45 & 25 & 7 & 55.56 & 15.56 \\
\hline 10_BF 2 & 52 & 29 & 12 & 55.77 & 23.08 \\
\hline $10 \mathrm{BF} 3$ & 63 & 23 & 6 & 36.51 & 9.52 \\
\hline $10 \mathrm{BF} 4$ & 53 & 35 & 10 & 66.04 & 18.87 \\
\hline $10 \mathrm{BS}$ & 33 & 14 & 6 & 42.42 & 18.18 \\
\hline $10 \mathrm{BS} 2$ & 43 & 12 & 5 & 27.91 & 11.63 \\
\hline $10 \mathrm{BS} 3$ & 63 & 13 & 4 & 20.63 & 6.35 \\
\hline
\end{tabular}




\begin{tabular}{|c|c|c|c|c|c|}
\hline Water & \multicolumn{3}{|c|}{ \# of Epithelial cells } & \multicolumn{2}{c|}{$\%$} \\
\cline { 2 - 6 } Samples & Total & EHEC & $\alpha$-actinin & EHEC & $\alpha$-actinin \\
\hline 10 BS 2 1 & 49 & 28 & 16 & 57.14 & 32.65 \\
\hline 10 BS 2 3 & 50 & 22 & 8 & 44.00 & 16.00 \\
\hline 10 NF 1 & 52 & 27 & 10 & 51.92 & 19.23 \\
\hline 10 NF 2 & 37 & 24 & 9 & 64.86 & 24.32 \\
\hline 10 NF 3 & 63 & 41 & 13 & 65.08 & 20.63 \\
\hline 10 NF 4 & 56 & 25 & 11 & 44.64 & 19.64 \\
\hline 10 NF 2 1 & 20 & 12 & 2 & 60.00 & 10.00 \\
\hline 10 NF_2 2 & 43 & 11 & 3 & 25.58 & 6.98 \\
\hline 10 NF_2 3 & 44 & 17 & 5 & 38.64 & 11.36 \\
\hline 10 NF 2 4 & 16 & 10 & 2 & 62.50 & 12.50 \\
\hline 10 NS 1 & 57 & 39 & 15 & 68.42 & 26.32 \\
\hline 10 NS 2 & 77 & 43 & 8 & 55.84 & 10.39 \\
\hline 10 NS 3 & 65 & 26 & 9 & 40.00 & 13.85 \\
\hline 10 NS 2 1 & 40 & 7 & 5 & 17.50 & 12.50 \\
\hline 10 NS 2 2 & 57 & 10 & 2 & 17.54 & 3.51 \\
\hline 10 NS 2 3 & 36 & 14 & 3 & 38.89 & 8.33 \\
\hline 10 SF 1 & 31 & 25 & 8 & 80.65 & 25.81 \\
\hline 10 SF 2 & 51 & 29 & 11 & 56.86 & 21.57 \\
\hline 10 SF 3 & 64 & 45 & 17 & 70.31 & 26.56 \\
\hline 10 SF 4 & 55 & 33 & 12 & 60.00 & 21.82 \\
\hline 10 SF 2 1 & 48 & 33 & 8 & 68.75 & 16.67 \\
\hline 10 SF 2 2 & 43 & 6 & 3 & 13.95 & 6.98 \\
\hline 10 SS 1 & 34 & 23 & 11 & 67.65 & 32.35 \\
\hline 10 SS 2 & 33 & 17 & 6 & 51.52 & 18.18 \\
\hline 10 SS 3 & 50 & 28 & 13 & 56.00 & 26.00 \\
\hline 10 SS 4 & 38 & 25 & 7 & 65.79 & 18.42 \\
\hline 10 SS 2 1 & 34 & 10 & 3 & 29.41 & 8.82 \\
\hline 10 SS 2 2 & 25 & 10 & 1 & 40.00 & 4.00 \\
\hline
\end{tabular}

Some examples of statistical analyses wcre shown bclow.

\section{Effect of EHEC type on Adherence}

t-Test: Two Samples Assuming Unequal Variance at $95 \%$ Confident interval

\begin{tabular}{lll}
\hline 2d_Buffer & Flocs & Supernatant \\
\hline Mean & 20.14 & 15.39 \\
Standard Deviation & 10.417109 & 6.587417 \\
Variance & 56.399293 & 43.39407 \\
Observations & 2 & 2 \\
Hypothesized Mean Difference & 0 & \\
df & 10 & \\
$P(T<=t)$ Two-tail & 0.26717309 & \\
$t$ Critical Two-tail & 2.6337693 & \\
t Stats & 1.1751069 & \\
\hline
\end{tabular}

Not Significantly Different 
t-Test: Two Samples Assuming Unequal Variance at 95\% Confident interval

\begin{tabular}{lll}
\hline 2d_SBR & Flocs & Supernatant \\
\hline Mean & 13.30 & 17.14 \\
Standard Deviation & 19.073844 & 8.644922 \\
Variance & 363.81154 & 74.73468 \\
Observations & 1 & 1 \\
Hypothesized Mean Difference & 0 & \\
df & 4 & \\
P(T<=t) Two-tail & 0.95026639 & \\
t Critical Two-tail & 3.4954064 & \\
t Stats & 0.0663726 \\
\hline
\end{tabular}

Not significantly Different

\begin{tabular}{lll}
\hline 10d_Buffer & Flocs & Supernatant \\
\hline Mean & 50.237676 & 38.94124 \\
Standard Deviation & 12.317618 & 12.9046 \\
Variance & 151.72372 & 166.5286 \\
Observations & 2 & 2 \\
Hypothesized Mean Difference & 0 & \\
df & 11 & \\
P(T<=t) Two-tail & 0.13769423 & \\
t Critical Two-tail & 2.5930967 & \\
t Stats & 1.6009426 & \\
\hline & Not Significantly Different \\
\hline & & \\
\hline 10d_NSBR & Flocs & Supernatant \\
\hline Mean & 51.65349 & 39.69966 \\
Standard Deviation & 14.345367 & 20.34706 \\
Variance & 205.78956 & 414.003 \\
Observations & 2 & 2 \\
Hypothesized Mean Difference & 0 & \\
df & 12 & \\
P(T<=t) Two-tail & 0.25201783 & \\
t Critical Two-tail & 2.5600275 & \\
t Stats & 1.2034207 & \\
\hline & Not Significantly Different \\
\hline
\end{tabular}


$\mathrm{t}$-Test: Two Samples Assuming Unequal Variance at 95\% Confident Interval

\begin{tabular}{lll}
\hline 10d_SBR & Flocs & Supernatant \\
\hline Mean & 66.955102 & 60.23792 \\
Standard Deviation & 10.784541 & 10.78454 \\
Variance & 116.30632 & 116.3063 \\
Observations & 1 & 1 \\
Hypothesized Mean Difference & 0 & \\
df & 6 & \\
P(T<=t) Two-tail & 0.35439084 \\
t Critical Two-tail & 2.9686817 & \\
t Stats & 1.0034273 & \\
\hline
\end{tabular}

Effect of Water Samples on Adherence

\begin{tabular}{lll}
\hline 2d_Flocs & Buffer & SBR \\
\hline Mean & 20.138889 & 13.30275 \\
Standard Deviation & 10.417109 & 19.07384 \\
Variance & 56.399293 & 363.8115 \\
Observations & 2 & 1 \\
Hypothesized Mean Difference & 0 & \\
df & 7 & \\
P(T<=t) Two-tail & 0.91633809 & \\
t Critical Two-tail & 2.8412433 & \\
t Stats & 0.1088995 & \\
\hline & Not Significantly Different \\
\hline & & \\
\hline 2d_Supernatant & Buffer & SBR \\
\hline Mean & 15.393048 & 17.14286 \\
Standard Deviation & 6.5874173 & 8.644922 \\
Variance & 43.394067 & 74.73468 \\
Observations & 2 & 1 \\
Hypothesized Mean Difference & 0 & \\
df & 7 & \\
P(T<=t) Two-tail & 0.67142806 & \\
t Critical Two-tail & 2.8412433 & \\
t Stats & 0.4425715 & \\
\hline & Not Significantly Different \\
\hline
\end{tabular}


t-Test: Two Samples Assuming Unequal Variance at 95\% Confident Interval

\begin{tabular}{lll}
\hline 10d_Flocs & Buffer & NSBR \\
\hline Mean & 50.237676 & 51.65349 \\
Standard Deviation & 12.317618 & 14.34537 \\
Variance & 151.72372 & 205.7896 \\
Observations & 2 & 2 \\
Hypothesized Mean Difference & 0 & \\
df & 7 & \\
P(T<=t) Two-tail & 0.24644567 & \\
t Critical Two-tail & 2.8412433 & \\
t Stats & 1.2647286 & \\
\hline & Not Significantly Different \\
\hline & & \\
\hline 10d_Supernatant & Buffer & NSBR \\
\hline Mean & 38.941243 & 39.69966 \\
Standard Deviation & 12.904597 & 20.34706 \\
Variance & 166.52862 & 414.003 \\
Observations & 2 & 2 \\
Hypothesized Mean Difference & 0 & \\
df & 10 & \\
P(T<=t) Two-tail & 0.94033377 & \\
t Critical Two-tail & 2.6337693 & \\
t Stats & 0.0767534 & \\
\hline
\end{tabular}

\section{Not Significantly Different}

\begin{tabular}{lll}
\hline 10d_Flocs & SBR & NSBR \\
\hline Mean & 66.955102 & 51.65349 \\
Standard Deviation & 10.784541 & 14.34537 \\
Variance & 116.30632 & 205.7896 \\
Observations & 1 & 2 \\
Hypothesized Mean Difference & 0 & \\
df & 10 & \\
P(T<=t) Two-tail & 0.07265310 & \\
t Critical Two-tail & 2.6337693 & \\
t Stats & 2.0060361 & \\
\hline
\end{tabular}


t-Test: Two Samples Assuming Unequal Variance at 95\% Confident Interval

\begin{tabular}{lll}
\hline 10d_Supernatant & SBR & NSBR \\
\hline Mean & 60.237921 & 39.69966 \\
Standard Deviation & 10.784541 & 20.34706 \\
Variance & 116.30632 & 414.003 \\
Observations & 1 & 2 \\
Hypothesized Mean Difference & 0 & \\
df & 8 & \\
P(T<=t) Two-tail & 0.06069796 & \\
t Critical Two-tail & 2.7515307 & \\
t Stats & 2.1817368 & \\
\hline
\end{tabular}

Effect of Incubation Period on Adherence

\begin{tabular}{lll}
\hline PBS_Flocs & $2 d$ & $10 d$ \\
\hline Mean & 20.138889 & 50.23768 \\
Standard Deviation & 10.417109 & 12.31762 \\
Variance & 56.399293 & 151.7237 \\
Observations & 2 & 2 \\
Hypothesized Mean Difference & 0 & \\
df & 11 & \\
P(T<=t) Two-tail & 0.00032312 & \\
$t$ Critical Two-tail & 2.5930967 & \\
t Stats & 5.1397365 & \\
\hline & Significantly Different \\
\hline & & \\
\hline SBR_Flocs & $2 d$ & $10 d$ \\
\hline Mean & 13.302752 & 66.9551 \\
Standard Deviation & 19.073844 & 10.78454 \\
Variance & 363.81154 & 116.3063 \\
Observations & 1 & 1 \\
Hypothesized Mean Difference & 0 & \\
df & 5 & \\
P(T<=t) Two-tail & 0.03067447 \\
$t$ Critical Two-tail & 3.1633863 \\
$t$ Stats & 2.9835428 \\
\hline & Not Significantly Different \\
\hline
\end{tabular}


t-Test: Two Samples Assuming Unequal Variance àt 95\% Confident Interval

\begin{tabular}{lll}
\hline PBS_Supernatant & $2 \mathrm{~d}$ & $10 \mathrm{~d}$ \\
\hline Mean & 15.393048 & 38.94124 \\
Standard Deviation & 6.5874173 & 12.9046 \\
Variance & 43.394067 & 166.5286 \\
Observations & 2 & 2 \\
Hypothesized Mean Difference & 0 & \\
df & 11 & \\
P(T<=t) Two-tail & 0.00502587 & \\
t Critical Two-tail & 2.5930967 & \\
t Stats & 3.4936966 \\
\hline & Significantly Different \\
\hline & & \\
\hline SBR_Supernatant & $2 d$ & $10 d$ \\
\hline Mean & 17.142857 & 60.23792 \\
Standard Deviation & 8.644922 & 10.78454 \\
Variance & 74.734677 & 116.3063 \\
Observations & 1 & 1 \\
Hypothesized Mean Difference & 0 & \\
df & 5 & \\
P(T<=t) Two-tail & 0.00238400 \\
t Critical Two-tail & 3.1633863 \\
t Stats & 5.6647696 \\
\hline & Significantly Different \\
\hline
\end{tabular}

t-Test: Two Samples Assuming Unequal Variance at 95\% Confident Interval

\begin{tabular}{lll}
\hline adherence & Control & 2_BF \\
\hline Mean & 72.931435 & 20.48998 \\
df & 13 & \\
$P(T<=t)$ Two-tail & 0.00000074 & \\
$t$ Critical Two-tail & 2.5326335 & \\
$t$ Stats & 8.9406967 & \\
\hline & Significantly Different \\
\hline
\end{tabular}


t-Test: Two Samples Assuming Unequal Variance at 95\% Confident Interval

\begin{tabular}{|c|c|c|}
\hline adherence & Control & 10 SF \\
\hline Mean & 72.931435 & 66.9551 \\
\hline df & 11 & \\
\hline$P(T<=t)$ Two-tail & 0.43514873 & \\
\hline t Critical Two-tail & 2.59309672 & \\
\hline \multirow[t]{2}{*}{ t Stats } & 0.80993573 & \\
\hline & \multicolumn{2}{|c|}{ Not Significantly Differen } \\
\hline adherence & Control & 10 SS \\
\hline Mean & 72.931435 & 60.23792 \\
\hline df & 11. & \\
\hline$P(T<=t)$ Two-tail & 0.06793376 & \\
\hline t Critical Two-tail & 2.59309672 & \\
\hline \multirow[t]{2}{*}{ t Stats } & 2.02412139 & \\
\hline & \multicolumn{2}{|c|}{ Not Significantly Different } \\
\hline
\end{tabular}

\section{Effect of EHEC type on $\alpha$-Accumulation}

t-Test: Two Samples Assuming Unequal Variance at 95\% Confident Interval

\begin{tabular}{lll}
\hline 2d_Buffer & Flocs & Supernatant \\
\hline Mean & 5.409093 & 4.032854 \\
Standard Deviation & 3.2372704 & 2.708315 \\
Variance & 12.813798 & 7.334972 \\
Observations & 2 & 2 \\
Hypothesized Mean Difference & 0 & \\
df & 10 & \\
P(T<=t) Two-tail & 0.47120019 & \\
t Critical Two-tail & 2.6337693 & \\
t Stats & 0.7488404 & \\
\hline
\end{tabular}


$\mathrm{t}$-Test: Two Samples Assuming Unequal Variance at $95 \%$ Confident Interval

\begin{tabular}{lll}
\hline 2d_SBR & Flocs & Supernatant \\
\hline Mean & 7.333171 & 2.331341 \\
Standard Deviation & 8.9323708 & 0.324405 \\
Variance & 79.787247 & 0.105239 \\
Observations & 1 & 1 \\
Hypothesized Mean Difference & 0 & \\
df & 4 & \\
$P(T<=t)$ Two-tail & 0.43443752 & \\
$t$ Critical Two-tail & 3.4954064 & \\
$\mathrm{t}$ Stats & 0.867858 & \\
\hline
\end{tabular}

Significantly Different

\begin{tabular}{lll}
\hline 10d_Buffer & Flocs & Supernatant \\
\hline Mean & 18.930251 & 20.54559 \\
Standard Deviation & 6.4397144 & 12.44897 \\
Variance & 41.469922 & 154.9769 \\
Observations & 2 & 2 \\
Hypothesized Mean Difference & 0 & \\
df & 11 & \\
P(T<=t) Two-tail & 0.78240464 & \\
t Critical Two-tail & 2.5930967 & \\
t Stats & 0.2830359 & \\
\hline & Not Significantly Different \\
\hline & & \\
\hline 10d_NSBR & Flocs & Supernatant \\
\hline Mean & 15.584156 & 12.48228 \\
Standard Deviation & 6.1442976 & 7.685614 \\
Variance & 37.752393 & 59.06866 \\
Observations & 2 & 2 \\
Hypothesized Mean Difference & 0 & \\
df & 12 & \\
P(T<=t) Two-tail & 0.43643150 & \\
t Critical Two-tail & 2.5600275 & \\
t Stats & 0.805087 \\
\hline & Not Significantly Different \\
\hline
\end{tabular}


Effect of Water Samples on $\alpha$-Accumulation

t-Test: Two Samples Assuming Unequal Variance at $95 \%$ Confident Interval

\begin{tabular}{lll}
\hline 2d_Flocs & Buffer & SBR \\
\hline Mean & 5.409093 & 7.333171 \\
Standard Deviation & 3.2372704 & 8.932371 \\
Variance & 12.813798 & 79.78725 \\
Observations & 2 & 1 \\
Hypothesized Mean Difference & 0 & \\
df & 7 & \\
P(T<=t) Two-tail & 0.74961931 \\
$\mathrm{t}$ Critical Two-tail & 2.8412433 \\
$\mathrm{t}$ Stats & 0.3319855 \\
\hline
\end{tabular}

\begin{tabular}{lll}
\hline & & \\
\hline 2d_Supernatant & Buffer & SBR \\
\hline Mean & 4.0328545 & 2.331341 \\
Standard Deviation & 2.7083154 & 0.324405 \\
Variance & 7.3349721 & 0.105239 \\
Observations & 2 & 1 \\
Hypothesized Mean Difference & 0 & \\
df & 7 & \\
P(T<=t) Two-tail & 0.18658831 & \\
t Critical Two-tail & 2.8412433 & \\
t Stats & 1.4640591 & \\
\hline & Not Significantly Different \\
\hline & & \\
\hline 10d_Flocs & SBR & NSBR \\
\hline Mean & 23.93894 & 15.58416 \\
Standard Deviation & 2.6132141 & 6.144298 \\
Variance & 6.8288878 & 37.75239 \\
Observations & 1 & 2 \\
Hypothesized Mean Difference & 0 & \\
df & 10 & \\
P(T<=t) Two-tail & 0.00813090 & \\
$t$ Critical Two-tail & 2.6337693 & \\
t Stats & 3.2913886 \\
\hline & Significantly Different \\
\hline
\end{tabular}




\begin{tabular}{lll}
\hline 10d_Supernatant & SBR & NSBR \\
\hline Mean & 23.738953 & 12.48228 \\
Standard Deviation & 2.6132141 & 7.685614 \\
Variance & 6.8288878 & 59.06866 \\
Observations & 1 & 2 \\
Hypothesized Mean Difference & 0 & \\
df & 8 & \\
$P(T<=t)$ Two-tail & 0.04433106 & \\
$t$ Critical Two-tail & 2.7515307 & \\
t Stats & 2.3830944 \\
\hline
\end{tabular}

Effect of Incubation Period on $\alpha$-Accumulation

t-Test: Two Samples Assuming Unequal Variance at $95 \%$ Confident Interval

\begin{tabular}{lll} 
PBS_Flocs & $2 \mathrm{~d}$ & $10 \mathrm{~d}$ \\
\hline Mean & 5.409093 & 18.93025 \\
Standard Deviation & 3.2372704 & 6.439714 \\
Variance & 12.813798 & 41.46992 \\
Observations & 2 & 2 \\
Hypothesized Mean Difference & 0 & \\
df & 11 & \\
$\mathrm{P}(T<=t)$ Two-tail & 0.00085561 & \\
$\mathrm{t}$ Critical Two-tail & 2.5930967 & \\
t Stats & 4.5314664 & \\
\hline
\end{tabular}

Significantly Different

\begin{tabular}{lll}
\hline PBS_Supernatant & $2 \mathrm{~d}$ & $10 \mathrm{~d}$ \\
\hline Mean & 4.0328545 & 20.54559 \\
Standard Deviation & 2.7083154 & 12.44897 \\
Variance & 7.3349721 & 154.9769 \\
Observations & 2 & 2 \\
Hypothesized Mean Difference & 0 & \\
df & 11 & \\
P(T<=t) Two-tail & 0.02178365 & \\
$t$ Critical Two-tail & 2.5930967 & \\
t Stats & 2.6702673 & \\
\hline
\end{tabular}


t-Test: Two Samples Assuming Unequal Variance at 95\% Confident Interval

\begin{tabular}{|c|c|c|}
\hline SBR_Supernatant & $2 d$ & $10 \mathrm{~d}$ \\
\hline Mean & 2.3313409 & 23.73895 \\
\hline Standard Deviation & 0.3244053 & 2.613214 \\
\hline Variance & 0.1052388 & 6.828888 \\
\hline Observations & 1 & 1 \\
\hline Hypothesized Mean Difference & 0 & \\
\hline$d f$ & 5 & \\
\hline$P(T<=t)$ Two-tail & 0.00796244 & \\
\hline t Critical Two-tail & 3.1633863 & \\
\hline \multirow{2}{*}{ Stats } & 4.2669126 & \\
\hline & \multicolumn{2}{|c|}{ Significantly Different } \\
\hline$\alpha$-actinin & Control & $2 S F$ \\
\hline Mean & 27.986212 & 7.333171 \\
\hline df & 10 & \\
\hline$P(T<=t)$ Two-tail & 0.03581331 & \\
\hline t Critical Two-tail & 2.6337693 & \\
\hline \multirow[t]{2}{*}{ t Stats } & 2.4240398 & \\
\hline & \multicolumn{2}{|c|}{ Not Significantly Different - } \\
\hline$\alpha$-actinin & Control & $10 S F$ \\
\hline Observations & 27.9862123 & 23.93894 \\
\hline$d f$ & 11 & \\
\hline$P(T<=t)$ Two-tail & 0.18861481 & \\
\hline t Critical Two-tail & 2.59309672 & \\
\hline \multirow[t]{2}{*}{ t Stats } & 1.40159955 & \\
\hline & \multicolumn{2}{|c|}{ Not Significantly Different } \\
\hline$\alpha$-actinin & Control & 10 SS \\
\hline Mean & 27.9862123 & 23.73895 \\
\hline df & 11 & \\
\hline$P(T<=t)$ Two-tail & 0.35384203 & \\
\hline t Critical Two-tail & 2.59309672 & \\
\hline \multirow[t]{2}{*}{ t Stats } & 0.96800932 & \\
\hline & \multicolumn{2}{|c|}{ Not Significantly Different } \\
\hline
\end{tabular}




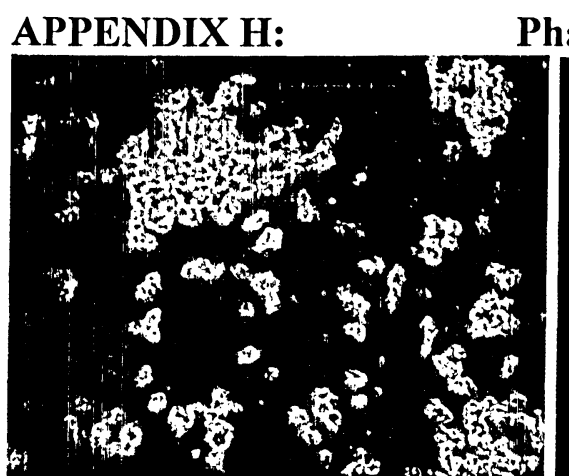

(a)

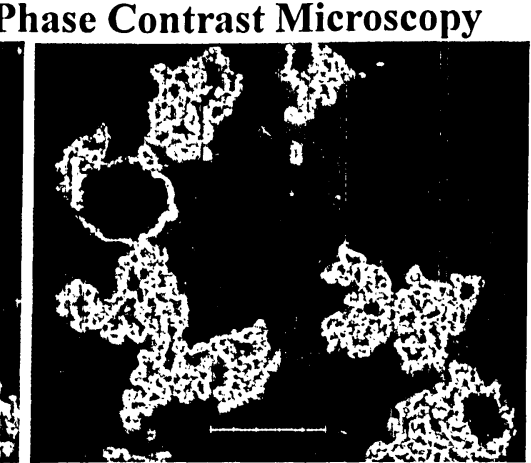

(b)

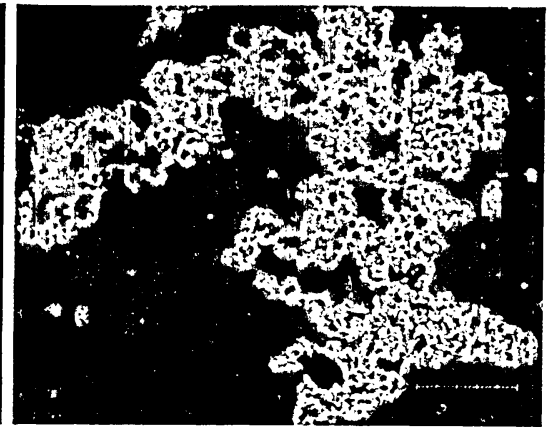

(c)

\section{EDTA treated flocs.}

Floc sample was treated with $1000 \mu \mathrm{g} / \mathrm{ml}$ EDTA for $105 \mathrm{~min}$ (4 EDTA washings).

Flocs were observed under phase contrast $\times 100$. Scale bar $=250 \mu \mathrm{m}$.

Most flocs were completely deflocculated into irregular and diffused flocs by EDTA (a), however, some flocs were dissociated to smaller flocs that became a size of EPS (b). Note that flocs contained dominant EPS areas (dark areas). In addition, large flocs were also observed (c).
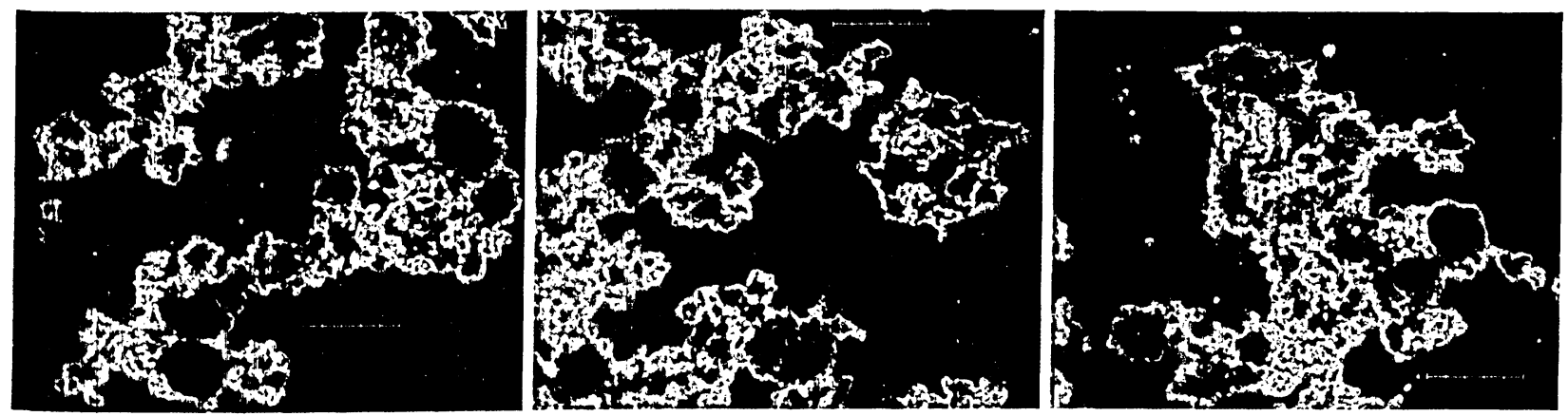

Control

Floc sample was treated with $0.1 \mathrm{M}$ PBS for 105 min (4 PBS washings).

Flocs were observed under phase contrast $\times 100$. Scale bar $=250 \mu \mathrm{m}$.

Rounded and firm Control flocs with dominant EPS area were observed. 


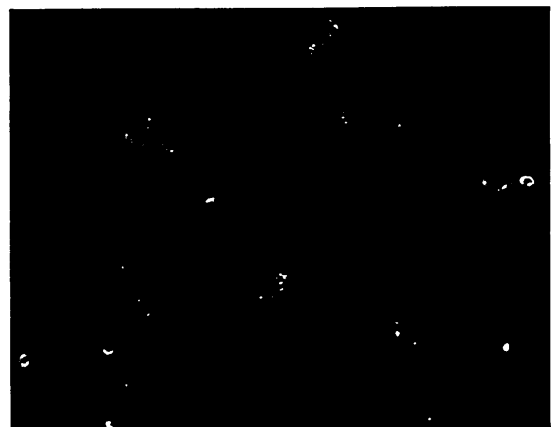

(a)

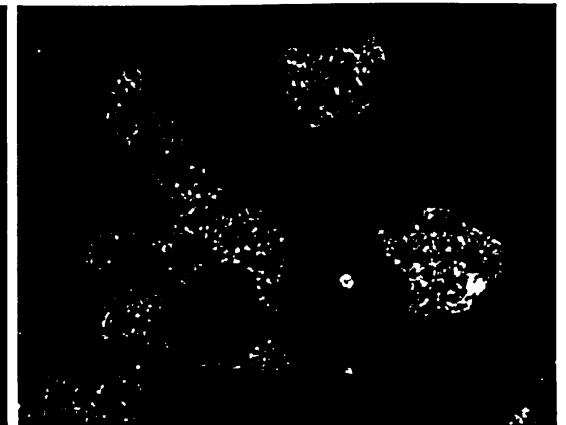

(b)

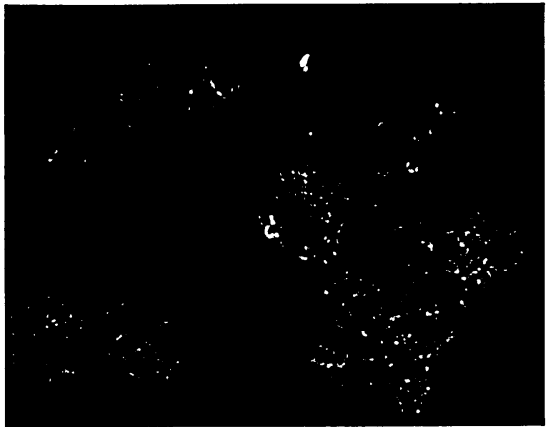

(c)

EDTA-proteinase $\mathrm{K}$ treated flocs

Flocs were observed under phase contrast $\times 100$. Scale bar $=250 \mu \mathrm{m}$.

Similar to EDTA treated flocs, most flocs were completely deflocculated into irregular and diffused flocs (a) however, some flocs dissociated into smaller flocs that were approximately the size of EPS in the original flocs (b and $c$ ). Note that those flocs contained dominant EPS areas (dark areas). Furthermore, some flocs appear to be composed of branches of dense EPS areas (c).

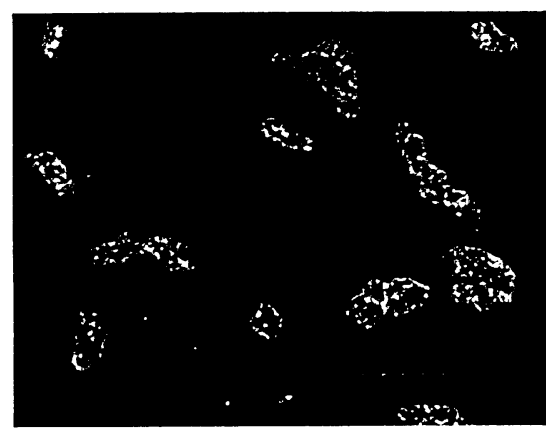

(a)

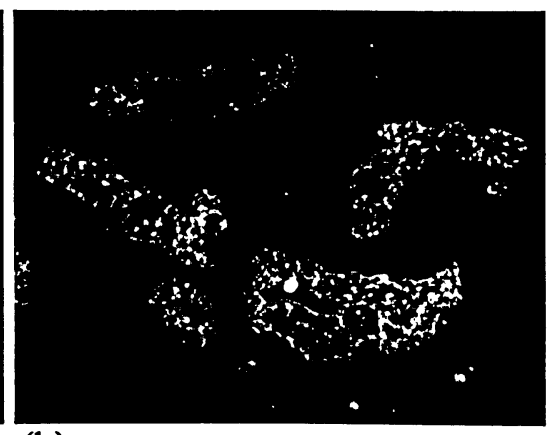

(b)

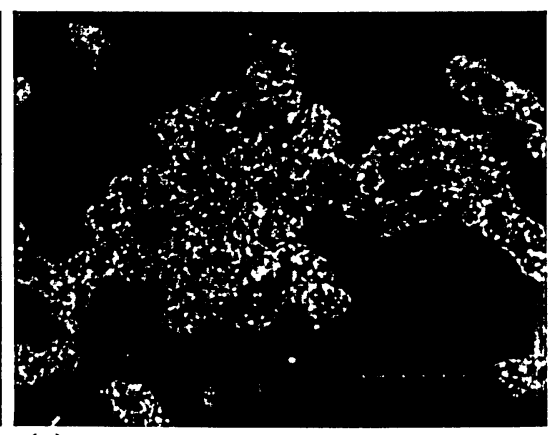

(c)

EDTA-pronase $\mathrm{E}$ treated flocs

Flocs were observed under phase contrast $\times 100$. Scale bar $=250 \mu \mathrm{m}$.

Similar to EDTA treated flocs, most flocs were completely deflocculated into irregular and diffused flocs (a) however, some flocs dissociated into smaller flocs that were approximately the size of EPS in the original flocs (b and $d$ ). Note that those flocs contained dominant EPS areas (dark areas). 


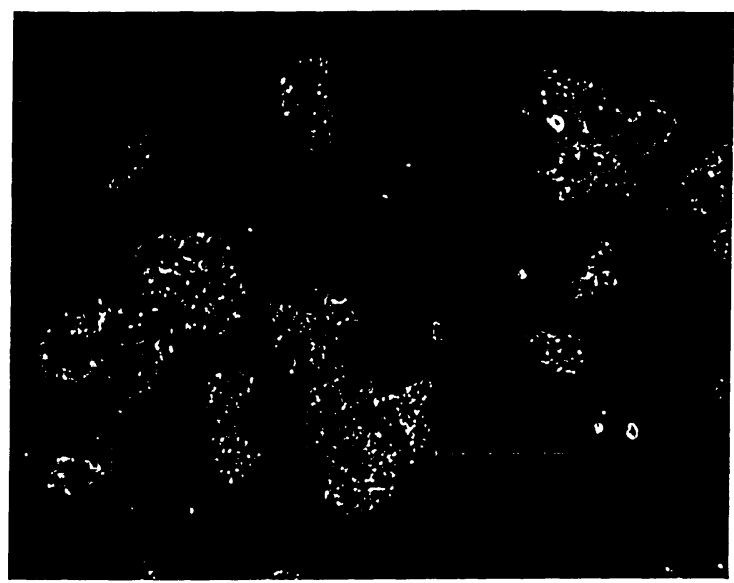

(a)

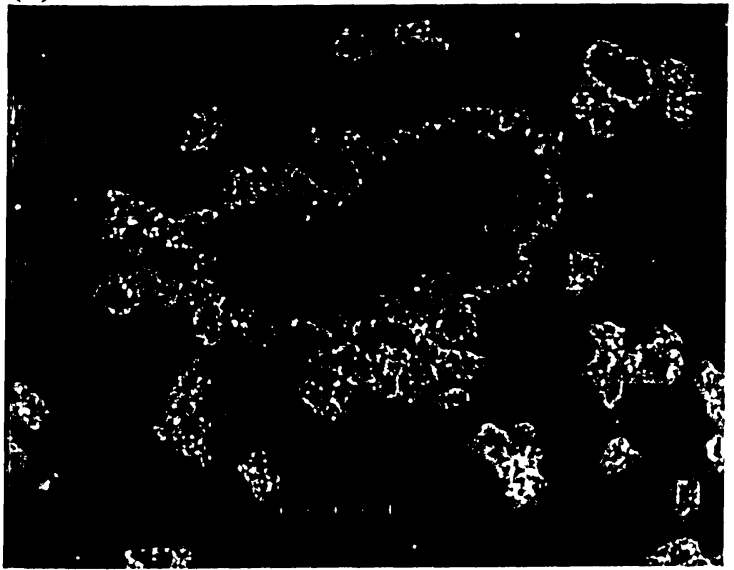

(b)

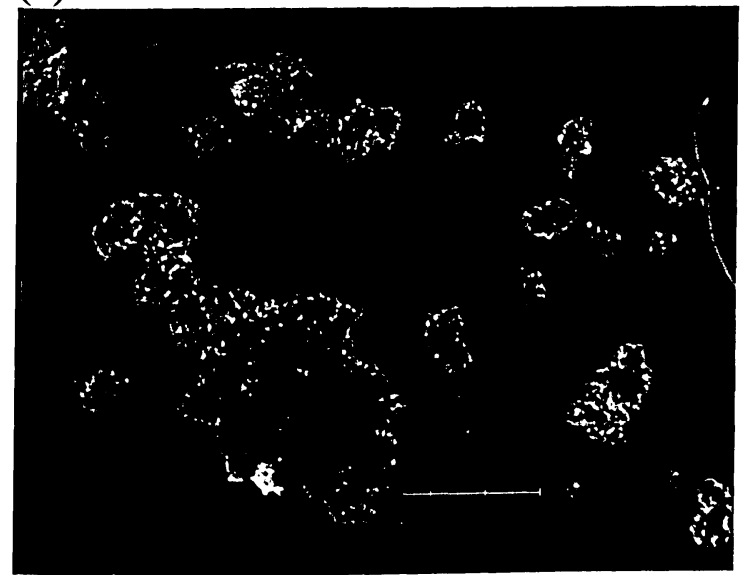

(c)

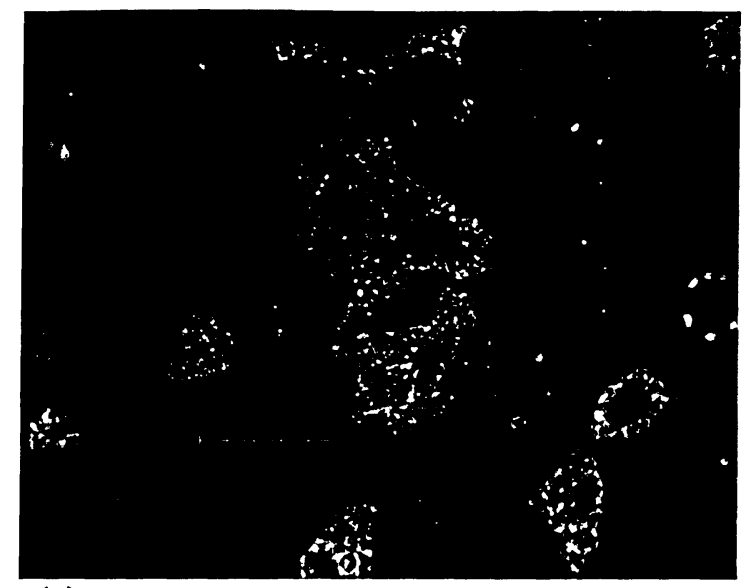

(a)

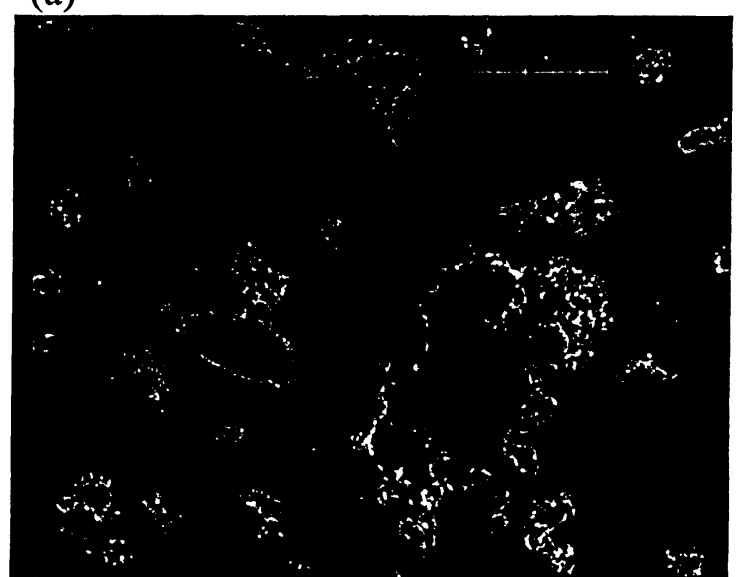

(b)

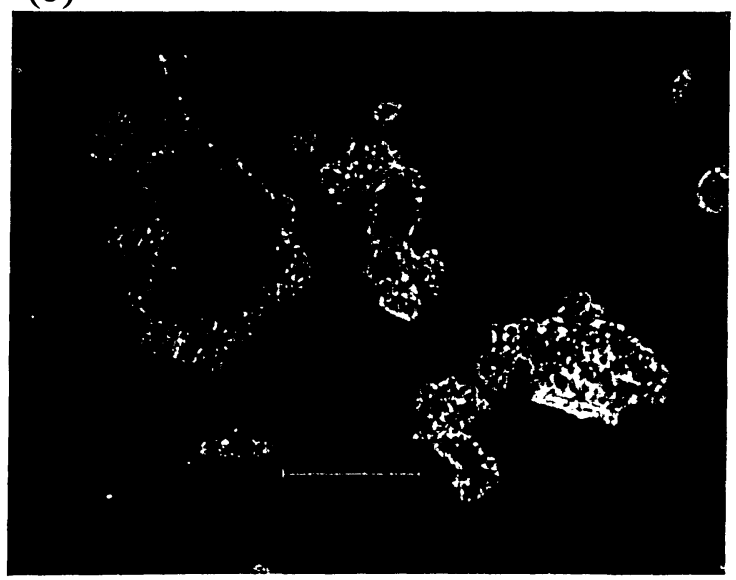

(c)

Flocs incubated with EHEC on 10-day incubation

$10^{8} \mathrm{CFU} / \mathrm{ml} E$. coli $0157: \mathrm{H} 7$ (EHEC) was inoculated and incubation with flocs suspended in (a) PBS buffer, (b) nutrients replenished SBR (NSBR, nutrients were added on 2-, 5-, and 7-day incubation) and (c) SBR. Flocs were observed under phase contrast x 100. Scale bar $=250 \mu \mathrm{m}$. Note that NSBR has more distinct EPS areas than the other two. 
APPENDIX I:

CLSM analysis

EPS Mapping

EPS Distribution-Nucleic Acids, Lipid-Hydrophobic Sites and Proteins
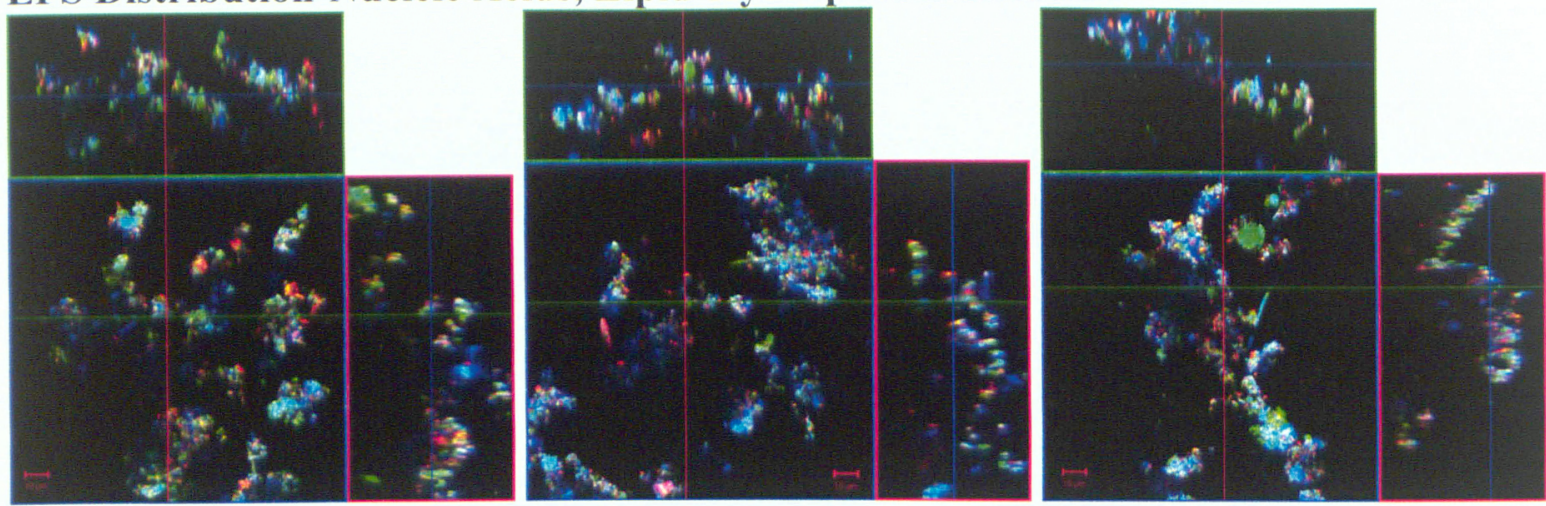

(a) EDTA treated flocs
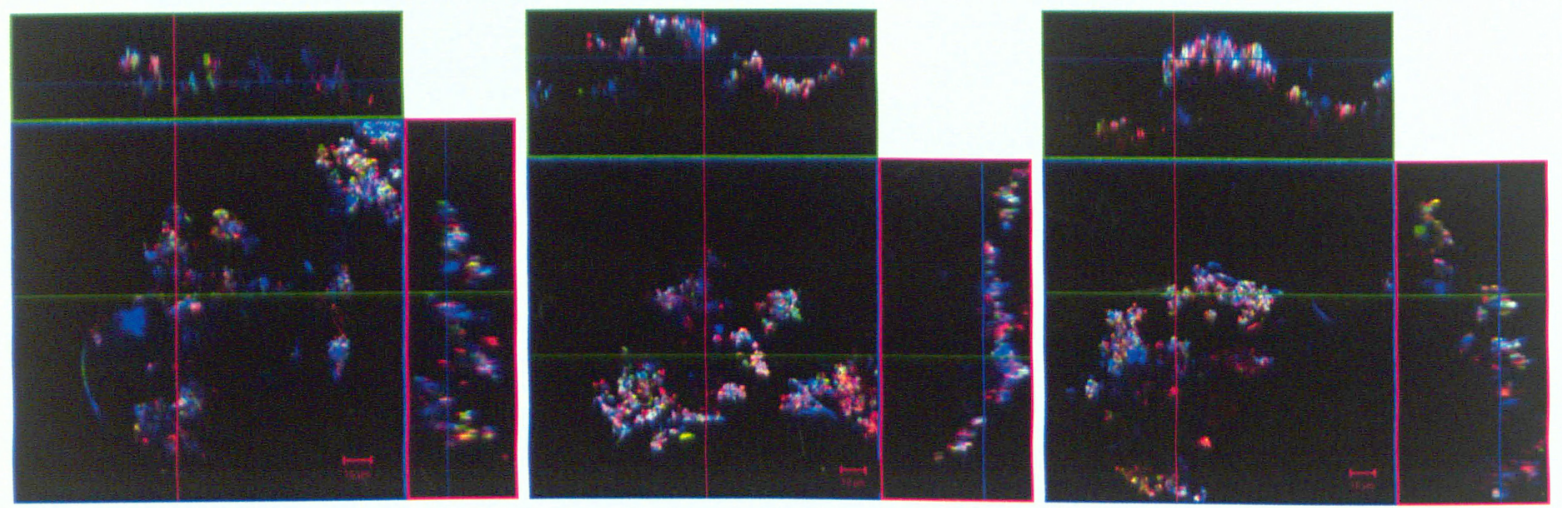

(b) Control flocs
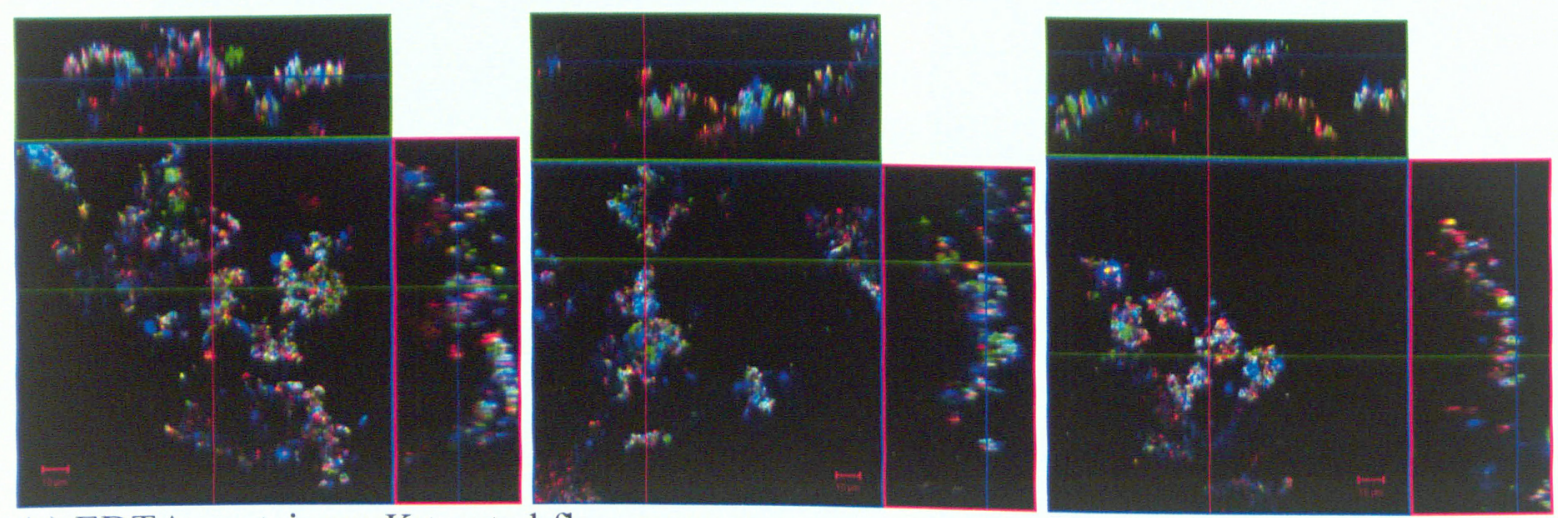

(c) EDTA-proteinase K treated flocs

Flocs were treated with $1000 \mu \mathrm{g} / \mathrm{ml}$ EDTA (a) or EDTA followed by $200 \mu \mathrm{g} / \mathrm{ml}$ proteinase K (c). Control flocs (b) and treated flocs were then stained with Syto 61 (nucleic acids, blue), Nile Red (lipid-hydrophobic sites, red) and SyproOrange (proteins, green). CLSM orthogonal micrographs are shown at z plane $(\mathrm{a})=36,32,24 \mu \mathrm{m},(\mathrm{b})=26,20,20 \mu \mathrm{m}$ and $(\mathrm{c})=24,20,14 \mu \mathrm{m}$. Scale bar $=$ $10 \mu \mathrm{m}$ 


\section{EPS Distribution-Carbohydrates}
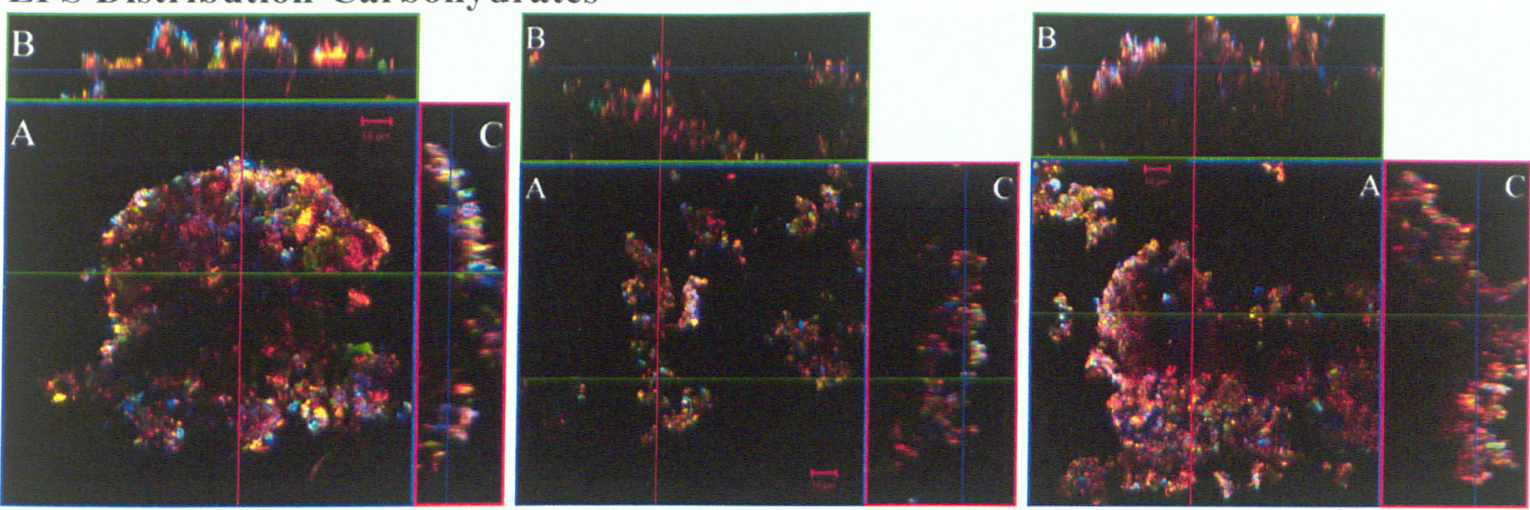

(a) EDTA treated flocs
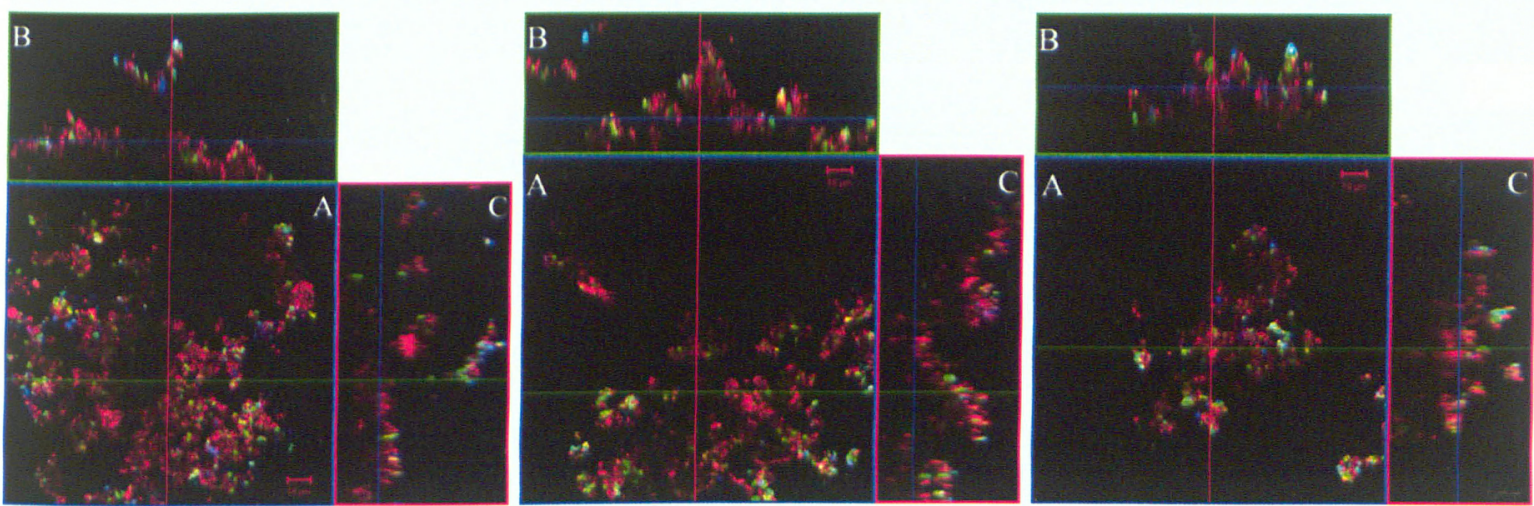

(b) Control
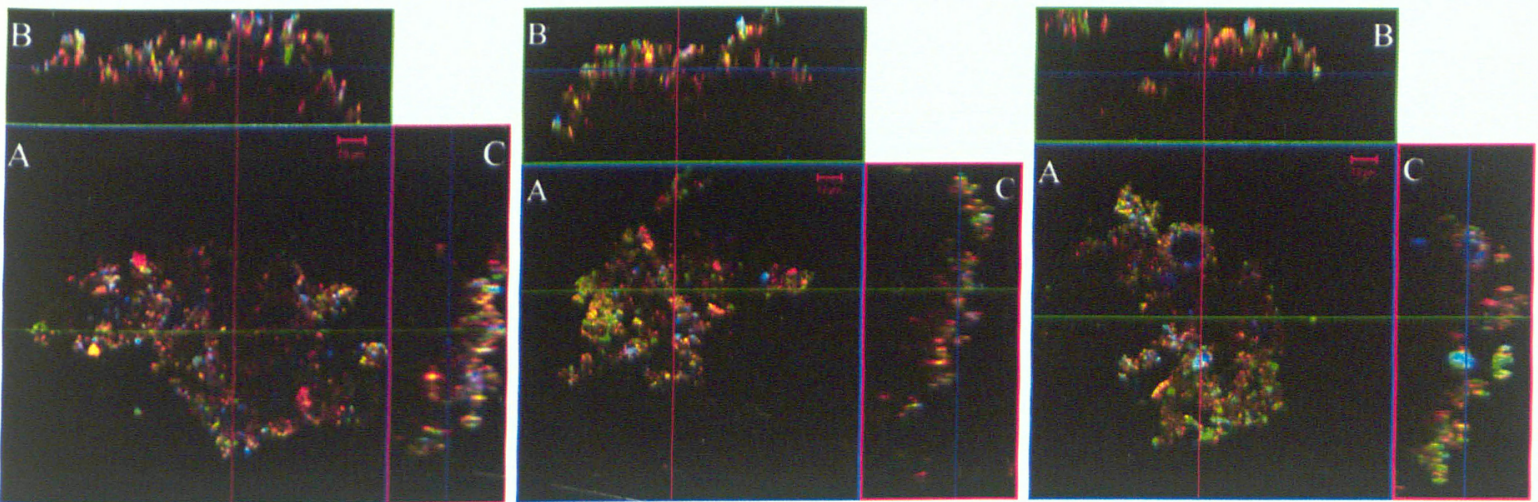

(c) EDTA-proteinase K treated flocs

Flocs were treated with $1000 \mu \mathrm{g} / \mathrm{ml}$ EDTA (a) or EDTA followed by $200 \mu \mathrm{g} / \mathrm{ml}$ proteinase K (c). Control flocs (b) and treated flocs were stained with ConA (Man and Glc residues, blue), WGA (GlcNAc residues, red), SBA (GalNAc and Gal residues, green). CLSM micrographs show at z plane $=(a)=22,22,20 \mu \mathrm{m},(b)=44,58,30 \mu \mathrm{m}$ and $(c)=22,26,26 \mu \mathrm{m}$. Scale bar $=10 \mu \mathrm{m}$. 


\section{Adherent EHEC Distribution in Flocs}

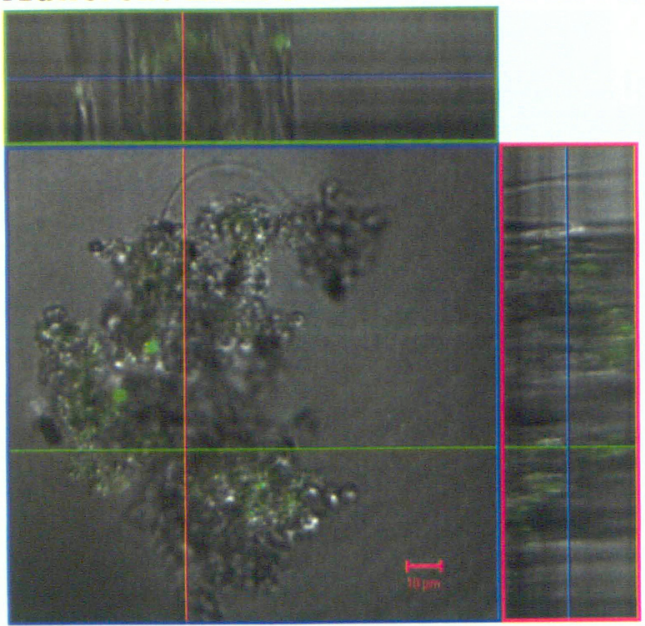

(a)

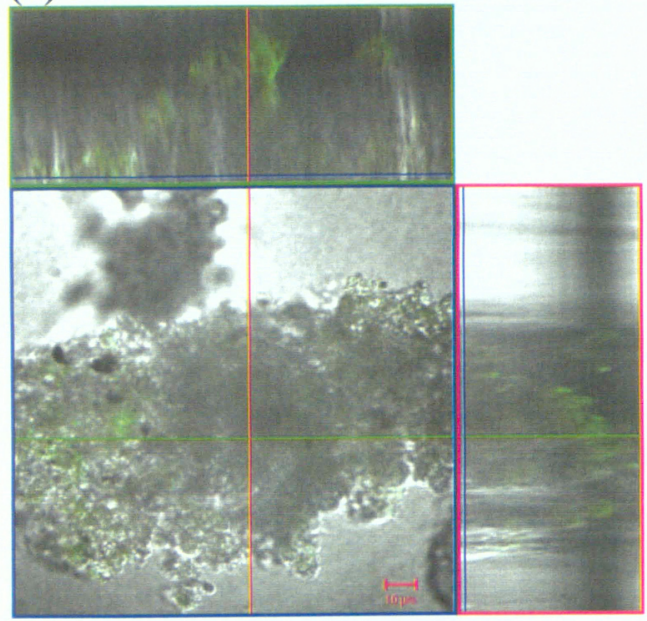

(c)

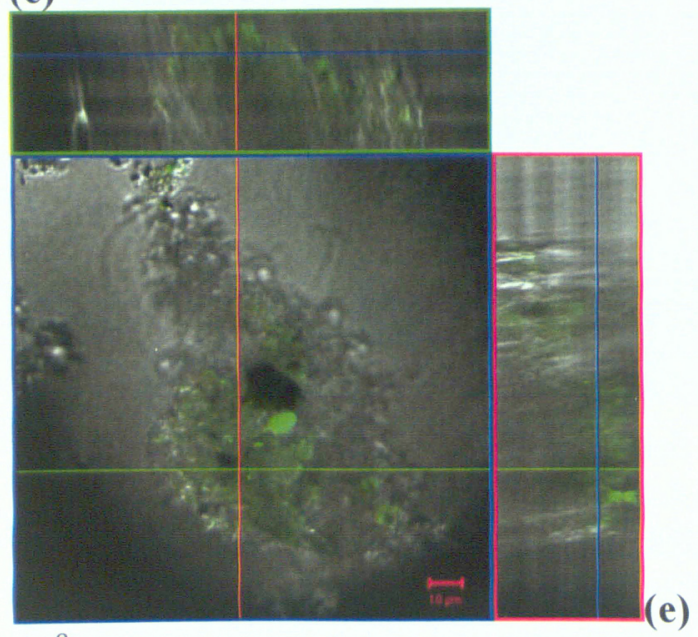

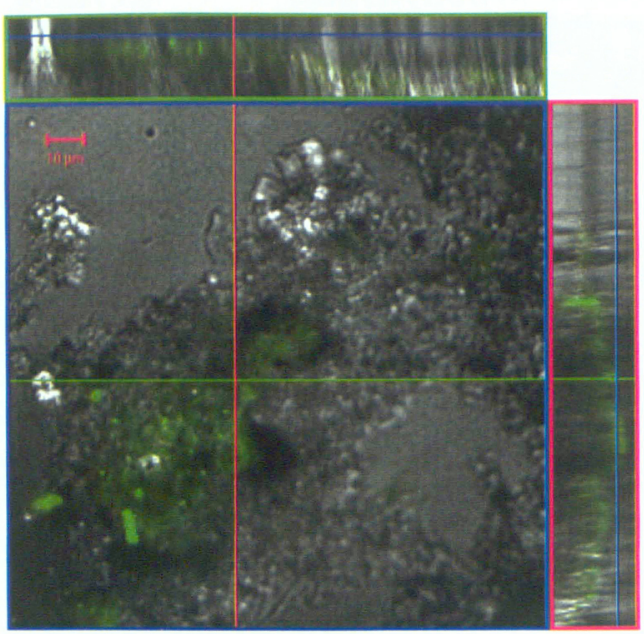

(b)

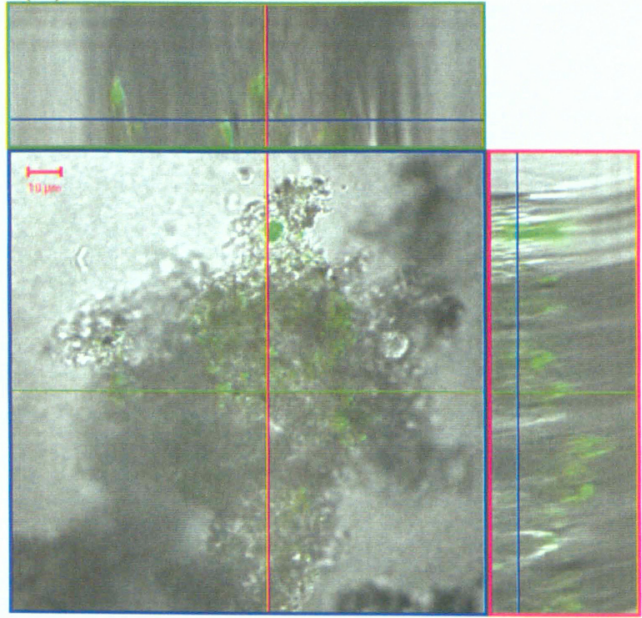

(d)

$10^{8} \mathrm{CFU} / \mathrm{ml}$ E. coli O157:H7 was incubated with flocs suspended in PBS buffer ((a) 2d, (c) $7 \mathrm{~d}$ incubation), NSBR ((d) 7d) and SBR ((b) 2d, (e) 7d). CLSM micrographs show adherent E. coli O157:H7 (GFP-green) in flocs. z plane $=(a) 20 \mu \mathrm{m},(\mathrm{b}) 5 \mu \mathrm{m}$, (c) $59 \mu \mathrm{m}$, (d) $37 \mu \mathrm{m}$, (e) $13 \mu \mathrm{m}$. Scale bar $=10 \mu \mathrm{m}$. 
Immunofluorescence Detection of $\alpha$-Actinin Assay
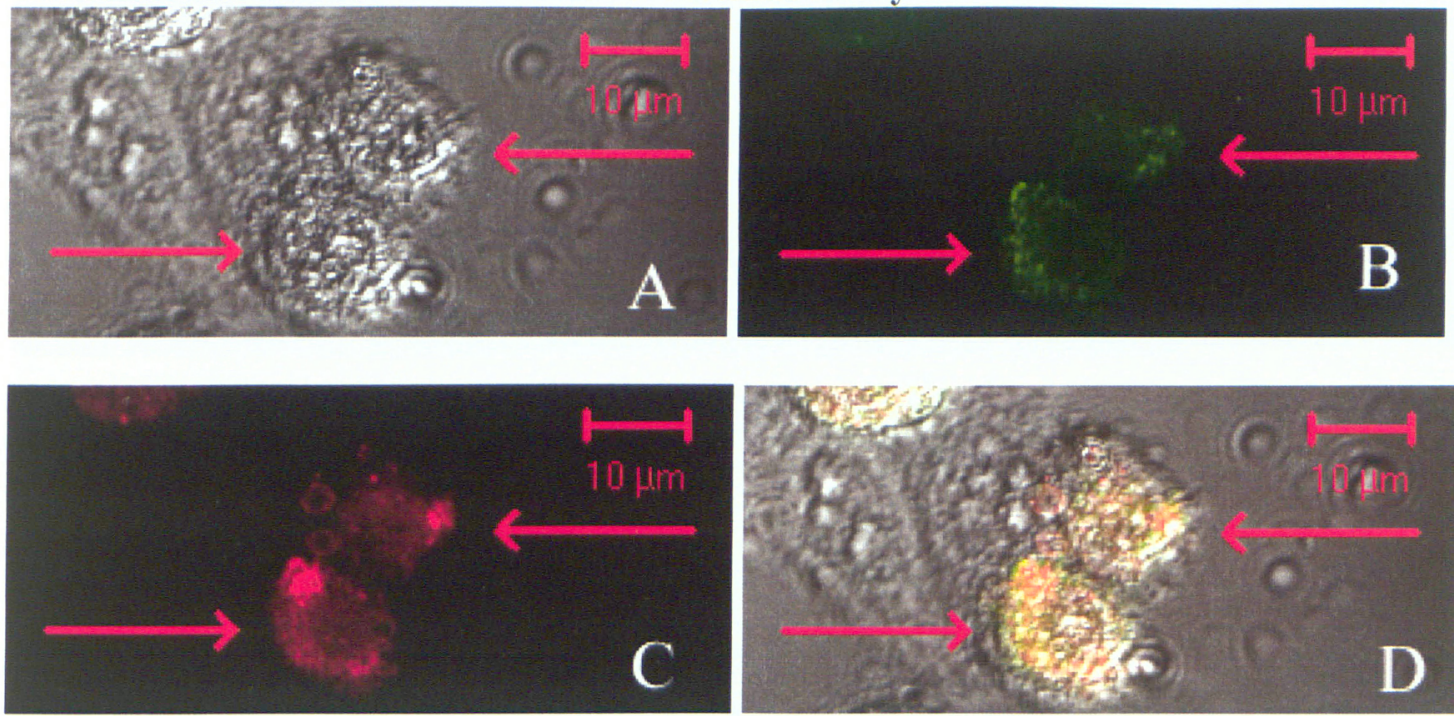

HEp-2 cells infected with EHEC from nutrient rich medium (positive control).

(A) transmission mode (B) O157 detection (C) $\alpha$-actinin detection (D) composite. Scale bar $=$ $10 \mu \mathrm{m}$. Bright foci of fluorescent yellow shows accumulation of $\alpha$-actinin.
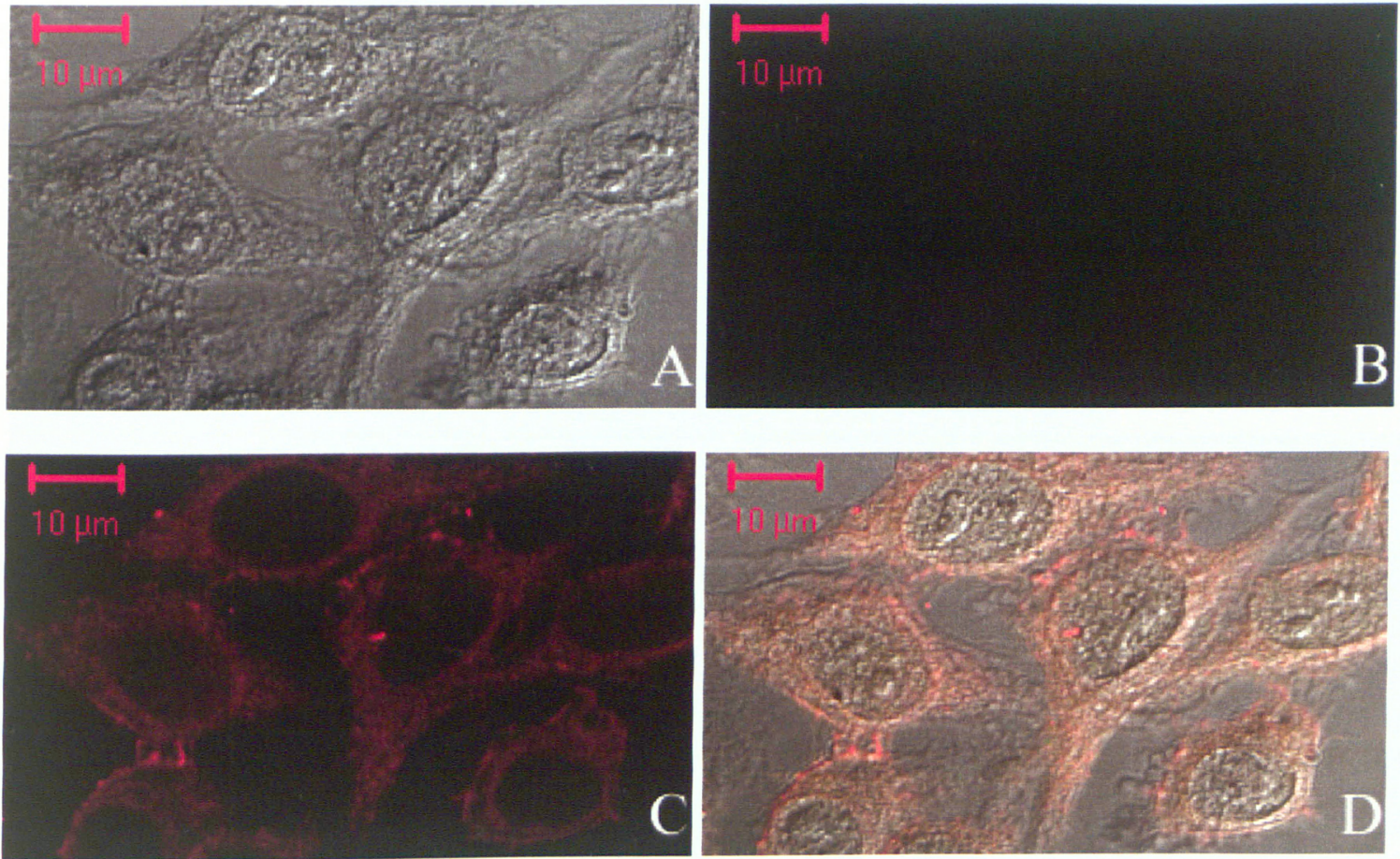

HEp-2 cells without EHEC (negatives control).

(A) transmission mode (B) O157 detection (C) $\alpha$-actinin detection (D) composite. Scale bar $=$ $10 \mu \mathrm{m}$. 

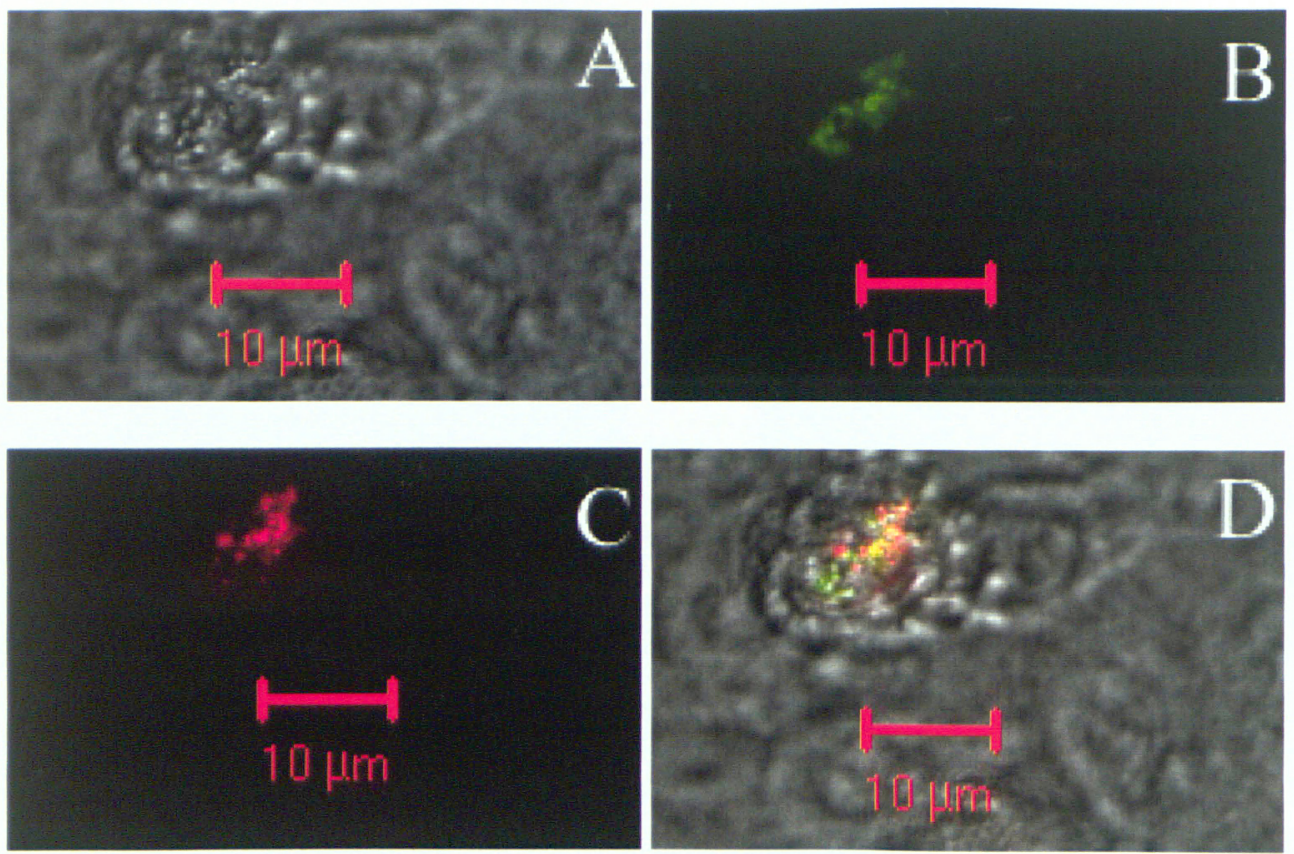

\section{HEp-2 cells infected with EHEC from 2_SF}
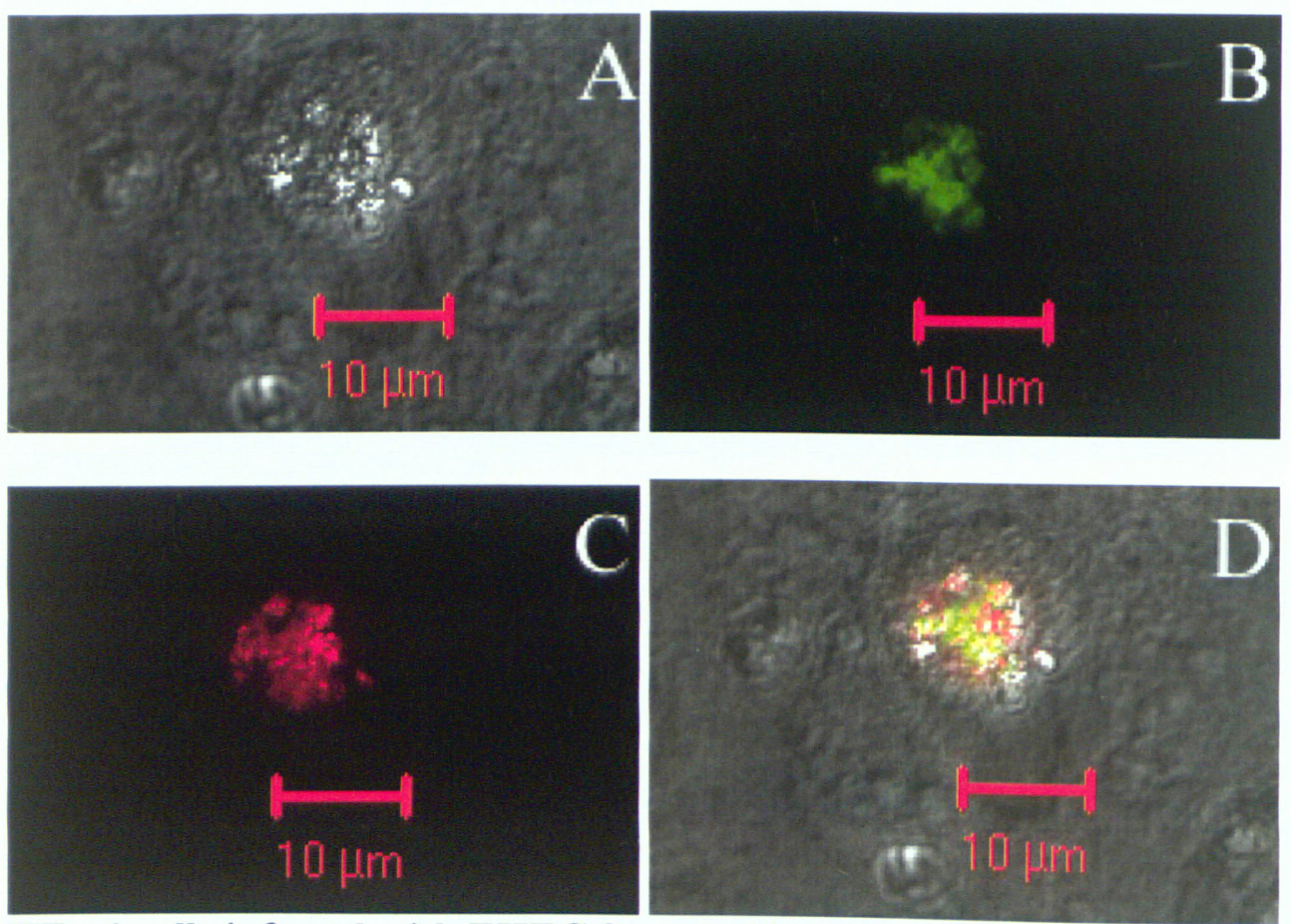

HEp-2 cells infected with EHEC from 2 SS

(A) transmission mode (B) $\mathrm{O} 157$ detection (C) $\alpha$-actinin detection (D) composite. Scale bar $=$ $10 \mu \mathrm{m}$ 

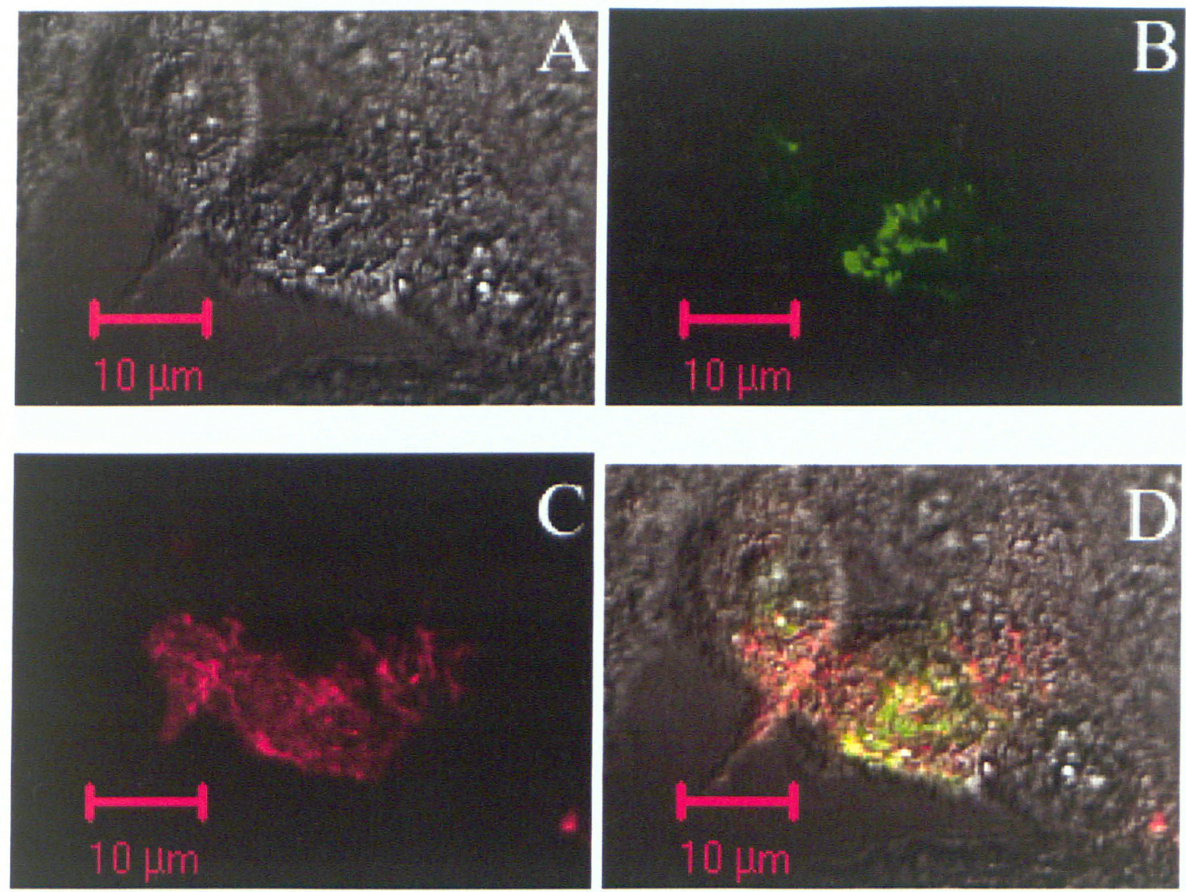

HEp-2 cells infected with EHEC from 10_BF
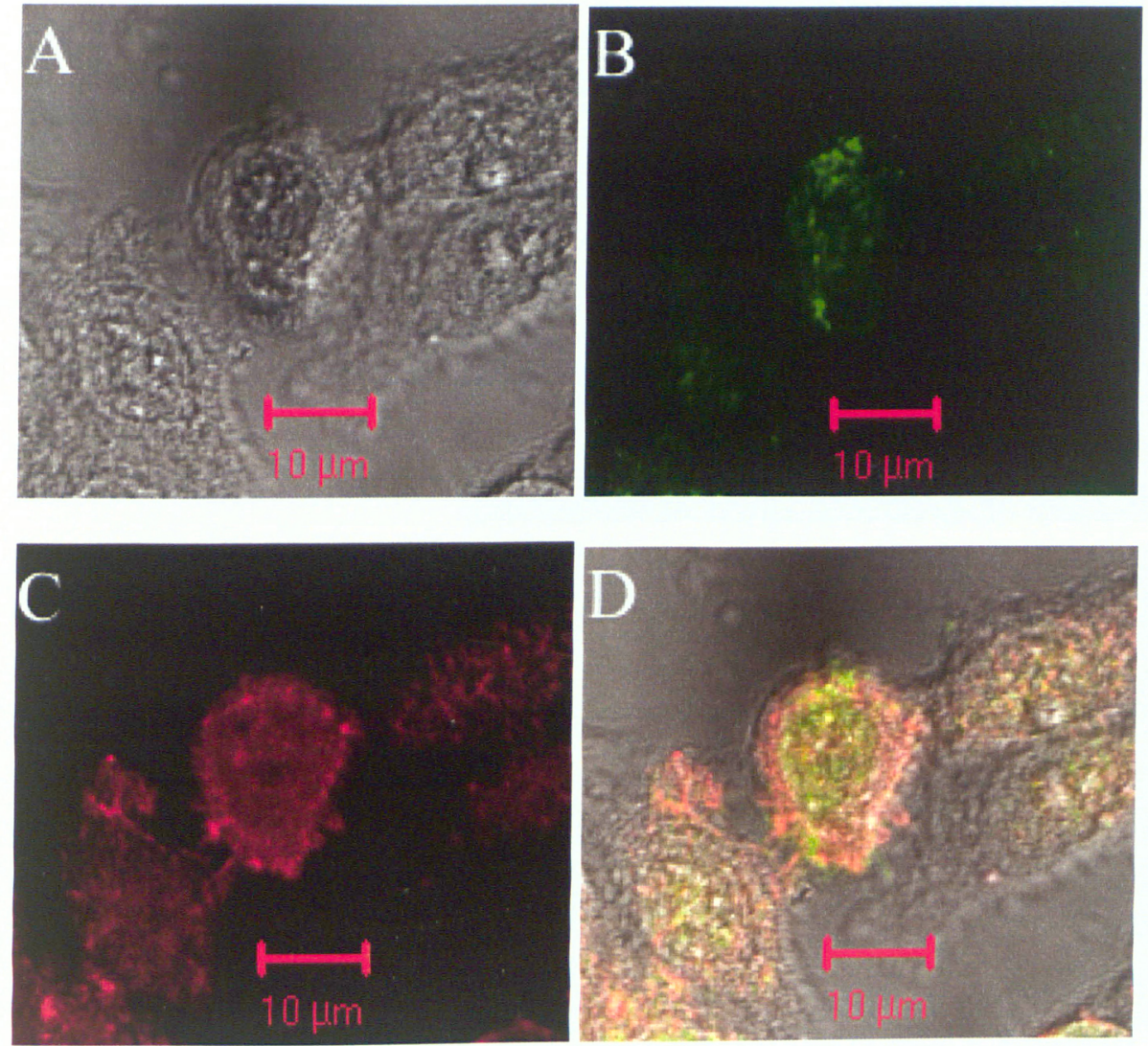

HEp-2 cells infected with EHEC from 10_BS

(A) transmission mode (B) $\mathrm{O} 157$ detection $(\mathrm{C}) \alpha$-actinin detection (D) composite. Scale bar $=$ $10 \mu \mathrm{m}$. 

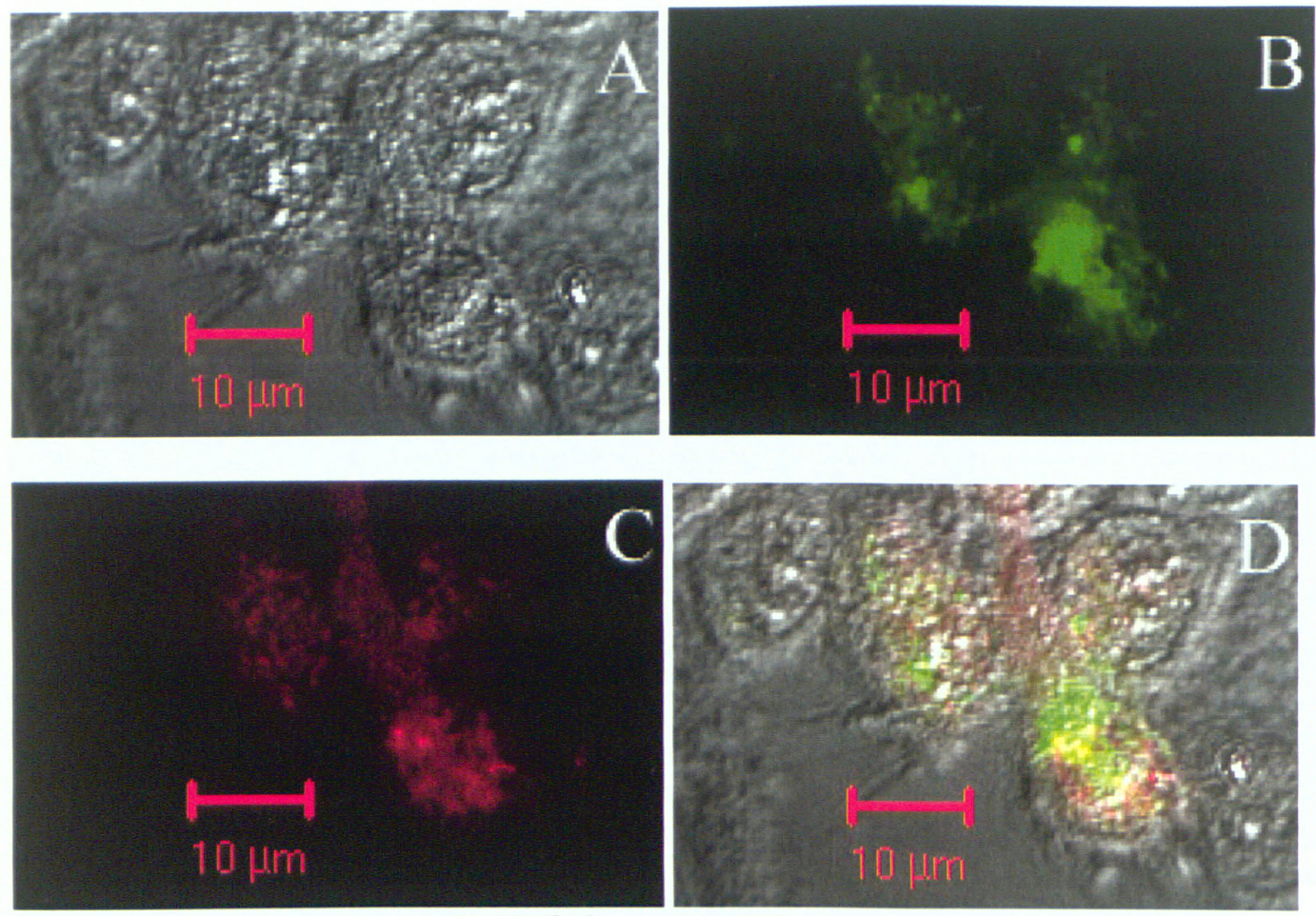

HEp-2 cells infected with EHEC from 10_NF
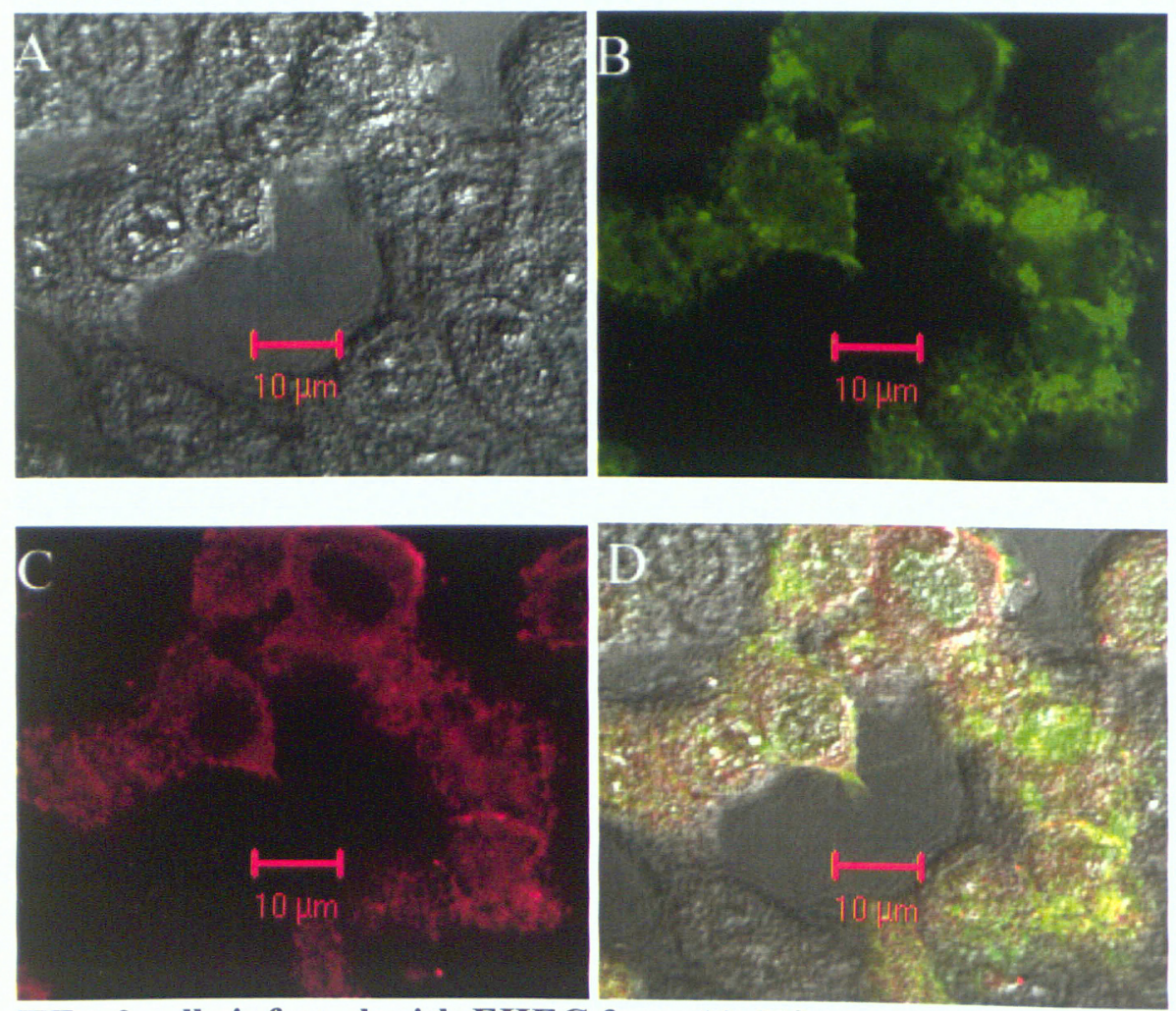

HEp-2 cells infected with EHEC from 10_NS

(A) transmission mode (B) $\mathrm{O} 157$ detection (C) $\alpha$-actinin detection (D) composite. Scale bar $=$ $10 \mu \mathrm{m}$. 

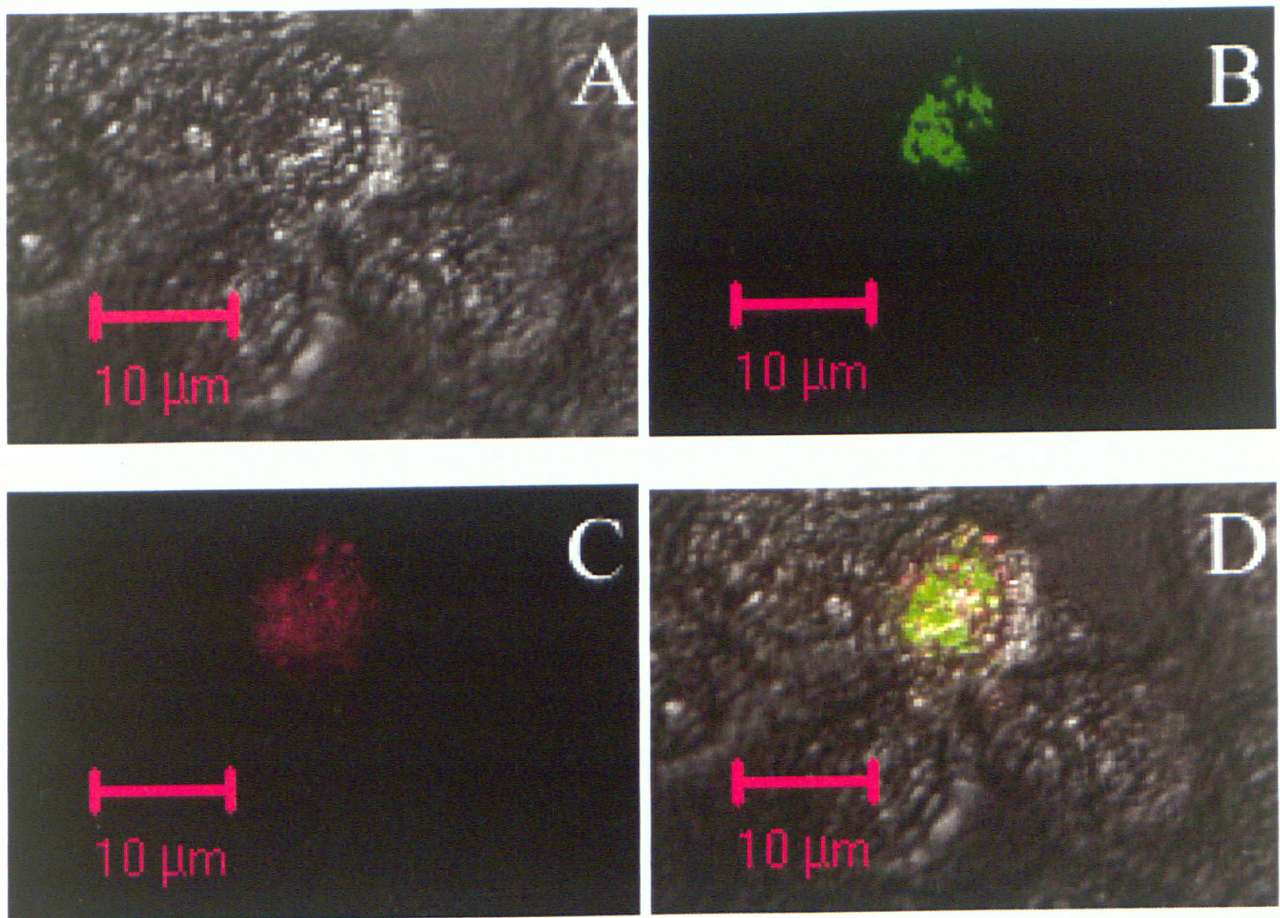

HEp-2 cells infected with EHEC from 10_SF
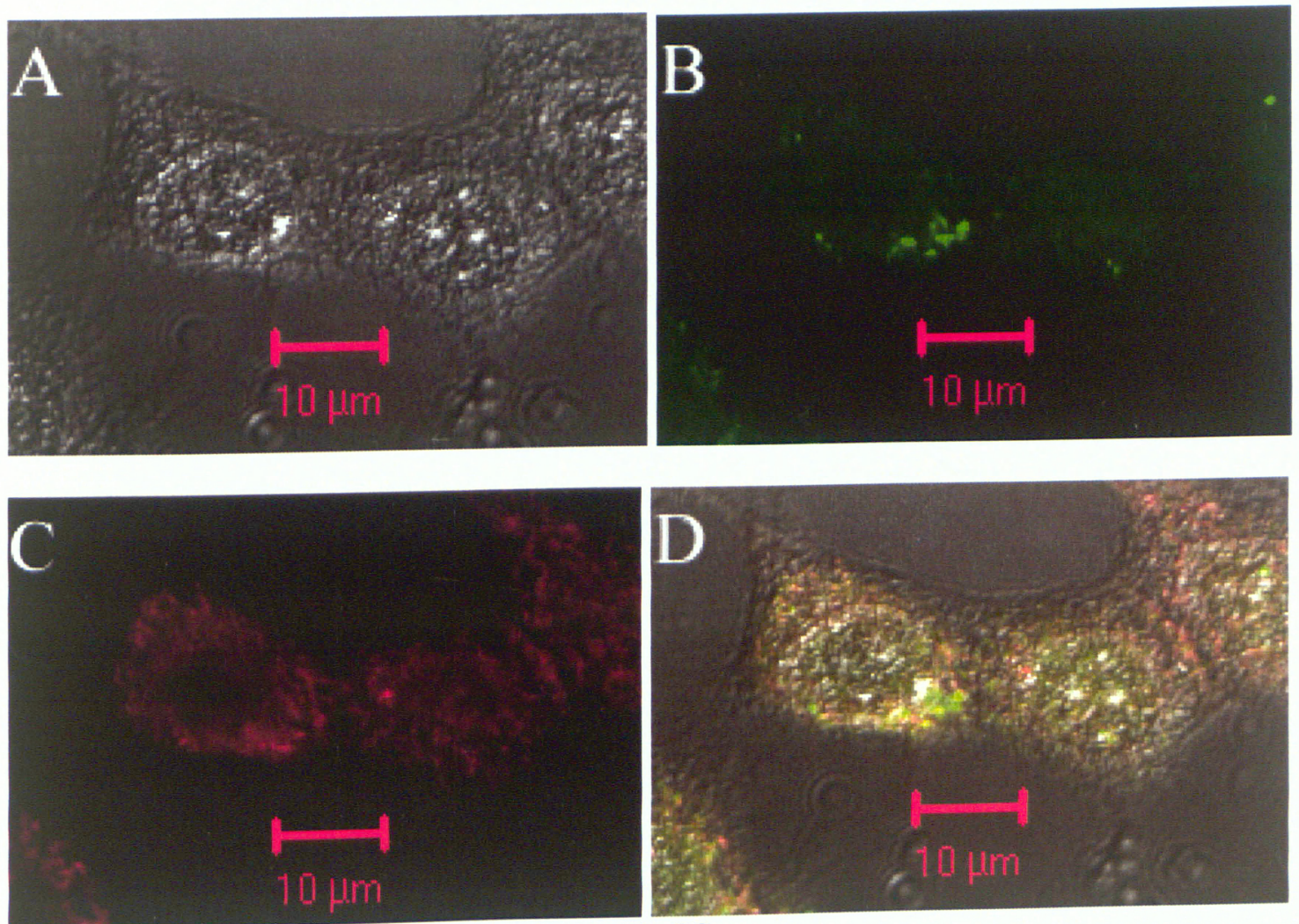

HEp-2 cells infected with EHEC from 10_SS

(A) transmission mode (B) O157 detection (C) $\alpha$-actinin detection (D) composite. Scale bar $=$ $10 \mu \mathrm{m}$. 